\title{
The Cellular Effects of Nicotine and Tobacco Particulate Matter on
} Monoamine Transporters

\author{
by \\ Kirsty Maree Danielson
}

\begin{abstract}
A thesis
submitted to the Victoria University of Wellington in fulfilment of the requirements for the degree of Doctor of Philosophy
\end{abstract}

Victoria University of Wellington 


\section{Abstract}

Cigarette smoking causes nearly 6 million deaths worldwide every year (WHO, 2011). Current smoking cessation therapies available to the public are only marginally effective (Jorenby, 2006; Balfour et al., 2000), partly due to our incomplete understanding of the molecular biology of smoking addiction. The majority of studies examining the molecular biology of smoking addiction have focused on nicotine alone. However, there is a growing body of evidence that non-nicotinic components of cigarette smoke contribute to smoking addiction. Nicotine has previously been shown to modulate the function of the monoamine transporters, but studies in the literature are often contradictory and this effect is not completely understood (see Danielson et al., 2011 for review). Furthermore, very few studies have examined the effects of non-nicotinic components of tobacco smoke on the monoamine transporters.

This thesis has examined the effects of nicotine and a tobacco extract (TPM) on the dopamine, serotonin, and norepinephrine transporters (DAT, NET, and SERT). Changes in monoamine transporter function, protein expression, and mRNA expression were measured ex vivo in discrete regions of the rat brain following chronic and acute in vivo nicotine and TPM treatment, and in vitro nicotine and TPM treatment. We found that nicotine and TPM affect monoamine transporter function, in a time- and dose-dependent manner, and that intact whole brain circuitry is required for these effects to be seen. In particular, nicotine $(0.35 \mathrm{mg} / \mathrm{kg}$ ) and TPM (containing $0.35 \mathrm{mg} / \mathrm{kg}$ nicotine) significantly decreased DAT function in the NAc at $30 \mathrm{~min}$. This effect did not result in a corresponding decrease in DAT protein expression and was mediated by nicotinic receptors containing $\beta 2$ subunits. Furthermore, TPM caused some changes in monoamine transporter function and mRNA expression that were not observed with nicotine alone. In functional studies this effect was particularly seen in the striatum of rats treated with nicotine $(0.35 \mathrm{mg} / \mathrm{kg})$ or TPM (containing $0.35 \mathrm{mg} / \mathrm{kg}$ nicotine). 
Overall these data demonstrate that nicotine affects monoamine transporter function in a nicotinic receptor-dependent manner, and that nicotine and TPM have different effects on monoamine transporter function and expression. This is the first study to examine the effects of TPM on monoamine transporter function, and supports previous evidence of a contribution of non-nicotinic components of cigarette smoke to neuroadaptations related to smoking. Findings from this study contribute to knowledge on the molecular biology of smoking addiction, which could in future lead to the development of more effective smoking cessation therapies. 


\section{Acknowledgements}

There are a lot of people I need to thank for their help during this ridiculous endeavour.

Firstly, I'd like to thank my supervisors Bronwyn Kivell and Penny Truman for all their guidance, encouragement, and help over the last four years. I would also like to thank Katie Brennan, John Miller, and Darren Day for their additional help over the years.

Thanks to the technicians in biology and psychology for all their help- Richard Moore for taking such good care of my rats, Neville Higginson and Craig Doney for endlessly fixing equipment in our lab, and Sushila Pillai for all the chats, giggling and general carry on. I would also like to thank all the admin staff in biology especially Mary Murray who always has a smile on her face for you.

A big thank you to Liz Richardson and the Awhina Whanau for all the support over the years. You helped to make this experience much easier.

Thanks to all the grad students past and present in the biology department who have gone through this with me and helped to keep me (somewhat) sane. Bridget Simonson, who practically became my significant other and always had a bottle of wine and a dream of Alpaca farming handy when needed. Miles Benton, who has put up with 8 years of Team Retardo, been my tech support, and (literally) dragged me out of bed for class- I never would have got past first year without you (but I still blame you for Frank).

My fellow lab mates (in no particular order) Peter Bosch, Leigh Walker, Fraser Putt, Ana Holley, Aashish Morani, Tori Catherwood, Xiaowen Yu, Grace Paske and Amy Hoo who were, luckily, great people to hang out with, so spending all my time with you over the past 4 years hasn't been too bad. Thanks for all the fun times, sharing of ideas, editing, and 
commiserations over failed experiments. My unfortunate undergrad volunteers, minions, and monkeys who spent so much time cleaning dishes, smooshing brains, and washing membranes: Pam, Mark, Fraser, Xiaowen, Leigh, Michelle, Portch and Liz. And the rest of you lot around the department that I see far too much of: Ryan Steel, Ariane Chan, Bede Busby (and the rest of the chem gen crew), and Jess Field.

I'd also like to thank my friends who helped me through this ordeal: Ang, Shane, and Dyani for giving me a temporary place to live (that turned into almost a year) and taking good care of me; Tamsyn for the peanut m\&ms, editing, and for always being there; Alex, Adrienne, Ellie, Theresa and everyone else who supported me through this and provided entertaining distractions.

Finally I'd like to thank my family. Mum and Dad for the constant encouragement and support (emotional and financial), and for feeding me up when I'm home. My brother Sam, for always asking how it's going, and then telling me he doesn't understand my geek speak. My sister Jess for all the late night phone calls and listening to my ranting. Her long suffering husband Bill for putting up with all of my incredibly stupid questions about computers. And my lovely niece and nephew, Mikayla and Wills, for being forever entertaining, and always wanting to do science experiments with me. I never could have got it done without you all.

Funding for this project was provided by Wellington Medical Research Foundation, Neurological Foundation, Victoria University of Wellington, and Environmental Science and Research. 


\section{Table of Contents}

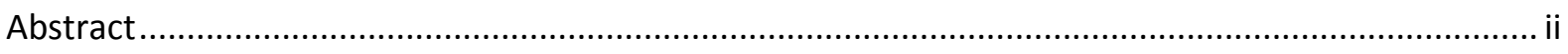

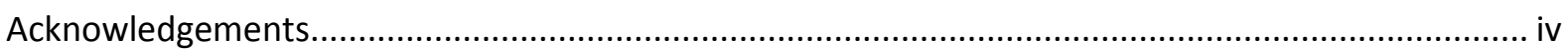

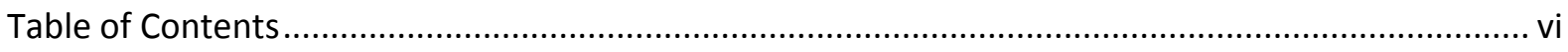

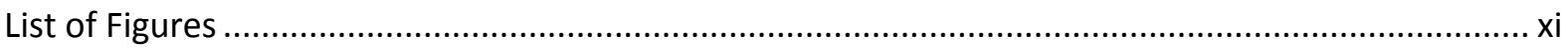

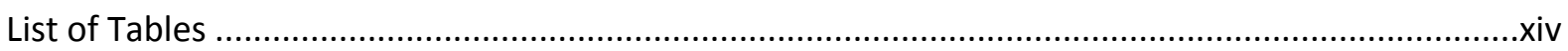

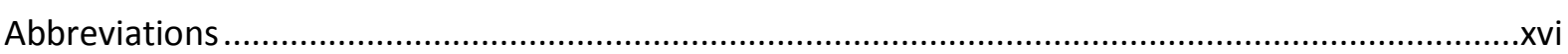

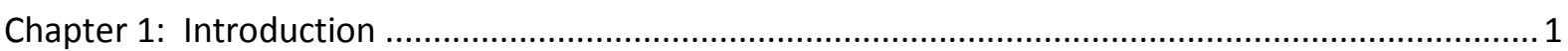

1.1 Tobacco Addiction and the Global Health Burden.................................................... 1

1.1.1 Cigarette Smoking is Addictive.......................................................................... 1

1.1.2 Current Smoking Cessation Therapies ........................................................... 4

1.2 The biochemical actions of tobacco smoke in the brain ...............................................

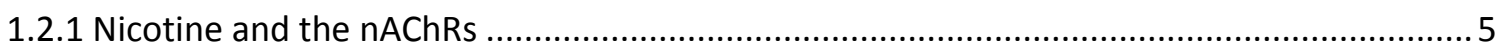

1.2.2 The effects of nicotine on monoaminergic systems ............................................ 7

1.2.3 The contribution of non-nicotinic tobacco components to smoking addiction .................10

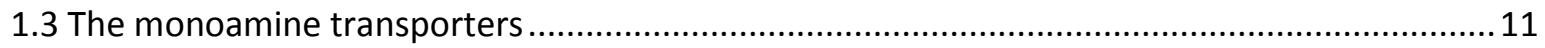

1.3.1 Location of the monoamine transporters in the CNS ........................................... 12

1.3.2 Regulation of the monoamine transporters ......................................................... 13

1.4 Cigarette Smoking and the Monoamine Transporters: human studies.............................. 17

1.4.1 Genetic Variation in Monoamine Transporters and Human Smoking Behaviour ...............17

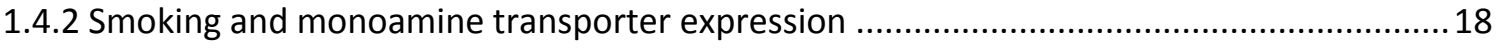

1.4.3 Monoamine Transporters as a Pharmacotherapeutic Target for Smoking Cessation .........19

1.5 The Effects of Nicotine and Cigarette Smoke on Monaomine Transporter Function: preclinical studies

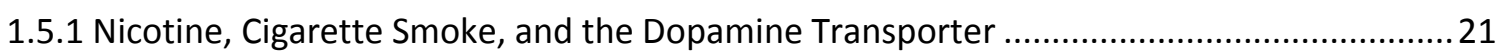

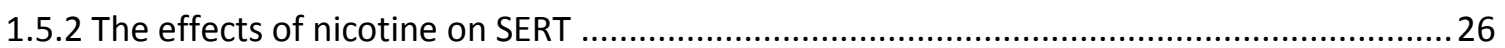


1.6 Mechanisms of Nicotinic Alteration of Monoamine Transporter Function............................28

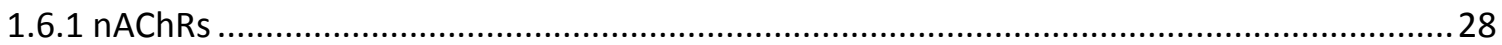

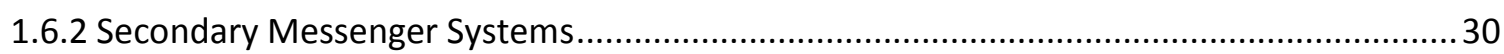

1.6.3 Nicotinic Regulation of Monoamine Transporter Gene Expression ................................33

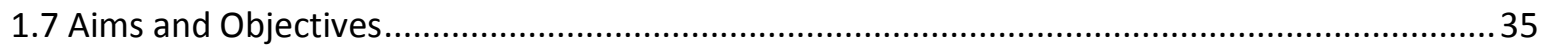

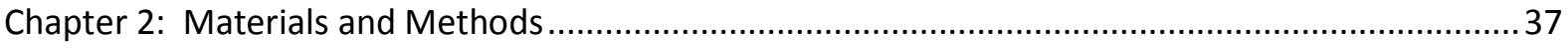

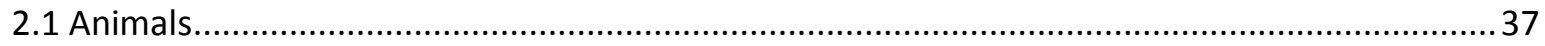

2.2 Nicotine and Tobacco Particulate Matter .................................................................... 37

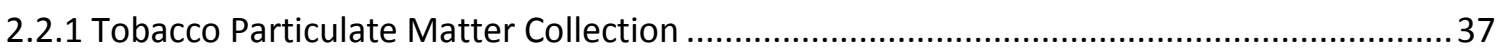

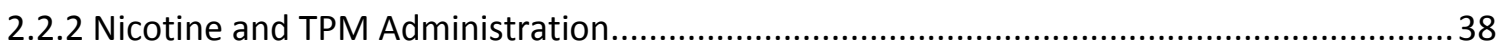

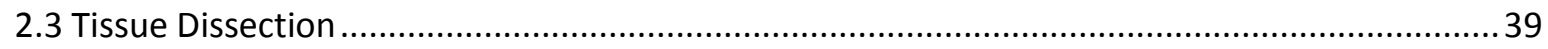

2.4 Rotating Disk Electrode Voltammetry (RDEV) .................................................... 40

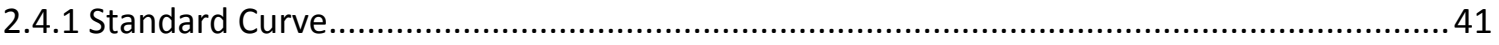

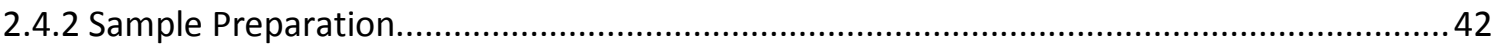

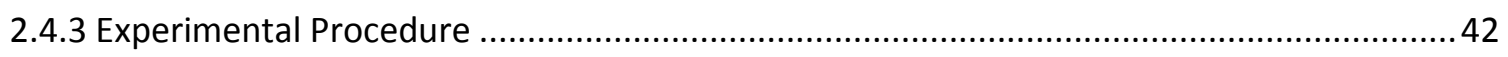

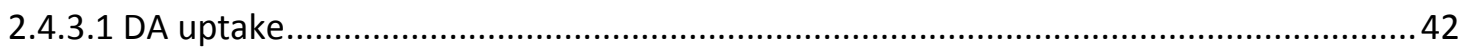

2.4.3.2 5-HT uptake............................................................................................. 43

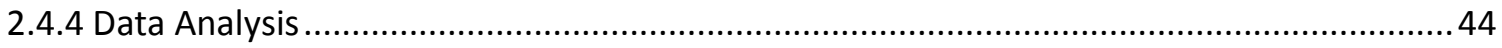

2.5 SDS Polyacrylamide Gel Electrophoresis and Western Blotting ....................................46

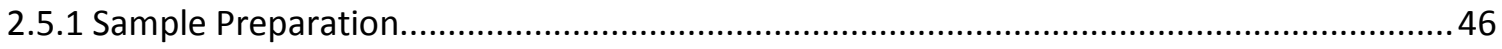

2.5.2 SDS-PAGE and Membrane Transfer ........................................................... 46

2.5.3 Western Blotting ....................................................................................... 46

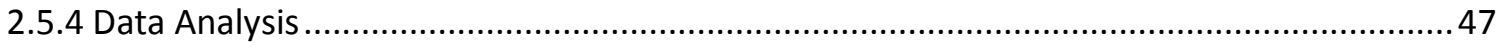

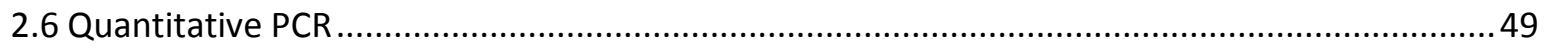

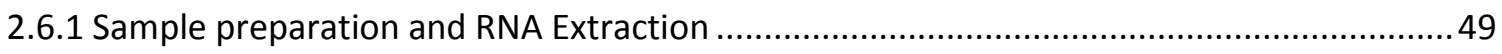

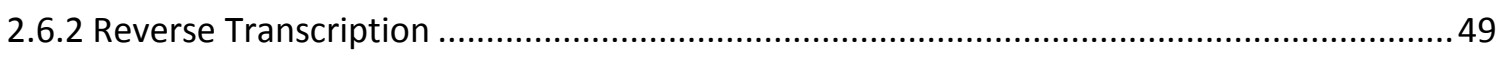

2.6.3 Real time PCR with SYBR Green Chemistry............................................................ 49 


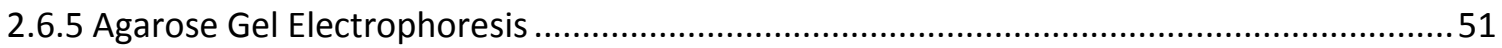

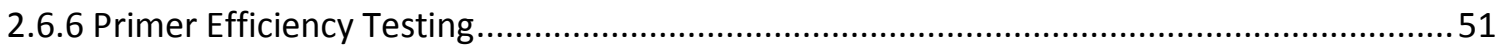

Chapter 3: The chronic effects of nicotine and TPM on DA and 5-HT uptake and monoamine

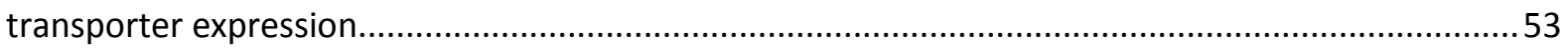

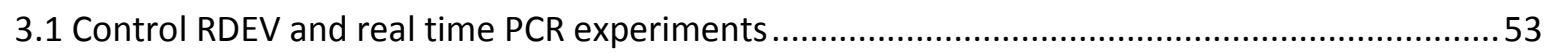

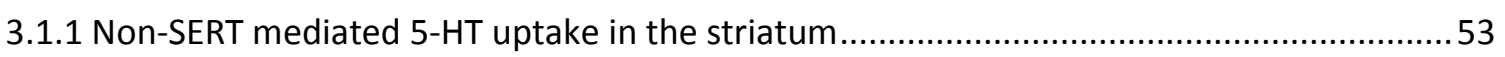

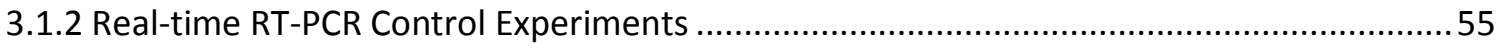

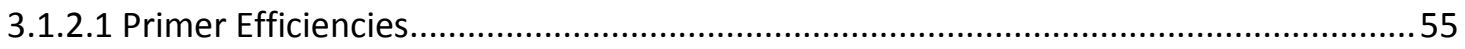

3.1.2.2 Agarose gel electrophoresis and melt curve analysis .................................................56

3.2 The effects of chronic nicotine and TPM on DAT function and expression................................58

3.2.1 Changes in DAT function and protein expression in the NAc, striatum, and PFC................58

3.2.2 Changes in DAT mRNA and protein expression in the VTA and SN ...............................62

3.3 The effects of chronic nicotine and TPM on NET function and expression ...............................64

3.3.1 Chronic nicotine ( $3 \mathrm{mg} / \mathrm{kg}$ ) causes a significant increase in DA uptake by NET in the PFC . 64

3.3.2 TPM but not nicotine causes a decrease in NET mRNA expression in the LC......................66

3.4 The effects of chronic nicotine and TPM on SERT function and expression.............................68

3.4.1 Chronic nicotine and TPM treatment has no significant effect on SERT function or protein expression in the striatum

3.4.2 SERT mRNA and protein expression in the DRN following chronic nicotine and TPM treatment.

Chapter 4: The acute effects of nicotine and TPM on DA and 5-HT uptake and monoamine transporter expression.

4.1 The in vitro effects of nicotine and TPM on monoamine uptake ........................................... 72

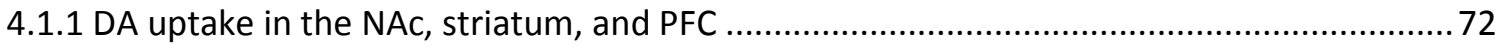

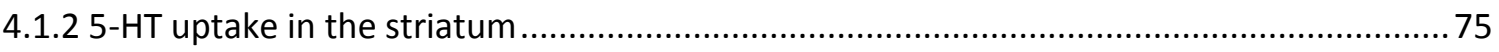

4.2 The effects of acute in vivo nicotine and TPM treatment on the monoamine transporters......76

4.2.1 The effects of nicotine and TPM on monoamine transporter function at $15 \mathrm{~min}$..............76

4.2.2 The effects of nicotine and TPM on monoamine transporter function at $30 \mathrm{~min}$..............79 
4.2.2.1 Nicotine and TPM decrease DAT function in the NAc at $30 \mathrm{~min}$ in a nicotinic receptora4 subunit- dependent manner

4.2.2.2 Nicotine and TPM have no effect on DA uptake in the striatum or PFC, or 5-HT uptake in the striatum at $30 \mathrm{~min}$

4.3 The effects of nicotine and TPM on monoamine transporter function and expression at $1 \mathrm{hr} .85$

4.3.1 DAT function and protein expression in the NAc, striatum, and PFC .85

4.3.2 DAT protein and mRNA expression in the VTA and SN 91

4.3.3 NET function and expression .93

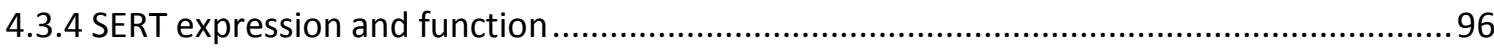

Chapter 5: Discussion 99

5.1 Significance 99

5.2 TPM as a model for smoking addiction 99

5.2.1 TPM and reward-related neuroadaptations...... .99

5.2.2 Animal models of tobacco dependence 100

5.2.3 TPM composition 101

5.2.4 Ethanol content in nicotine and TPM treatments 103

5.3 Chronic effects of nicotine and TPM on monoamine transporter function and expression .... 104

5.2.1 DAT function and expression following chronic nicotine and TPM treatment... 105

5.2.2 NET function and expression 109

5.2.3 SERT function and expression 111

Acute effects of nicotine and TPM on monoamine transporter function and expression 114

5.3.1 DA uptake and DAT protein expression in the NAC 114

5.3.2 DA uptake and DAT protein expression in the striatum 117

5.3.3 DA uptake by DAT and DAT protein expression in the PFC 119

5.3.4 DAT protein and mRNA expression in the VTA and SN 119

5.3.5 NET function and expression in the PFC and LC 120

5.3.6 SERT function and expression in the striatum and DRN 121

Key Findings 122 
Nicotine and TPM alter DAT function and expression in the NAC.....

Future Directions

Overall Significance

Appendices.

Appendix I: Solutions

Appendix II: Representative Western blots

Appendix III: Cyclophilin A mRNA expression across treatment groups 134

References 135 


\section{List of Figures}

Figure 1.1: Monoamine neurotransmission at the synapse ...............................................

Figure 1.2: Pentameric structure of $n A C h R s$ and subunit composition of $\alpha 4 \beta 2$ and $\alpha 7$ receptors

Figure 1.3: Selected neuronal pathways for monoamine neurotransmission in the rat brain 9

Figure 1.4: Monoamine transporter structure with putative glycosylation and phosphorylation sites for DAT, NET and SERT. .16

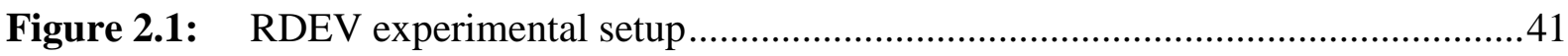

Figure 2.2: $\quad$ RDEV data analysis .45

Figure 3.1: D-22 and desipramine have no significant effect on 5-HT uptake in the striatum of drug naive rats

Figure 3.2: Efficiencies of primers used in this study .55

Figure 3.3: Representative data from real-time PCR experiments .57

Figure 3.4: The effects of chronic nicotine and TPM on DAT function and protein expression in the NAc

Figure 3.5: DAT function and protein expression in the striatum following chronic nicotine and TPM treatment

Figure 3.6: DAT function and protein expression in the PFC following chronic nicotine and TPM treatment

Figure 3.7: DAT mRNA and protein expression in the VTA and SN following chronic nicotine and TPM treatment

Figure 3.8: Chronic nicotine $(3 \mathrm{mg} / \mathrm{kg})$ treatment increases DA uptake by NET in the PFC but has no significant effect on NET protein expression 
Figure 3.9: The chronic effects of nicotine and TPM on NET mRNA and protein expression in the $\mathrm{LC}$

Figure 3.10: Chronic nicotine and TPM treatment has no effect on SERT function (A) or protein expression $(\mathrm{B})$ in the rat striatum

Figure 3.11: SERT mRNA and protein expression in the DRN following chronic nicotine and TPM treatment

Figure 4.1: In vitro nicotine and TPM treatment has no significant effect on DA uptake in isolated tissue

Figure 4.2: $\quad$ In vitro TPM treatment significantly decreases 5-HT uptake by SERT in the striatum

Figure 4.3: Nicotine and TPM cause no significant changes in monoamine uptake at 15 $\min$

Figure 4.4: Nicotine and TPM significantly decrease DAT function in the NAc at 30 min in a mecamylamine-sensitive manner

Figure 4.5: The effects of $\alpha 4$ and $\alpha 7$ nicotinic receptor antagonism on nicotine- and TPM-induced decreases in DAT function .82

Figure 4.6: The effects of nicotine and TPM on monoamine uptake in the striatum and PFC.

Figure 4.7: Nicotine and TPM have no effect on DAT function and expression in the NAc at $1 \mathrm{hr}$ .86

Figure 4.8: TPM, but not nicotine, increased DAT function in the striatum at $1 \mathrm{hr}$. .88

Figure 4.9: Nicotine and TPM have no effect on DA uptake by DAT in the PFC.... .90

Figure 4.10: DAT mRNA and protein expression in the VTA and SN $1 \mathrm{hr}$ after nicotine or TPM treatment

Figure 4.11: DA uptake by NET and NET protein expression in the PFC $1 \mathrm{hr}$ after drug treatment.

Figure 4.12: NET mRNA and protein expression in the LC $1 \mathrm{hr}$ after drug treatment .95 
Figure 4.13: SERT function and expression in the striatum at $1 \mathrm{hr}$ .97

Figure 4.14: SERT mRNA and protein expression in the DRN at $1 \mathrm{hr}$. .98

Figure A2.1: Representative Western blots for antibodies used in this study 133 


\section{List of Tables}

Table 1.1: Location, size and number of exons for the human DAT, SERT and NET genes

Table 1.2: The effects of chronic nicotine and cigarette smoke on DAT function .31

Table 1.3: The effects of acute nicotine on DAT function .32

Table 2.1: $\quad$ Reference coordinates and mean tissue weights for brain dissections .40

Table 2.2: $\quad$ Primary and Secondary Antibodies used for Western Blotting .48

Table 2.3: $\quad$ Primers used for quantitative PCR .50

Table 3.1: $\quad$ 5-HT uptake kinetics with D-22 and desipramine treatment in rat striatum .....54

Table 3.2: DAT kinetic data for chronic nicotine and TPM treatment .62

Table 3.3: $\Delta \mathrm{Ct}$ values for DAT mRNA expression in the SN and VTA following chronic nicotine and TPM treatment. .64

Table 3.4: NET kinetics in the PFC following chronic nicotine and TPM treatment .66

Table 3.5: $\Delta \mathrm{Ct}$ values for NET mRNA expression in the LC following chronic nicotine and TPM treatment

Table 3.6: SERT kinetics in the striatum following chronic nicotine and TPM treatment....

Table 3.7: $\triangle \mathrm{CT}$ values for SERT mRNA expression in the DRN following chronic nicotine and TPM treatment. .70

Table 4.1: $\quad$ DAT and NET kinetics from in vitro nicotine and TPM treatment .73

Table 4.2: $\quad$ Kinetic data for 5-HT uptake in the striatum following in vitro nicotine and TPM treatment .75

Table 4.3: Kinetic data for DA and 5-HT uptake at 15 min following nicotine and TPM treatment 
Table 4.4: Kinetic data for DAT function in the NAc at $30 \mathrm{~min}$

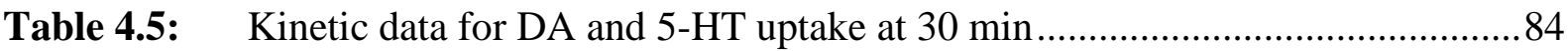

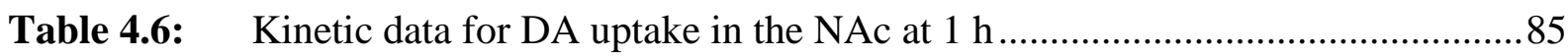

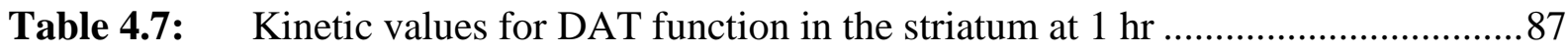

Table 4.8: $\quad V_{\max }$ and $\mathrm{K}_{\mathrm{m}}$ values for DA uptake in the PFC $1 \mathrm{~h}$ after drug treatment ..........89

Table 4.9: $\Delta$ Ct values for DAT mRNA expression in the VTA and SN........................91

Table 4.10: Kinetic data for DA uptake by NET in the PFC $1 \mathrm{~h}$ after drug treatment.........93

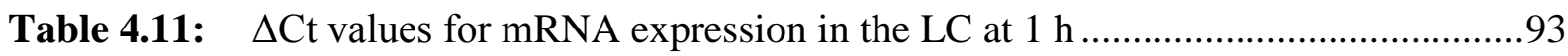

Table 4.12: $V_{\max }$ and $K_{m}$ values for 5-HT uptake by SERT in the striatum $1 \mathrm{~h}$ after

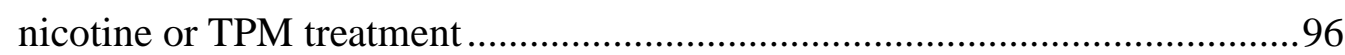

Table 4.13: $\quad \Delta \mathrm{Ct}$ values for SERT mRNA expression in the DRN at $1 \mathrm{~h} \ldots \ldots \ldots \ldots \ldots \ldots \ldots \ldots . . . . . . . . . . . . .98$

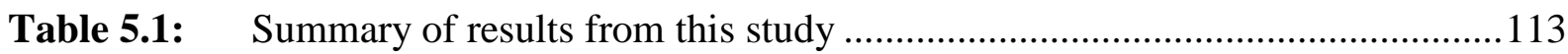

Table A3.1: $\quad$ Mean cyc A Ct values for chronic nicotine and TPM treatments ...................134

Table A3.2: $\quad$ Mean cyc A Ct values for acute nicotine and TPM treatments ......................134 


\section{Abbreviations}

5-HT

5HTTLPR

ADHD

CamK

COMT

DA

DAT

DRN

GABA

i.p.

i.v.

LC

$\mathrm{DH} \beta \mathrm{E}$

MAO

MAPK

MLA

NAc

nAChR

$\mathrm{NE}$

NET

NRT

PFC

PKA

PKC

PKG

s.c.

SERT

$\mathrm{SN}$

TMD 5-hydroxytryptamine, serotonin

5-HT transporter long promoter region

attention deficit hyperactivity disorder

$\mathrm{Ca}^{2+} /$ calmodulin-dependent protein kinase

catechol-o-methyl transferase

dopamine

dopamine transporter

dorsal raphe nuclei

$\gamma$-aminobutyric acid

intraperitoneal

intravenous

locus coeruleus

Dihydro-beta-erythroidine

monoamine oxidase

mitogen activated protein kinase

methyllycaconitine

nucleus accumbens

nicotinic acetylcholine receptor

norepinephrine

norepinephrine transporter

nicotine replacement therapies

prefrontal cortex

protein kinase $\mathrm{A}$

protein kinase $\mathrm{C}$

protein kinase $\mathrm{G}$

subcutaneous

serotonin transporter

substantia nigra

trans-membrane domain 
TPM

$\mathrm{V}_{\max }$

VNTR

VTA tobacco particulate matter

maximal velocity of uptake

variable nucleotide tandem repeat

ventral tegmental area 


\section{Chapter 1: Introduction}

\subsection{Tobacco Addiction and the Global Health Burden}

Cigarette smoke causes nearly 6 million deaths per year worldwide (WHO, 2011), and 5000 deaths per year in New Zealand alone (New Zealand Ministry of Health, 2005). It is now common knowledge that smoking contributes to a plethora of diseases including lung cancer, cardiovascular disease and emphysema (see Fagerstrom, 2002 for review). There are currently more than 1 billion smokers worldwide, half of whom will die of smoking related illnesses (WHO, 2011). Cigarette smoking is highly addictive and anecdotally reported as being one of the most difficult drugs to quit. Effective smoking cessation therapies are essential to limit the global health burden that is produced by cigarette smoking. However, our current understanding of smoking addiction at the biological level is poor, and this is reflected in the limited success of current smoking cessation aids. Therefore, research needs to address both the biological mechanisms underlying smoking addiction, and possible pharmacotherapeutic aids to assist in quit attempts.

\subsubsection{Cigarette Smoking is Addictive}

Cigarette smoke contains over 4000 components, of which, the tobacco alkaloid nicotine is the major neurologically active compound (see Balfour 2002, for review). Numerous studies have demonstrated that nicotine is an addictive compound; it acts as a reinforcer in self-administration studies in rats (Corrigall and Coen, 1989) and non-human primates (Le Foll et al., 2007), reduces intra-cranial self-stimulation reward thresholds (Bozarth et al. 1998), and acts on the reward circuitry of the brain in a manner similar to other psychostimulant drugs (Balfour et al., 2002). Nicotine dependence can be described by three separate stages that are each characterised by different molecular events, neuroadaptations, and subjective experiences (see De Biasi and Dani, 2011 for review). The initiation of drug taking comprises a mixture of rewarding and aversive effects and involves the excess release of dopamine (DA) in the mesolimbic system to mediate rewarding and reinforcing effects (Singer et al., 2004; Dichiara and Imperato, 1988; 
Nisell et al., 1996). Chronic nicotine exposure then results in a dependant stage where vast neurochemical changes occur including nicotinic acetylcholine receptor (nAChR) up-regulation (Brennan et al., 2010) and alterations in monoamine neurotransmitter signalling (Shearman et al., 2008), as well endogenous opioid (Xue et al., 2008), glutamate and $\gamma$-amminobutyric acid (GABA) systems (Yu et al., 2010). Finally, the withdrawal stage occurs upon cessation of nicotine exposure (De Biasi and Dani 2011). This stage is typically characterised by feelings of irritability, dysphoria and anxiety. At the molecular level the withwrawal stage involves neurochemical changes including decreases in synaptic DA in the nucleus accumbens (NAc) and increased DA release in the prefrontal cortex (PFC) (De Biasi and Dani 2011).

The mesolimbic reward pathway of the brain consists of dopaminergic cell bodies in the ventral tegmental area (VTA) that project to the NAc and PFC (Figure 1.3). All drugs of abuse affect this pathway either directly or indirectly to cause DA release in these regions, particularly in the NAc (Volkow et al., 2007). This produces reward and reinforcement, and is heavily implicated in the initiation of drug abuse. Nicotine and cigarette smoke also produce this increase in DA release in the NAc (Brody et al., 2010). Inhaled cigarette smoke is taken into the lungs and absorbed through the alveoli into the blood stream. From here, nicotine rapidly reaches the brain and exerts its effects within 10 seconds of inhalation (Benowitz, 1995). In the brain, nicotine binds to the nAChRs throughout the central nervous system and induces DA release in the VTA (Singer et al., 2004), NAc (Dichiara and Imperato, 1988), PFC (Nisell et al., 1996) and striatum (Scholze et al., 2007). Additionally, nicotine induces the release of the monoamines serotonin (5-hydroxytryptamine; 5-HT) in the dorsal raphe nuclei (DRN) (Ma et al., 2005) and striatum (Yu and Wecker, 1994); and norepinephrine (NE) in the PFC (Rossi et al., 2005), hippocampus, and striatum (Scholze et al., 2007). Following release into the synapse, the monoamine neurotransmitters bind to post-synaptic receptors and cause further downstream signalling. The activity of the neurotransmitters is primarily terminated by re-uptake via the monoamine transporters, after which they are either repackaged into vesicles or degraded by monoamine oxidases (MAO) (Figure 1.1) (see Bortolato et al., 2008 for review). 


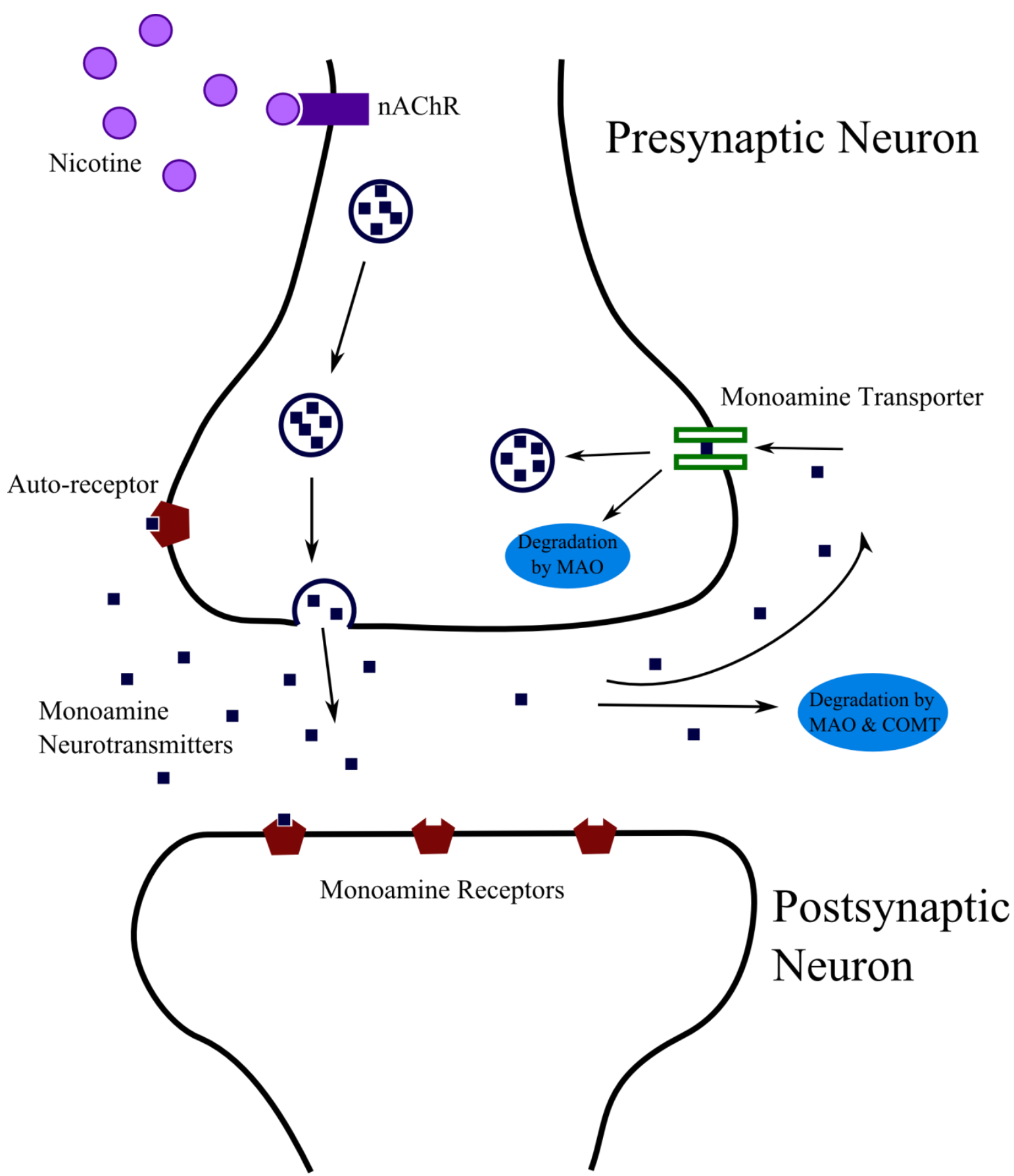

Figure 1.1: Monoamine neurotransmission at the synapse. Nicotine binds to acetylcholine receptor (nAChRs) on the presynaptic neuron and induces the vesicular release of monoamines in the synapse. Once released, the monoamines bind to receptors on the postsynaptic neurons and cause further downstream signalling. The monoamines also bind to auto-receptors on the presynaptic neuron that regulate their release. Clearance of the monoamines from the synapse occurs via degradation by monoamine oxidase (MAO) and catechol-o-methyl transferase (COMT), or through re-uptake by the 
monoamine transporters in the peri-synaptic space. Following re-uptake, the monoamines are either re-packaged into vesicles or degraded by MAO.

\subsubsection{Current Smoking Cessation Therapies}

Current smoking cessation therapies centre on nicotine replacement therapies (NRT), and include nicotine patches, inhalers, nasal sprays and gums. It has been reported that the delivery method for NRT makes no significant difference to the success of quit attempts, with smoking abstinence rates of 20\% (gum), 21\% (patch), 24\% (spray) and 24\% (inhaler) over 12 weeks (Hajek et al., 1999). The rationale behind using NRT for smoking cessation is that replacing the addictive component of cigarette smoke, nicotine, should reduce the unpleasant withdrawal effects of quitting and increase the likelihood of abstinence from cigarette smoking (Di Matteo et al., 2007). However, studies have shown that NRTs offer only approximately a 10\% success rate after one year (see Balfour et al., 2000a for review).

More recently the non-nicotine smoking cessation aids varenicline (Coe et al., 2005) and bupropion (Hurt et al., 1997) have been developed. Varenicline is a synthetic drug that is a partial nicotinic agonist and binds specifically to $\alpha 4 \beta 2$ receptors (Coe et al., 2005). Bupropion is an atypical anti-depressant that has shown efficacy as a smoking cessation aid (see Dwoskin et al., 2006 for review). However, the mechanism of bupropion's antismoking properties is currently unclear. It is known to be a non-selective inhibitor of the dopamine transporter (DAT) and the norepinephrine transporter (NET) and a partial antagonist of nAChRs, suggesting that modulation of monoamine transporter function may modulate smoking addiction (Paterson et al., 2007). These non-nicotinic pharmacotherapies show an improved 1 year success rate of $23 \%$ for varenicline and 14.6\% for bupropion (Jorenby et al., 2006) compared with 10\% for NRT (Balfour et al., 2000a).

In addition to bupropion and varenicline, cytisine is a non-nicotinic smoking cessation therapy that has been used in Eastern Europe for forty years (Etter 2006). It is a partial nAChR agonist that specifically binds to $\alpha 4 \beta 2$ receptors. Past studies examining cytisine 
are methodologically flawed; however, they report some efficacy as a smoking cessation aid, with reported quit rates of 13.8-70\% with up to 12 months follow up (Etter 2006). Recently West et al. (2011) performed the first randomized, double-blind, placebocontrolled trial of cytisine and found it to be significantly more efficacious than placebo at aiding smoking cessation. The sustained 12 month abstinence rate for subjects on a four week course of cytisine was $8.4 \%$ vs. $2.4 \%$ for placebo, and the authors suggested that extending the treatment course could produce better abstinence rates. Although some non-nicotinic pharmacotherapies are showing significant improvements over NRT, success rates are still disappointingly low. In light of this there is a definite need for an improved understanding of the smoking addiction process to aid the development of new alternatives to current cessation therapies.

\subsection{The biochemical actions of tobacco smoke in the brain}

\subsubsection{Nicotine and the nAChRs}

The nAChRs are ligand-gated ion channels that are endogenously activated by acetylcholine (ACh), and are found in both the central nervous system CNS and periphery (Deutch et al., 1987; reviewed in Brennan et al., 2010). Neuronal nAChRs are pentameric structures composed of $\alpha 2-\alpha 10$ and $\beta 2-\beta 4$ subunits (Figure 1.2) (Anand et al. 1991). Typically they consist of a mixture of both $\alpha$ and $\beta$ subunits, the exception being the homomultimeric $\alpha 7$ receptors. nAChRs are expressed throughout the brain, including the VTA and NAc, and are located in both the peri-synaptic and extra-synaptic areas (Brennan et al. 2010). They are found on a diverse range of neurons including dopaminergic (Janhunen and Ahtee, 2007), serotonergic, norephinephric (Bitner and Nikkel 2002), GABAergic (Yang et al., 2011), and glutamatergic (Jones and Wonnacott, 2004) neurons, and thus have a complex role in modulating responses to both endogenous and exogenous stimuli. They have been shown to functionally, and in some cases

physically, interact with several other receptors including muscarinic, glutamate, and D2/D3 DA receptors (Marchi and Grilli 2010). Numerous nAChR subtypes have been implicated in smoking reinforcement and addiction including $\alpha 4 \beta 2, \alpha 6 \beta 2, \alpha 4 \alpha 6 \beta 2$, $\alpha 6 \beta 2 \beta 3, \alpha 4 \alpha 5 \beta 2$ and $\alpha 7$ (Brennan et al., 2010). The $\alpha 4 \beta 2$ and $\alpha 7$ subtypes are the two most abundant in the brain, and the most commonly implicated in nicotine reinforcement and reward (Salminen et al. 2004; Salminen et al. 2007; Scholze et al. 2007). Binding of 
nicotine to the $\alpha$ subunit of $\mathrm{nAChRs}$ causes a conformational change in the receptor and opening of the cation channel. This causes influx of $\mathrm{Na}^{+}$or $\mathrm{Ca}^{2+}$ ions into the neuron and can result in the release of neurotransmitters such as DA, serotonin (5hydroxytryptamine; 5-HT) and NE (reviewed in Brennan et al. 2010). Continuous activation of the nAChRs leads to a desensitised state that has a higher affinity for agonist than receptors in standby. Typically this will lead to down-regulation of the nAChRs; however, chronic nicotine causes an up-regulation of receptors. The mechanism for this up-regulation is not fully understood, but it is believed that the receptors have an increased affinity for nicotine rather than an increased number of receptors being present. In this up-regulated state the receptors have different standby, activation and desensitised states and may have slower desensitisation rates (Brennan et al., 2010). Interestingly, Ambrose et al. (2007) found that tobacco particulate matter (TPM) increased nAChR expression in a cell culture model to a significantly greater extent than nicotine alone (Ambrose et al., 2007).

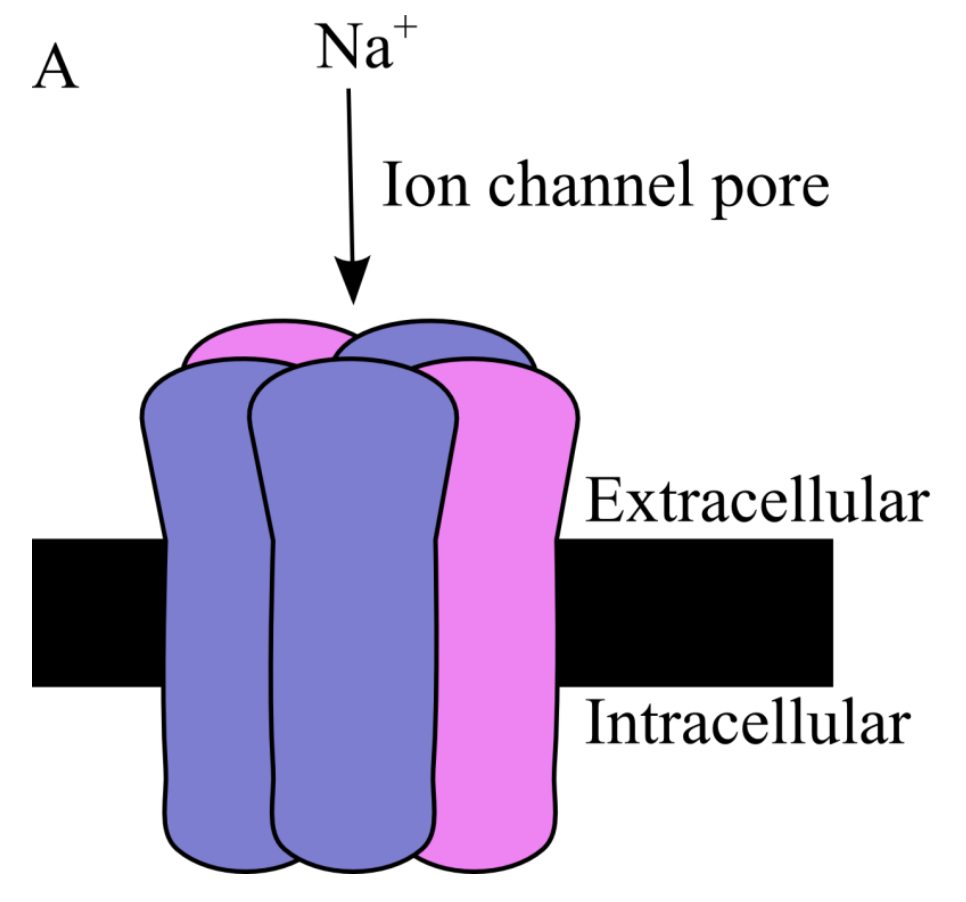

B

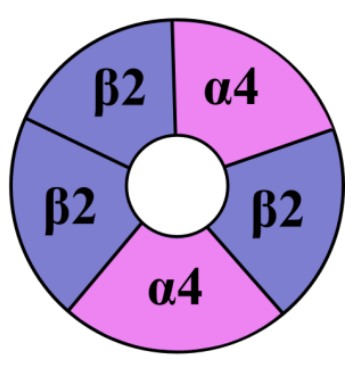

Figure 1.2: Pentameric structure of $n A C h R s$ and subunit composition of $\alpha 4 \beta 2$ and $\alpha 7$ receptors. (A) nAChRs are arranged in a pentameric structure forming a pore in the centre for $\mathrm{Na}^{+}$and $\mathrm{Ca}^{2+}$ influx. (B) Arrangement of subunits for the heteromeric $\alpha 4 \beta 2$ receptor and homomultimeric $\alpha 7$ receptor. 


\subsubsection{The effects of nicotine on monoaminergic systems}

The monoamines DA, 5-HT and NE are integral to numerous systems in the brain and have all been shown to be involved in drug abuse and addiction. Nicotine affects synaptic monoamine concentrations across a number of brain regions. Nicotine-induced release of monoamines has been shown to be both $\mathrm{Ca}^{2+}$ dependent and elicited by $\mathrm{nAChR}$ activation (Rao et al., 2003). Dopamine in particular is classically associated with natural reward systems and addiction (Kelley and Berridge 2002). The mesolimbic dopaminergic reward pathway is considered the brain's major mechanism for incurring reinforcement and reward, and as mentioned above, nicotine stimulates this pathway. In addition to DA release in the NAc and PFC, nicotine stimulates the nigro-striatal pathway to induce DA release in the dorsal striatum, which has been implicated in the locomotor effects of nicotine, and habit learning. Increased DA overflow in the dorsal striatum of individual human subjects has also been associated with the hedonic effects of smoking (Barrett et al., 2004). Upon release into the synapse, DA interacts with pre- and post-synaptic receptors. The pre-synaptic D2/D3 DA auto-receptors provide a negative-feedback system for DA release and have been shown to functionally interact with nAChRs (Marchi and Grilli 2010). It is hypothesized that stimulation of the nAChRs facilitates function of the auto-receptors to prevent further DA release, and that the D2/D3 receptors may directly inhibit $\beta 2$ nicotinic receptors in rat NAc through a physical interaction. Interestingly, D2/D3 receptors have also been shown to interact with DAT (Bolan et al., 2007).

Serotonergic systems are involved in the regulation of a wide range of systems in the brain including mood, anxiety, cognition, emotion, memory, and learning (Murphy et al. 2004). Research on smoking addiction has primarily focused on DA systems; however, 5-HT has also been shown to be involved in stimulant and reward effects of nicotine, and nicotine withdrawal (Seth et al., 2002). The response of serotonergic systems to nicotine is complex and not completely understood. Nicotine has been shown to increase $\left[{ }^{3} \mathrm{H}\right] 5$ HT release from striatal synaptosomes (Reuben and Clarke, 2000), but has also been shown to reduce striatal 5-HT in nicotine self-administering rats (Boules et al., 2010). Nicotinic receptors and $5-\mathrm{HT}_{3}$ serotonin receptors have been shown to co-localize on rat striatal nerve terminals (Nayak et al., 2000), and may cross-regulate one another (Dougherty and Nichols, 2009). In addition, serotonergic systems also interact with DA 
neurotransmission to affect reward in an indirect manner, including the inhibition of DA neurons in the VTA by 5-HT raphe projections (Di Matteo et al., 2002).

Norepinephrine is involved in mood, alertness and arousal, as well as heart rate regulation, glucose metabolism and fight or flight responses (Weinshenker and Schroeder 2007). Although not traditionally a focus of research on substance abuse disorders, norepinephrine has more recently been implicated in the neurobiology of drug addiction, and NE neurotransmission has recently been targeted for the development of psychostimulant addiction treatments (Sofuoglu and Sewell 2009). Nicotine has been shown to cause the release of $\mathrm{NE}$ in a wide range of brain regions including the hippocampus, frontal cortex, striatum, cerebellum and midbrain (Anderson et al., 2000). There is currently limited information in the literature on the effects of nicotine on norepinephric systems in the brain. Norepinephrine is heavily implicated in clinical depression in humans (Goddard et al., 2010), and it has been hypothesised that subjects with clinical depression may self-medicate with smoking (Balfour et al., 2000c). In addition, the smoking cessation agent bupropion acts in part by blocking NET (Dwoskin et al., 2006). This suggests that NE is involved in the biochemical basis of smoking addiction. 


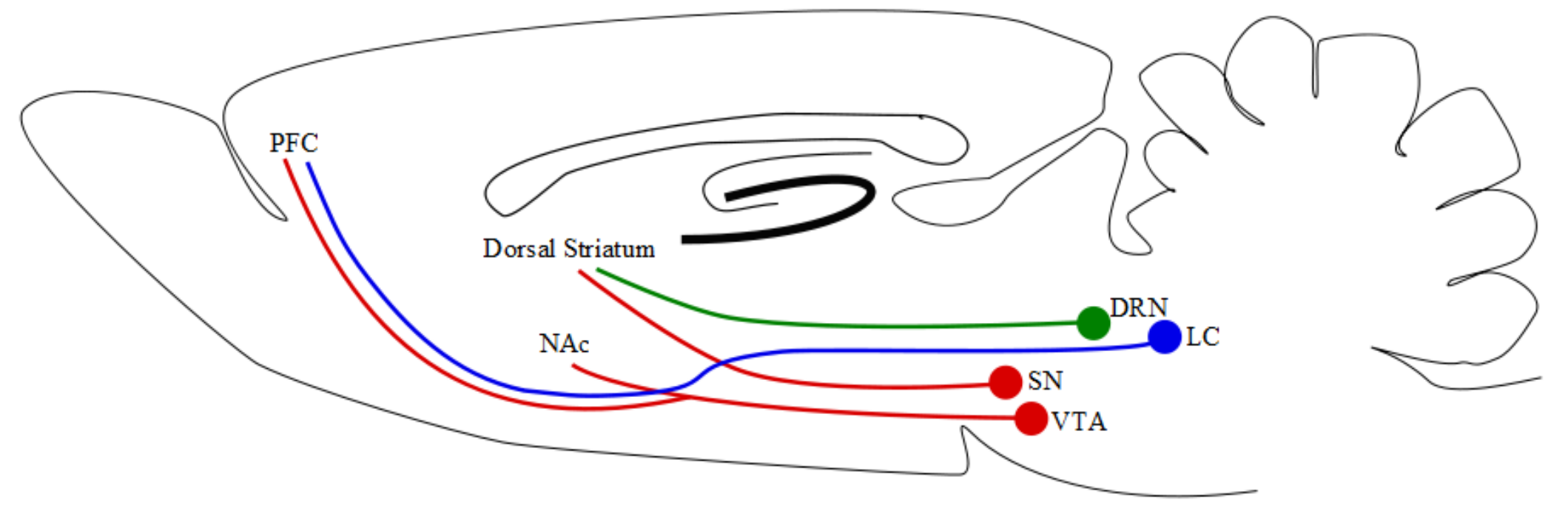

Figure 1.3: Selected neuronal pathways for monoamine neurotransmission in the rat brain. Dopaminergic pathways (red) relevant to addiction include: the mesolimbic reward pathway which consists of cell bodies in the ventral tegmental area (VTA) that project to the nucleus accumbens (NAc) and prefrontal cortex (PFC); and the nigrostriatal pathway, consisting of cell bodies in the substantia nigra (SN) that project to the dorsal striatum. Norepinephric cell bodies in the locus coeruleus (LC) also project to the PFC (blue); and serotonergic cell bodies in the dorsal raphe nuclei (DRN) project to the dorsal striatum (green). 


\subsubsection{The contribution of non-nicotinic tobacco components to smoking addiction}

Nicotine alone is a relatively weak reinforcer in self-administration studies in animals (Stolerman and Jarvis, 1995), contradictory to the apparently high addictive nature of tobacco smoking in humans (Kandel et al., 1997). Nicotine in the form of NRTs has been reported to have a low abuse liability (West et al., 2000), as well as a limited efficacy in aiding smoking cessation (Balfour et al., 2000a). There are over 4000 components present in cigarette smoke, some of which have been shown to be neurologically active and may contribute to smoking addiction. For example, acetaldehyde is a major component of cigarette smoke which has been shown to increase firing rates of VTA neurons (Foddai et al., 2004), and to increase acquisition of nicotine self-administration in adolescent, but not adult, rats (Belluzzi et al., 2005). Furthermore, Touiki et al. (2007) showed that a tobacco extract produced stronger inhibition of dorsal raphe serotonergic neurons when compared to a matched dose of nicotine (Touiki et al., 2007). In humans, de-nicotinised tobacco smoke has been shown to decrease craving for cigarettes over nicotine inhalers, and to delay onset of smoking a preferred brand cigarette (Barrett, 2010). Furthermore, smokers given the choice between de-nicotinised tobacco smoke and intravenous (i.v.) nicotine will preferentially self-administer the de-nicotinised tobacco smoke (Rose et al., 2010). The choice of tobacco smoke over nicotine could be due to several factors including sensory cues, pharmacologically active compounds in tobacco smoke, or a mixture of the two. An overwhelming majority of the research into tobacco addiction has focused on nicotine alone, and further research into the contribution of non-nicotinic components of tobacco smoke on addiction is warranted.

One of the most thoroughly researched non-nicotinic compounds to date is the MAO inhibitors, which are believed to contribute to smoking addiction by preventing the degradation of monoamines, thus increasing the reward signal generated by nicotine (see Lewis et al., 2007 for review). Human smokers have been shown to have decreased MAO activity in the brain, and recently several studies that have found that MAO inhibition increases nicotine self-administration in the rat (Guillem et al., 2005; Guillem et al., 2006; Villegier et al., 2007). This has been shown with both acute (Villegier et al., 2007) and chronic (Guillem et al., 2005) MAO inhibition, and may be mediated through MAO A inhibition rather than MAO B inhibition (Guillem et al., 2006). Another compound of interest is nornicotine, a metabolite of nicotine that is also present in 
tobacco and cigarette smoke (Crooks et al., 1997; Stedman, 1968). Nornicotine evokes DA release from rat NAc slices (Green et al., 2001), and is self-administered by rats (Bardo et al., 1999), suggesting that it has rewarding properties. In addition to nornicotine the minor alkaloids cotinine, myosmine, anatabine, and anabasine are also found in cigarette smoke and together make up 2-3\% of the total alkaloid content in tobacco (Clemens et al., 2009). The addition of the five minor tobacco alkaloids to nicotine has been shown to increase nicotine-induced locomotor activity, locomotor sensitization, and self-administration over nicotine alone in rats (Clemens et al., 2009). Anatabine, cotinine and myosmine were also shown to individually increase locomotor activity in rats (Clemens et al., 2009). This suggests that the minor tobacco alkaloids have addictive properties and may augment nicotine addiction. Overall, there is strong suggestion that components of tobacco smoke other than nicotine contribute to smoking addiction. Additional research to understand these effects is required and care should be taken when extrapolating conclusions about smoking behaviour based on nicotine research alone.

\subsection{The monoamine transporters}

The monoamine transporters are a highly conserved group of $\mathrm{Na}^{+} / \mathrm{Cl}^{-}$symporters containing 620, 617 and 630 amino acid residues for DAT, NET and the serotonin transporter (SERT) respectively (see Torres et al., 2003 for review). The human DAT, NET and SERT proteins are encoded by the SLC6A3, SLC6A2 and SLC6A4 genes respectively. They range in size from 37-65 kb and contain 13-15 exons (Table 1.1). Polymorphisms in these genes have been associated with a wide range of disorders including attention deficit hyperactivity disorder (ADHD), bipolar disorder and substance abuse (see Gainetdinov and Caron, 2003 for review). 
Table 1.1: Location, size and number of exons for the human DAT, SERT and NET genes.

\begin{tabular}{lllc}
\hline & Location & Size & Number of exons \\
\hline SLC6A3 (DAT) & $5 \mathrm{p} 15.3$ & $65 \mathrm{~kb}$ & 15 \\
SLC6A4 (SERT) & $17 \mathrm{q} 11.2$ & $37.8 \mathrm{~kb}$ & 13 \\
SLC6A2 (NET) & $16 \mathrm{q} 12.2$ & $45 \mathrm{~kb}$ & 14 \\
\hline
\end{tabular}

The monoamine transporter proteins contain twelve highly conserved trans-membrane domains (TMDs), with more variable N- and C- terminals located on the cytoplasmic side of the cell. Binding and transport of the monoamines is facilitated by the binding of $\mathrm{Na}^{+}$ and $\mathrm{Cl}^{-}$to the transporter (Howell and Kimmel 2008). Upon binding of the monoamine neurotransmitter and the two ions, the transporter undergoes a conformational change and internalizes the ions and the neurotransmitter. DAT co-transports two $\mathrm{Na}^{+}$and one $\mathrm{Cl}^{-}$ ion with each DA molecule, while SERT and NET co-transport one $\mathrm{Na}^{+}$and one $\mathrm{Cl}^{-}$ion each (Howell and Kimmel 2008). Additionally, SERT transports $\mathrm{K}^{+}$in an anti-port fashion to return to its original state (Murphy et al. 2004). The monoamine transporters employ the $\mathrm{Na}^{+}$gradient generated by $\mathrm{Na}^{+} / \mathrm{K}^{+}$ATPase to facilitate this transport (Howell and Kimmel 2008).

Uptake by the transporters is mostly monoamine specific; however, DAT and NET have the ability to take up either DA or NE (Gainetdinov and Caron 2003). This has particularly been observed in areas of the brain with high norephinephric innervations, such as the PFC, where NET may be responsible for a significant portion of DA uptake (Dichiara et al. 1992). Additionally, NET may provide a compensatory mechanism in DA uptake when DAT is impaired. Carboni et al. (2006) showed that when DAT activity is attenuated by a specific blocker, synaptic DA levels are increased by a further $100 \%$ in the presence of a NET blocker in the NAc shell of rats (Carboni et al. 2006).

\subsubsection{Location of the monoamine transporters in the CNS}

In the central nervous system the monoamine transporters DAT, SERT and NET are located in the perisynapse, and are found almost exclusively on the neurons containing 
the corresponding monoamine neurotransmitter (Torres et al., 2003). DAT is typically found in cells co-expressing tyrosine hydroxylase. Dopaminergic cell bodies are located primarily in the VTA and substantia nigra (SN) (Ciliax et al., 1999) and it is in these regions that the highest expression of DAT mRNA is found. DAT protein is also expressed in these areas as well as in terminal regions of the neurons including the striatum, NAc, olfactory tubercle, layers of the cingulate cortex and the PFC. Some DAT cell bodies have also been visualized in the hypothalamus; however, expression of DAT mRNA and protein is not as high in this region as the VTA and SN (see Howell and Kimmel, 2008 for review).

Serotonin transporters are found extensively throughout the brain; with serotonergic cell bodies located in the raphe nuclei in the brainstem (see Murphy et al., 2004 for review). The highest levels of SERT mRNA as well as protein are found in these regions, particularly in the DRN. Serotonin transporter protein levels are also high in the cerebral cortex, hippocampus, ventral striatum and hypothalamus. Intermediate levels of SERT are found in the midbrain, thalamus and dorsal striatum and low levels are in the cortex with virtually none in the cerebellum. Norepinephrine transporters are found less extensively in the brain, with the highest amounts present in the locus coeruleus (LC), and raphe nuclei (see Hoffman et al., 1998 for review). Norepinephrine transporters are located in cells that are both tyrosine hydroxylase and dopamine $\beta$-hydroxylase positive. Norepinephric cell bodies are also found in the LC, as is the majority of NET mRNA. Moderate levels of NET are found in the hypothalamus and midline thalamic nuclei, with lower expression in the cortex, hippocampus and striatum.

\subsubsection{Regulation of the monoamine transporters}

Monoamine transporter activity is regulated on several different levels including the velocity of monoamine uptake, and trafficking of the transporters to or from the cell surface (sees Kristensen et al., 2011 for review). The transporters are functional at the cell surface, where they are most likely associated with membrane lipid rafts, and are constitutively internalised to create a steady-state distribution split between the cell surface and intracellular domain. Following internalization, transporters may be either degraded, or form part of the intracellular pool available for rapid recycling back to the cell membrane (Melikian 2004). It has been shown that $\mathrm{N}$-linked glycosylation and 
oligomerisation of the transporters is essential for their trafficking to the cell surface, where they most likely function as homomultimeric complexes (see Melikian, 2004 for review). In addition, export from the endoplasmic reticulum to the cell surface is also regulated by the $\mathrm{C}$ terminus of the transporters (Kristensen et al., 2011). Putative Nlinked glycosylation sites on the monoamine transporters have been located in the large extracellular loop between TMDs three and four (Figure 1.4). There are three proposed sites in human DAT and NET and two in human SERT (Blakely et al., 1994; Li et al., 2004a). De-glycosylation generally results in internalisation of the transporters and thus a decrease in monoamine uptake. It does not, however, appear to affect transporter function or ligand binding to the transporters (Kristensen et al., 2011).

DAT, NET and SERT contain several putative intracellular phosphorylation sites that are involved in their regulation (Figure 1.4). Phosphorylation of these sites is involved in trafficking of the transporters to and from the cell surface, and kinases may also regulate transporter catalytic activity through phosphorylation (Apparsundaram et al., 2001; Zhu et al., 2004). Protein kinase $\mathrm{C}$ (PKC) is the best characterised kinase known to phosphorylate the monoamine transporters. It has been shown to increase phosphorylation levels of DAT, NET, and SERT, and to down-regulate their activity, most likely through transporter internalization (Kirstensen et al., 2011). There is, however, some suggestion that phosphorylation by PKC may initially inactivate transporter function through a trafficking-independent mechanism; and PKC-mediated DAT internalisation may require concurrent ubiquitination.

In addition to PKC there are several other kinases that are known to phosphorylate and regulate the monoamine transporters. It has been demonstrated that DAT is phosphorylated on the $\mathrm{N}$-terminus by numerous kinases including; mitogen activated protein kinases (MAPK), protein kinase $\mathrm{A}(\mathrm{PKA})$ and $\mathrm{Ca}^{2+} /$ calmodulin-dependent protein kinase (CamK) $\alpha$ (Kristensen et al., 2011). How this phosphorylation affects the function and cellular distribution of DAT in each case is not entirely clear. PKA has been shown to up-regulate DAT (Batchelor and Schenk, 1998), and inhibition of MAPK kinase has been shown to decrease DAT phosphorylation and activity (Moron et al., 2003). SERT has been shown to be phosphorylated by protein kinase $G(P K G)$ and PKA. PKG 
phosphorylation increases SERT function; however, it is not known whether this is due to redistribution of SERT to the cell surface or an increase in the catalytic activity of the transporter (Kristensen et al., 2011). In addition, inhibition of p38 MAPK decreases SERT phosphorylation and cell surface expression (Zhu et al., 2004). NET phosphorylation has been less extensively studied. It has been reported that CaMKII phosphorylates a segment of the N-terminus of NET; and CaMKII stimulation increases NET activity (Kristensen et al., 2011). Dephosphorylation of the monoamine transporters is an equally important mechanism for transporter regulation. It has been proposed that the monoamine transporters remain in a relatively dephosphorylated state the majority of the time due to tonic phosphatase activity. Both protein phosphatase I and protein phosphatase 2A act at DAT, NET and SERT, and the catalytic subunit of protein phosphatase $2 \mathrm{~A}$ has been found to co-immunoprecipitate with all of the monoamine transporters (Kristensen et al., 2011).

Substrates of the monoamine transporters may also regulate trafficking between the cell surface and interior. Amphetamine and DA have both been shown to induce endocytosis of DAT (Saunders et al., 2000; Chi and Reith, 2003), while cocaine and methylphenidate increase DAT cell surface expression (Daws et al., 2002; Little et al., 2002). Furthermore, amphetamine stimulates internalisation of NET in a CaMKII- and syntaxin1A-dependent manner (Dipace et al., 2007). Serotonin is believed to have a biphasic effect on SERT cell surface expression (Kristensen et al., 2011). Lower 5-HT concentrations appear to stabilize SERT expression at the cell surface, and higher concentrations reduce cell surface expression. The cellular mechanisms for this regulation of the monoamine transporters have not been fully elucidated. One theory is that the transporter conformation may determine likelihood of internalisation, so that an inward-facing DAT protein is more likely to be endocytosed than an outward-facing protein (Kristensen et al., 2011). In addition to substrate regulation, the monoamine transporters may be regulated by co-localised receptors. One example of this is the interaction between the $\mathrm{D}_{2} \mathrm{DA}$ receptor and DAT. Activation of the $\mathrm{D}_{2} \mathrm{DA}$ receptor has been shown to increase DAT function in a trafficking dependent manner (Bolan et al., 2007). There is currently no information in the literature on interactions between SERT or NET and their respective monoamine receptors; however, it would be of interest to establish whether there is a similar relationship as that observed with $\mathrm{D}_{2}$ and DAT. 


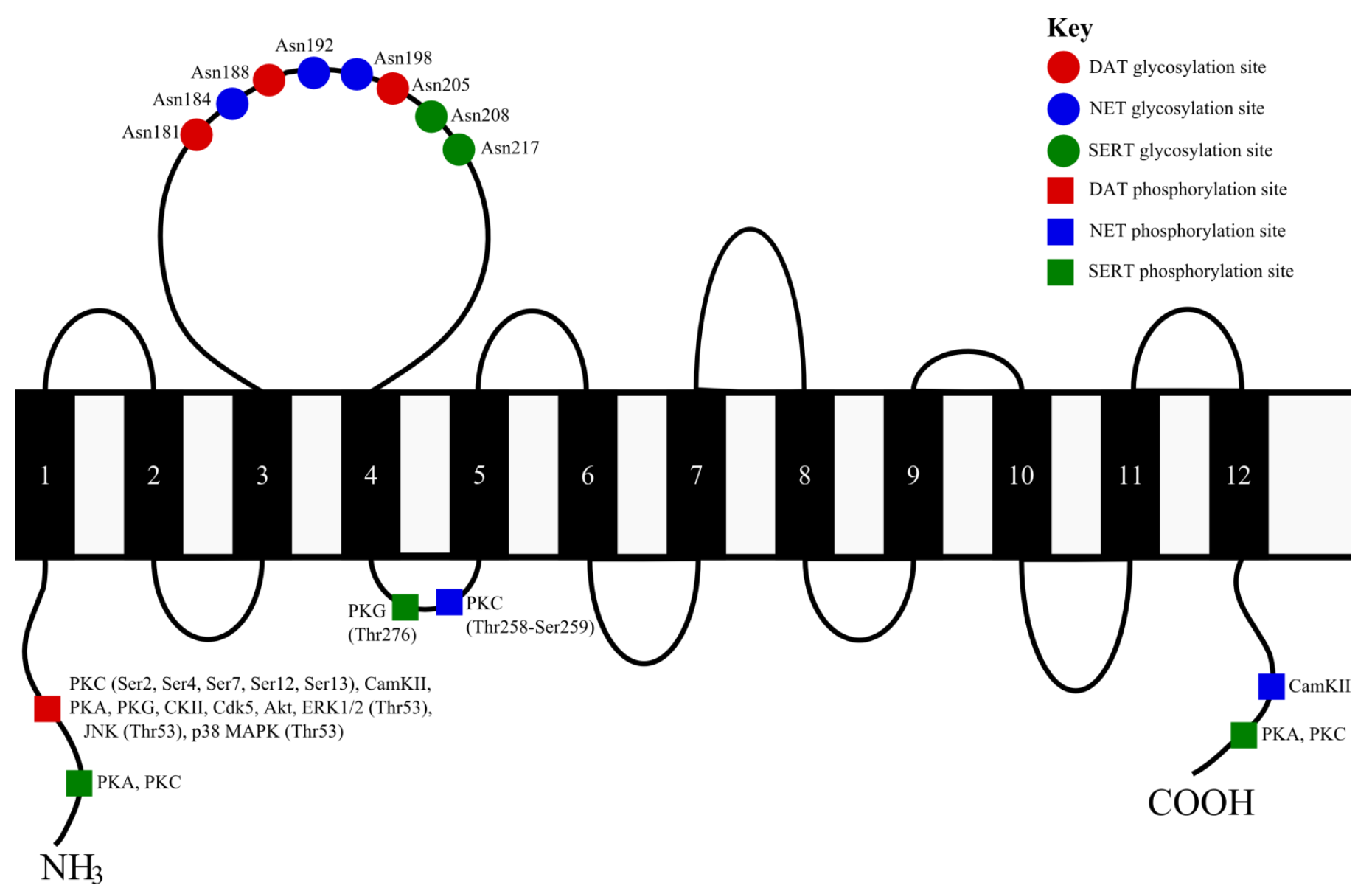

Figure 1.4: Monoamine transporter structure with putative glycosylation and phosphorylation sites for DAT, NET and SERT. Asn, asparagine; PKC, protein kinase C; PKA, protein kinase A; PKG, protein kinase G; CamKII, $\mathrm{Ca}^{2+} /$ calmodulin kinase II; CKII, casein kinase II; Cdk5, cyclin-dependant kinase 5; ERK 1/2, extracellular signal regulated kinase 1/2; JNK, c-Jun $\mathrm{NH}_{2}$-terminal kinase; MAPK, mitogen activated protein kinase. Compiled from Kristensen et al. (2011). 


\subsection{Cigarette Smoking and the Monoamine Transporters: human studies}

\subsubsection{Genetic Variation in Monoamine Transporters and Human Smoking Behaviour}

Numerous twin studies have indicated that smoking addiction has a heritable component (see Li et al., 2004b and Arinami et al., 2000 for review). The contribution of inheritance in smoking dependence is debatable and has been estimated to be between 0.04 and 0.86 . In recent years a substantial number of candidate gene polymorphisms have been proposed to contribute to smoking addiction. The dopamine transporter gene contains a polymorphic $40 \mathrm{bp}$ variable nucleotide tandem repeat (VNTR) sequence at the 3' untranslated region that has been implicated in smoking initiation and dependence (Kang et al., 1999). Each DAT allele contains between three and eleven repeats of this VNTR, with the nine and ten repeat (9r, 10r) alleles being the most common. Individuals homozygous for the 10r allele show significantly higher DAT availability than individuals with the 9r allele (Laucht et al. 2008). Studies have indicated that individuals with the 9r allele are less likely to be smokers or to start smoking before the age of 16 (Lerman et al., 1999). Adolescent individuals homozygous for the 10r allele are more likely to begin smoking daily at a younger age, and show significantly less intention to quit smoking when compared to other allele carriers (Laucht et al., 2008). Furthermore, individuals homozygous for the 10r allele who began smoking daily before the age of 14 were found to be heavier smokers at age 19 (Schmid et al., 2009).

Another DAT polymorphism that has been implicated in smoking behaviour is the $\mathrm{G}>\mathrm{A}$ transversion at position rs27072 in the 3' untranslated region (Ling et al., 2004). This transversion produces what is commonly referred to as the DAT A allele. Ling et al. (2004) found a significant association between the DAT A allele and smoking onset in under 18 year olds but not severe nicotine dependence (Ling et al., 2004). Sieminska et al. (2009) found that the DAT A allele carriers remained abstinent longer during quit attempts, and that 9r allele carriers had a decreased risk of smoking initiation under the age of 20 (Sieminska et al., 2009). Furthermore, it was found that individuals who carried the DAT A and 9r alleles in combination had a decreased risk of smoking regularly under the age of 20, compared to individuals who carried neither of these alleles (Sieminska et al., 2009). 
The SERT gene contains two VNTR polymorphisms (Li et al., 2004b). One of these is located in the second intron and has no apparent relevance to smoking dependence. The second, known as the 5-HT transporter long promoter region (5HTTLPR) is located upstream of the coding region in the transcriptional control region. The long, or L-type, allele contains a $44 \mathrm{bp}$ insertion that the short, or S-type, allele does not. The S-type allele displays decreased transcriptional activity compared to the L-type allele (Heils et al., 1996). Gerra et al. (2005) have found that the S-type allele is associated with early onset of smoking in teenagers (Gerra et al., 2005). They also found that in Caucasian high school students the homozygous S-type allele was more common amongst smokers than non-smokers, as well as being more predominant in heavy smokers. In contrast, Ishikawa et al. (1999) found that in Japanese males the L allele is significantly more predominant in smokers than non-smokers, and that individuals with the S/S genotype are more likely to be non-smokers or to be successful in quit attempts (Ishikawa et al., 1999). This inconsistency highlights the importance of considering factors such as age, gender and ethnic background when examining the genetics of smoking addiction.

Present understanding of the genetic contribution to smoking addiction is incomplete and needs to be further developed. As stated, however, there is evidence that genetic polymorphisms play a role in the development of tobacco addiction, and there are likely to be multiple genes that contribute to this. Acquiring knowledge of an individual's genetic vulnerability to smoking addiction may help direct prevention and cessation therapy resources to where they will be more effective. In future, pharmacotherapies may be developed based upon an individual's genetic makeup.

\subsubsection{Smoking and monoamine transporter expression}

To date, there have been few studies investigating the effects of cigarette smoke on the function of monoamine transporters in human smokers. [ ${ }^{99 \mathrm{~m}} \mathrm{Tc}$ ] TRODAT-1 specifically binds to DAT, and has been used in several single-photon emission computed tomography imaging studies in human smokers (Krause et al., 2002; Newberg et al., 2007; Yang et al., 2008). A significant decrease in [ ${ }^{99 \mathrm{~m}} \mathrm{Tc}$ ] TRODAT-1 binding is seen in 
the striatum of human smokers compared to non-smokers. This decrease in DAT in human smokers is consistent with the DA hypothesis of drug addiction, whereby decreased DAT availability results in increased synaptic DA and increased reward (see Pierce and Kumaresan, 2006 for review).

The observed decrease in binding to DAT in human smokers has not been seen with NET. Klimek et al. (2001) analysed $\left[{ }^{3} \mathrm{H}\right]$ nisoxetine binding to NET in the LC of human post mortem brains. They found that there was no significant difference in binding between smokers and non-smokers, suggesting that smoking has no effect on NET density in the LC (Klimek et al. 2001). This is consistent with the findings of Andreasen et al. (2009), who found no change in $\left[{ }^{3} \mathrm{H}\right]$ nisoxetine binding in hippocampal and cortical membrane preparations from mice treated with chronic nicotine $(40-50 \mathrm{mg} / \mathrm{kg} / \mathrm{day}$ oral $>2$ months $)$ (Andreasen et al., 2009). These findings suggest that the effects of nicotine and cigarette smoke may differ for the different transporters. There are so little data to date on the effects of nicotine or cigarette smoke on SERT and NET so that it is difficult to draw many conclusions. Further study on these transporters should begin to make their role in smoking addiction clearer.

\subsubsection{Monoamine Transporters as a Pharmacotherapeutic Target for Smoking}

\section{Cessation}

Polymorphisms in the monoamine transporter genes have been associated with several psychiatric conditions including ADHD (Franke et al., 2008; Joung et al., 2009), depression (Clarke et al., 2010) and schizophrenia (Cordeiro et al., 2010). These conditions are associated with the dysfunction of monoamine systems and monoamine reuptake inhibitors are commonly prescribed for the treatment of mental illnesses, particularly for depression (Butler and Meegan, 2008; Christman et al., 2004). Interestingly, smoking rates are higher amongst patients with these psychiatric disorders than the general population. Lasser et al. (2000) reported that in the United States the current smoking rate for individuals with reported mental illness was $41 \%$ compared to $22.5 \%$ in the general population (Lasser et al., 2000). The prevalence of smoking in 
schizophrenic patients has been shown to be between $45-88 \%$, and $40-60 \%$ in individuals with clinically significant symptoms of depression (Kalman et al., 2005). Furthermore, subjects with ADHD are approximately twice as likely to become dependent on tobacco compared to the general population (Gray and Upadhyaya, 2009).

Methylphenidate (Ritalin) and $d$-amphetamine are commonly prescribed pharmacotherapies for $\mathrm{ADHD}$ that act on the monoamine transporters to increase monoaminergic neurotransmission (Heal et al., 2009). Studies have shown that both methylphenidate and $d$-amphetamine dose-dependently increase smoking in healthy adult smokers when administered acutely (Rush et al., 2005; Vansickel et al., 2007; Cousins et al., 2001). Methylphenidate also increases smoking behaviour in sustained-release form (Vansickel et al., 2009). Acute methylphenidate has also been shown to increase the rate of nicotine self-administration in adult male rats (Wooters et al., 2008), and $d$ amphetamine increased the choice of smoking over money in healthy human smokers (Tidey et al., 2000). In contrast atomoxetine, a specific NET inhibitor, was shown to have no effect on smoking behaviour (Vansickel et al., 2007). These findings at first appear contradictory to the actions of bupropion, a proven smoking cessation aid that works at least in part by blocking DAT and NET function. However, bupropion has been shown to increase smoking behaviour when administered acutely, and only works as a cessation aid with chronic administration (Cousins et al., 2001). This suggests that alteration of monoamine transporter function, in particular DAT, may lead to changes in smoking behaviour and susceptibility to addiction.

Bupropion is currently the only approved smoking cessation aid that affects the function of monoamine transporters. However, several anti-depressants have been tested for their anti-smoking properties (Miller et al., 2002; Prochazka et al., 1998; Rauhut et al., 2002). Depression is a common withdrawal symptom in people attempting to quit smoking, and it has even been suggested that people may smoke to self-medicate due to depression (Lerman et al., 1998). It is therefore logical that antidepressants would be a good basis for smoking cessation treatments. Antidepressants that have been investigated to date include the tricyclic antidepressants reboxetine and nortirptyline, and the selective serotonin reuptake inhibitor fluoxetine (see Hughes et al., 2007 for review). 
Reboxetine is a selective NET inhibitor that has been found to inhibit nAChR function (Miller et al., 2002). It has recently been shown to attenuate nicotine self administration in rats at rates similar to mecamylamine; however, it also attenuates food-maintained responding (Paterson et al., 2008; Rauhut et al., 2002). Nortriptyline inhibits NET function and SERT to a lesser extent. In a randomised trial conducted by Prochazka et al. (1998) nortriptyline was shown to increase short term cessation rates with small reductions in withdrawal (Prochazka et al., 1998). It was shown to double the odds of patients quitting smoking (Polosa and Benowitz, 2011), and did not differ from bupropion in 1 year abstinence rates (Hall et al., 2002). Fluoxetine is the most commonly investigated selective serotonin reuptake inhibitor for smoking cessation. It has been shown to have some anti-smoking effects in patients with a history of severe depression; however it does not seem to produce any significant benefits in non-depressed patients (Blondal et al., 1999).

\subsection{The Effects of Nicotine and Cigarette Smoke on Monaomine Transporter Function: preclinical studies}

\subsubsection{Nicotine, Cigarette Smoke, and the Dopamine Transporter}

Nicotine has been shown to increase DAT function in the PFC (Middleton et al., 2004; Zhu et al., 2009), striatum (Middleton et al., 2004) and NAc (Hart and Ksir, 1996). Using in vivo voltammetry techniques, acute systemic nicotine treatment has been shown to decrease DA peak amplitudes in the NAc, striatum and PFC of the rat, indicating an increase in DA clearance (see Table 1.2 for a summary of the effects of nicotine and cigarette smoke on DAT) (Hart and Ksir, 1996; Middleton et al., 2004). A single dose of $0.4 \mathrm{mg} / \mathrm{kg}$ subcutaneous (s.c.) nicotine produced a maximal decrease in signal amplitude of $50 \%$ of the baseline value in the NAc at 60 min post-injection (Hart and Ksir, 1996). The decrease in peak amplitude was dose-dependent with s.c. administration of nicotine at doses between 0.03 and $0.3 \mathrm{mg} / \mathrm{kg}$ (free base) in both the striatum and PFC; however, the striatum and PFC displayed differences in dose-response to nicotine (Middleton et al., 2004). In the PFC a U-shaped dose-response curve was observed with maximal decrease in signal amplitude at $0.14 \mathrm{mg} / \mathrm{kg}$ nicotine at $30 \mathrm{~min}$ post-injection. In the striatum a 
maximal response was observed with $0.3 \mathrm{mg} / \mathrm{kg}$ (s.c.) nicotine at $45 \mathrm{~min}$ post-injection in a monophasic dose-response (Middleton et al., 2004). This work suggests that nicotine increases DAT function in the striatum, NAc and PFC in a region-specific manner.

Further support for increases in DAT function following nicotine treatment have been demonstrated by radioactive DA uptake studies in striatal and prefrontocortical synaptosome preparations (Middleton et al., 2007a; Zhu et al., 2009). Middleton et al. (2007a) obtained striatal synaptosomes from rats 5, 10, 40 and 60 min following a single exposure to nicotine $(0.32 \mathrm{mg} / \mathrm{kg}$ s.c.) and found a $25 \%$ increase in maximal velocity of uptake $\left(\mathrm{V}_{\max }\right)$ of $\left[{ }^{3} \mathrm{H}\right] \mathrm{DA}$ at 10 and 40 min only. However, no overall change in DAT protein levels or cell surface expression was revealed using [ $\left.{ }^{3} \mathrm{H}\right] \mathrm{GBR} 12935$ binding and synaptosomal biotinylation methods, indicating that the observed changes may be trafficking-independent (Middleton et al., 2007a).

Contrary to the findings of Middleton et al. (2007a), Zhu et al. (2009) found no significant change in $\left[{ }^{3} \mathrm{H}\right] \mathrm{DA}$ uptake in striatal synaptosomes obtained from rats $15 \mathrm{~min}$ to $24 \mathrm{hr}$ following acute nicotine exposure at 0.3 or $0.8 \mathrm{mg} / \mathrm{kg}$ nicotine (s.c.) (Zhu et al., 2009). However, there was a trend towards an increase in $\mathrm{V}_{\max }$ of approximately $20 \%$ that approached significance. A significant increase in $\mathrm{V}_{\max }$ of $\left[{ }^{3} \mathrm{H}\right] \mathrm{DA}$ uptake in PFC synaptosomes from rats treated with 0.8 , but not $0.3 \mathrm{mg} / \mathrm{kg}$ nicotine (s.c.) was observed at $15 \min \left(55 \%\right.$ increase in $\left.\mathrm{V}_{\max }\right)$ and $30 \min \left(87 \%\right.$ increase in $\left.\mathrm{V}_{\max }\right)$ following nicotine exposure. In transporter binding assays the DAT specific radioligand $\left[{ }^{3} \mathrm{H}\right] \mathrm{WIN} 35,428$ showed no change in overall DAT binding in PFC synaptosomes. However, biotinylation studies and Western blot analysis of synaptosomes showed a $32 \%$ increase in DAT cell surface expression $30 \mathrm{~min}$ following $0.8 \mathrm{mg} / \mathrm{kg}$ nicotine. This increase was not as great in magnitude as the $87 \%$ increase in $\mathrm{V}_{\max }$, suggesting that increased DAT activity may not be entirely trafficking dependent (Zhu et al., 2009). Further research into the mechanism by which nicotine modulates DAT trafficking and cell surface expression is warranted, including clarification of the role of trafficking in DAT up-regulation. 
There has been some research to suggest that nicotine causes a decrease, rather than an increase in DA uptake. Earlier studies by Izenwasser et al. (1991) and Yamashita et al. (1995) reported decreases in $\left[{ }^{3} \mathrm{H}\right] \mathrm{DA}$ uptake in minced striatal tissue and PC12 cells (endogenously expressing DAT) following nicotine treatment $(1 \mu \mathrm{M} ; 10 \mu \mathrm{M}-10 \mathrm{mM})$ (Izenwasser et al., 1991; Yamashita et al., 1995). This discrepancy is most likely due to differences between in vitro and in vivo treatment. Interestingly, Zhu et al. (2009) found that PFC synaptosomes from in vivo treated rats showed an $87 \%$ increase in $\mathrm{V}_{\max }$ of $\left[{ }^{3} \mathrm{H}\right] \mathrm{DA}$ uptake, whereas in vitro treatment (1 $\mathrm{nM}-10 \mu \mathrm{M}$ nicotine) of synaptosomes resulted in no change in uptake (Zhu et al., 2009). This is consistent with the findings of Izenwasser et al. (1991) and Drew and Werling (2003), that in vitro nicotine treatment (1 $\mu \mathrm{M} ; 1-50 \mu \mathrm{M})$ did not alter DA uptake in striatal and prefrontocortical synaptosomes respectively (Drew and Werling, 2003; Izenwasser et al., 1991). This indicates that whole brain circuitry affects the modulation of transporter activity by nicotine, and is required for more biologically relevant experiments.

The majority of research on the effects of nicotine on monoamine transporters has been conducted using acute nicotine treatment; however, human smokers expose themselves to nicotine and cigarette smoke chronically. The few studies that have examined chronic nicotine treatment have reported conflicting results. Drew and Werling (2003) measured DA uptake by PFC synaptosomes prepared from chronically treated animals $(2 \mathrm{mg} / \mathrm{kg}$ (s.c.) $2 \mathrm{x}$ daily for 10 days) and interestingly found no difference in DA uptake between nicotine and saline treated animals (Drew and Werling, 2003). This is consistent with the findings of Izenwasser and Cox (1992) and Carr et al. (1989) who found no change in $\left[{ }^{3} \mathrm{H}\right] \mathrm{DA}$ uptake in chopped striatal or accumbal tissue from rats treated with $6 \mathrm{mg} / \mathrm{kg} / \mathrm{day}$ nicotine for 7 days via osmotic minipumps (Izenwasser and Cox, 1992); or in striatal or NAc synaptosomes from chronically treated rats $(3 \mathrm{mg} / \mathrm{kg} /$ day nicotine via s.c. osmotic minipump). However, Rahman et al. (2004) found a significant increase in DA uptake in the NAc of nicotine self-administering rats (i.v. for 25 days) 12-24 hours after final selfadministration session, using no-net-flux microdialysis and in vivo extraction fraction techniques (Rahman et al., 2004). Interestingly, they found no difference between selfadministering animals and the yoked nicotine group that received passive infusions of nicotine paired to the self-administering animals. Both the self-administering group and yoked nicotine group showed an increase in DAT function over the yoked saline group 
with extraction fractions of $86 \%, 91 \%$ and $77 \%$ respectively. Hadjiconstantinou et al. (2011) investigated the effects of withdrawal from chronic nicotine on DAT function in mice using radioactive uptake in striatal synaptosomes. Animals were treated with 2 $\mathrm{mg} / \mathrm{kg}$ nicotine (s.c.) 4 times daily for 14 days and sacrificed 4-72 hrs after final drug treatment. A $27-38 \%$ increase in DAT function was found 12-24 hrs into withdrawal, with no change at 4 or $8 \mathrm{hrs}$, and function returned to normal by $48 \mathrm{hrs}$. It should be noted that both Rahman et al. (2004) and Hadjiconstantinou et al. (2011) used chronic models that consisted of longer treatments (14-25 days), compared to only 7-10 days used by other researchers. The discrepancy in results may be due to differences in response to nicotine between sub-chronic and chronic dosing. In addition, the length of time in nicotine withdrawal may also make a significant difference to DAT function. Overall, these findings suggest that there could be differences in the modulation of DAT by acute and chronic nicotine treatments whereby acute nicotine administration results in an increase in DAT function, while chronic or sub-chronic treatment results in no change in function.

In addition to having a direct effect on DA uptake by DAT, nicotine has also been shown to modulate DAT activity by enhancing amphetamine-induced efflux of DA in PFC and striatal, but not NAc, slices prepared from rats (Drew et al., 2000; Drew and Werling, 2003; Jutkiewicz et al., 2008). This effect was seen in response to acute in vitro (5 $\mu \mathrm{M}$ nicotine) treatment and following nicotine challenge $(5 \mu \mathrm{M})$ to slices from chronically treated animals ( $2 \mathrm{mg} / \mathrm{kg}$ (s.c.) $2 \mathrm{x}$ daily for 10 days) in PFC synaptosomes (Drew et al., 2000; Drew and Werling, 2003). In striatal slices, this effect was seen following both in vivo nicotine $(0.32 \mathrm{mg} / \mathrm{kg})$ treatment and in vitro treatment $(10 \mu \mathrm{M}$ nicotine) (Jutkiewicz et al., 2008). It is interesting to note that nicotine enhanced amphetamine-induced efflux in vivo and in vitro (Jutkiewicz et al., 2008) and with both chronic and acute treatments (Drew et al., 2000; Drew and Werling, 2003). This contrasts to the discrepancies in the literature of the direct effect of nicotine on DA uptake by DAT with different treatments (Hart and Ksir, 1996; Middleton et al., 2004; Izenwasser et al., 1991; Yamashita et al., 1995; Drew and Werling, 2003). This could suggest that nicotine may act via different pathways and mechanisms for the direct effect of DA uptake by DAT compared to amphetamine induced efflux through DAT. Furthermore, this work indicates that there could be differences in response to stimulant pharmacotherapies including 
methylphenidate and $d$-amphetamine between smokers and non-smokers. Methylphenidate and $d$-amphetamine have been shown to increase smoking behaviour in humans (Rush et al., 2005; Vansickel et al., 2007; Cousins et al., 2001) and are commonly prescribed to patients with ADHD, who have a high prevalence of smoking (Gray and Upadhyaya, 2009). In light of this, further research into the effects of coadministered nicotine and amphetamine or other stimulants on the monoamine transporters would be beneficial in developing tailored smoking cessation aids for individuals on stimulant medications.

To date, few studies have investigated the effects of cigarette smoke or non-nicotinic compounds found in cigarette smoke on the monoamine transporters. Miller et al. (2007) used $\left[{ }^{3} \mathrm{H}\right]$ GBR12935 binding to determine the changes in DAT protein levels in the midbrain of guinea pigs exposed to cigarette smoke (Miller et al., 2007). The animals were exposed to cigarette smoke from three cigarettes for approximately one hour twice daily for seven weeks prior to sacrifice. A 52\% increase in $\left[{ }^{3} \mathrm{H}\right] \mathrm{GBR} 12935$ binding was found in crude membrane preparations compared to control animals. This finding contrasts to previous work by Middleton et al. (2007a) that showed no change in overall DAT protein levels in rat synaptosomes following nicotine treatment (Middleton et al., 2007a); however, the findings of Middleton et al. (2007a) were from rats that were exposed to nicotine acutely. This suggests that there may be differences in nicotinic modulation of DAT between species, at different time points, or that non-nicotinic compounds in cigarette smoke may also modulate DAT expression. Research into the effects of non-nicotinic components of cigarette smoke is severely lacking and is required to confirm this.

One non-nicotinic compound that has been studied is nornicotine, a metabolite of nicotine that is present in cigarette smoke. It has been shown to be neurologically active and induces the release of DA in slice preparations (Dwoskin et al., 2001). Recently Middleton et al. (2007b) showed that nornicotine $(0.35-12 \mathrm{mg} / \mathrm{kg}$ (s.c.)) decreased DAT function using in vivo voltammetry in the striatum of rats, in contrast to nicotine which has been shown to increase DAT activity (Middleton et al., 2007b). The authors suggested that this discrepancy could be due to nornicotine activating a different subset of 
nAChRs to those activated by nicotine. This finding highlights the importance of considering the effects of non-nicotinic compounds present in cigarette smoke when investigating smoking addiction.

The decreased binding of TRODAT to DAT in the striatum of human smokers found by Krause et al. (2002), Newberg et al. (2007) and Yang et al. (2008) is inconsistent with animal studies described above, where there was either an increase or no change in overall DAT binding (Middleton et al., 2007a; Miller et al., 2007). There are several possible explanations for these differences. Firstly, there are vast differences between human smoking behaviour and nicotine dosing regiments for animals including; inhaled cigarette smoke compared to injections, the number of nicotine treatments per day compared to what a human smoker will smoke, and the self-administering behaviour of human smokers compared to the forced injections often received by animals. It should also be noted that in chronic models of nicotine administration animals often receive either a consistent infusion of nicotine via minipump, or a single large injection of nicotine in a day. This does not accurately reflect the peaks and falls in plasma nicotine concentration seen in human smokers over the period of a day. In addition to this, human smokers expose themselves to cigarette smoke chronically; whereas, many animal studies focus solely on single nicotine administrations. Current research suggests that chronic nicotine may have no effect on DA uptake by DAT. In consideration of the changes seen in human smokers, it could be speculated that an initial increase in DA uptake by DAT is counteracted by a decrease in DAT expression with chronic administration. Finally, while most animal studies investigate nicotine alone, there are over 4000 compounds in cigarette smoke, some of which are neurologically active and are likely to contribute to cigarette smoking addiction (Fowles and Dybing, 2003).

\subsubsection{The effects of nicotine on SERT}

Despite numerous investigations linking the serotonergic system to tobacco addiction, few studies have examined the effects of nicotine on SERT (see Fletcher et al., 2008 for review). Awtry and Werling (2003) found significant increases in $\left[{ }^{3} \mathrm{H}\right] 5$-HT uptake in rat synaptosomal preparations of the hippocampus and PFC following nicotine treatment (Awtry and Werling, 2003). Single $0.7 \mathrm{mg} / \mathrm{kg}$ (s.c.) nicotine injections given $15-75 \mathrm{~min}$ 
prior to sacrifice gave significant increases in SERT $V_{\max }$ at 15, 30 and 45 min for the $\mathrm{PFC}$, and at $60 \mathrm{~min}$ only for the hippocampus. Chronic nicotine delivery $(0.7 \mathrm{mg} / \mathrm{kg}$ twice daily for 10 days) resulted in significant increases in $\left[{ }^{3} \mathrm{H}\right] 5-\mathrm{HT}$ uptake in the PFC (>200\%) and the hippocampus (150\%). These increases were accompanied by a $36 \%$ increase in $\left[{ }^{3} \mathrm{H}\right]$ paroxetine binding in the PFC and a $64 \%$ increase in the hippocampus, indicating that the increase in $\left[{ }^{3} \mathrm{H}\right] 5-\mathrm{HT}$ uptake is at least in part due to an increase in SERT density. In addition to this, $4 \mu \mathrm{M}$ in vitro additions of nicotine to PFC synaptosomes resulted in a 75\% increase in $\left[{ }^{3} \mathrm{H}\right] 5$-HT uptake (Awtry and Werling, 2003). In summary, the effects of nicotine on SERT differ from those on DAT, in that an increase in 5-HT uptake is observed with both acute and chronic, and in vivo and in vitro nicotine treatment. However, as was observed with DAT, nicotine induced changes in SERT function appears to be brain region specific. Future research to confirm these findings as well as establishing the mechanism responsible for the increase in 5-HT uptake is necessary to better characterise the effects of nicotine on SERT.

\subsubsection{The effects of nicotine on NET}

There has been only one published study on the effects of nicotine on NE uptake to date. Recently, Itoh et al. (2010) found a dose- and time-dependant increase in $\left[{ }^{3} \mathrm{H}\right] \mathrm{NE}$ uptake in cultured bovine adrenal medullary cells (endogenously expressing NET) in response to nicotine (0.1-10 $\mu \mathrm{M})$ (Itoh et al., 2010). This effect was seen over a 5 day period with the greatest increase in uptake observed between 2-3 days. Subsequently, cells incubated with different concentrations of nicotine for 2 days showed a monophasic dose response to nicotine, with the greatest increase in uptake (161\% of control) observed with $10 \mu \mathrm{M}$ nicotine. Furthermore, a significant increase in $\mathrm{V}_{\max }$, with no change in $\mathrm{K}_{\mathrm{m}}$, was observed in cells incubated with $10 \mu \mathrm{M}$ nicotine for 2 days. The DNA-dependant RNA polymerase inhibitor actinomycin D, and the ribosomal protein synthesis inhibitor cylcoheximide, were used to determine whether the observed change in NET function was due to transcriptional or translational regulation of NET. Both actinomycin D and cycloheximide produced a small inhibition of basal NE uptake, reducing uptake to $78 \%$ and $77 \%$ respectively; however, only cylcoheximide attenuated the nicotine induced increase in NE uptake. Furthermore, the proteosome inhibitor MG132 had no significant effect on NET function (Itoh et al., 2010). This would suggest that modulation of NET by nicotine may be partially due to an increase in protein synthesis, independent of an 
increase in gene transcription. However, due to the nonspecific nature of these compounds results should be interpreted with extreme caution as a number of other systems may have been affected that could have nonspecific downstream effects on NET.

To the best of the authors knowledge there have been no studies on the effects of nicotine or cigarette smoke on NE uptake in laboratory animals. Zhu et al. (2009) did examine DA uptake by NET in PFC synaptosomes $30 \mathrm{~min}$ after $0.8 \mathrm{mg} / \mathrm{kg}$ nicotine (s.c.). They found no change in the Vmax or Km of DA uptake using a radioactive uptake assay. It is surprising that there have not been studies on the effects of nicotine or cigarette smoke on NET considering that the smoking cessation therapy bupropion works in part by blocking this transporter. Nicotine has been shown to increase NE levels in the PFC, hippocampus and striatum (Rossi et al., 2005; Scholze et al., 2007) and there is increasing evidence that NE is involved in the pathology of drug addiction (see Weinshenker and Schroeder, 2007 for review). The contribution of NE to forming a pathological addictive state is partly mediated through its effects on DA release; however, there is also evidence for an independent NE pathway involved in drug addiction, particularly for ethanol and opiates (Weinshenker and Schroeder, 2007). In addition, it has been suggested that NE contributes to the withdrawal state of a number of drugs of abuse, including nicotine (Sofuoglu and Sewell 2008). Therefore, it would be highly beneficial for future research to ascertain how nicotine and cigarette smoke affect the function of NET.

\subsection{Mechanisms of Nicotinic Alteration of Monoamine Transporter Function}

\section{$\underline{1.6 .1 \mathrm{nAChRs}}$}

Nicotine does not directly interact with DAT (Izenwasser et al., 1991). Instead, it has been consistently demonstrated that monoamine transporter activity is modulated by nAChRs (Awtry et al., 2006; Izenwasser et al., 1991; Middleton et al., 2004; Middleton et al., 2007b; Yamashita et al., 1995; Zhu et al., 2009). Modulation of DAT activity has been shown to be nicotinic receptor specific as atropine, a muscarinic antagonist, has no effect on nicotine induced changes in DAT function (Yamashita et al., 1995). Mecamylamine and hexamethonium are nAChR antagonists that are nonspecific for 
nAChR subtypes. Mecamylamine has been shown to attenuate nicotine effects on DAT in the PFC, NAc and striatum (Drew et al., 2000; Hart and Ksir, 1996; Middleton et al., 2004; Yamashita et al., 1995; Zhu et al., 2009), and SERT in the PFC (Awtry et al., 2006). Both mecamylamine and hexamethonium have been shown to attenuate the effects of nicotine on NET in bovine adrenal medullary cells (Itoh et al., 2010). Interestingly, Zhu et al. (2009) found that mecamylamine not only attenuates the increase in $\mathrm{V}_{\max }$ produced by nicotine, but it also attenuates the nicotine induced increase in DAT cell surface expression in the PFC (Zhu et al., 2009). Mecamylamine also blocked the nornicotine induced decrease in DA uptake observed by Middleton (2007b). This research suggests that $\mathrm{nAChR}$ antagonism modulates DAT, NET and SERT function, by blocking the effects of nicotine on the transporters. However, the mechanism by with this occurs remains to be determined and additional research using specific $\mathrm{nAChR}$ antagonists is also needed to determine which $\mathrm{nAChR}$ subtypes are responsible for the observed effects.

Several studies have investigated the involvement of specific nAChR subtypes and they have been shown to vary in their ability to modulate monoamine transporter function. Dihydro-beta-erythroidine $(\mathrm{DH} \beta \mathrm{E})$ is a $\beta 2 \mathrm{nAChR}$ antagonist that has been shown to attenuate the nicotine induced increases in DAT function, and amphetamine stimulated DA efflux in PFC synaptosomes (Drew et al., 2000; Zhu et al., 2009). DHßE also attenuates the nicotine induced increase in SERT uptake in PFC synaptosomes (Awtry et al., 2006). These results suggest that $\alpha 4 \beta 2 \mathrm{nAChRs}$ are important in nicotinic modulation of monoamine transporter function. There is some evidence for the involvement of $\alpha 7$ receptors in nicotinic modulation of monoamine transporter function. Zhu et al. (2009) found that the $\alpha 7$ antagonist methyllycaconitine blocked the nicotine induced increase in DAT function (Zhu et al., 2009). In contrast Drew et al. (2000) found that the $\alpha 7$ antagonist $\alpha$-bungarotoxin did not have any effect on nicotine induced increases in amphetamine stimulated DA efflux (Drew et al., 2000). Similarly, Itoh et al. (2010) reported no change in nicotine induced increases in NET function following $\alpha$ bungarotoxin treatment (Itoh et al., 2010). This may be due to the different systems modulating DA uptake by DAT and DA efflux via DAT. Different nAChR subtypes may also be responsible for the modulation of the different monoamine transporters. More work is necessary before any definitive conclusions can be drawn. 


\subsubsection{Secondary Messenger Systems}

There has been some work conducted on secondary messenger involvement in nicotinic modulation of monoamine transporters. Drew and Werling (2001) and Drew et al. (2003) found that the PKC inhibitor chelerythrine blocked the nicotinic enhancement of amphetamine induced DA release (Drew and Werling, 2001; Drew and Werling, 2003). Furthermore, it was found that CamKII inhibitors did not attenuate nicotine effects (Drew and Werling, 2001). Awtry et al. (2006) found that PKA stimulation increased 5-HT uptake; whereas, the PKA blocker Rp-cAMP caused a decrease in uptake. In addition, Rp-cAMP was shown to block 5-HT uptake following nicotine treatment, indicating that modulation of SERT by nAChRs is PKA-dependent (Awtry et al., 2006). Itoh et al. (2010) found no effect on nicotine induced increases in NET function with H-89 (a cAMP-dependent protein kinase inhibitor), U0126 (mitogen activated protein kinase kinase inhibitor), calphositn C (PKC inhibitor), or the Rho kinase inhibitors Fasudil and Y27632 (Itoh et al., 2010). It was found; however, that nicotinic effects on NET were completely abolished by removing extracellular calcium. The CaMKII inhibitor KN-93 significantly inhibited increases in NET function; however, the inactive analogue KN-92 produced a similar effect. It was then found that both analogues suppressed the nicotine induced ${ }^{45} \mathrm{Ca}^{2+}$ influx, suggesting that it was the lack of calcium and not CaMKII inhibition responsible for this observation. In summary, the effects of nicotine on NET appear to require calcium influx into the cell, but no specific signalling pathways have been shown to be required. It is not currently known how calcium influx affects NET to produce the nicotine induced increase in uptake, and further research on this is necessary for clarification.

It should be noted that activation of signalling pathways such as PKA and PKC may not be due to a direct effect of nAChR stimulation. Binding of nicotine to the nAChRs induces the release of DA into the synapse, which in turn activates DA receptors including the D2 auto-receptor, which has been shown to modulate DAT function (Bolan et al., 2007). Therefore, care should be taken when extrapolating conclusions from research on signalling pathways, as the effects of blocking or stimulating these pathways on a whole system can have multiple and indirect effects. 
Table 1.2: The effects of chronic nicotine and cigarette smoke on DAT function.

\begin{tabular}{|c|c|c|c|c|c|}
\hline & Animal & Treatment & Effect & Mechanism & Author \\
\hline \multirow[t]{2}{*}{ PFC } & Rat & $\begin{array}{l}2 \mathrm{mg} / \mathrm{kg} \text { nicotine s.c. } 2 \mathrm{x} \text { daily, } 10 \\
\text { days; } 1-50 \mu \mathrm{M} \text { nicotine in vitro }\end{array}$ & no change in uptake & & $\begin{array}{l}\text { Drew and Werling } \\
2003\end{array}$ \\
\hline & Rat & $\begin{array}{l}2 \mathrm{mg} / \mathrm{kg} \text { nicotine s.c. } 2 \mathrm{x} \text { daily, } 10 \\
\text { days followed by } 5 \mu \mathrm{M} \text { nicotine in } \\
\text { vitro }\end{array}$ & $\begin{array}{l}\text { inc. amphetamine-induced DA } \\
\text { efflux (no difference between } \\
\text { chronic nicotine and chronic saline } \\
\text { pre-treatment) }\end{array}$ & $\begin{array}{l}\text { Attenuated by } \mathrm{DH} \beta \mathrm{E} \& \text { the } \\
\text { PKC inhibitor chelerythrine }\end{array}$ & $\begin{array}{l}\text { Drew and Werling } \\
2003\end{array}$ \\
\hline \multirow[t]{2}{*}{ NAc } & Rat & self-administration i.v. for 25 days & inc. uptake & & Rahman et al. 2003 \\
\hline & Rat & $\begin{array}{l}6 \mathrm{mg} / \mathrm{kg} / \text { day nicotine for } 7 \text { days via } \\
\text { osmotic minipump } \\
3 \mathrm{mg} / \mathrm{kg} / \text { day for } 14 \text { days via } \\
\text { osmotic minipump }\end{array}$ & no change in uptake & & $\begin{array}{l}\text { Izenwasser and Cox } \\
1992 \\
\text { Carr et al. } 1989\end{array}$ \\
\hline \multirow[t]{5}{*}{ Striatum } & Rat & $\begin{array}{l}6 \mathrm{mg} / \mathrm{kg} / \text { day nicotine for } 7 \text { days via } \\
\text { osmotic minipump }\end{array}$ & no change in uptake & & $\begin{array}{l}\text { Izenwasser and Cox } \\
1992\end{array}$ \\
\hline & $\begin{array}{l}\text { Guinea } \\
\text { pig }\end{array}$ & $\begin{array}{l}\text { Cigarette smoke } \sim 1 \text { hr } 2 \text { x daily, } 7 \\
\text { weeks }\end{array}$ & $52 \%$ inc. DAT binding & & Miller et al. 2007 \\
\hline & Human & Cigarette smokers & dec. in $\left[{ }^{99 \mathrm{~m}} \mathrm{Tc}\right] \mathrm{TRODAT}-1$ binding & & $\begin{array}{l}\text { Krause et al. 2002; } \\
\text { Newberg et al. } \\
\text { 2007; Yang et al. }\end{array}$ \\
\hline & Mouse & $\begin{array}{l}2 \mathrm{mg} / \mathrm{kg} \text { nicotine s.c. } 4 \mathrm{x} \text { daily, } 14 \\
\text { days, sacrificed } 4-72 \mathrm{hrs} \text { after final } \\
\text { treatment. }\end{array}$ & $\begin{array}{l}27-38 \% \text { increase in function } 12-24 \\
\text { hrs into withdrawal, no change at } 4 \\
\text { or } 8 \text { hrs, function normal by } 48 \text { hrs. }\end{array}$ & & $\begin{array}{l}2008 \\
\text { Hadjiconstantinou } \\
\text { et al. } 2011\end{array}$ \\
\hline & Rat & $\begin{array}{l}3 \mathrm{mg} / \mathrm{kg} / \text { day for } 14 \text { days via } \\
\text { osmotic minipump }\end{array}$ & No change in uptake. & & Carr et al. (1989) \\
\hline
\end{tabular}


Table 1.3: The effects of acute nicotine on DAT function.

\begin{tabular}{|c|c|c|c|c|c|}
\hline & Animal & Treatment & Effect & Mechanism & Author \\
\hline \multirow[t]{3}{*}{ PFC } & Rat & $0.1-0.8 \mathrm{mg} / \mathrm{kg}$ nicotine s.c. & inc. uptake, max at $0.4 \mathrm{mg} / \mathrm{kg}$ & Attenuated by mecamylamine & Middleton et al. 2004 \\
\hline & Rat & $0.8 \mathrm{mg} / \mathrm{kg}$ nicotine s.c. & $\begin{array}{l}55 \% \text { inc. uptake }\left(\mathrm{V}_{\max }\right) \text { at } 15 \mathrm{~min}, 87 \% \text { inc. } \\
\text { uptake }\left(\mathrm{V}_{\max }\right) \text { at } 30 \text { min }\end{array}$ & $\begin{array}{l}\text { Attenuated by mecamylamine, MLA \& } \\
\text { DH } \beta E .32 \% \text { inc. DAT cell surface } \\
\text { expression at } 30 \text { min. }\end{array}$ & Zhu et al. 2009 \\
\hline & Rat & $5 \mu \mathrm{M}$ nicotine in vitro & inc. amphetamine-induced DA efflux & $\begin{array}{l}\text { Attenuated by DH } \beta E \& \text { mecamylamine } \\
\text { but not } \alpha \text {-bungarotoxin }\end{array}$ & Drew et al. 2000 \\
\hline \multirow[t]{3}{*}{ NAc } & Rat & $0.4 \mathrm{mg} / \mathrm{kg}$ nicotine s.c. & inc. uptake & Attenuated by mecamylamine & Hart and Ksir 1996 \\
\hline & Rat & $5 \mu \mathrm{M}$ nicotine in vitro & no change in amphetamine-induced efflux & & Drew et al. 2000 \\
\hline & Rat & $0.1 \mathrm{mg} / \mathrm{kg}$ s.c. & no change in synaptosomes & & Carr et al. 1989 \\
\hline \multirow[t]{7}{*}{ Striatum } & Rat & $0.1-0.8 \mathrm{mg} / \mathrm{kg}$ nicotine s.c. & inc. uptake, $\max$ at $0.8 \mathrm{mg} / \mathrm{kg}$ s.c. & $\begin{array}{l}\text { Attenuated by } 1.5 \mathrm{mg} / \mathrm{kg} \\
\text { mecamylamine }\end{array}$ & Middleton et al. 2004 \\
\hline & Rat & $0.32 \mathrm{mg} / \mathrm{kg}$ nicotine s.c. & $25 \%$ inc. uptake $\left(\mathrm{V}_{\max }\right)$ at $10 \& 40 \mathrm{~min}$ & $\begin{array}{l}\text { no change in DAT density or cell } \\
\text { surface expression }\end{array}$ & $\begin{array}{l}\text { Middleton et al. } \\
\text { 2007a }\end{array}$ \\
\hline & Rat & $\begin{array}{l}0.8 \mathrm{mg} / \mathrm{kg} \text { nicotine s.c.; } 1 \mathrm{nM}- \\
10 \mu \mathrm{M} \text { nicotine in vitro }\end{array}$ & no change in uptake & & Zhu et al. 2009 \\
\hline & Rat & $1 \mu \mathrm{M}$ nicotine in vitro & no change in synaptosomes & & $\begin{array}{l}\text { Izenwasser et al. } \\
1991\end{array}$ \\
\hline & Rat & $1 \mu \mathrm{M}$ nicotine in vitro & dec. uptake in chopped tissue & $\begin{array}{l}\text { Attenuated by chlorisondamine and } \\
\text { mecamylamine }\end{array}$ & $\begin{array}{l}\text { Izenwasser et al. } \\
1991\end{array}$ \\
\hline & Rat & $5 \mu \mathrm{M}$ nicotine in vitro & no change in amphetamine-induced efflux & & Drew et al. 2000 \\
\hline & Rat & $\begin{array}{l}10 \mu \mathrm{M} \text { nicotine in vitro; } 0.32 \\
\mathrm{mg} / \mathrm{kg} \text { s.c. nicotine }\end{array}$ & increase in amphetamine-induce efflux & & Jutkiewicz et al. 2008 \\
\hline $\begin{array}{l}\text { Cell } \\
\text { models }\end{array}$ & PC12 cells & $10 \mu \mathrm{M}-10 \mathrm{mM}$ nicotine & dec. uptake & $\begin{array}{l}\text { Attenuated by hexamethonium \& } \\
\text { mecamylamine }\end{array}$ & Yamashita et al. 1995 \\
\hline
\end{tabular}




\subsubsection{Nicotinic Regulation of Monoamine Transporter Gene Expression}

In addition to being regulated at the level of functional activity and protein expression, the monoamine transporters may be modulated through altered gene expression. Animal studies by Awtry and Werling (2003) and Miller et al. (2007) have shown increases in SERT and DAT protein expression in response to nicotine and cigarette smoke respectively (Awtry and Werling, 2003; Miller et al., 2007). In contrast, human studies have shown decreases in DAT protein in the brain of smokers compared to non-smokers (Krause et al., 2002; Newberg et al., 2007; Yang et al., 2008). A possible mechanism responsible for these observed changes in protein expression is through altered gene expression. There have been several recent studies that examined the effects of nicotine and cigarette smoke on monoamine transporter gene expression ( $\mathrm{Li}$ et al., 2004c; Semba and Wakuta, 2008; Itoh et al., 2010).

Semba and Wakuta (2008) measured SERT mRNA production in the DRN of rats using in situ hybridization following both chronic (6 mg/kg/day (s.c.) via minipump, 12 days) and acute $(0.5 \mathrm{mg} / \mathrm{kg}$ intraperitoneal (i.p.) 2 hours before sacrifice) nicotine treatment (Semba and Wakuta, 2008). A significant decrease in SERT mRNA expression was found in rats treated chronically, up to two days into withdrawal. Furthermore, coadministration of the non-nicotinic smoking cessation aid Bupropion significantly antagonised the increase in SERT mRNA expression to levels comparable to controls. No change was found in acutely treated animals (Semba and Wakuta, 2008). This decrease in SERT mRNA expression does not correlate to the increase in SERT protein observed by Awtry and Werling (2003); however, the dosing regimens differ (Awtry and Werling, 2003). Although the time period is comparable, Semba and Wakuta (2008) used a significantly larger dose of nicotine for treating animals in a continuous manner via minipump, which could lead to differences in response to nicotine. Future research should address the differences between protein and mRNA expression profiles of SERT by directly comparing samples from animals that have received the same dosing regimens before any conclusions can be drawn. 
A study in rats by Li et al. (2004) showed that chronic nicotine and cigarette smoke exposure caused an increase in DAT mRNA expression in the VTA and SN (Li et al., 2004c). Animals were given either $3 \mathrm{mg}$ oral nicotine daily, or passively inhaled cigarette smoke in tightly sealed boxes for 10, 30 or $60 \mathrm{~min}$, three times a day, for four weeks. DAT mRNA expression was measured using in situ hybridization and RNAse protection assay. Interestingly, exposure to cigarette smoke for $30 \mathrm{~min}$ daily resulted in a $152.5 \%$ increase in DAT mRNA expression compared to control, where nicotine alone resulted in a 126.4\% increase ( $\mathrm{Li}$ et al., 2004c). Hadjicontantinou et al. (2011) also found an increase in DAT mRNA expression using in situ hybridization in the SN and VTA of mice in response to chronic nicotine. This effect was seen in response to 14 days treatment of $2 \mathrm{mg} / \mathrm{kg}$ nicotine 4 times daily, and produced 20-41\% increases in expression 12-48 hrs following final nicotine treatment. In contrast to this, Ferrari et al. (2001) found no change in DAT mRNA levels in the VTA or SN using in situ hybridization 24 hours after rats received a single $0.4 \mathrm{mg} / \mathrm{kg}$ (i.p.) nicotine injection (Ferrari et al., 2002). This inconsistency may be due to differences in the effects of acute and chronic dosing on mRNA expression. Furthermore the route of nicotine administration and doses are vastly different. Lastly, it should be noted that the increase in DAT mRNA expression shown in the study by Li et al. (2004c) is small, and that without an accompanying increase in protein expression the molecular relevance of it is questionable.

Ohyama et al. (2010) recently reported that nicotine enhanced transcription of the DAT gene in SK-N-SH cells transiently transfected with human DAT (Ohyama et al., 2010). The 5' flanking region of the DAT gene which contains the promotor was analysed using luciferase reporter assays. It was found that $5 \mu \mathrm{M}$ nicotine treatment for 24 hours enhanced promoter activity, and that this enhancement was abolished by the deletion of intron 1. A concentration dependent increase in activity was also observed at $0.1-100 \mu \mathrm{M}$ nicotine that was blocked by the nicotinic antagonist hexamethonium, suggesting that the effect is dependent on $\mathrm{nAChR}$ activation. The authors propose a novel nicotinic responsive element in the human DAT genes somewhere between -3478 to -1036 that is responsible for these changes. This enhanced promoter activity suggests that nicotine increases the gene expression of DAT, which would be consistent with the findings of $\mathrm{Li}$ et al. (2004), that nicotine and cigarette smoke increase DAT mRNA expression (Li et al., 2004). 
Itoh et al. (2010) measured NET mRNA expression in bovine adrenal medullary cells using RT-PCR following 2 days treatment with $10 \mu \mathrm{M}$ nicotine (Itoh et al., 2010). They found a slight but non-significant increase in NET mRNA expression which appears consistent with their finding that the DNA-dependent RNA polymerase inhibitor cyclohexin had no effect on nicotine induced increases in NE uptake (Itoh et al., 2010). This is, however, the only study that has looked at NET gene expression in response to nicotine to date and further work is necessary to validate this finding. It would be particularly beneficial to investigate nicotine's effect on NET mRNA expression in specific brain regions of laboratory animals to ascertain the effects of nicotine in an intact whole system.

\subsection{Aims and Objectives}

The overall aim of this study is to examine the effects of nicotine and TPM on DAT, NET, and SERT in discrete regions of the rat brain. No previous study has compared the effects of nicotine on the monoamine transporters to a tobacco extract. By investigating the effects of TPM as well as nicotine we may obtain a greater understanding of the contribution of non-nicotinic components of tobacco smoke to smoking-related neuroadaptations. In future this could lead to the development of more efficacious smoking cessation pharmacotherapies.

The specific objectives of this study were (1) to examine the effects of nicotine and TPM on monoamine transporter function, protein expression, and mRNA expression in chronic and acute treatment models; (2) to determine whether any changes in monoamine transporter function were nAChR-dependent, and whether nAChRs containing $\alpha 7$ or $\beta 2$ subunits were involved where changes were observed; (3) to directly compare the effects of nicotine and TPM to establish whether or not they have differential effects on the monoamine transporters.

Based on the previously published literature, we expect that nicotine and TPM will cause changes in monoamine transporter function. It is well established that elevated levels of mesolimbic DA is involved in the development of drug addiction, particularly in the NAc (Singer et al., 2004; Dichiara and Imperatio, 1988; Nisell et al., 1996). For this reason, a 
decrease in DA uptake in these brain regions in response to nicotine would be expected to contribute to an addiction state. Conversely, there are reports of nicotine increasing monoamine transporter function (Zhu et al., 2009; Itoh et al., 2010; Awtry and Werling, 2003), which may provide a feedback mechanism in response to excess monoamine release. Regardless of the direction of change in monoamine transporter function, we expect that changes in response to nicotine alone will be $\mathrm{nAChR}$ dependent.

Furthermore, we predict differences between TPM treatment and nicotine alone, based on recently reported differences in the pharmacological profile of tobacco extracts compared to nicotine. 


\section{Chapter 2: Materials and Methods}

\subsection{Animals}

Male Sprague-Dawley rats weighing between 240 and $340 \mathrm{~g}$ were used for all experiments. Animals were housed in the Victoria University of Wellington animal housing facility in groups of 3-4 per cage and maintained on a $12 \mathrm{hr}$ light/dark cycle with free access to food and water. Subsequent to treatment with nicotine or TPM animals were euthanized by $\mathrm{CO}_{2}$ asphyxiation followed by rapid decapitation. All experiments were conducted with approval from the Victoria University of Wellington Animal Ethics Committee.

\subsection{Nicotine and Tobacco Particulate Matter}

\subsubsection{Tobacco Particulate Matter Collection}

Tobacco Particulate Matter (TPM) for this study was provided by the Institute of Environmental Science and Research Ltd (ESR) (Wellington). The extract contains combustion products from tobacco smoke representative of what a human smoker would typically inhale. The TPM was produced following the methods outlined by Ambrose et al. (2007). Briefly, Holiday Special Filter cigarettes (a leading New Zealand brand of cigarettes) were sent to Labstat International Inc. (Kitchener, Canada) where they were combusted using a smoking machine, and combustion products were collected on Cambridge filter pads. These filter pads were stored at $-20^{\circ} \mathrm{C}$ until required and products were extracted in absolute ethanol. The extract was analysed for nicotine content using a mass spectrometer and nitrogen phosphorous detector. Typically, the nicotine concentration was between 1-1.5 mg/mL. Two separate batches of TPM were used in this study and experiments were batch controlled. All chronic and $1 \mathrm{hr}$ time point experiments utilised one batch of TPM, while 15 and 30 min experiments were performed with the second batch. 


\subsubsection{Nicotine and TPM Administration}

Animals were administered nicotine, TPM or vehicle in acute or chronic regimens via i.p. injection. (-)-Nicotine hydrogen tartrate salt (Sigma) was used for nicotine treatments and stated doses represent the free base weight. Stock solutions of TPM in 100\% ethanol were diluted with $1 \mathrm{x}$ phosphate buffered saline (PBS, $137 \mathrm{mM} \mathrm{NaCl}, 2.7 \mathrm{mM} \mathrm{KCl}, 8.1$ $\mathrm{mM}$ Na2HPO4, $1.5 \mathrm{mM} \mathrm{KH} 2 \mathrm{PO} 4, \mathrm{pH}$ 7.4) (Appendix I) so that the endogenous nicotine content of the TPM would match the nicotine only injection solutions. All injection solutions contained $8 \%$ ethanol to match the ethanol content of the TPM extract. Vehicle consisted of $8 \%$ ethanol in 1x PBS. Both chronic and acute regimens were used in this study. For chronic treatments, 4 daily injections were chosen to better mimic the peaks and falls in plasma nicotine that are observed in human smokers, rather than a single large dose of nicotine. Chronic regimens consisted of $4 \mathrm{x}$ injections daily with $2 \mathrm{hrs}$ between each treatment over a period of 10 days. Ten days was chosen as the treatment period because it has previously been used in chronic nicotine administration studies examining monoamine transporter activity (Drew and Werling, 2003; Awtry and Werling, 2003). The total daily dose was either 0.35 or $3 \mathrm{mg} / \mathrm{kg}$ nicotine, or TPM containing $0.35 \mathrm{mg} / \mathrm{kg}$ nicotine. Animals were killed 14-16 hrs following final injection, so that the greatest time between first and last killed animal in each chronically treated group was 2 hrs. This time point also fell just before the animal would have received its first daily injection. The above doses represent a low ( $0.35 \mathrm{mg} / \mathrm{kg}$ nicotine) and high ( $3 \mathrm{mg} / \mathrm{kg}$ nicotine) dose and were chosen for several reasons: they fall roughly within the range of what a rat will selfadminister (Corrigall and Coen, 1989; Boules et al., 2010), they are comparable to doses used in previous studies (Middleton et al., 2004; Middleton et al., 2007a; Hart and Ksir, 1996; Drew and Werling, 2003; Rahman et al., 2003), and they should produce plasma nicotine levels comparable to nicotine plasma levels in human smokers (Matta et al., 2007).

Acute treatments consisted of a single i.p. injection of $0.35 \mathrm{mg} / \mathrm{kg}$ nicotine or dose matched TPM. Animals were euthanized $15 \mathrm{~min}, 30 \mathrm{~min}$ or $1 \mathrm{hr}$ following injection. The effects of nicotine on monoamine transporter function appear to be heavily timedependent; therefore, a range of times was chosen based on previously reported times where alterations in monoamine transporter function was observed (Zhu et al., 2009; Hart and Ksir, 1996; Awtry and Werling, 2003). The $3 \mathrm{mg} / \mathrm{kg}$ nicotine treatment was not used 
in acute treatments due to adverse effects observed in the animals in preliminary experiments. When nicotinic antagonists were used (with acute treatments only), animals received a single injection (i.p.) of $1.5 \mathrm{mg} / \mathrm{kg}$ mecamylamine $\mathrm{HCl}$ (salt weight; Tocris), 8 $\mathrm{mg} / \mathrm{kg} \mathrm{DH} \beta \mathrm{E}$ hydrobromide (salt weight), or $10 \mathrm{mg} / \mathrm{kg}$ methyllacotinine citrate (MLA) (salt weight, Tocris). These doses were chosen based on published work by Zhu et al. (2009). Nicotinic antagonists were administered $20 \mathrm{~min}$ prior to nicotine, TPM or control treatment, and the vehicle was 1x PBS (pH7.4).

\subsection{Tissue Dissection}

Following removal of the brain, discrete brain regions were dissected using an acrylic stereotaxic brain matrixes block (Alto, AgnTho'sAB, Sweden), based on coordinates from Paxinos and Watson (2005) (see Table 2.1). A single side of the PFC and dorsal striatum was used for each experiment, whereas both sides of the NAc, SN, VTA, DRN and LC were pooled for experiments. This is an accepted and widely used method of tissue dissection (Heffner et al., 1980; Corcoran et al., 2011); however, the midbrain regions used in this study are small and not very clearly defined in the rat. While every effort was made to be precise in all tissue dissections, due to the small size of some of the brain regions examined it cannot be claimed that samples taken contained solely the specified regions. In particular, the SN and VTA are very small and situated closely together in the brain. Therefore, samples labelled as SN and VTA are perhaps best described to contain predominantly, but not always exclusively, the region stated. All tissue samples were weighed to check dissection consistency (see Table 2.1). Following dissection, samples were either immediately homogenized in TRIzol ${ }^{\circledR}$ LS Reagent (Invitrogen) for RNA extraction and frozen at $-80^{\circ} \mathrm{C}$, or frozen dry in microcentrifuge tubes at $-80^{\circ} \mathrm{C}$ for use in RDEV and Western blotting experiments. 
Table 2.1: Reference coordinates and mean tissue weights for brain dissections.

\begin{tabular}{lll}
\hline Brain Region & Interaural Coordinates & $\begin{array}{l}\text { Tissue weight in mg } \\
\text { (mean } \pm \text { SEM) }\end{array}$ \\
\hline PFC & +12 to +14 & $12.3 \pm 0.2$ \\
Dorsal Striatum & +9 to +11 & $15.1 \pm 0.5$ \\
NAc & +9 to +11 & $11.3 \pm 0.2$ \\
SN & +3 to +4 & $7.6 \pm 0.3$ \\
VTA & +2 to +3 & $7.5 \pm 0.3$ \\
DRN & +1 to +2 & $7.4 \pm 0.4$ \\
LC & -1 to 0 & $6.8 \pm 0.3$
\end{tabular}

Values are mean \pm SEM. Values for NAc, SN, VTA, DRN, and LC represent pooled weights of both sides of the structure. Coordinates from Pax and Watson (2005).

\subsection{Rotating Disk Electrode Voltammetry (RDEV)}

RDEV is an electrochemical technique that measures the uptake of DA, NE, and 5-HT by the monoamine transporters (Hagan et al., 2010; Burnette et al., 1996; Earles et al., 1998). The experimental setup consists of a rotating glassy carbon electrode (Pine Instruments, special order AFMDO3GC, Pennsylvania) that is lowered into a sample chamber containing an auxiliary platinum electrode and a $\mathrm{Ag} / \mathrm{AgCl}$ reference electrode (Figure 2.1). The rotating electrode keeps samples in the chamber homogenous and creates a diffusion layer around the submerged electrode. Monoamines in this layer are oxidised at the electrode and release 1 or 2 electrons which produces a measureable current. Because the contents of the chamber is constantly mixed, new species continuously replace those already in the diffusion layer, so that old oxidation products are removed and new monoamines are available at the electrode. As monoamines are taken up by tissue there is a reduction in free monoamines, and a decrease in the current produced by oxidation products. This decrease can then be used to calculate the rate of monoamine uptake by the monoamine transporters. 


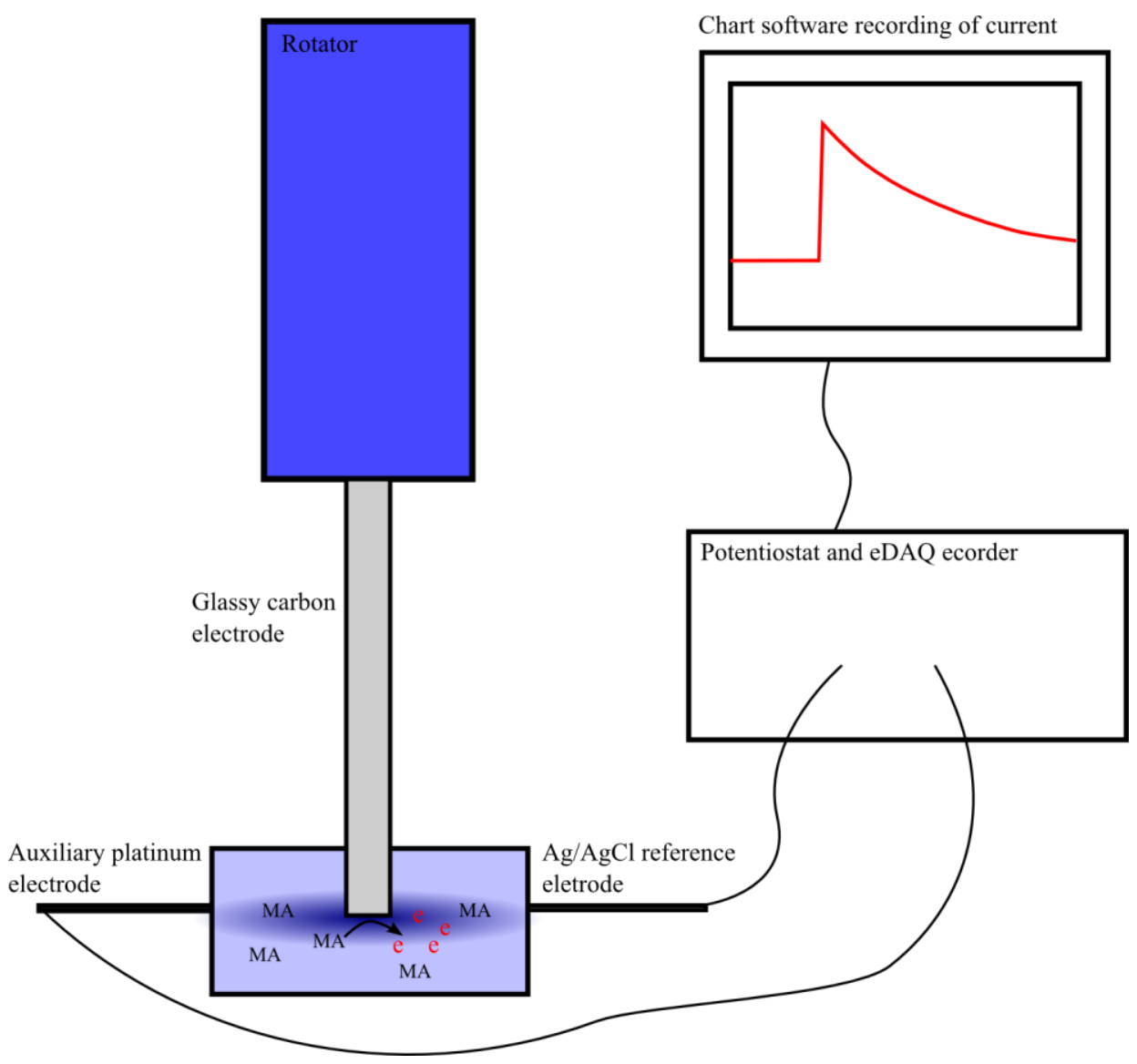

Figure 2.1: RDEV experimental setup. The rotating glassy carbon electrode is lowered into a sample chamber containing an auxiliary platinum electrode and $\mathrm{Ag} / \mathrm{AgCl}$ reference electrode. The glassy carbon electrode is rotated at $2000 \mathrm{rpm}$ and $+450 \mathrm{mV}$ potential was applied relative to the $\mathrm{Ag} / \mathrm{AgCl}$ electrode. This causes monoamines (MA) to oxidize and release electrons, which are measured as a current by eDAQ ecorder and recorded in chart software. In the presence of tissue, monoamines are taken up by the monoamine transporters, resulting in a decreased current. The rate of uptake can be measured from the slope of the line on chart software.

\subsubsection{Standard Curve}

Prior to each experiment a standard concentration-response curve was produced by adding increasing amounts of DA (0.5-2 $\mu \mathrm{M}$; Tocris) or 5-HT (0.1-1.5 $\mu \mathrm{M}$; Tocris) to KREBS buffer (130 mM NaCl, $1.3 \mathrm{mM} \mathrm{KCl,} 2.2 \mathrm{mM} \mathrm{CaCl}_{2}, 1.2 \mathrm{mM} \mathrm{MgSO} 4.6 \mathrm{H}_{2} 0,1.2$ $\mathrm{mM} \mathrm{KH}{ }_{2} \mathrm{PO}_{4}, 10 \mathrm{mM}$ HEPES, $10 \mathrm{mM}$ D-glucose, $\mathrm{pH}$ 7.4) (Appendix 1). The increase in the current with each monoamine addition was used to calculate a linear regression that allowed nA readings from these experiments to be converted into $\mu \mathrm{M}$ concentrations. 


\subsubsection{Sample Preparation}

Frozen tissue samples were used in all RDEV experiments. In a recent paper, Volz et al. (2009) established that frozen tissue samples could be used for RDEV experiments. This was confirmed in our laboratory by Dr. Bridget Simonson who showed that SERT function in frozen tissue was measurable with no significant difference to fresh tissue following up to one week of frozen storage (unpublished data). Thus, for these experiments tissue was frozen for up to one week, and each data set was generated from tissue that had been frozen for the same number of days. Tissue samples frozen dry at $80^{\circ} \mathrm{C}$ were thawed at room temperature for $20 \mathrm{~min}$. Following this, they were minced in $300 \mu \mathrm{L}$ of ice-cold KREBS buffer on a glass petri dish for $30 \mathrm{sec}$ with ice-cold razor blades. Samples were then collected in a microcentrifuge tube and allowed to settle to the bottom of the tube before the supernatant was removed and replaced with $37^{\circ} \mathrm{C}$ KREBS aerated with carbogen gas $\left(95 \% \mathrm{O}_{2}, 5 \% \mathrm{CO}_{2}\right)$. This was repeated 8 times to wash the tissue thoroughly before removing it in $296 \mu \mathrm{L}$ of aerated KREBS to add to the RDEV chamber (kindly donated by J. B. Justice Jnr.).

\subsubsection{Experimental Procedure}

The rotating glassy carbon electrode was rotated at $2000 \mathrm{rpm}$ by an MSR rotator (Pine Instruments), and $\mathrm{a}+450 \mathrm{mV}$ potential was applied relative to the $\mathrm{Ag} / \mathrm{AgCl}$ reference electrode by an eDAQ potentiostat EA161 (eDAQ, NSW, Australia). Chart software (eDAQ, NSW, Australia) was used to save the current produced, which was recorded by an eDAQ ecorder 201 (eDAQ, NSW, Australia).

\subsubsection{DA uptake}

For most experiments the low to infinite trans model was employed, consisting of multiple DA additions (0.5-4 $\mu \mathrm{M})$ to a single sample in increasing concentrations. This has been shown to give comparable results to the zero trans model, which consists of a single addition to each tissue sample. The low to infinite trans model was used in this case to reduce the number of animals required for each experiment. Upon commencement of the experiment the current $(\mathrm{nA})$ was allowed to reach a stable baseline before the first $\mathrm{DA}$ addition. The $\mathrm{nA}$ was left to reach this same baseline value before each subsequent addition. When a single DA $(2 \mu \mathrm{M})$ addition was used, the $\mathrm{nA}$ was 
allowed to reach baseline, DA was added, and nA measurement was continued for $30 \mathrm{~s}$. Because NET is responsible for a large portion of DA uptake in the PFC (Dichiara et al., 1992), $1 \mu \mathrm{Mdesipramine-HCl} \mathrm{(Sigma)} \mathrm{was} \mathrm{used} \mathrm{as} \mathrm{a} \mathrm{NET} \mathrm{inhibitor} \mathrm{in} \mathrm{all} \mathrm{experiments} \mathrm{on}$ DAT function in PFC tissue samples, as previously described by Zhu et al. (2009). The desipramine- $\mathrm{HCl}$ was added after baseline and incubated for $5 \mathrm{~min}$ prior to the first DA addition. Dopamine uptake by NET in the NAc and striatum is minimal (Moron et al., 2002) and NET has not been blocked in DA uptake experiments in these brain regions in previous experiments (Hart and Ksir 1996; Middleton et al., 2007a). For these reasons, desipramine- $\mathrm{HCl}$ was not used in DA uptake experiments in the NAc and striatum. The DAT inhibitor GBR12909 (1 $\mu \mathrm{M}$, Tocris) was used as described above in place of desipramine to measure DA uptake by NET in the PFC. $1 \mu \mathrm{M}$ GBR12909 was chosen because it has previously been shown to completely block DA uptake by DAT in the PFC (Drew and Werling, 2003). Serotonin transporter inhibitors were not used in DA uptake experiments due to the low affinity of SERT for DA (Moron et al., 2002). For in vitro experiments $2 \mu \mathrm{M}$ nicotine, TPM (containing $2 \mu \mathrm{M}$ nicotine), or vehicle were added to the chamber following baseline for 5 min prior to first DA addition. Upon completion of each data set the tissue was removed from the chamber and homogenised in $300 \mu \mathrm{L}$ RIPA buffer (10 mM Tris-HCl, 150 mM NaCl, 1 mM EDTA, 1\% Triton-X-100, 0.1\% SDS, $1 \%$ sodium deoxycholate, $\mathrm{pH} 7.5$, (Appendix 1)) containing $10 \mu \mathrm{L} / \mathrm{mL}$ protease inhibitor (Sigma) with a small plastic pestle for use in Western blotting experiments. The rotating electrode was cleaned between each set of DA additions with milliQ water on a BuechlerMicrocloth (Pine Instruments) by rotating it on the cloth at $2000 \mathrm{rpm}$ for $30 \mathrm{~s}$. The electrode was cleaned more thoroughly after each set of experiments with 0.05 micron aluminium slurry on BuechlerMicrocloth by hand. This was followed by cleaning with milliQ water as described above.

\subsubsection{5-HT uptake}

Measurement of 5-HT uptake was conducted using a protocol recently established in our laboratory by Dr. Bridget Simonson (unpublished data). Experiments were performed as described for DA uptake with the following changes; 5-HT concentrations ranged from 0.25-3 $\mu \mathrm{M}$, and the DAT inhibitor GBR12909 $(1 \mu \mathrm{M})$ was used in all experiments as DAT is found in the striatum and impedes measurement of SERT function. Recently, Hagan et al. (2011) found that 5-HT uptake in whole brain mouse synaptosomes was partially non-SERT mediated and that transporters with a low affinity for 5-HT may 
contribute to 5-HT clearance in this system. To confirm that the 5-HT uptake we measured was SERT specific control experiments were run with the low affinity transporter inhibitor 1'-diethyl-2,2'-cyanine iodide (D-22, $10 \mu \mathrm{M}$, Sigma) as outlined by Hagan et al. (2011). D-22 was suspended in a 1\% 1:1 dimethylformamide and methanol solution. Tissue samples were allowed to baseline and D-22 was added to the RDEV chamber for $5 \mathrm{~min}$ prior to the first 5-HT addition. The NET inhibitor desipramine-HCl (1 $\mu \mathrm{M}$, Sigma) was also used as a control to evaluate whether 5-HT uptake occurred via NET. Desipramine, or PBS vehicle, was added to the RDEV chamber following baseline and incubated for 5 min prior to the first 5-HT addition as described above.

\subsubsection{Data Analysis}

Monoamine uptake was measured $1 \mathrm{~s}$ following either DA or 5-HT addition. This was done by taking $10 \mathrm{~s}$ of $\mathrm{nA}$ data (chart software) and plotting a linear regression (Microsoft Office Excel) to find the change in current per $1 \mathrm{~s}$ (Figure 2.2). The $\mathrm{R}^{2}$ value of each regression was calculated and anything less than 0.95 was not used in the final data. The concentration curve plotted for each experiment was then used to convert the nA value into $\mu \mathrm{M}$, and this value was normalised to the weight of the tissue used. The final measurement is expressed as uptake in pmol/s/g. Values were then entered into GraphPad 5 software (GraphPad Software Inc, La Jolla, CA, USA), and for low to infinite trans model data a Michaelis-Menten curve was fitted. The $\mathrm{V}_{\max }$ and $\mathrm{K}_{\mathrm{m}}$ of each individual repeat was calculated and the average and SEM of these was computed. Student's unpaired t-tests were performed for each treatment group on $V_{\max }$ and $\mathrm{K}_{\mathrm{m}}$ values, or on uptake values for single addition experiments, to determine whether significant differences were attained. Significance was defined as $\mathrm{p}<0.05$. 


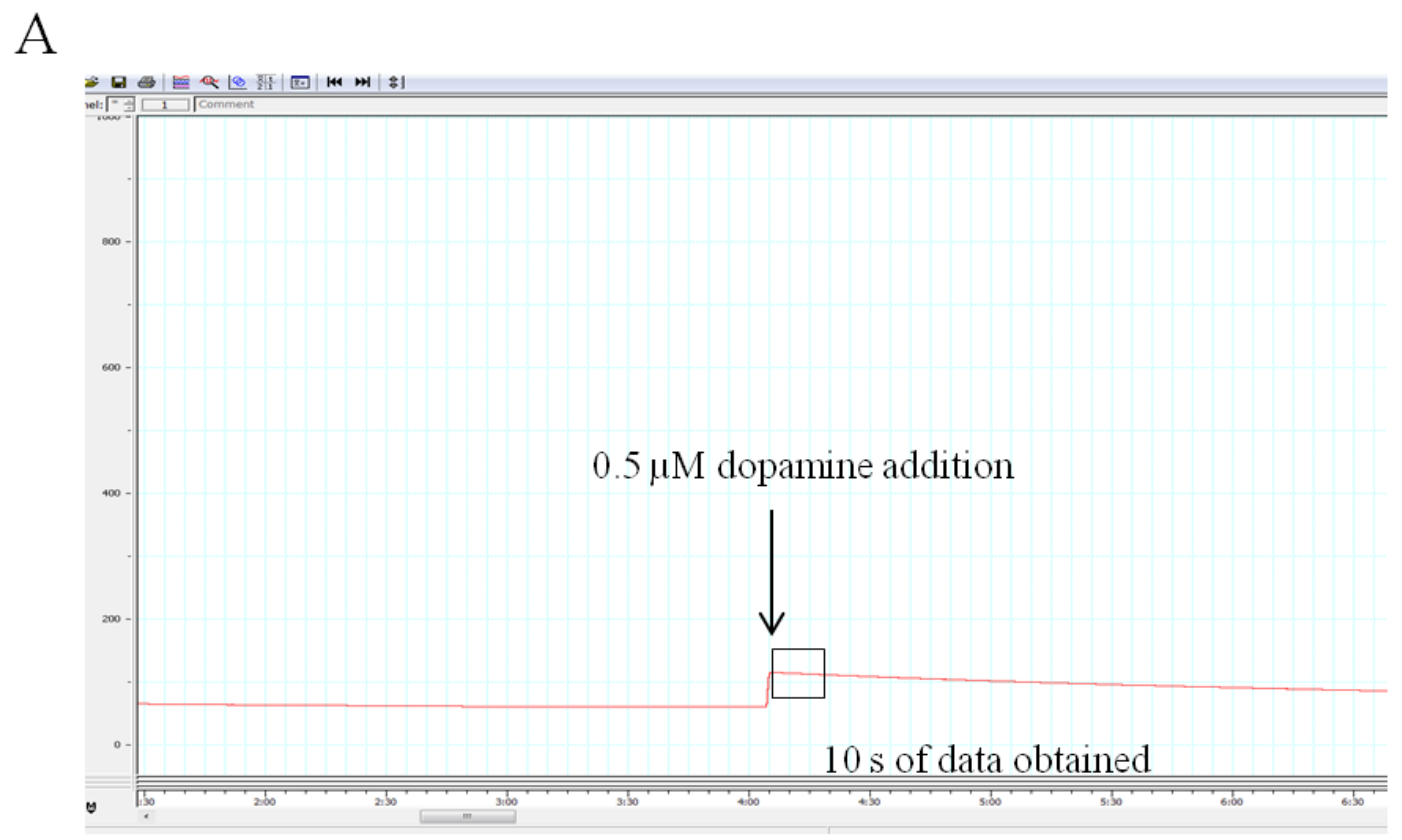

B

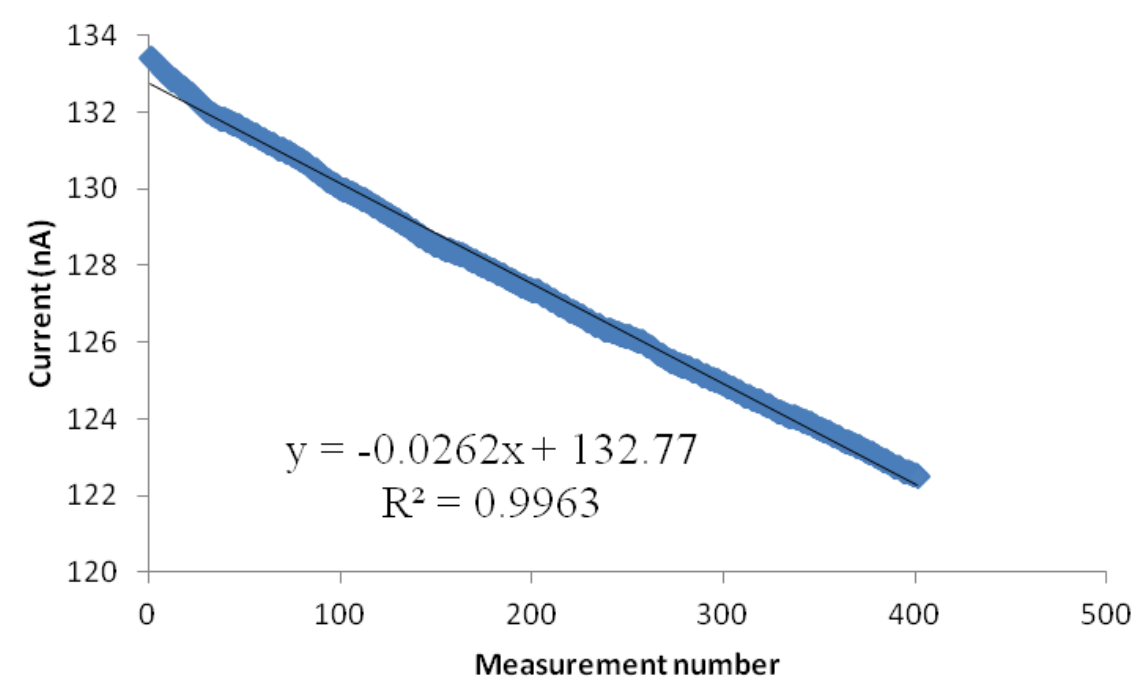

Figure 2.2: RDEV data analysis. Following DA addition $10 \mathrm{~s}$ of uptake data is collected from chart software (A) and plotted in Microsoft excel (B). Initial uptake of monoamines is linear, and the slope of this line is used to calculate the rate of uptake of monoamines. 


\subsection{SDS Polyacrylamide Gel Electrophoresis and Western Blotting}

\subsubsection{Sample Preparation}

Following RDEV experiments, minced tissue from the PFC, striatum and NAc, were homogenised in RIPA buffer containing $10 \mu \mathrm{L} / \mathrm{mL}$ protease inhibitors. Samples from midbrain regions (VTA, SN, LC and DRN) that had previously been frozen at $-80^{\circ} \mathrm{C}$ were allowed to thaw at room temperature for 20 min before being homogenized in $300 \mu \mathrm{L}$ RIPA buffer (containing $10 \mu \mathrm{L} / \mathrm{mL}$ protease inhibitor, Sigma) with a small plastic pestle. Samples were then centrifuged at $12,000 \mathrm{~g}$ for $10 \mathrm{~min}$ at $4^{\circ} \mathrm{C}$ to allow pelleting of DNA and large cellular components. The supernatant was transferred to a fresh tube and an aliquot taken to measure protein concentration using the bicinchoninic acid (BCA) assay (Pierce). Absorbance was measured at $562 \mathrm{~nm}$ using an automated multi-well plate reader (Versamax, Molecular Devices, Sunnyvale, CA). A $20 \mu \mathrm{L}$ aliquot of each sample was incubated with $5 \mu \mathrm{L} 5 \mathrm{x}$ reducing buffer (62.5 mM Tris- $\mathrm{HCl}, \mathrm{pH} 6.8,2 \%$ SDS, $20 \%$ glycerol, 1\% bromophenol blue (Appendix 1)) containing 10\% $\beta$-mercaptoethanol (Sigma) at room temperature for 5 min prior to loading into the gel.

\subsubsection{SDS-PAGE and Membrane Transfer}

15 well SDS-PAGE gels (10\% separating gel, $4 \%$ stacking gel) (Appendix I) were made the day prior to experiment and refrigerated in paper towels soaked with distilled water overnight. $20 \mu \mathrm{L}$ of sample containing $30 \mu \mathrm{g}$ protein was loaded into each well along side $1 \mu \mathrm{L}$ of Precision Plus Protein ${ }^{\mathrm{TM}}$ Dual Colour standard (Bio-Rad). Gels were run at $120 \mathrm{~V}$ for $90 \mathrm{~min}$ in $1 \mathrm{x}$ running buffer (3.5 mM SDS, $25 \mathrm{mM}$ Tris base, $190 \mathrm{mM}$ glycine (Appendix I)) and transferred onto an Immobilon-FL polyvinylidinedifluoride (PVDF) membrane $(0.2 \mu \mathrm{M}$ pore size, Millipore Corporation, MA) that was pre-soaked in methanol for $5 \mathrm{~min}$, prior to soaking in transfer buffer (190 mM glycine, $25 \mathrm{mM}$ Tris, $20 \%$ methanol) (Appendix 1). The transfer was run in transfer buffer at $20 \mathrm{~V}, 4^{\circ} \mathrm{C}$, for 18 hr.

\subsubsection{Western Blotting}

Following transfer, membranes were removed and placed briefly into $1 \mathrm{x}$ Tris buffered saline (TBS, $50 \mathrm{mMTris}$ base, $150 \mathrm{mMNaCl}, \mathrm{pH}$ 7.5) (Appendix I) to remove excess 
transfer buffer. They were then blocked with 5\% donkey serum (Millipore) in TBS containing $0.1 \%$ Tween-20 (T-TBS) for $1 \mathrm{hr}$ at room temperature, followed by incubation with primary antibodies (see Table 2.2 for antibodies and concentrations) in T-TBS containing 5\% donkey serum overnight (approximately $18 \mathrm{~h}$ ). The following day membranes were washed in T-TBS $3 \mathrm{x}$ for $5 \mathrm{~min}$, and were incubated with an anti-goat DyLite $^{\mathrm{TM}} 649$ conjugated secondary antibody (Jackson Immunoresearch) in the dark for 1 $\mathrm{hr}$ at room temperature. This was followed by $3 \times 5 \mathrm{~min}$ washes in TBS and the membranes were visualised using a Fuji film laser scanner (Fujifilm FLA-5100, Tokyo, Japan) with a $635 \mathrm{~nm}$ laser and DBR1 filter. The membranes were stripped in stripping buffer (Appendix I) for $40 \mathrm{~min}$ and washed $3 \mathrm{x}$ for 20 min each with T-TBS before being probed for $\alpha$-tubulin. This was done as described above except membranes were blocked with $10 \%$ milk powder in T-TBS, and incubation with the primary antibody was for $1 \mathrm{hr}$ only (see Table 2.2). Representative full blots for the antibodies used in this study are in Appendix II.

\subsubsection{Data Analysis}

Western blots were analysed using Image $\mathbf{J}$ software to obtain the density of bands. The densities for bands corresponding to DAT, NET and SERT were normalised to $\alpha$-tubulin expression in each sample. This relative expression was then expressed as a percentage relative to control within membrane, and plotted using GraphPad Prism software as mean \pm SEM. The SEM for controls was obtained from raw data values for all samples and adjusted for an average of $100 \%$. One-way ANOVA with Bonferroni post-hoc analysis was performed to measure significance which was defined as $\mathrm{p}<0.05$. 
Table 2.2: Primary and Secondary Antibodies used for Western Blotting.

\begin{tabular}{|c|c|c|c|c|c|c|}
\hline Epitope & $\begin{array}{l}\text { Primary or } \\
\text { Secondary }\end{array}$ & $\begin{array}{l}\text { Host, Isotype, } \\
\text { Clonality }\end{array}$ & Manufacturer & $\begin{array}{l}\text { Blocking } \\
\text { Solution }\end{array}$ & $\begin{array}{l}\text { Dilution } \\
\text { Factor }\end{array}$ & $\begin{array}{l}\text { Incubation } \\
\text { time }\end{array}$ \\
\hline DAT (C-20) & Primary & Goat, IgG, Polyclonal & $\begin{array}{l}\text { Santa Cruz } \\
\text { Biotechnology }\end{array}$ & $\begin{array}{l}\text { 5\% Donkey } \\
\text { Serum (Millipore) }\end{array}$ & $1: 300$ & Overnight \\
\hline NET (K-15) & Primary & Goat, IgG, Polyclonal & $\begin{array}{l}\text { Santa Cruz } \\
\text { Biotechnology }\end{array}$ & $\begin{array}{l}5 \% \text { Donkey } \\
\text { Serum (Millipore) }\end{array}$ & $1: 200$ & Overnight \\
\hline $\begin{array}{l}\text { SERT (C- } \\
20)\end{array}$ & Primary & Goat, IgG, Polyclonal & $\begin{array}{l}\text { Santa Cruz } \\
\text { Biotechnology }\end{array}$ & $\begin{array}{l}5 \% \text { Donkey } \\
\text { Serum (Millipore) }\end{array}$ & $1: 300$ & Overnight \\
\hline $\begin{array}{l}\text { alpha- } \\
\text { tubulin }\end{array}$ & Primary & $\begin{array}{l}\text { Rabbit, IgG, } \\
\text { Polyclonal }\end{array}$ & Abcam & $10 \%$ milk powder & $1: 5,000$ & $1 \mathrm{hr}$ \\
\hline Goat IgG & $\begin{array}{l}\text { Secondary } \\
\text { (DyLite }^{\mathrm{TM}} 649 \\
\text { conjugated) }\end{array}$ & $\begin{array}{l}\text { Donkey, IgG, } \\
\text { Polyclonal }\end{array}$ & $\begin{array}{l}\text { Jackson } \\
\text { Immunoresearch } \\
\text { Laboratories Inc. }\end{array}$ & N/A & $1: 5,000$ & $1 \mathrm{hr}$ \\
\hline Rabbit IgG & $\begin{array}{l}\text { Secondary (ECL } \\
\text { Plex CY5 } \\
\text { conjugated) }\end{array}$ & Goat, IgG, Polyclonal & Amersham & N/A & $1: 5,000$ & $1 \mathrm{hr}$ \\
\hline
\end{tabular}




\subsection{Quantitative PCR}

\subsubsection{Sample preparation and RNA Extraction}

Tissue samples were immediately homogenised in $300 \mu \mathrm{L}$ TRIzol $^{\circledR}$ LS Reagent (Invitrogen) and frozen at $-80^{\circ} \mathrm{C}$ until required. Samples were thawed on ice and centrifuged at $12,000 \mathrm{~g}$ for $10 \mathrm{~min}$ at $4^{\circ} \mathrm{C}$ to pellet excess cellular debris, and the supernatant was removed to a clean tube. $200 \mu \mathrm{L}$ of chloroform was added per $\mathrm{mL}$ of Trizol $^{\mathrm{TM}}$ reagent and samples were vigorously shaken, incubated at room temperature for $3 \mathrm{~min}$, and centrifuged at $12,000 \mathrm{~g}$ for $15 \mathrm{~min}\left(4^{\circ} \mathrm{C}\right)$. The upper aqueous layer was removed to a fresh microcentrifuge tube containing an equal volume of $70 \%$ molecular grade ethanol and the sample was thoroughly mixed. This was then transferred to a High Pure Filter tube and purified using a High Pure RNA Isolation Kit (Roche) according to manufacturer's protocol. The final product was collected in $50 \mu \mathrm{L}$ elution buffer and the yield was measured using a ND-1000 Spectrophotometer (Nanodrop, Wilmington, DE) by measuring sample absorbance at $260 \mathrm{~nm}$. The 260/280 $\mathrm{nm}$ absorbance ratio was also measured as an indication of sample purity, and samples with a reading of 1.8-2.0 were considered sufficiently pure for use.

\subsubsection{Reverse Transcription}

$500 \mathrm{ng}$ of RNA per reaction was reverse transcribed in the presence of RNAseOUT (Invitrogen) using SuperScript ${ }^{\mathrm{TM}}$ III Reverse Transcriptase (Invitrogen). The reaction was carried out at $50^{\circ} \mathrm{C}$ using oligo $(\mathrm{dT})_{18}(2.5 \mu \mathrm{M})$ for specific reverse transcription of mRNA to cDNA.

\subsubsection{Real time PCR with SYBR Green Chemistry}

Real time PCR was conducted using Platinum ${ }^{\circledR}$ SYBR ${ }^{\circledR}$ Green qPCRSuperMix-UDG (Invitrogen) and either an iQ4 real-time PCR detection system based on an iCycler platform (Bio-Rad, Hercules, CA) (for all acute experiments), or a Rotor-Gene ${ }^{\mathrm{TM}} 6000$ (Corbett Life Sciences) (for all chronic experiments). $1 \mu \mathrm{L}$ of cDNA was used in each reaction with a total reaction volume of $25 \mu \mathrm{L}$. Specific primers for one of DAT, NET, SERT or cyclophilin A (cyc A) (Invitrogen) were used in each reaction to a final concentration of $200 \mathrm{nM}$. Fluorescein $(20 \mathrm{nM})$ (Invitrogen) was also added to the 
reaction to allow collection of background well-factors, which allows for the correction of non-uniformity in fluorescence. Negative control reactions containing RNA or $\mathrm{H}_{2} \mathrm{O}$ were included in every experiment. Cycling conditions consisted of: an initial step of $50^{\circ} \mathrm{C}$ for $2 \mathrm{~min}$, denaturation at $95^{\circ} \mathrm{C}$ for $3 \mathrm{~min}$, and amplification over 35 cycles of $95^{\circ} \mathrm{C}, 15 \mathrm{~s} ; 55$ ${ }^{\circ} \mathrm{C}, 30 \mathrm{~s} ; 72{ }^{\circ} \mathrm{C}, 30 \mathrm{~s}$. The initial step was included to eliminate any contaminating PCR products. Platinum ${ }^{\circledR}$ SYBR ${ }^{\circledR}$ Green qPCRSuperMix-UDG contains uracil DNA glycolase (UDG) and dUTP instead of dTTP, therefore any PCR product from previous PCR amplifications will contain uracil which will be digested by UDG.

Melt curve analysis was also conducted at the end of each cycle to analyse the purity of PCR products. This consisted of increasing the temperature of the reaction from $72{ }^{\circ} \mathrm{C}-$ $94.5^{\circ} \mathrm{C}$ in $0.5^{\circ} \mathrm{C}$ increments every $10 \mathrm{~s}$. As the temperature of the reaction rises, double stranded DNA will melt apart at a specific temperature depending on the sequence, which results in a reduction in fluorescent signal from intercalated SYBR green. A graph is then plotted of the first derivative of relative fluorescence units over temperature versus temperature of the reaction mixture (dRFU/dTvs. T), and specific PCR products will produce a distinct peak in the graph. Therefore if a single product is expected a single distinct peak should be seen, whereas a diffuse peak in the lower temperature range indicates the presence of primer dimer. Melt curve analysis was also carried out on negative controls to ensure that there was no contamination.

Table 2.3: Primers used for quantitative PCR.

\begin{tabular}{lll}
\hline $\begin{array}{l}\text { Primer } \\
\text { Target }\end{array}$ & Primer Sequence 5'-3, & \\
\hline & Forward & Reverse \\
cyc A & GGG GAG AAA GGA TTT GGC TA & ACA TGC TTG CCA TCC ACC CTG \\
DAT & CATGCTGCTCACTCTGGGTA & AGCACGCCAAAGAGGATAGA \\
NET & TCATCTCCTGCCAGAAAACC & CCCTCTCTGCCTTCTCAATG \\
SERT & GGCGGTTTCCTTACATA & TCCTGGGCGAAGTAGTTGGT \\
\end{tabular}




\subsubsection{Data Analysis}

All samples were run in duplicate and the average $\mathrm{Ct}$ value was used in analysis. Any duplicates with $\mathrm{Ct}$ values differing by more than 0.5 were not used in the final data. The $\mathrm{Ct}$ value of the housekeeper gene cyc A was subtracted from the $\mathrm{Ct}$ value for the gene of interest in each sample to calculate the $\Delta \mathrm{Ct}$ value. Cyc $\mathrm{A}$ was chosen as a housekeeper gene as it is commonly used and has previously been shown to not be affected by nicotine (Weisinger et al., 1999). Furthermore, mean cyc A Ct values did not differ across treatment groups (Appendix III). Delta $\mathrm{Ct}$ values were plotted in GraphPad Prism software and a one-way ANOVA with Bonferroni post-hoc analysis was performed for each group. A difference of $1 \mathrm{Ct}$ value represents a doubling or halving in expression, with an increase in $\mathrm{Ct}$ representing a decrease in mRNA expression and vice versus. Estimations of relative mRNA expression were calculated from the $\Delta \Delta \mathrm{Ct}$ ( $\Delta \mathrm{Ct}$ treatment $-\Delta \mathrm{Ct}$ control group) and expressed as a percentage.

\subsubsection{Agarose Gel Electrophoresis}

PCR product was visualised on $2 \%$ agarose gels to ensure that a single product of the expected size was present. Gels were prepared by microwaving $1 \mathrm{~g}$ of agarose (Invitrogen) with $50 \mathrm{~mL}$ of $1 \mathrm{x}$ Tris-acetate EDTA buffer (TAE) (Appendix I) and were then placed in an electrophoresis tank containing 1x TAE buffer. Samples were prepared by mixing $18 \mu \mathrm{L}$ neat PCR product with $2 \mu \mathrm{L}$ of BlueJuice ${ }^{\mathrm{TM}}$ (Invitrogen). The entire sample was loaded into the gel and electrophoresis was conducted at $100 \mathrm{~V}$ for $40 \mathrm{~min}$. Gels were then stained with $2 \mu \mathrm{g} / \mathrm{mL}$ ethidium bromide (Invitrogen) in 1x Tris EDTA (TE) buffer for $30 \mathrm{~min}$, followed by $15 \mathrm{~min}$ de-staining in $\mathrm{dH}_{2} \mathrm{O}$. Gels were visualised using the KODAK Gel Logic 100 system (Kodak).

\subsubsection{Primer Efficiency Testing}

Primer efficiency is important for sensitivity in real time PCR reactions. Primer efficiencies were calculated for all primers used in this study. PCR products purified by agarose gel electrophoresis were used as template. Following electrophoresis bands were excised and homogenised in $500 \mu \mathrm{L}$ of $1 \mathrm{x}$ TE buffer, followed by heating at $60^{\circ} \mathrm{C}$ for 1 hr. Template was then serially diluted from $10^{1}-10^{4}$, the equivalent to $3.3 \mathrm{Ct}$ values between each dilution, and a quantitative PCR reaction was conducted as described 
above. Dilutions were run in triplicate and the average $\mathrm{Ct}$ value was plotted against the $\log$ of the fold dilution. Primer efficiency was then calculated using the equation:

Primer Efficiency = (10(1/slope) $)$-1 (Modified from Peters et al., (2004))

Ideally primer efficiencies should be approximately 100\%; efficiencies less than $100 \%$ indicate the presence of primer dimer, while those greater than $100 \%$ indicate the presence of non-specific products. 


\section{Chapter 3: The chronic effects of nicotine and TPM on DA and 5-HT uptake and monoamine transporter expression}

\subsection{Control RDEV and real time PCR experiments}

\subsubsection{Non-SERT mediated 5-HT uptake in the striatum}

Recently Hagan et al. (2011) showed that 5-HT uptake in whole mouse brain synaptosomes was partially mediated by non-SERT uptake (Hagan et al. 2011). To confirm that 5-HT uptake observed in rat striatum in this study was SERT-mediated, we conducted control experiments with D-22, an inhibitor of low affinity 5-HT transporters including the organic cation transporters, plasma membrane monoamine transporter, and extraneuronal monoamine transporter. The NET inhibitor desipramine-HCl was also used in control experiments. Minced striatal tissue from drug naive animals was treated with D-22 $(10 \mu \mathrm{M})$ or desipramine-HCl $(1 \mu \mathrm{M}) 5$ min prior to first 5-HT addition and uptake was measured. The dopamine transporter inhibitor GBR12909 (1 $\mu \mathrm{M})$ was incubated with the tissue concurrently with the other inhibitors. Neither D-22 nor desipramine had any significant effect on 5-HT uptake (Figure 3.1) in these preparations. There appears to be slight decrease in $\mathrm{V}_{\max }$ values with both treatments; however, this was accompanied by a slight decrease in $\mathrm{K}_{\mathrm{m}}$ and statistical analysis showed no significant change in $\mathrm{V}_{\max }$ (Student's t-test, vehicle vs. desipramine $\mathrm{p}=0.3936$, vehicle vs. $\mathrm{D}-22$ $\mathrm{p}=0.4938$ ) (Figure 3.1). It was, therefore, concluded that 5-HT uptake in our system was entirely SERT-mediated. 
A

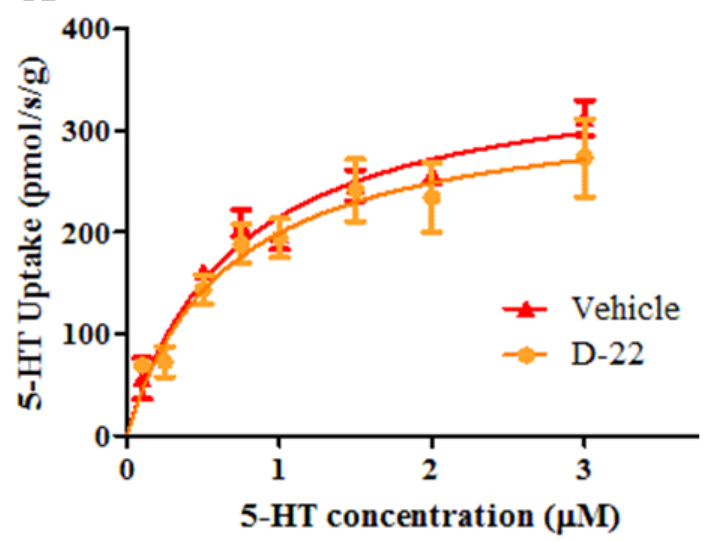

B

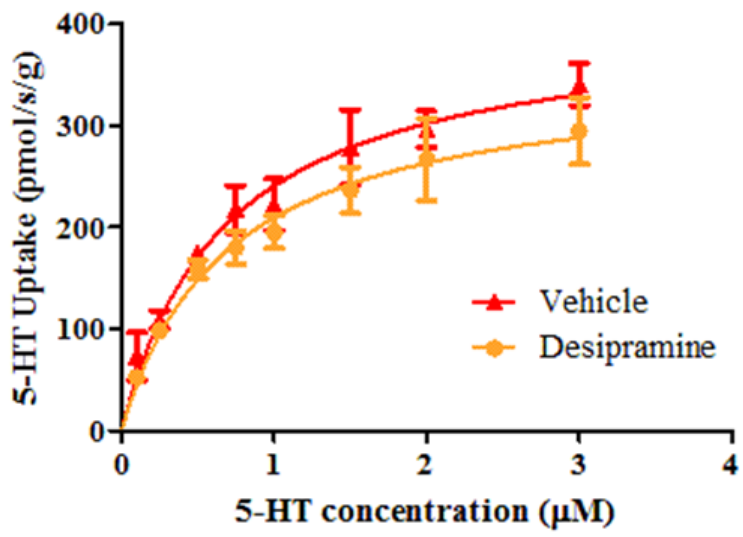

Figure 3.1: D-22 and desipramine have no significant effect on 5-HT uptake in the striatum of drug naive rats. Minced striatal tissue from drug naive rats was preincubated with D-22 $(10 \mu \mathrm{M})(\mathbf{A})$, desipramine $(1 \mu \mathrm{M})(\mathbf{B})$, or respective vehicles for 5 min prior to the first 5-HT addition. $1 \mu \mathrm{M}$ GBR2909 was also pre-incubated with each tissue sample for $5 \mathrm{~min}$. Neither D-22 nor desipramine caused a significant change in 5HT uptake. Data points are mean $\pm \operatorname{SEM}(n=4-5)$.

Table 3.1: 5-HT uptake kinetics with D-22 and desipramine treatment in rat striatum.

\begin{tabular}{|l|l|l|}
\hline Treatment & $\mathbf{V}_{\mathbf{m a x}}(\mathbf{p m o l} / \mathbf{s} / \mathbf{g})$ & $\mathbf{K}_{\mathbf{m}}(\boldsymbol{\mu M})$ \\
\hline Vehicle (A) & $367 \pm 33$ & $0.68 \pm 0.11$ \\
\hline D-22 & $328 \pm 44$ & $0.62 \pm 0.08$ \\
\hline Vehicle (B) & $413 \pm 28$ & $0.73 \pm 0.10$ \\
\hline Desipramine & $354 \pm 53$ & $0.67 \pm 0.13$ \\
\hline
\end{tabular}

Values are mean \pm SEM. 


\subsubsection{Real-time RT-PCR Control Experiments}

\subsubsection{Primer Efficiencies}

Primer efficiencies were calculated for all primer sets used in this study. Purified PCR product was serially diluted and amplified in triplicate, and the average $\mathrm{Ct}$ value was plotted against the log dilution (Figure 3.2). Primer efficiencies were calculated from the slope of the line and are; DAT, 97.7\%; NET, 98.4\%; SERT, $102.5 \%$; and cyc A, 98.9\%. Ideally primer efficiencies should be $100 \%$ for optimal results; all primer pairs used in this study have efficiencies close to $100 \%$.
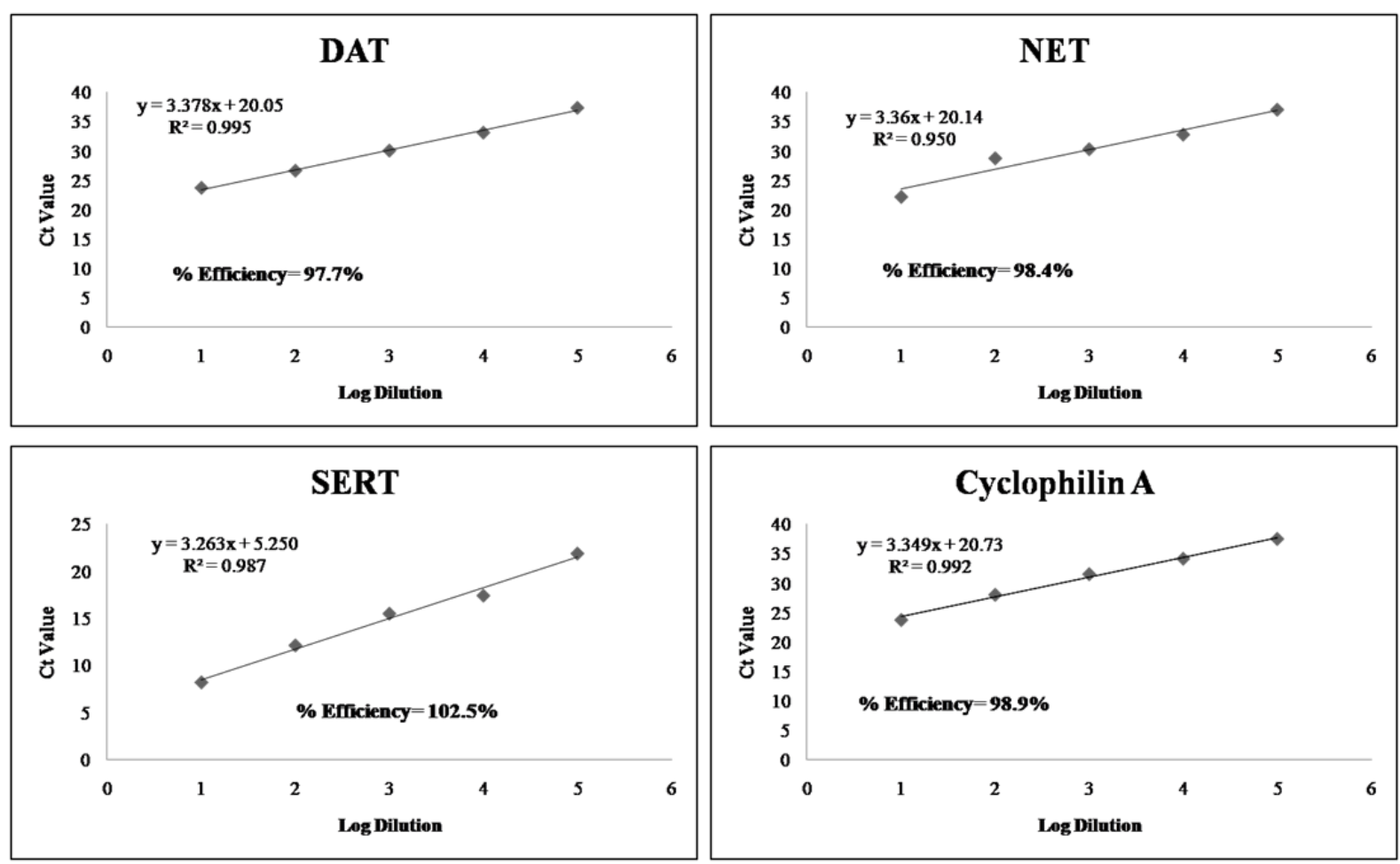

Figure 3.2: Efficiencies of primers used in this study. Purified PCR product dilutions were amplified in triplicate and the average $\mathrm{Ct}$ value was plotted against the log of the dilution. $\mathrm{R}^{2}$ values show the fit of the trend line to data, and the slope of this trend line was used to calculate efficiencies displayed on the graphs. 


\subsubsection{Agarose gel electrophoresis and melt curve analysis}

PCR product was separated on a $2 \%$ agarose gel to confirm the presence of a single band of product at the correct size. All products showed a distinct single band that corresponded to the predicted size of the product (DAT, $228 \mathrm{bp}$; NET, $106 \mathrm{bp}$; SERT, 340 bp; cyc A, $287 \mathrm{bp}$ ) (Figure 3.3A). Melt-curve analysis was also conducted following amplification to confirm the presence of specific products. Rate of change of fluorescence is plotted against temperature and a single product is represented by a single peak in the graph. Figure 3.3B-D shows representative trace images of data generated through real time PCR with the corresponding melt-curve for primer sets used. Distinct single peaks were seen for DAT $\left(86^{\circ} \mathrm{C}\right)$, NET $\left(80^{\circ} \mathrm{C}\right)$, SERT $\left(86^{\circ} \mathrm{C}\right)$ and cyc A $\left(83^{\circ} \mathrm{C}\right)$. Low levels of non-specific product was seen at $73-85^{\circ} \mathrm{C}$ most likely corresponding to some primer dimer formation. Negative control samples containing $\mathrm{H}_{2} \mathrm{O}$ or equimolar RNA in place of template were run with each experiment and melt-curve profile analysis showed no specific products for these samples (Figure 3.3E). 
A
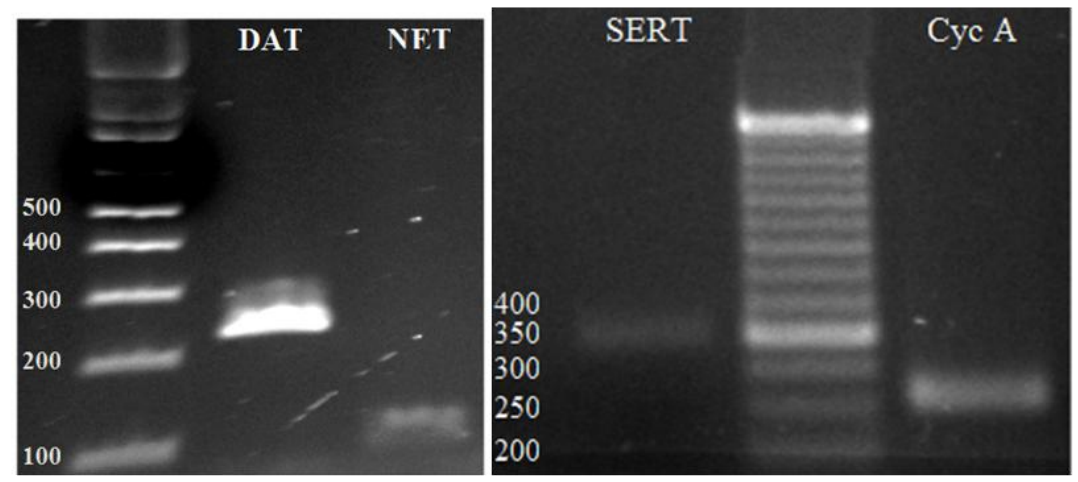

B

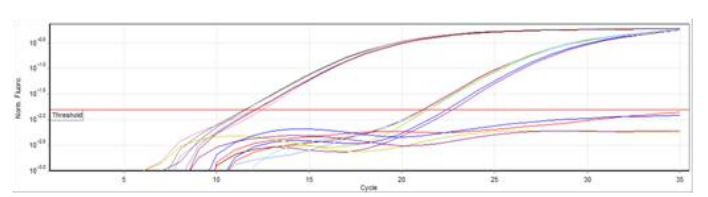

C

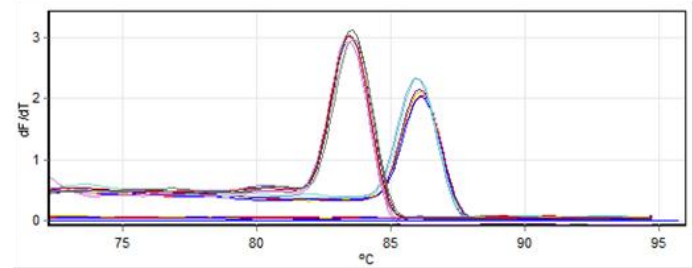

D
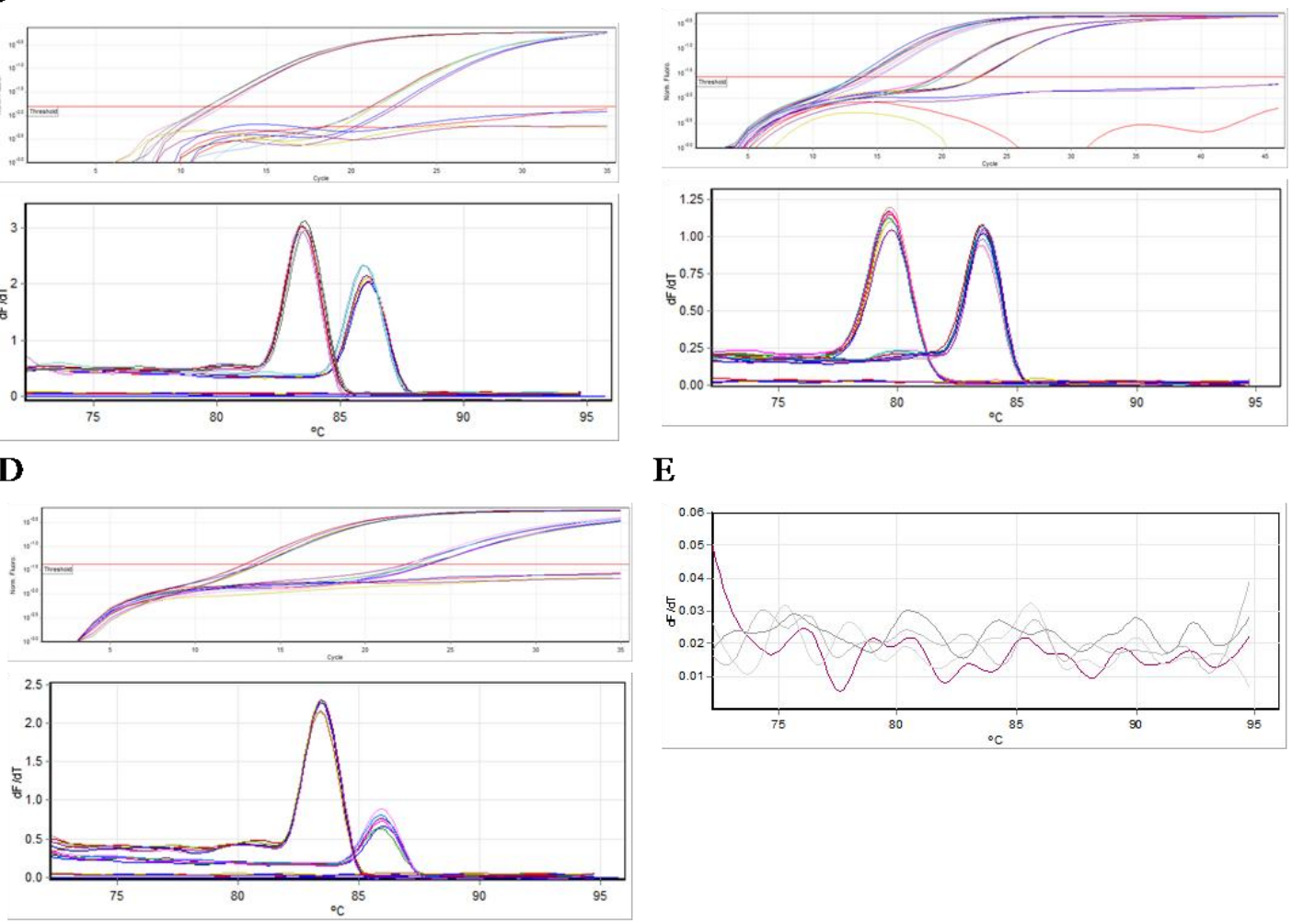

E

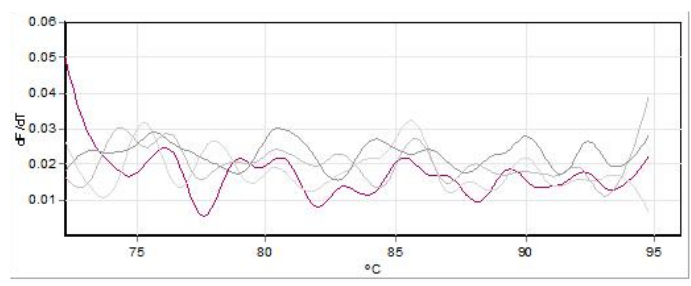

Figure 3.3: Representative data from real-time PCR experiments.

(A) Representative agarose gels of PCR products showing a single band in each lane corresponding to the expected product size (DAT, 228 bp; NET, 106 bp; SERT, 340 bp; cyc A, 287 bp). (B-D) Representative trace images and melt curve profiles for DAT (B), NET (C), SERT (D) and cyc A (B-D). All samples were run in duplicate, and duplicates of RNA and $\mathrm{H}_{2} \mathrm{O}$ negative controls (samples that stay below the threshold line in the trace image) were run with each experiment. Cyc A amplification was run concurrently with every sample analysis for use as a housekeeper gene. The melt curve profile analysis shows distinct peaks for DAT $\left(86^{\circ} \mathrm{C}\right)$, NET $\left(80^{\circ} \mathrm{C}\right)$, SERT $\left(86^{\circ} \mathrm{C}\right)$ and cyc A $\left(83^{\circ} \mathrm{C}\right) \mathrm{PCR}$ products, with low levels of product at $73-85^{\circ} \mathrm{C}$ for all primer pairs. (E) Representative melt curve profile analysis for negative controls shows no specific PCR product. 


\subsection{The effects of chronic nicotine and TPM on DAT function and expression}

\subsubsection{Changes in DAT function and protein expression in the NAc, striatum, and PFC}

Animals were treated with nicotine $(0.35$ or $3 \mathrm{mg} / \mathrm{kg}$ ), TPM (matched to $0.35 \mathrm{mg} / \mathrm{kg}$ nicotine dose), or control for 10 days and euthanized 14-16 hrs after the final treatment. Brain regions of interest were dissected to assess DAT function, protein expression, and mRNA expression using RDEV, Western blotting, and real time PCR respectively. The kinetic parameters $\mathrm{V}_{\max }$ and $\mathrm{K}_{\mathrm{m}}$ were determined for DA uptake in all RDEV experiments (Table 3.2). There was no significant change in DAT function seen in the NAc following any treatment (Figure 3.4A); however, there was a significant increase in protein expression seen in response to $0.35 \mathrm{mg} / \mathrm{kg}$ nicotine and TPM $(\mathrm{p}<0.05$, one-way ANOVA with Bonferroni post-hoc analysis) (Figure 3.4B). A trend towards an increase with 3 $\mathrm{mg} / \mathrm{kg}$ nicotine was also observed that did not reach significance. No change in function or protein expression was observed in the striatum (Figure 3.5) or PFC (Figure 3.5). 
$\mathbf{A}$

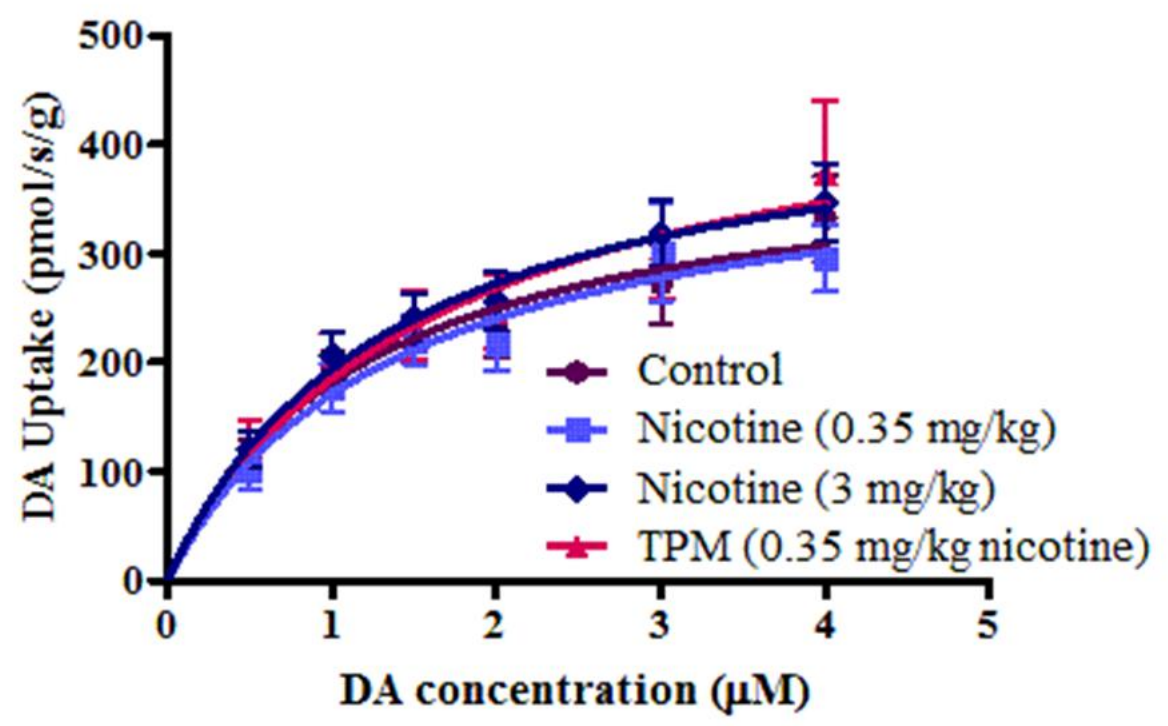

B

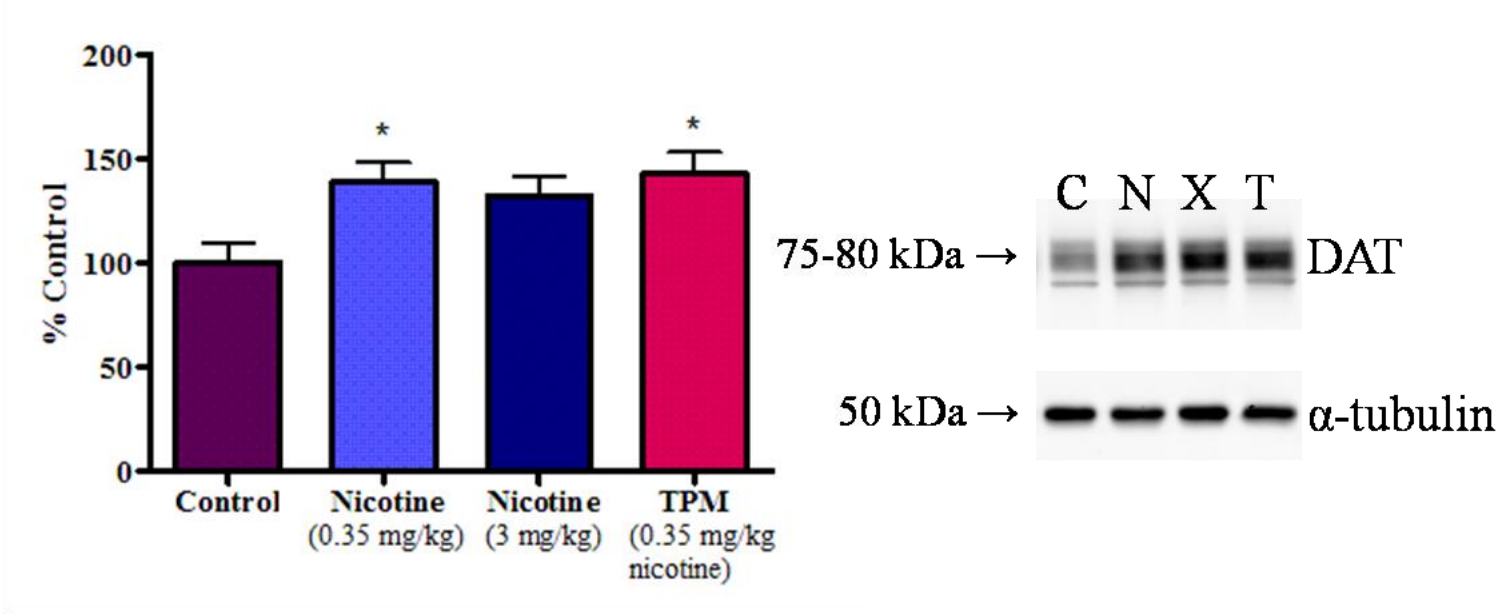

Figure 3.4: The effects of chronic nicotine and TPM on DAT function and protein expression in the NAc. (A) DAT function was measured ex vivo in minced NAc tissue from rats treated in vivo for 10 days with nicotine, TPM or control. No significant change was found between treatment groups. Data points show mean \pm SEM $(n=5-7)$.

Graph demonstrating DAT protein expression accompanied by representative Western blot (C, control; $\mathrm{N}$, nicotine (0.35 mg.kg); X, nicotine (3 mg/kg); T, TPM). Chronic nicotine $(0.35 \mathrm{mg} / \mathrm{kg}$ ) and TPM (containing $0.35 \mathrm{mg} / \mathrm{kg}$ nicotine) treatment significantly increased DAT protein expression in the NAc compared to control. Bars represent mean \pm SEM. ${ }^{*} \mathrm{p}<0.05$, one-way ANOVA with Bonferroni post-hoc analysis $(\mathrm{n}=8-9)$. 
$\mathbf{A}$

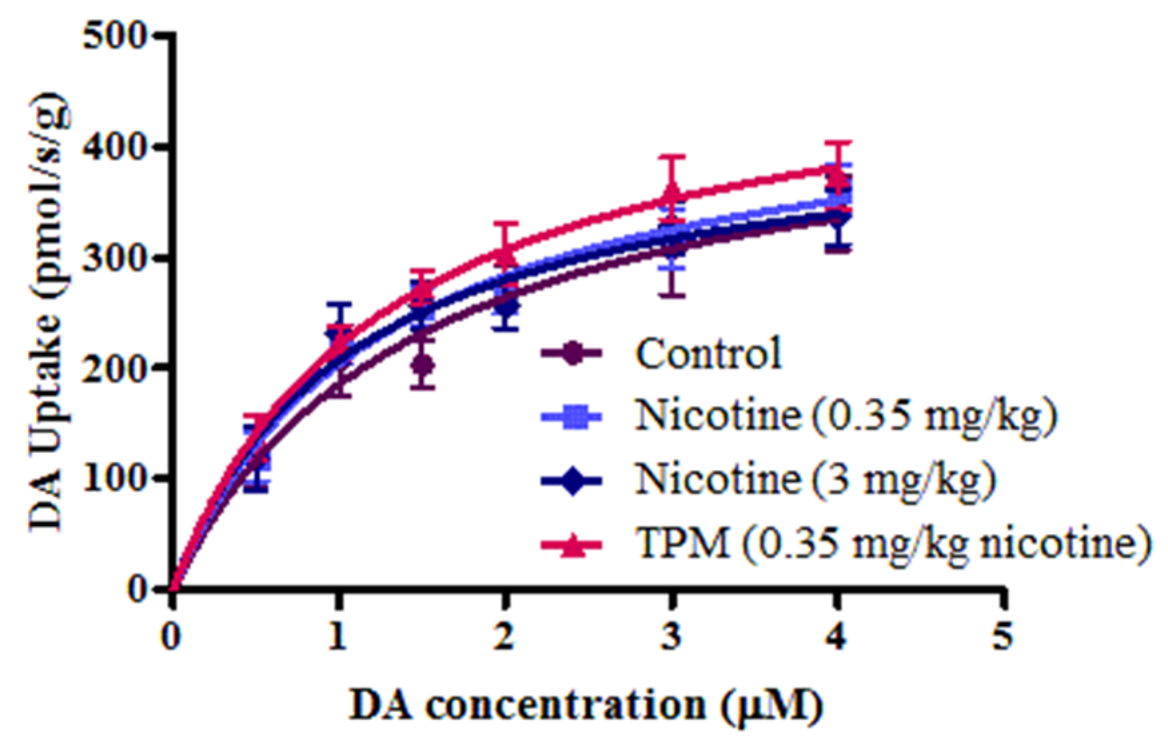

B

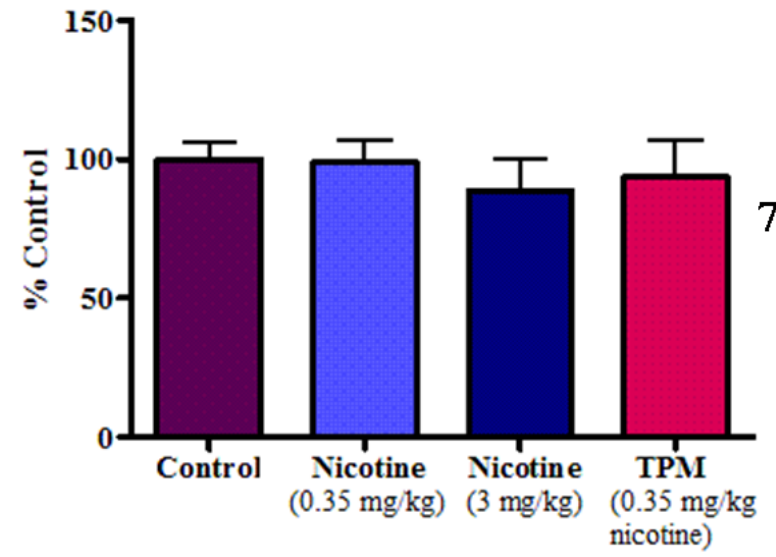

$50 \mathrm{kDa} \rightarrow---\alpha$-tubulin

Figure 3.5: DAT function and protein expression in the striatum following chronic nicotine and TPM treatment. Chronic nicotine $(0.35$ and $3 \mathrm{mg} / \mathrm{kg})$ and TPM (containing $0.35 \mathrm{mg} / \mathrm{kg}$ nicotine) treatment had no significant effect on DAT function (A) or protein expression $(\mathbf{B})$ in minced striatal tissue from rats treated in vivo for 10 days $(\mathrm{C}$, control; $\mathrm{N}$, nicotine $(0.35 \mathrm{mg} / \mathrm{kg})$; X, nicotine (3 mg/kg); T, TPM). Data points and bars represent mean \pm SEM $(n=5-7)$. 
A
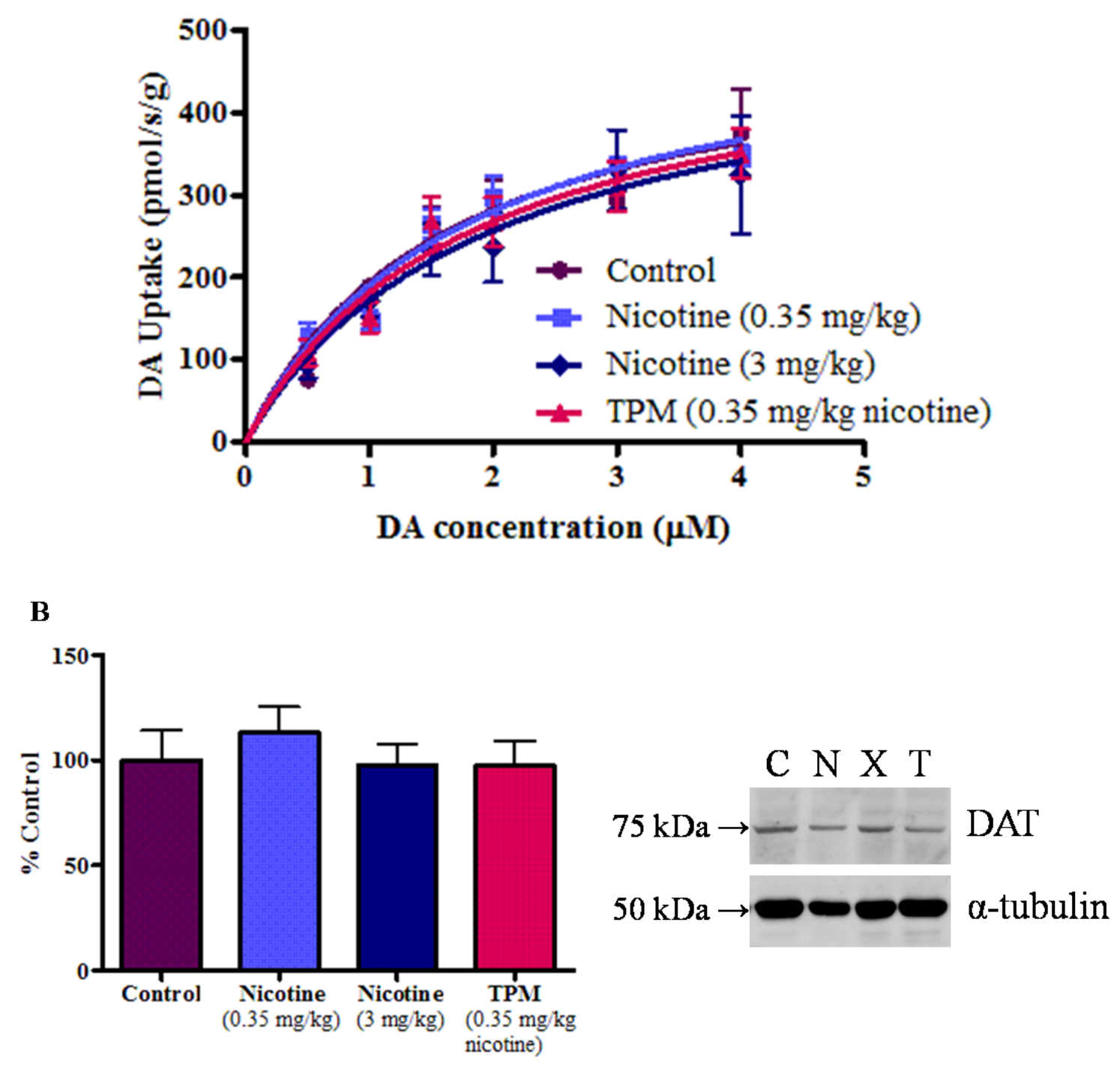

Figure 3.6: DAT function and protein expression in the PFC following chronic nicotine and TPM treatment. Ten days treatment with nicotine $(0.35$ or $3 \mathrm{mg} / \mathrm{kg})$ and TPM (containing $0.35 \mathrm{mg} / \mathrm{kg}$ nicotine) had no effect on DAT function (A) or protein expression (B) in the PFC (C, control; $\mathrm{N}$, nicotine $(0.35 \mathrm{mg} / \mathrm{kg}) ; \mathrm{X}$, nicotine $(3 \mathrm{mg} / \mathrm{kg}) ; \mathrm{T}$, TPM) following 10 days of in vivo treatment. Data points and bars represent mean \pm SEM (n= 4-6). 
Table 3.2: DAT kinetic data for chronic nicotine and TPM treatment.

\begin{tabular}{|l|l|l|l|}
\cline { 2 - 4 } \multicolumn{5}{|c|}{} & Treatment & $\mathbf{V}_{\mathbf{m a x}}(\mathbf{p m o l} / \mathbf{s} / \mathbf{g})$ & $\mathbf{K}_{\mathbf{m}}(\boldsymbol{\mu M})$ \\
\hline \multirow{5}{*}{ NAc } & Control & $429 \pm 69$ & $1.20 \pm 0.34$ \\
\cline { 2 - 4 } & Nicotine $(0.35 \mathrm{mg} / \mathrm{kg})$ & $381 \pm 44$ & $1.33 \pm 0.21$ \\
\cline { 2 - 4 } & Nicotine $(3 \mathrm{mg} / \mathrm{kg})$ & $447 \pm 43$ & $1.52 \pm 0.23$ \\
\cline { 2 - 4 } & TPM $(0.35 \mathrm{mg} / \mathrm{kg}$ nicotine $)$ & $443 \pm 84$ & $1.35 \pm 0.28$ \\
\hline \multirow{5}{*}{ Ptriatum } & Control & $480 \pm 44$ & $1.72 \pm 0.27$ \\
\cline { 2 - 4 } & Nicotine $(0.35 \mathrm{mg} / \mathrm{kg})$ & $461 \pm 27$ & $1.30 \pm 0.17$ \\
\cline { 2 - 4 } & Nicotine $(3 \mathrm{mg} / \mathrm{kg})$ & $457 \pm 34$ & $1.33 \pm 0.18$ \\
\cline { 2 - 4 } & TPM $(0.35 \mathrm{mg} / \mathrm{kg} \mathrm{nicotine})$ & $512 \pm 54$ & $1.30 \pm 0.37$ \\
\hline & Control & $497 \pm 87$ & $1.73 \pm 0.28$ \\
\cline { 2 - 4 } & Nicotine $(0.35 \mathrm{mg} / \mathrm{kg})$ & $502 \pm 54$ & $2.10 \pm 0.49$ \\
\cline { 2 - 4 } & Nicotine $(3 \mathrm{mg} / \mathrm{kg})$ & $671 \pm 102$ & 5.22 \\
\cline { 2 - 4 } & TPM $(0.35 \mathrm{mg} / \mathrm{kg}$ nicotine $)$ & $518 \pm 47$ & \\
\hline
\end{tabular}

Values are mean \pm SEM.

\subsubsection{Changes in DAT mRNA and protein expression in the VTA and SN}

DAT mRNA and protein expression was measured in VTA and SN tissue from chronically treated animals using real time PCR and Western blotting. Both nicotine doses ( 0.35 and $3 \mathrm{mg} / \mathrm{kg}$ ) and TPM (containing $0.35 \mathrm{mg} / \mathrm{kg}$ nicotine) caused a significant decrease in DAT protein expression in the SN $(27-36 \%$; $<<0.05$, one-way ANOVA with Bonferroni post-hoc analysis); however, there was no significant change in the VTA (Figure 3.7B). The observed decrease in protein expression in the $\mathrm{SN}$ was not due to changes in mRNA expression (Figure 3.7A) as there was no significant difference between $\Delta \mathrm{Ct}$ values for control and treatment groups (Table 3.3). 


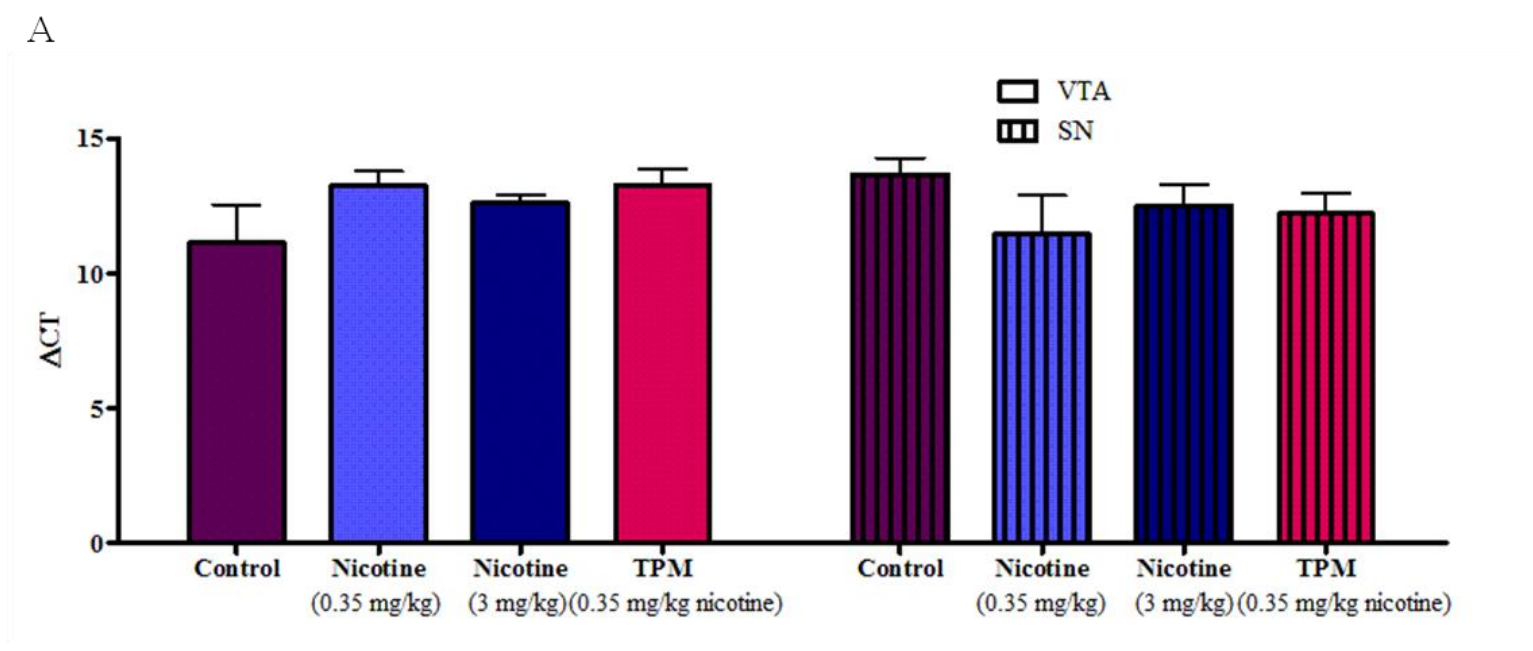

$\mathrm{B}$

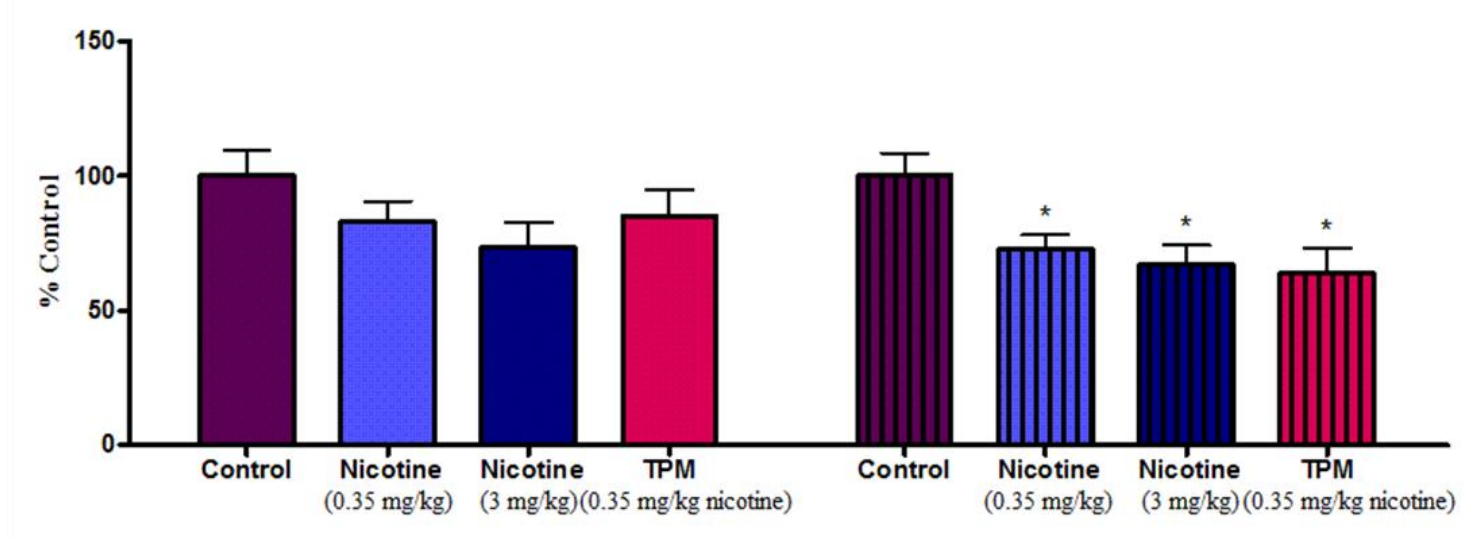

C

$\mathrm{D}$

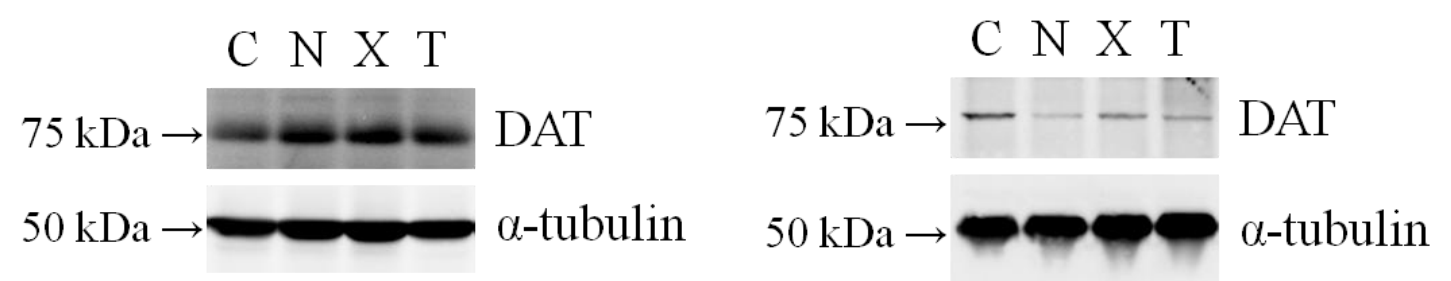

Figure 3.7: DAT mRNA and protein expression in the VTA and SN following chronic nicotine and TPM treatment. Nicotine $(0.35$ and $3 \mathrm{mg} / \mathrm{kg})$ and $\mathrm{TPM}$ (containing $0.35 \mathrm{mg} / \mathrm{kg}$ ) caused no significant change in DAT mRNA expression in the VTA and SN following 10 days treatment (A); however, there was a significant decrease in DAT protein expression in the SN but not the VTA (B). Representative blots for the VTA (C) and SN (D) are shown below the graphs. Bars represent mean \pm SEM *p $<0.05$, one-way ANOVA with Bonferroni post-hoc analysis $(n=6-9)$. C, control; N, nicotine $(0.35 \mathrm{mg} / \mathrm{kg}) ; \mathrm{X}$, nicotine $(3 \mathrm{mg} / \mathrm{kg}) ; \mathrm{T}, \mathrm{TPM}$. 
Table 3.3: $\Delta C$ t values for DAT mRNA expression in the SN and VTA following chronic nicotine and TPM treatment.

\begin{tabular}{|l|l|l|}
\hline Treatment & $\Delta$ CT value SN & $\Delta$ CT value VTA \\
\hline Control & $13.7 \pm 0.6$ & $11.1 \pm 1.4$ \\
\hline Nicotine $(0.35 \mathrm{mg} / \mathrm{kg})$ & $11.4 \pm 1.4$ & $13.3 \pm 0.6$ \\
\hline Nicotine $(3 \mathrm{mg} / \mathrm{kg})$ & $12.5 \pm 0.8$ & $13.3 \pm 0.5$ \\
\hline TPM $(0.35 \mathrm{mg} / \mathrm{kg}$ nicotine $)$ & $12.2 \pm 0.8$ & $12.6 \pm 0.3$ \\
\hline
\end{tabular}

Values are mean \pm SEM.

\subsection{The effects of chronic nicotine and TPM on NET function and expression}

$\underline{3.3 .1 \text { Chronic nicotine }(3 \mathrm{mg} / \mathrm{kg}) \text { causes a significant increase in DA uptake by NET }}$ in the PFC

RDEV and Western blotting were used to measure DA uptake by NET and NET protein expression in the PFC following 10 days nicotine $(0.35$ and $3 \mathrm{mg} / \mathrm{kg}$ ) and TPM (containing $0.35 \mathrm{mg} / \mathrm{kg}$ nicotine) treatment. Nicotine at a dose of $3 \mathrm{mg} / \mathrm{kg}$, but not 0.35 $\mathrm{mg} / \mathrm{kg}$ or TPM (containing $0.35 \mathrm{mg} / \mathrm{kg}$ nicotine), caused an increase in DA uptake by NET (Figure 3.8). The $\mathrm{V}_{\max }$ and $\mathrm{K}_{\mathrm{m}}$ values for the nicotine (3 $\mathrm{mg} / \mathrm{kg}$ ) treatment groups were both significantly increased compared to the control group (Table 3.4) at $76 \%$ $(\mathrm{p}<0.05)$ and 69\% $(\mathrm{p}<0.01)$ (Student's t-test). An increase in $\mathrm{K}_{\mathrm{m}}$ denotes a decrease in binding of the neurotransmitter to the transporter and thus often a decrease in uptake; however, in this case the increase in $\mathrm{V}_{\max }$ was large enough counteract any binding effects and an overall increase in uptake was seen. This change in uptake was not accompanied by any change in protein expression for the $3 \mathrm{mg} / \mathrm{kg}, \quad 0.35 \mathrm{mg} / \mathrm{kg}$ nicotine, or TPM containing $0.35 \mathrm{mg} / \mathrm{kg}$ nicotine (Figure $3.8 \mathrm{~B}$ ). 
$\mathbf{A}$

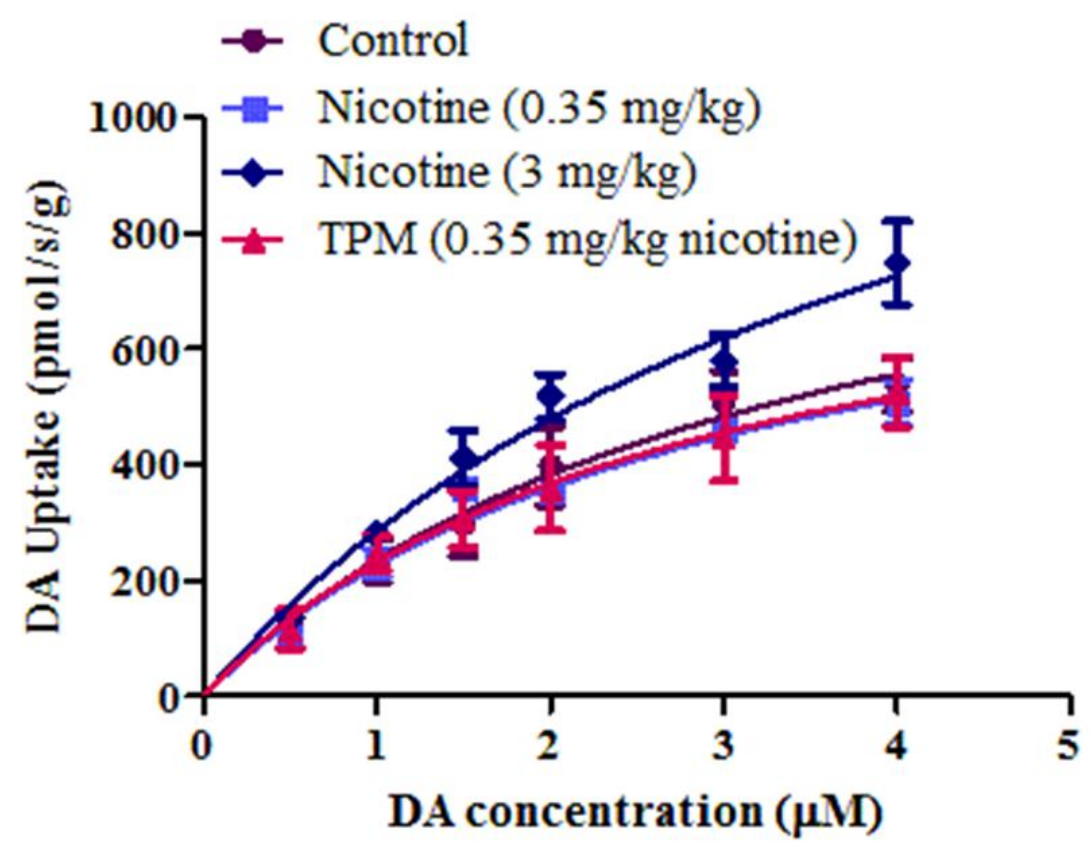

B

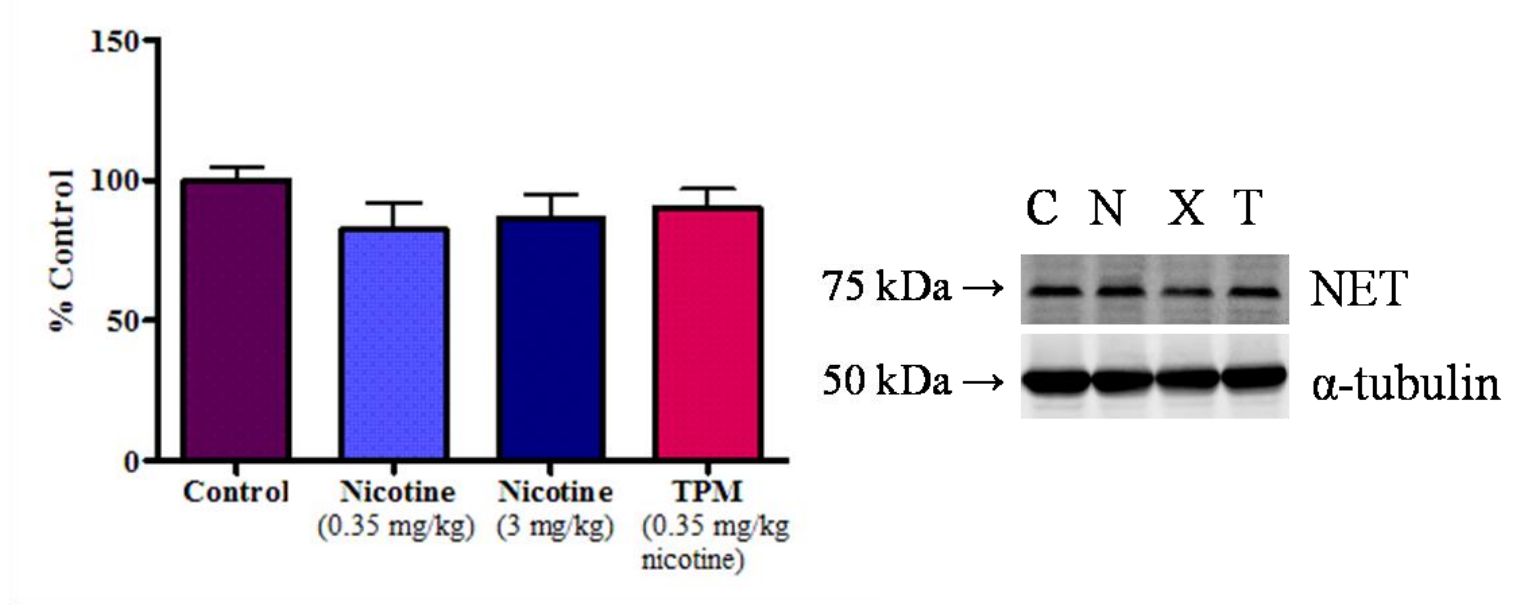

Figure 3.8: Chronic nicotine $(3 \mathrm{mg} / \mathrm{kg})$ treatment increases DA uptake by NET in the PFC but has no significant effect on NET protein expression. (A) Ten days 3 $\mathrm{mg} / \mathrm{kg}$ nicotine treatment, but not $0.35 \mathrm{mg} / \mathrm{kg}$ nicotine or TPM (containing $0.35 \mathrm{mg} / \mathrm{kg}$ nicotine) treatment, increases DA uptake by NET in the PFC. (B) Chronic nicotine and TPM have no significant effect on NET protein expression in the PFC $(\mathrm{C}$, control; N, nicotine $(0.35 \mathrm{mg} / \mathrm{kg}) ; \mathrm{X}$, nicotine $(3 \mathrm{mg} / \mathrm{kg}) ; \mathrm{T}, \mathrm{TPM})$. Data points and bars represent mean $\pm \operatorname{SEM}(n=4-8)$. 
Table 3.4: NET kinetics in the PFC following chronic nicotine and TPM treatment.

\begin{tabular}{|l|l|l|}
\hline Treatment & $\mathbf{V}_{\mathbf{m a x}}(\mathbf{p m o l} / \mathrm{s} / \mathbf{g})$ & $\mathbf{K}_{\mathbf{m}}(\boldsymbol{\mu M})$ \\
\hline Control & $797 \pm 83$ & $2.37 \pm 0.24$ \\
\hline Nicotine $(0.35 \mathrm{mg} / \mathrm{kg})$ & $885 \pm 44$ & $3.03 \pm 0.14$ \\
\hline Nicotine $(3 \mathrm{mg} / \mathrm{kg})$ & $1406 \pm 162^{*}$ & $4.01 \pm 0.25^{* *}$ \\
\hline TPM $(0.35 \mathrm{mg} / \mathrm{kg}$ nicotine $)$ & $988 \pm 122$ & $3.60 \pm 0.68$ \\
\hline
\end{tabular}

Values are mean \pm SEM. ${ }^{*} \mathrm{p}<0.05$ compared to control, $* * \mathrm{p}<0.01$ compared to control, Student's t-test.

\subsubsection{TPM but not nicotine causes a decrease in NET mRNA expression in the LC}

Real time PCR experiments on LC tissue from chronically treated animals $(0.35$ or 3 $\mathrm{mg} / \mathrm{kg} /$ day nicotine or TPM containing $0.35 \mathrm{mg} / \mathrm{kg} /$ day nicotine for 10 days) showed that TPM but not nicotine caused a significant decrease in NET mRNA expression $(\mathrm{p}<0.05$, one-way ANOVA with Bonferroni post-hoc analysis) (Figure 3.9A). The difference in $\Delta \mathrm{Ct}$ value between control and TPM was 4.5 Ct values (Table 3.5), which corresponds to a $95.5 \%$ decrease in mRNA. This change in mRNA expression was not accompanied by a change in protein expression for TPM treated animals or the nicotine treated groups (Figure 3.9B). 
A

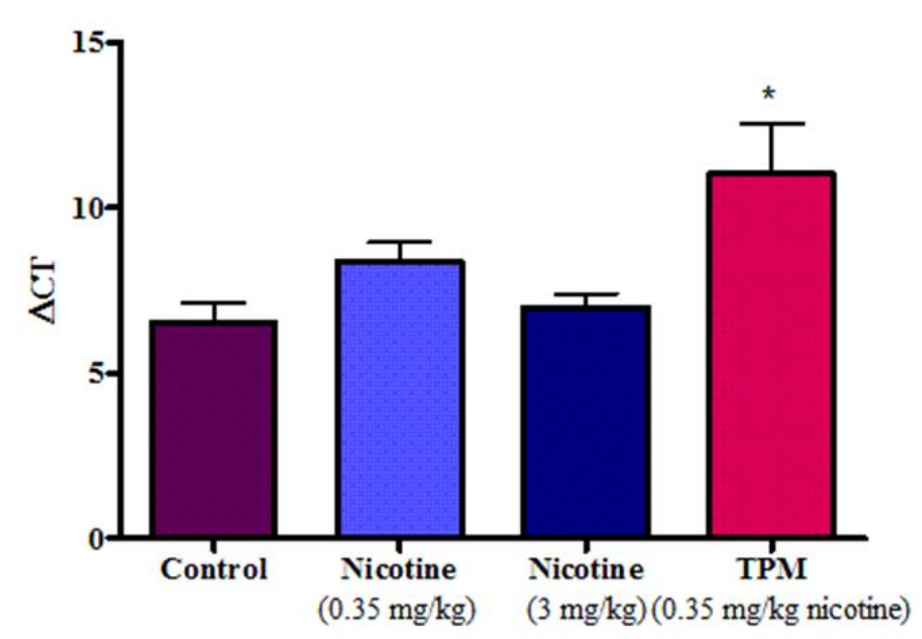

B

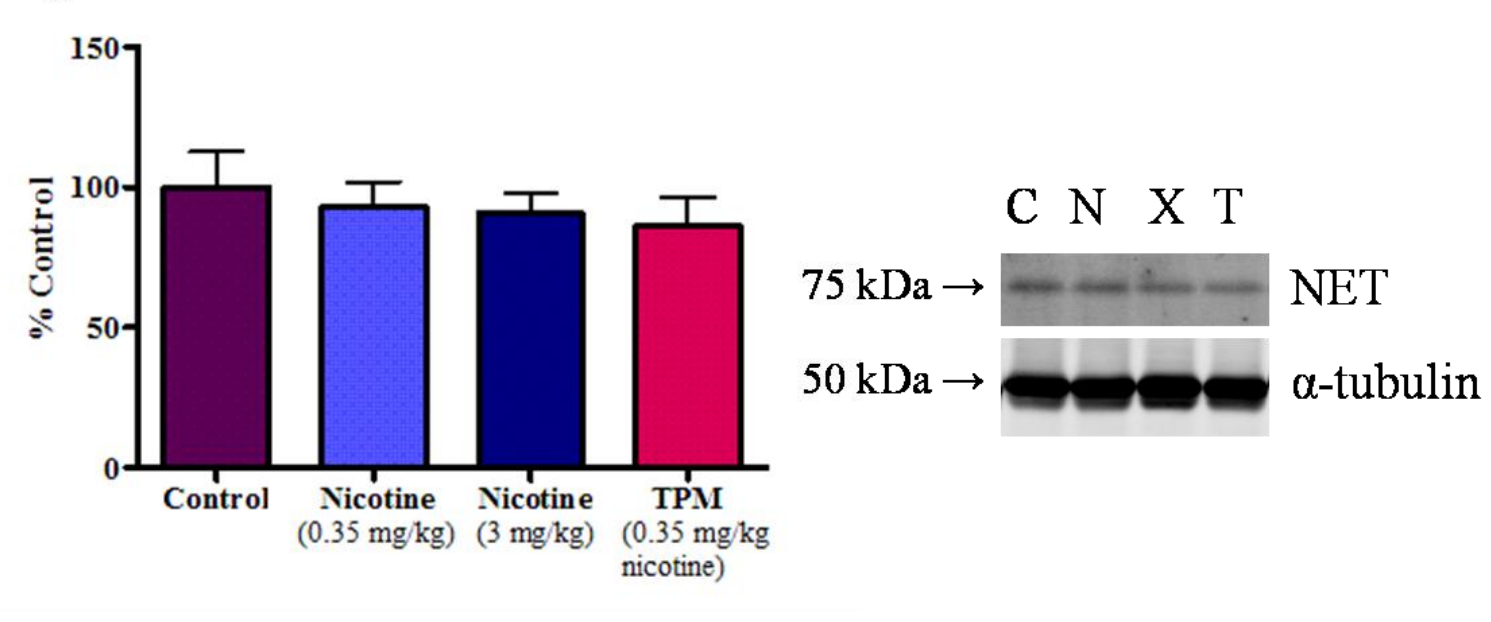

Figure 3.9: The chronic effects of nicotine and TPM on NET mRNA and protein expression in the LC. (A) TPM (containing $0.35 \mathrm{mg} / \mathrm{kg}$ nicotine) significantly decreased NET mRNA expression in the LC (represented as an increase in $\Delta \mathrm{Ct}$ ), whereas nicotine $(0.35$ and $3 \mathrm{mg} / \mathrm{kg}$ ) had no significant effect. (B) Nicotine and TPM had no significant effect on NET protein expression in the LC (C, control; $\mathrm{N}$, nicotine $(0.35 \mathrm{mg} / \mathrm{kg}) ; \mathrm{X}$, nicotine $(3 \mathrm{mg} / \mathrm{kg}) ; \mathrm{T}, \mathrm{TPM}) . \quad$ Bars represent mean \pm SEM $(\mathrm{n}=6-9) . * \mathrm{p}<0.05$ compared to control, one-way ANOVA with Bonferroni post-hoc analysis. 
Table 3.5: $\Delta C t$ values for NET mRNA expression in the LC following chronic nicotine and TPM treatment.

\begin{tabular}{|l|l|}
\hline Treatment & $\Delta$ CT value \\
\hline Control & $6.5 \pm 0.6$ \\
\hline Nicotine $(0.35 \mathrm{mg} / \mathrm{kg})$ & $8.4 \pm 0.6$ \\
\hline Nicotine $(3 \mathrm{mg} / \mathrm{kg})$ & $7.0 \pm 0.4$ \\
\hline TPM $(0.35 \mathrm{mg} / \mathrm{kg}$ nicotine $)$ & $11.0 \pm 1.5^{*}$ \\
\hline
\end{tabular}

Values are mean \pm SEM. *p <0.05 compared to control, one-way ANOVA with Bonferroni post-hoc analysis.

\subsection{The effects of chronic nicotine and TPM on SERT function and expression}

$\underline{\text { 3.4.1 Chronic nicotine and TPM treatment has no significant effect on SERT function }}$ or protein expression in the striatum

Animals were treated with 0.35 or $3 \mathrm{mg} / \mathrm{kg}$ nicotine or TPM containing $0.35 \mathrm{mg} / \mathrm{kg}$ nicotine for 10 days prior to sacrifice. Striatal tissue from chronically treated animals was used in RDEV and Western blotting experiments to assess the function and protein expression of SERT. No significant changes were found in either function or protein expression (Figure 3.10). Table 3.6 shows the $\mathrm{V}_{\max }$ and $\mathrm{K}_{\mathrm{m}}$ values for SERT function in this experiment.

Table 3.6: SERT kinetics in the striatum following chronic nicotine and TPM treatment.

\begin{tabular}{|l|l|l|}
\hline Treatment & $\mathbf{V}_{\max }(\mathbf{p m o l} / \mathbf{s} / \mathbf{g})$ & $\mathbf{K}_{\mathbf{m}}(\boldsymbol{\mu M})$ \\
\hline Control & $269 \pm 16$ & $1.12 \pm 0.30$ \\
\hline Nicotine $(0.35 \mathrm{mg} / \mathrm{kg})$ & $274 \pm 38$ & $0.80 \pm 0.13$ \\
\hline Nicotine $(3 \mathrm{mg} / \mathrm{kg})$ & $248 \pm 39$ & $0.86 \pm 0.21$ \\
\hline TPM $(0.35 \mathrm{mg} / \mathrm{kg}$ nicotine $)$ & $326 \pm 62$ & $0.81 \pm 0.21$ \\
\hline
\end{tabular}

Values are mean \pm SEM. 
A

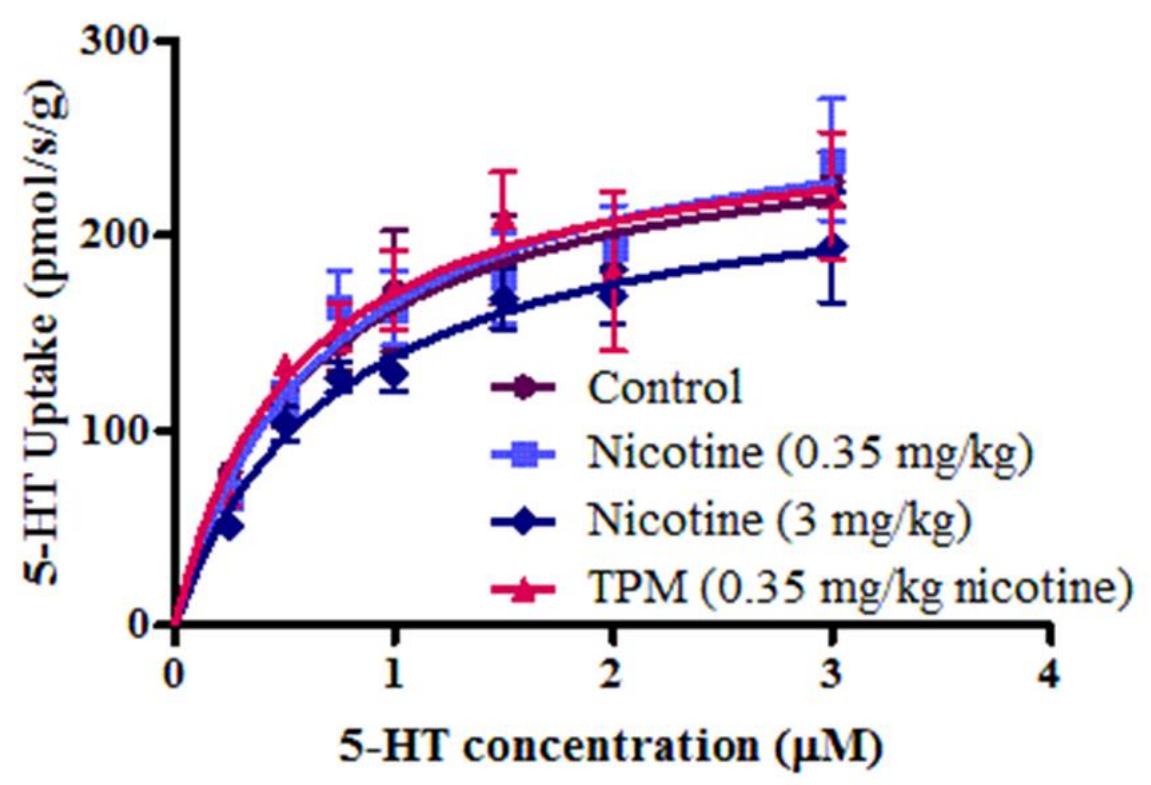

B

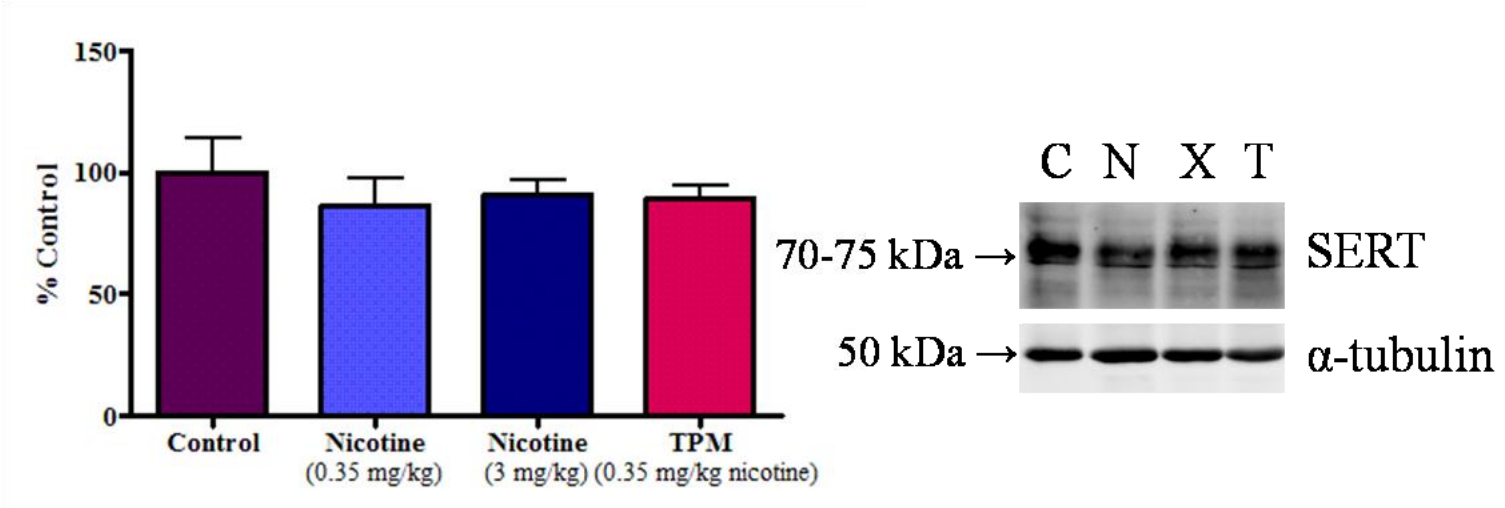

Figure 3.10: Chronic nicotine and TPM treatment has no effect on SERT function (A) or protein expression (B) in the rat striatum. Animals were sacrificed following 10 days nicotine $(0.35$ and $3 \mathrm{mg} / \mathrm{kg}$ ) and TPM (containing $0.35 \mathrm{mg} / \mathrm{kg}$ nicotine) treatment. Data points and bars represent mean \pm SEM $(\mathrm{C}$, control; $\mathrm{N}$, nicotine $(0.35$ $\mathrm{mg} / \mathrm{kg}) ; \mathrm{X}$, nicotine $(3 \mathrm{mg} / \mathrm{kg}) ; \mathrm{T}, \mathrm{TPM})(\mathrm{n}=4-6)$. 
3.4.2 SERT mRNA and protein expression in the DRN following chronic nicotine and TPM treatment

Nicotine and TPM treatment caused no significant changes in SERT mRNA and protein expression compared to control in the DRN (Figure 3.11). Interestingly, TPM (containing $0.35 \mathrm{mg} / \mathrm{kg}$ nicotine) did cause a significant decrease in SERT mRNA expression (2.3 Ct values) compared to the $0.35 \mathrm{mg} / \mathrm{kg}$ nicotine dose $(\mathrm{p}<0.05$, one-way ANOVA with Bonferroni post-hoc analysis) (Table 3.7). This difference corresponds to a $91 \%$ decrease in mRNA in the TPM treatment group compared to the $0.35 \mathrm{mg} / \mathrm{kg}$ nicotine group; however, no corresponding decrease in protein expression was observed (Figure 3.11B).

Table 3.7: $\triangle C$ T values for SERT mRNA expression in the DRN following chronic nicotine and TPM treatment.

\begin{tabular}{|l|l|}
\hline Treatment & $\Delta$ CT value \\
\hline Control & $10.7 \pm 0.8$ \\
\hline Nicotine $(0.35 \mathrm{mg} / \mathrm{kg})$ & $9.5 \pm 0.5$ \\
\hline Nicotine $(3 \mathrm{mg} / \mathrm{kg})$ & $12.6 \pm 0.9$ \\
\hline TPM $(0.35 \mathrm{mg} / \mathrm{kg}$ nicotine $)$ & $13.0 \pm 0.9^{*}$ \\
\hline
\end{tabular}

Values are mean \pm SEM. ${ }^{*} \mathrm{p}<0.05$ compared to nicotine $(0.35 \mathrm{mg} / \mathrm{kg})$, one-way ANOVA with Bonferroni post-hoc analysis. 
A

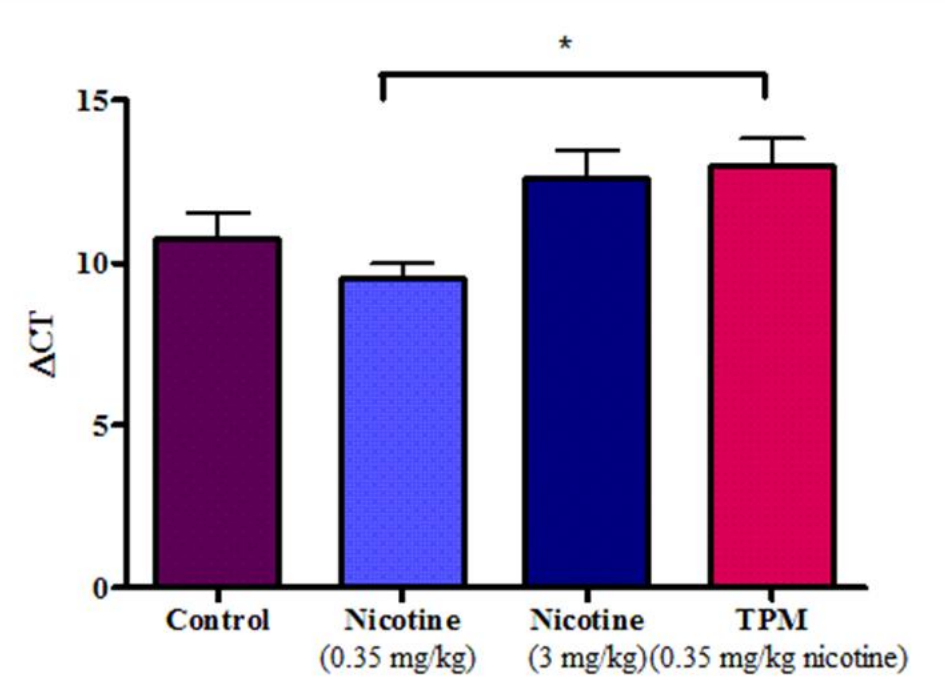

B

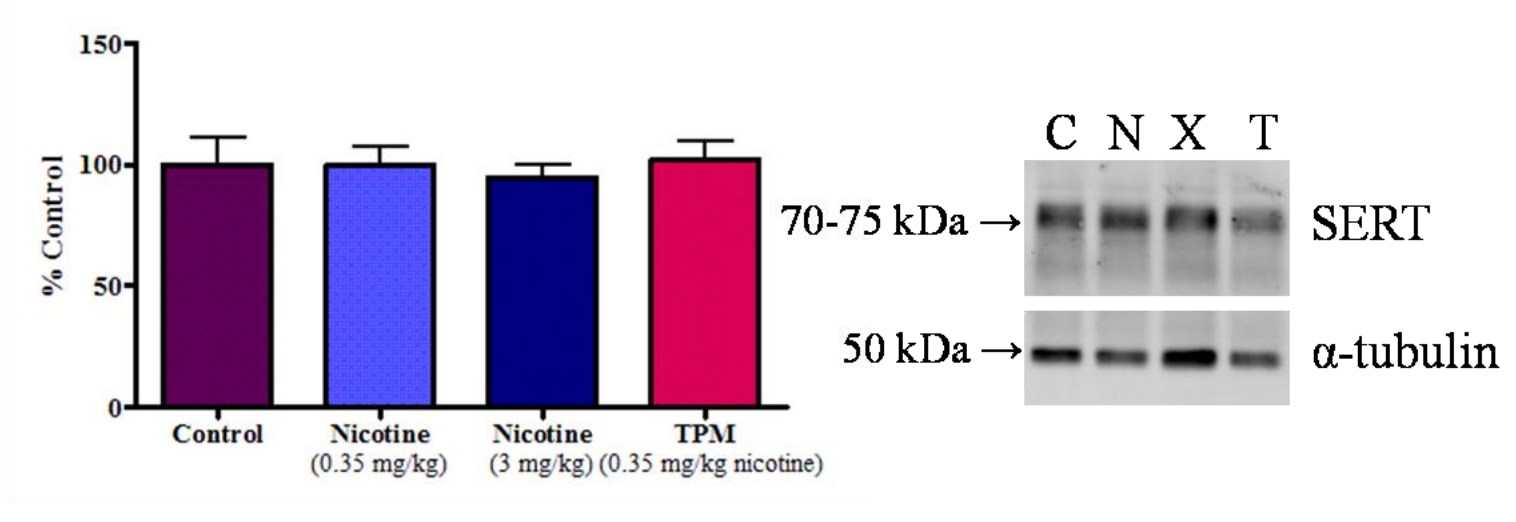

Figure 3.11: SERT mRNA and protein expression in the DRN following chronic nicotine and TPM treatment. (A) Nicotine and TPM have no significant effect on SERT mRNA expression compared to control; however, TPM (containing $0.35 \mathrm{mg} / \mathrm{kg}$ nicotine) causes a significant decrease in SERT mRNA expression compared to 0.35 $\mathrm{mg} / \mathrm{kg}$ nicotine. (B) Nicotine and TPM have no significant effect on SERT protein expression in the DRN. Bars represent mean \pm SEM, ${ }^{*} \mathrm{p}<0.05$ one-way ANOVA with Bonferroni post-hoc analysis $(n=5-6)$. 


\section{Chapter 4: The acute effects of nicotine and TPM on DA and 5-HT uptake and monoamine transporter expression}

\subsection{The in vitro effects of nicotine and TPM on monoamine uptake}

\subsubsection{DA uptake in the NAc, striatum, and PFC}

The in vitro effects of nicotine and TPM on DA uptake were assessed using tissue from drug naive animals. Nicotine $(2 \mu \mathrm{M})$ or TPM (containing $2 \mu \mathrm{M}$ nicotine) were incubated with minced tissue for $5 \mathrm{~min}$ prior to the first DA addition. Neither nicotine nor TPM caused any significant change in DA uptake by DAT in the NAc, striatum or PFC, or DA uptake by NET (Figure 4.1) using RDEV. Nicotine did cause a significant increase in $\mathrm{K}_{\mathrm{m}}$ compared to control in the NAc (Table 4.1); however, this was accompanied by a nonsignificant increase in $\mathrm{V}_{\max }$ that resulted in no change in uptake overall. 
Table 4.1: DAT and NET kinetics for DA uptake from in vitro nicotine and TPM treatment.

\begin{tabular}{|c|c|c|c|}
\hline & Treatment & $\mathrm{V}_{\max }(\mathrm{pmol} / \mathrm{s} / \mathrm{g})$ & $\mathbf{K}_{\mathrm{m}}(\boldsymbol{\mu M})$ \\
\hline \multirow{3}{*}{ DAT NAc } & Control & $400 \pm 51$ & $0.92 \pm 0.23$ \\
\hline & Nicotine $(0.35 \mathrm{mg} / \mathrm{kg})$ & $442 \pm 40$ & $1.66 \pm 0.25 *$ \\
\hline & TPM (0.35 mg/kg nicotine) & $358 \pm 56$ & $0.68 \pm 0.09$ \\
\hline \multirow{3}{*}{ DAT Striatum } & Control & $390 \pm 41$ & $0.91 \pm 0.09$ \\
\hline & Nicotine $(0.35 \mathrm{mg} / \mathrm{kg})$ & $408 \pm 53$ & $0.92 \pm 0.13$ \\
\hline & TPM $(0.35 \mathrm{mg} / \mathrm{kg}$ nicotine $)$ & $448 \pm 51$ & $1.16 \pm 0.12$ \\
\hline \multirow{3}{*}{ DAT PFC } & Control & $419 \pm 62$ & $0.90 \pm 0.13$ \\
\hline & Nicotine $(0.35 \mathrm{mg} / \mathrm{kg})$ & $409 \pm 41$ & $1.09 \pm 0.18$ \\
\hline & TPM (0.35 mg/kg nicotine) & $384 \pm 74$ & $0.81 \pm 0.17$ \\
\hline \multirow{3}{*}{ NET PFC } & Control & $516 \pm 75$ & $1.45 \pm 0.15$ \\
\hline & Nicotine $(0.35 \mathrm{mg} / \mathrm{kg})$ & $494 \pm 40$ & $1.58 \pm 0.15$ \\
\hline & TPM (0.35 mg/kg nicotine) & $509 \pm 48$ & $1.83 \pm 0.53$ \\
\hline
\end{tabular}

Values are mean \pm SEM. ${ }^{*} \mathrm{p}<0.05$ compared to control, Student's t-test. 


\section{A. DAT NAc}

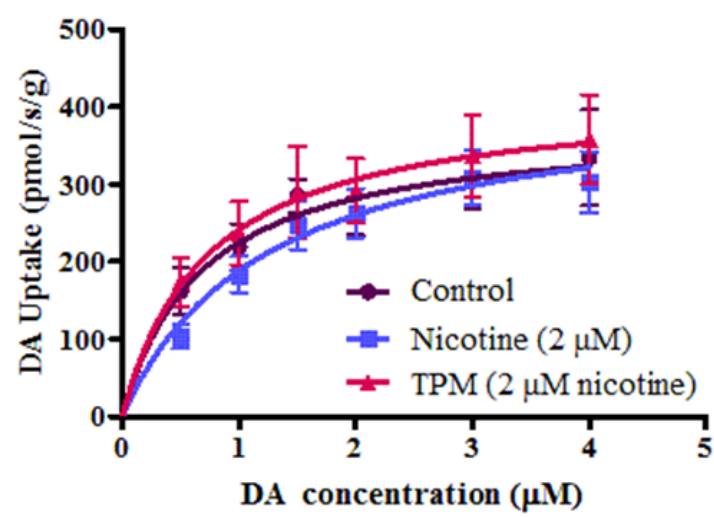

C. DAT PFC

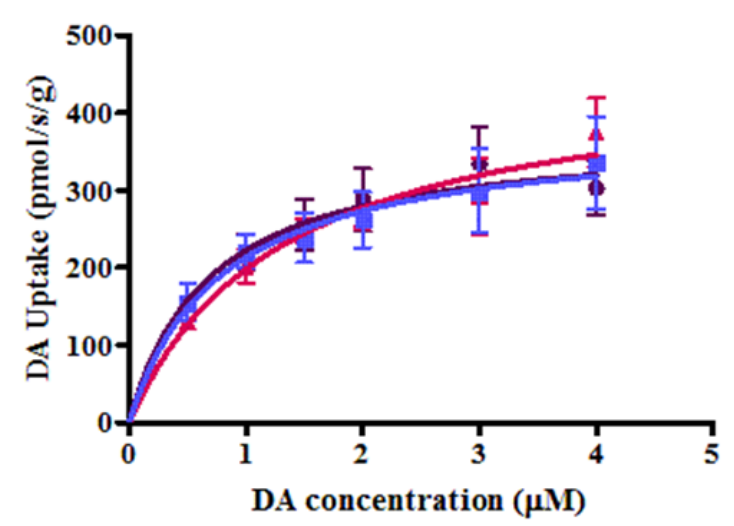

B. DAT Striatum

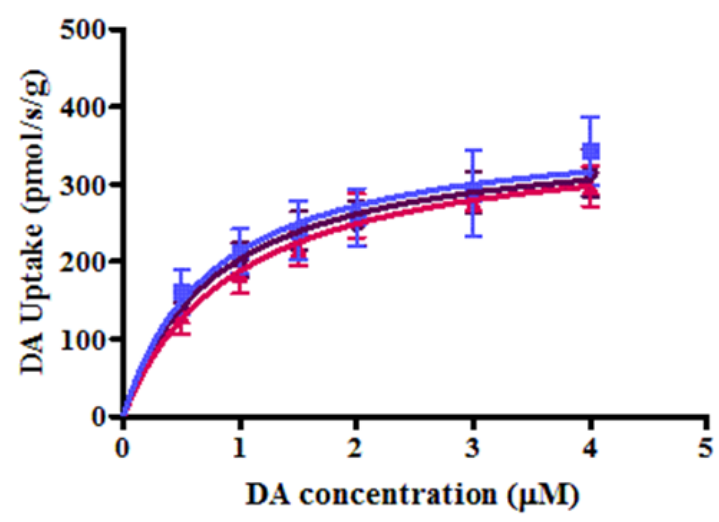

D. NET PFC

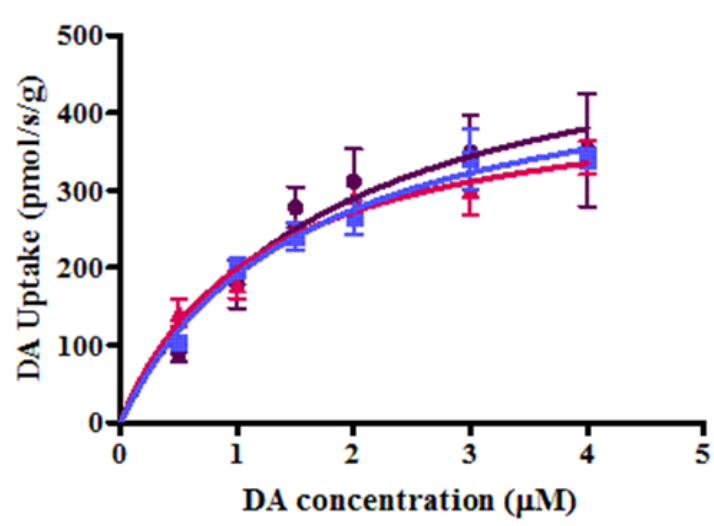

Figure 4.1: In vitro nicotine and TPM treatment has no significant effect on DA uptake in isolated tissue. Tissue from drug naive rats was treated with control, nicotine $(2 \mu \mathrm{M})$, or TPM (containing $2 \mu \mathrm{M}$ nicotine) 5 min prior to the first DA addition. It had no significant effect on DAT mediated DA uptake in the NAc (A) $(n=7-9)$, striatum (B) $(n=6)$, or PFC $(\mathbf{C})(n=6-7)$; or on NET mediated DA uptake in the PFC (D) $(n=4-5)$. Data points represent mean \pm SEM. 


\subsubsection{5-HT uptake in the striatum}

Striatal tissue from drug naive animals was incubated with PBS or the non-selective, noncompetitive nicotinic acetylcholine receptor antagonist mecamylamine $(1 \mu \mathrm{M})$ for $5 \mathrm{~min}$, followed by treatment with control, nicotine $(2 \mu \mathrm{M})$, or TPM (containing $2 \mu \mathrm{M}$ nicotine) for 5 min prior to the first 5-HT addition. TPM, but not nicotine, significantly decreased SERT function compared to control (Figure 4.2). This decrease was characterised by a decrease in $31.5 \%$ decrease in $\mathrm{V}_{\max }$ for the PBS/TPM treatment group compared to PBS/control ( $p<0.05$, Student's test), with no significant change in $K_{m}$ (Table 4.2). Pretreatment with mecamylamine had no effect on control, and did not completely antagonise the effects of TPM. The mecamylamine/TPM treatment group had a $\mathrm{V}_{\max }$ 25.8\% lower than PBS/control. This is a slightly higher uptake than the PBS/TPM group, but this difference is not significant. Furthermore, the mecamylamine/TPM group had a higher $\mathrm{K}_{\mathrm{m}}$ value than PBS/TPM. This increase in both $\mathrm{V}_{\max }$ and $\mathrm{K}_{\mathrm{m}}$ resulted in no significant overall difference in 5-HT uptake between the PBS/TPM and mecamylamine/TPM treatment groups.

Table 4.2: Kinetic data for 5-HT uptake in the striatum following in vitro nicotine and TPM treatment.

\begin{tabular}{|l|l|l|}
\hline Treatment & $\mathbf{V}_{\mathbf{m a x}}(\mathbf{p m o l} / \mathbf{s} / \mathbf{g})$ & $\mathbf{K}_{\mathbf{m}}(\boldsymbol{\mu M})$ \\
\hline PBS/Control & $460 \pm 52$ & $0.94 \pm 0.13$ \\
\hline PBS/Nicotine $(2 \mu \mathrm{M})$ & $413 \pm 36$ & $0.66 \pm 0.12$ \\
\hline PBS/TPM $(2 \mu \mathrm{M}$ nicotine $)$ & $315 \pm 33 *$ & $0.67 \pm 0.10$ \\
\hline Mec/Control & $429 \pm 37$ & $0.85 \pm 0.11$ \\
\hline Mec/TPM $(2 \mu \mathrm{M}$ nicotine $)$ & $346 \pm 67$ & $1.05 \pm 0.28$ \\
\hline
\end{tabular}

Values are mean \pm SEM. ${ }^{*} \mathrm{p}<0.05$ compared to PBS/Control, Student's t-test. PBS, phosphate buffered saline; Mec, mecamylamine. 


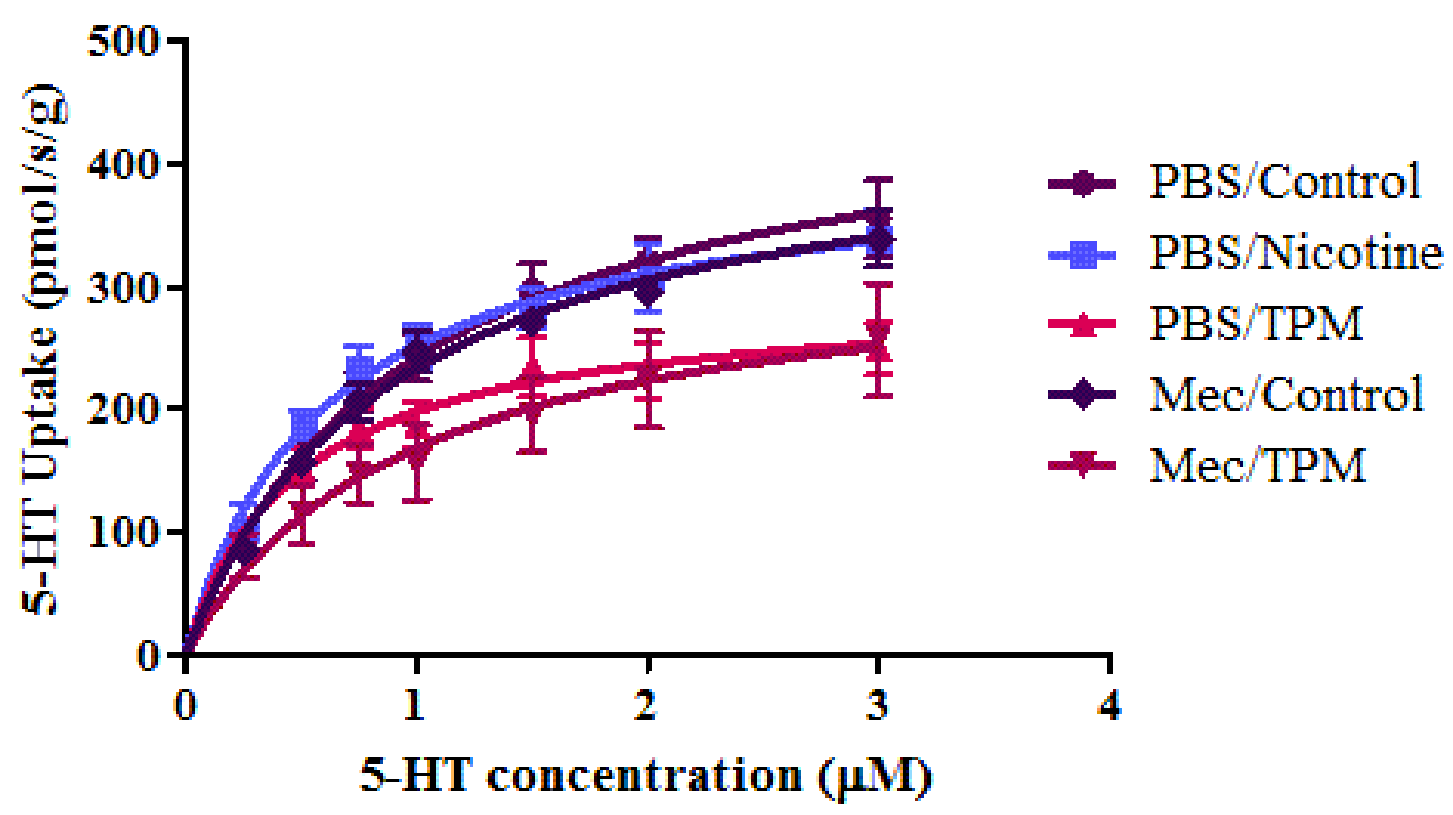

Figure 4.2: In vitro TPM treatment significantly decreases 5-HT uptake by SERT in the striatum. TPM (containing $2 \mu \mathrm{M}$ nicotine) significantly decreased 5-HT uptake in drug naive rat striatal tissue. Nicotine $(2 \mu \mathrm{M})$ had no significant effect on uptake. Mecamylamine $(1 \mu \mathrm{M})$ pre-treatment did not affect uptake in control treated tissue and did not completely antagonise TPM-induced decreases in 5-HT uptake. Data points represent mean \pm SEM $(n=4-8)$ (PBS, phosphate buffered saline; TPM, tobacco particulate matter; mec, mecamylamine).

\subsection{The effects of acute in vivo nicotine and TPM treatment on the monoamine transporters}

Animals were treated in vivo with control, nicotine $(0.35 \mathrm{mg} / \mathrm{kg}$ ) or TPM (containing 0.35 $\mathrm{mg} / \mathrm{kg}$ nicotine) and sacrificed $15 \mathrm{~min}, 30 \mathrm{~min}$, or $1 \mathrm{hr}$ after treatment. DAT, NET and SERT function were assessed ex vivo using RDEV and, additionally, monoamine transporter protein and mRNA expression were measured at the $1 \mathrm{hr}$ time-point.

\subsubsection{The effects of nicotine and TPM on monoamine transporter function at $15 \mathrm{~min}$}

Nicotine and TPM treatment had no significant effect on DAT, NET or SERT function in any brain region (Figure 4.3). In the NAc TPM did significantly increase the $\mathrm{K}_{\mathrm{m}}$ by $54 \%$ compared to control ( $\mathrm{p}<0.05$, Student's t-test) (Table 4.3); however, this was 
accompanied by a modest, non-significant increase in $\mathrm{V}_{\max }$ and resulted in no overall change in uptake (Figure 4.3A). Similarly, the $\mathrm{K}_{\mathrm{m}}$ of SERT function in the striatum was significantly increased (88\%) with nicotine treatment (Table 4.3). This was also accompanied by an increase in $\mathrm{V}_{\max }$ and resulted in no overall change in 5-HT uptake (Figure 4.3E).

Table 4.3: Kinetic data for DA and 5-HT uptake at 15 min following nicotine and TPM treatment.

\begin{tabular}{|c|c|c|c|}
\hline & Treatment & $V_{\max }(p m o l / s / g)$ & $\mathbf{K}_{\mathbf{m}}(\boldsymbol{\mu} \mathbf{M})$ \\
\hline \multirow{3}{*}{ DAT NAc } & Control & $580 \pm 61$ & $1.09 \pm 0.15$ \\
\hline & Nicotine $(0.35 \mathrm{mg} / \mathrm{kg})$ & $619 \pm 58$ & $1.64 \pm 0.35$ \\
\hline & TPM (0.35 mg/kg nicotine) & $628 \pm 62$ & $1.69 \pm 0.22 *$ \\
\hline \multirow{3}{*}{ DAT Striatum } & Control & $359 \pm 46$ & $0.78 \pm 0.13$ \\
\hline & Nicotine $(0.35 \mathrm{mg} / \mathrm{kg})$ & $345 \pm 37$ & $1.01 \pm 0.18$ \\
\hline & TPM $(0.35 \mathrm{mg} / \mathrm{kg}$ nicotine $)$ & $325 \pm 51$ & $1.02 \pm 0.29$ \\
\hline \multirow{3}{*}{ DAT PFC } & Control & $517 \pm 73$ & $1.55 \pm 0.26$ \\
\hline & Nicotine $(0.35 \mathrm{mg} / \mathrm{kg})$ & $614 \pm 84$ & $1.94 \pm 0.42$ \\
\hline & TPM $(0.35 \mathrm{mg} / \mathrm{kg}$ nicotine $)$ & $648 \pm 79$ & $2.11 \pm 0.26$ \\
\hline \multirow{3}{*}{ NET PFC } & Control & $586 \pm 19$ & $1.60 \pm 0.52$ \\
\hline & Nicotine $(0.35 \mathrm{mg} / \mathrm{kg})$ & $661 \pm 54$ & $1.74 \pm 0.06$ \\
\hline & TPM $(0.35 \mathrm{mg} / \mathrm{kg}$ nicotine $)$ & $626 \pm 78$ & $1.71 \pm 0.31$ \\
\hline \multirow{3}{*}{ SERT Striatum } & Control & $417 \pm 54$ & $0.60 \pm 0.08$ \\
\hline & Nicotine $(0.35 \mathrm{mg} / \mathrm{kg})$ & $510 \pm 42$ & $1.13 \pm 0.20^{*}$ \\
\hline & TPM $(0.35 \mathrm{mg} / \mathrm{kg}$ nicotine $)$ & $481 \pm 49$ & $0.88 \pm 0.16$ \\
\hline
\end{tabular}

Values are mean \pm SEM. ${ }^{*} \mathrm{p}<0.05$ compared to control, Student's t-test. 
A. DAT NAc

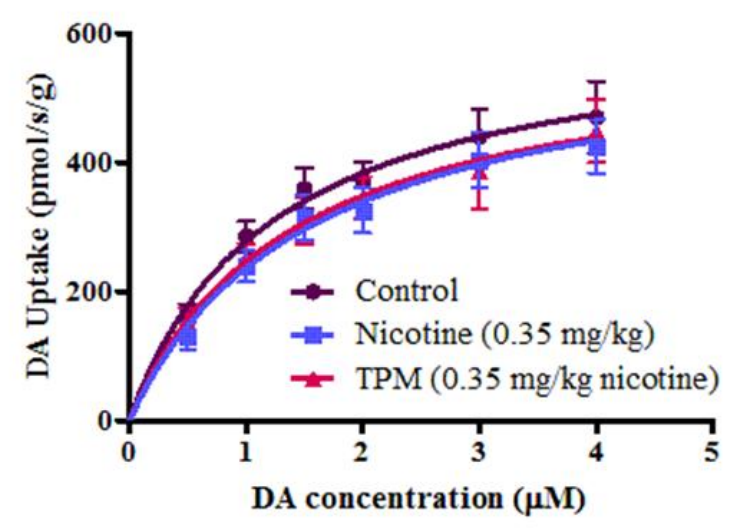

C. DAT PFC

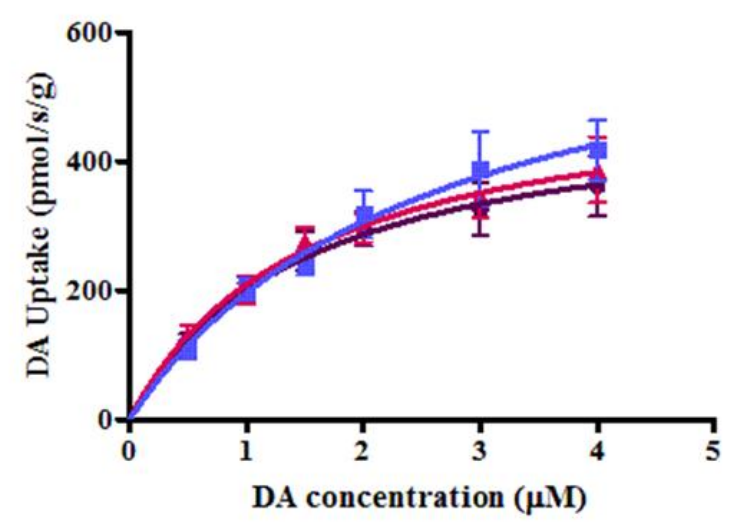

B. DAT Striatum

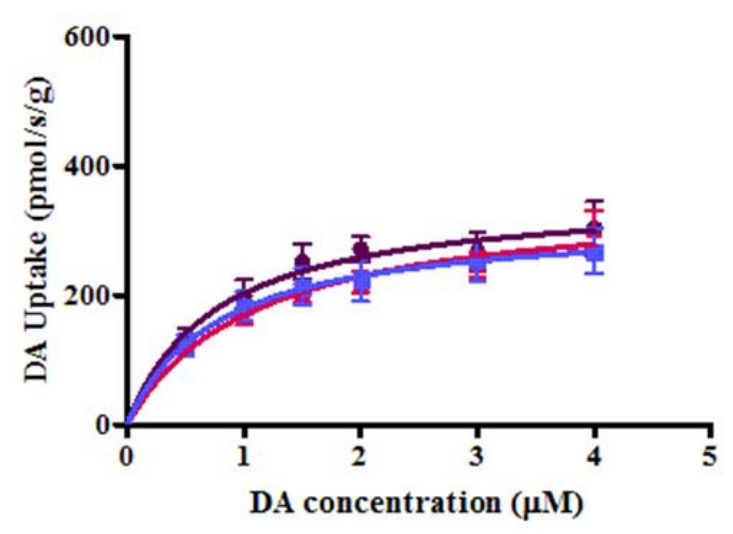

D. NET PFC

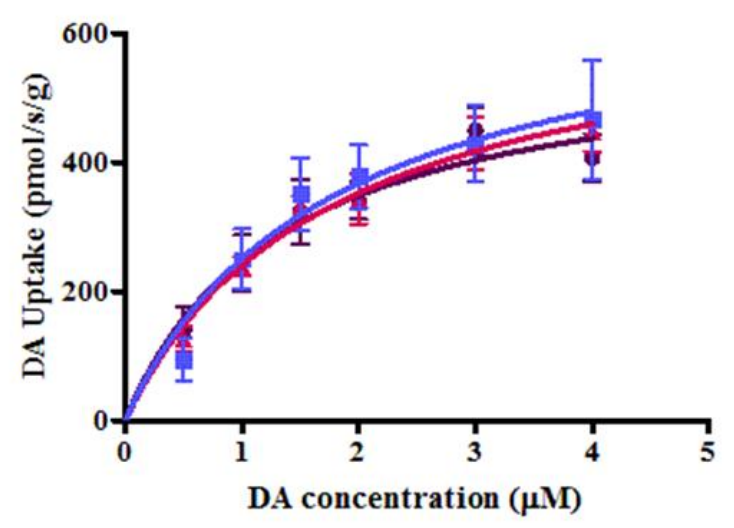

\section{E. SERT Striatum}

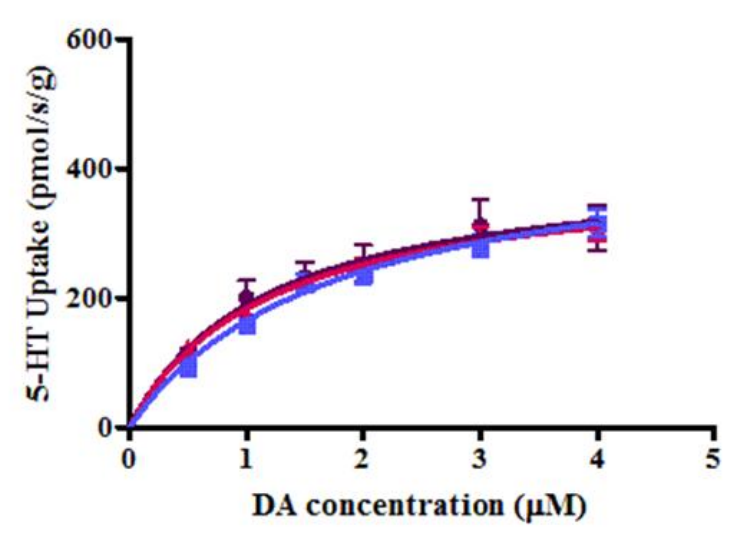

Figure 4.3: Nicotine and TPM cause no significant changes in monoamine uptake at 15 min. Rats were treated with control, nicotine $(0.35 \mathrm{mg} / \mathrm{kg}$ ), or TPM (containing 0.35 $\mathrm{mg} / \mathrm{kg}$ nicotine) $15 \mathrm{~min}$ prior to sacrifice, and monoamine transporter function was assessed ex vivo using RDEV. Drug treatments had no significant effect on DA uptake by DAT in the NAc $(n=6)(\mathbf{A})$, striatum $(n=6-8)(\mathbf{B})$ or PFC $(n=8-9)(\mathbf{C})$. There were also no changes in DA uptake by NET in the PFC $(n=4)(D)$, or 5-HT uptake by SERT in the striatum $(n=5-6)(\mathbf{E})$. Data points represent mean \pm SEM. 


\subsubsection{Nicotine and TPM decrease DAT function in the NAc at $30 \mathrm{~min}$ in a nicotinic} receptor- $\alpha 4$ subunit- dependent manner

Nicotine $(0.35 \mathrm{mg} / \mathrm{kg}$ ) and TPM (containing $0.35 \mathrm{mg} / \mathrm{kg}$ nicotine) treatment caused a decrease in DAT function in the NAc in animals sacrificed 30 min following treatment (Figure 4.4A). This change was not facilitated by a decrease in protein expression (Figure 4.4D). Kinetic data showed that for both nicotine and TPM there was a decrease in $\mathrm{V}_{\max }\left(30.6 \%\right.$ and $17.9 \%$ respectively; $\mathrm{p}<0.05$, Student's t-test), with no change in $\mathrm{K}_{\mathrm{m}}$ (Table 4.4). To test whether this decrease was nicotinic receptor-dependant, the nonspecific nicotinic antagonist mecamylamine (1.5 mg/kg i.p.) or PBS vehicle was used to pre-treat animals $20 \mathrm{~min}$ prior to nicotine $(0.35 \mathrm{mg} / \mathrm{kg}$ ), TPM (containing $0.35 \mathrm{mg} / \mathrm{kg}$ nicotine), or control injection. Mecamylamine treatment inhibited the observed decrease in DAT function (Figure 4.4B-C) and completely attenuated the decrease in $\mathrm{V}_{\text {max }}$ seen for the PBS/TPM and PBS/Nicotine treatment groups (Table 4.4).

To investigate specific nicotinic receptors that could be mediating the effects of nicotine and TPM, the $\alpha 4$ and $\alpha 7$ receptor subtype specific antagonists $\mathrm{DH} \beta \mathrm{E}(8 \mathrm{mg} / \mathrm{kg}$ salt weight) and MLA (10 mg/kg salt weight), respectively, were used. Animals were pretreated with the antagonists or PBS vehicle 20 min prior to control, nicotine $(0.35 \mathrm{mg} / \mathrm{kg})$ or TPM (containing $0.35 \mathrm{mg} / \mathrm{kg}$ nicotine) treatment as described above. Tissue was then subjected to a single $2 \mu \mathrm{M}$ DA addition to measure uptake. The $2 \mu \mathrm{M}$ DA concentration was chosen as this is close to the $K_{m}$ value obtained in kinetic data above (Table 4.4). Single additions of DA showed a decrease in DA uptake with PBS/nicotine (19.4\%) ( $\mathrm{p}<0.05$, Student's t-test) and PBS/TPM (26.8\%) compared to control. This decrease was attenuated by pre-treatment with $\operatorname{DH} \beta E(\beta 2$ antagonist; $8 \mathrm{mg} / \mathrm{kg})(\mathrm{p}<0.05$, Student's ttest) but not MLA ( $\alpha 7$ antagonist; $10 \mathrm{mg} / \mathrm{kg}$ ) for both nicotine and TPM treatments (Figure 4.5). 


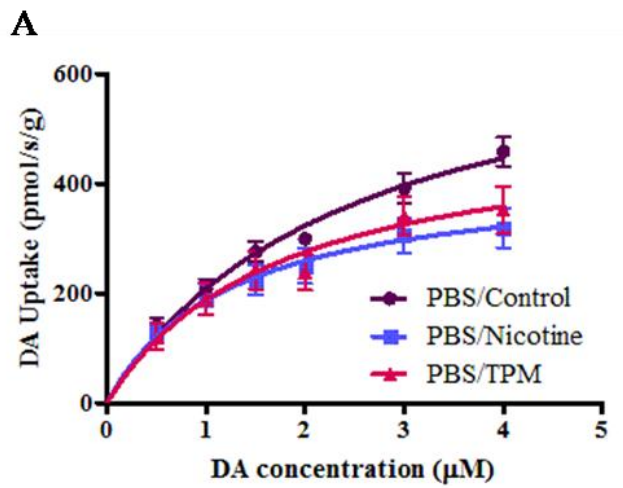

B
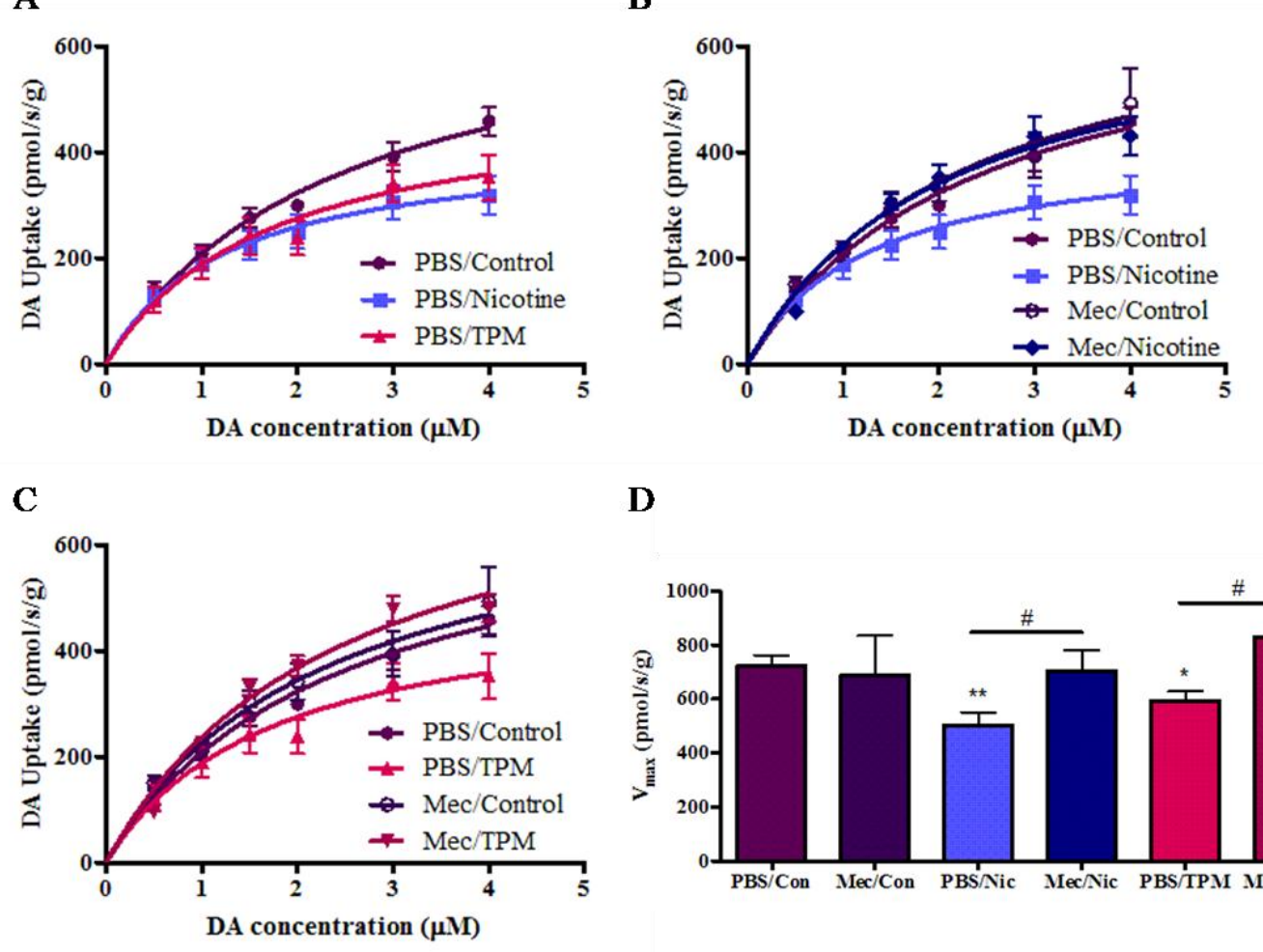

D

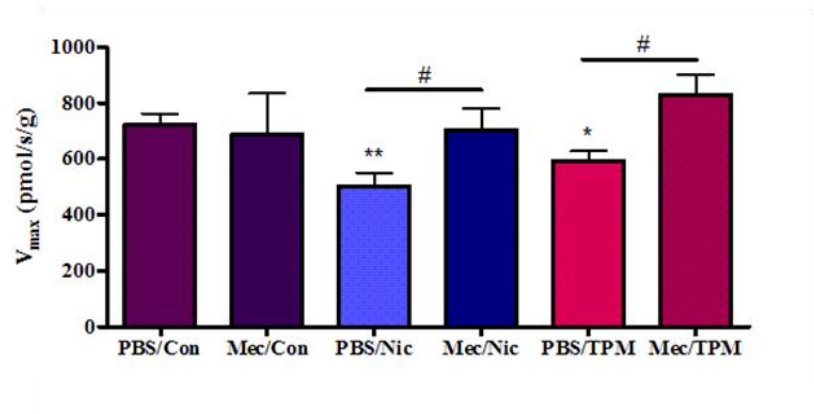

E

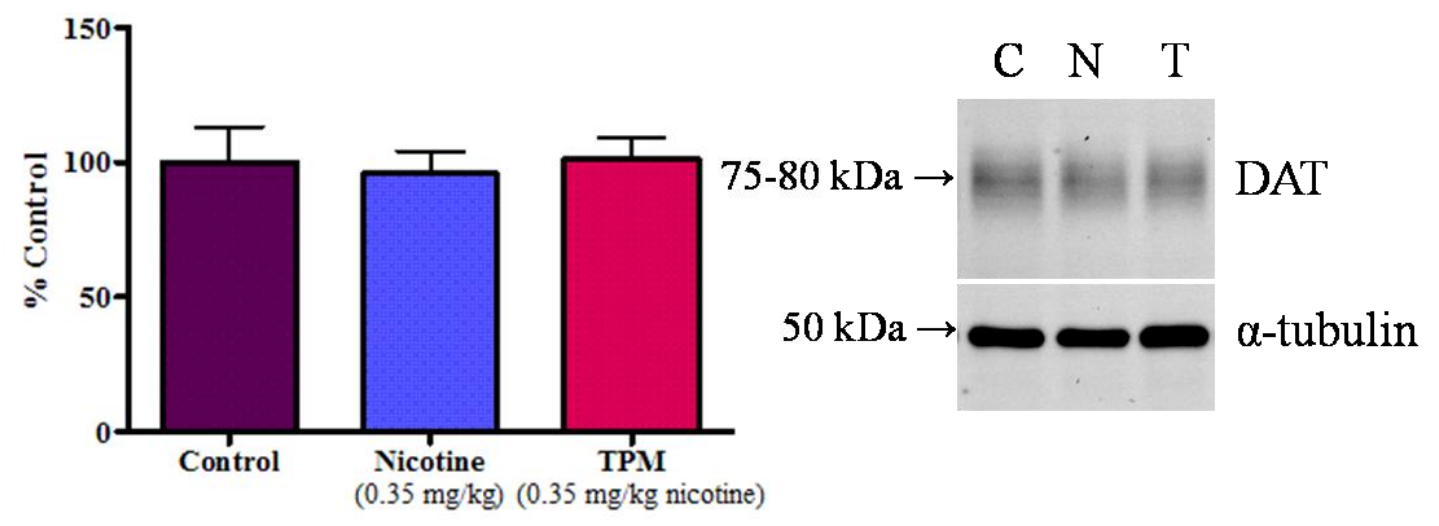

Figure 4.4: Nicotine and TPM significantly decrease DAT function in the NAc at 30 min in a mecamylamine-sensitive manner. Animals were treated with mecamylamine $(1.5 \mathrm{mg} / \mathrm{kg})$ or PBS vehicle $20 \mathrm{~min}$ prior to nicotine $(0.35 \mathrm{mg} / \mathrm{kg})$, TPM $(0.35 \mathrm{mg} / \mathrm{kg}$ nicotine) or control treatment, and sacrificed $30 \mathrm{~min}$ later. Both PBS/Nicotine and PBS/TPM significantly decreased DAT function (A) and had no effect on DAT protein expression in the NAc (E) $(\mathrm{n}=7-9)$. The decrease in DAT function produced by nicotine (B) and TPM (C) was attenuated by pre-treatment with the nicotinic antagonist mecamylamine $(n=4-6) . \quad V_{\max }$ values for all treatment groups are represented in (D) C, control; N, nicotine; T, TPM. Values and bars represent mean \pm SEM. ${ }^{*} \mathrm{p}<0.05$ compared to control, \#p<0.05 comparing drug to drug + mec, Student's t-test. 
Table 4.4: Kinetic data for DAT function in the NAc at 30 min.

\begin{tabular}{|l|l|l|}
\hline Treatment & $\mathbf{V}_{\mathbf{m a x}}(\mathbf{p m o l} / \mathrm{s} / \mathbf{g})$ & $\mathbf{K}_{\mathbf{m}}(\boldsymbol{\mu M})$ \\
\hline PBS/Control & $723 \pm 39$ & $2.51 \pm 0.22$ \\
\hline PBS/Nicotine $(0.35 \mathrm{mg} / \mathrm{kg})$ & $502 \pm 49^{* *}$ & $2.15 \pm 0.50$ \\
\hline PBS/TPM $(0.35 \mathrm{mg} / \mathrm{kg}$ nicotine $)$ & $594 \pm 34^{*}$ & $2.57 \pm 0.54$ \\
\hline Mec/Control & $687 \pm 148$ & $1.98 \pm 0.56$ \\
\hline Mec/Nicotine $(0.35 \mathrm{mg} / \mathrm{kg})$ & $704 \pm 78^{\#}$ & $1.86 \pm 0.27$ \\
\hline Mec/TPM $(0.35 \mathrm{mg} / \mathrm{kg} \mathrm{nicotine})$ & $822 \pm 91^{\#}$ & $2.17 \pm 0.35$ \\
\hline
\end{tabular}

Values are mean \pm SEM. ${ }^{*} \mathrm{p}<0.05, * * \mathrm{p}<0.01$ compared to PBS/Control, ${ }^{*} \mathrm{p}<0.05$ compared to corresponding treatment pre-treated with PBS, Student's t-test. PBS, phosphate buffered saline; Mec, mecamylamine. 


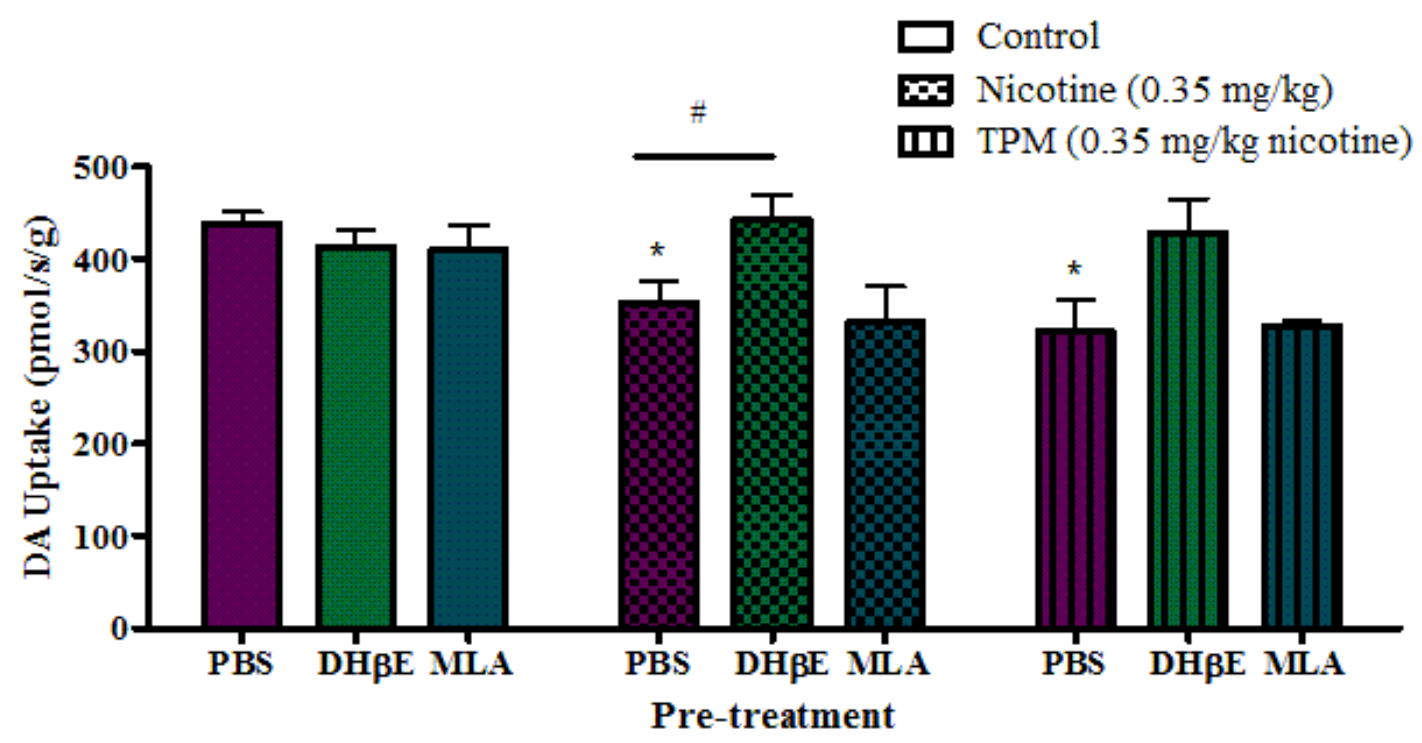

Figure 4.5: The effects of $\alpha 4$ and $\alpha 7$ nicotinic receptor antagonism on nicotine- and TPM-induced decreases in DAT function. Animals were pretreated with PBS, the $\beta 2$ subunit inhibitor DH $\beta E(8 \mathrm{mg} / \mathrm{kg})$, or $\alpha 7$ subunit inhibitor MLA $(10 \mathrm{mg} / \mathrm{kg})$ followed by control, nicotine $(0.35 \mathrm{mg} / \mathrm{kg}$ ), or TPM (containing $0.35 \mathrm{mg} / \mathrm{kg}$ nicotine) $20 \mathrm{~min}$ later. A single DA addition $(2 \mu \mathrm{M})$ was then added to the tissue and uptake measured. DH $\beta E$ completely attenuated the decrease in uptake caused by nicotine and TPM; MLA had no significant effect $(n=3-4)$. The difference between PBS/TPM and PBS/DH $\beta E$ is not significant but is trending towards significance $(p=0.089) . * p<0.05$ compared to PBS/Control, ${ }^{*} \mathrm{p}<0.05$ comparing drug to drug + mec, Student's t-test. 
4.2.2.2 Nicotine and TPM have no effect on DA uptake in the striatum or PFC, or 5-HT uptake in the striatum at 30 min

Nicotine $(0.35 \mathrm{mg} / \mathrm{kg}$ ) and TPM (containing $0.35 \mathrm{mg} / \mathrm{kg}$ nicotine) had no effect on DA uptake by DAT in striatal or PFC tissue from animals sacrificed $30 \mathrm{~min}$ following treatment (Figure 4.6). DA uptake by NET and 5-HT uptake by SERT were also unaffected by drug treatments (Figure 4.6). There was no significant effect on the $\mathrm{K}_{\mathrm{m}}$ or $\mathrm{V}_{\max }$ of DAT, NET or SERT in any of these brain regions (Table 4.5).

A

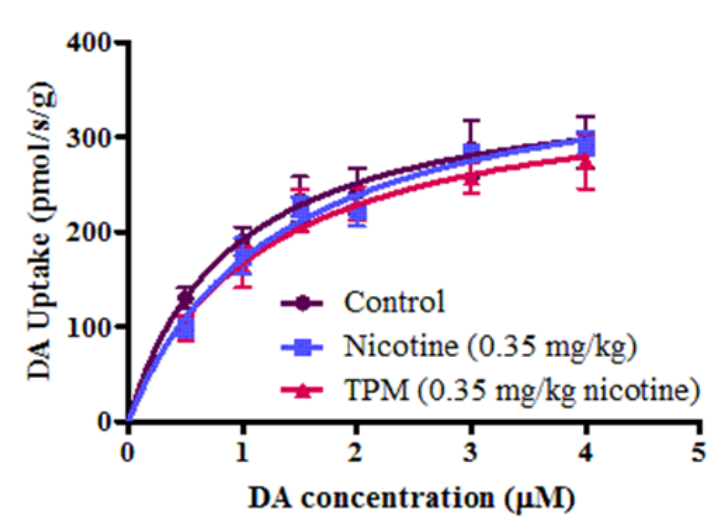

C

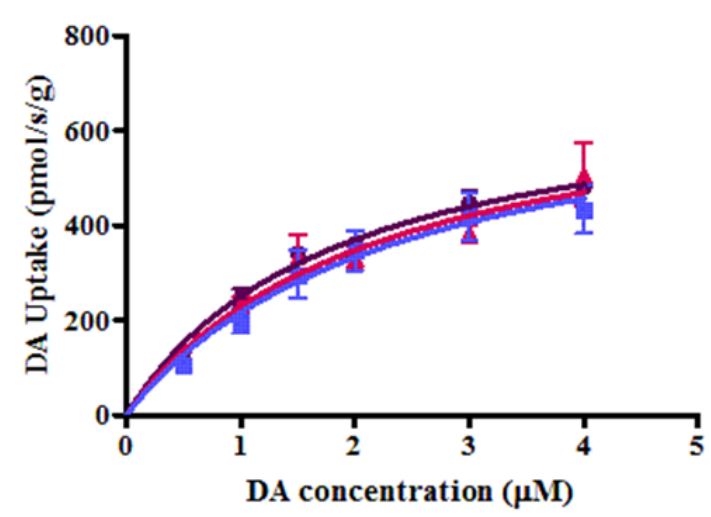

B

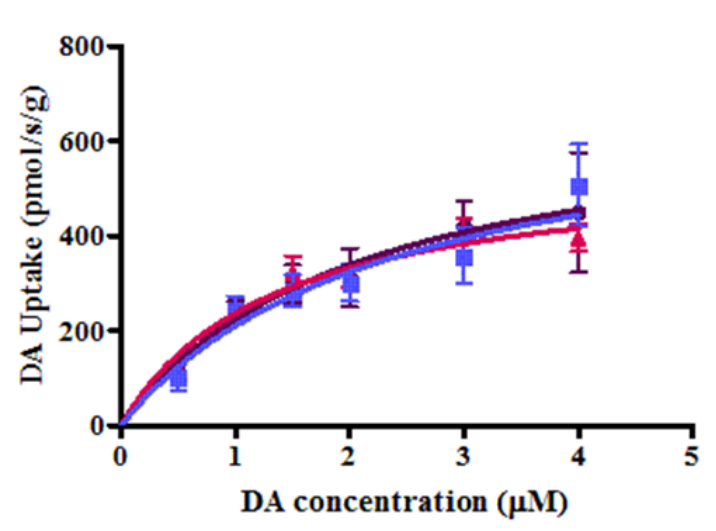

D

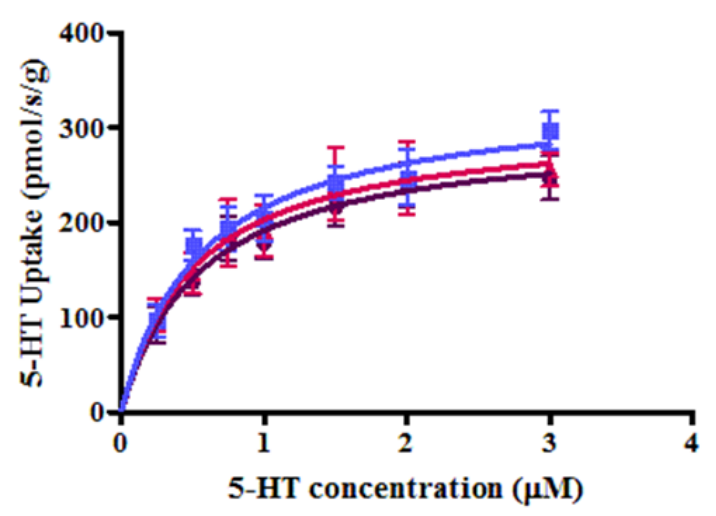

Figure 4.6: The effects of nicotine and TPM on monoamine uptake in the striatum and PFC. Animals were treated with control, nicotine $(0.35 \mathrm{mg} / \mathrm{kg}$ ) or TPM (containing $0.35 \mathrm{mg} / \mathrm{kg}$ nicotine) and sacrificed $30 \mathrm{~min}$ following treatment. Ex vivo uptake studies showed no change in DA uptake by DAT in the striatum $(n=4)(A)$; DA uptake by DAT in the PFC (n=6-7) (B); DA uptake by NET in the PFC $(n=3-4)(\mathbf{C})$; or 5-HT uptake by SERT in the striatum $(n=4)(D)$. Data points are mean \pm SEM. 
Table 4.5: Kinetic data for DA and 5-HT uptake at $30 \mathrm{~min}$

\begin{tabular}{|l|l|l|l|}
\cline { 2 - 4 } & Treatment & $\mathbf{V}_{\mathbf{m a x}}(\mathbf{p m o l} / \mathrm{s} / \mathbf{g})$ & $\mathbf{K}_{\mathbf{m}}(\boldsymbol{\mu M})$ \\
\hline \multirow{4}{*}{ DAT Striatum } & Control & $365 \pm 38$ & $0.90 \pm 0.098$ \\
\cline { 2 - 4 } & Nicotine $(0.35 \mathrm{mg} / \mathrm{kg})$ & $397 \pm 12$ & $1.34 \pm 0.15$ \\
\cline { 2 - 4 } & TPM $(0.35 \mathrm{mg} / \mathrm{kg}$ nicotine $)$ & $378 \pm 28$ & $1.31 \pm 0.15$ \\
\hline \multirow{4}{*}{ DAT PFC } & Control & $559 \pm 103$ & $1.54 \pm 0.28$ \\
\cline { 2 - 4 } & Nicotine $(0.35 \mathrm{mg} / \mathrm{kg})$ & $572 \pm 67$ & $1.69 \pm 0.37$ \\
\cline { 2 - 4 } & TPM $(0.35 \mathrm{mg} / \mathrm{kg} \mathrm{nicotine})$ & $537 \pm 90$ & $1.40 \pm 0.21$ \\
\hline \multirow{5}{*}{ SERT PFC } & Control & $740 \pm 32$ & $2.04 \pm 0.27$ \\
\cline { 2 - 4 } & Nicotine $(0.35 \mathrm{mg} / \mathrm{kg})$ & $748 \pm 36$ & $2.27 \pm 0.40$ \\
\cline { 2 - 4 } & TPM $(0.35 \mathrm{mg} / \mathrm{kg} \mathrm{nicotine})$ & $730 \pm 71$ & $2.14 \pm 0.18$ \\
\hline & Control & $300 \pm 22$ & $0.60 \pm 0.11$ \\
\cline { 2 - 4 } & Nicotine $(0.35 \mathrm{mg} / \mathrm{kg})$ & $313 \pm 27$ & $0.59 \pm 0.12$ \\
\cline { 2 - 4 } & TPM $(0.35 \mathrm{mg} / \mathrm{kg} \mathrm{nicotine})$ & $339 \pm 23$ & $0.60 \pm 0.09$ \\
\hline
\end{tabular}

Values are mean \pm SEM. 


\subsection{The effects of nicotine and TPM on monoamine transporter function and expression at $1 \mathrm{hr}$}

\subsubsection{DAT function and protein expression in the NAc, striatum, and PFC}

Rats were sacrificed $1 \mathrm{hr}$ after treatment with control, nicotine $(0.35 \mathrm{mg} / \mathrm{kg})$, or TPM (containing $0.35 \mathrm{mg} / \mathrm{kg}$ nicotine), and ex vivo function and protein expression were measured using RDEV and Western blotting respectively. In the NAc no significant change in either function or protein expression was seen (Figure 4.7), including no significant changes in the $\mathrm{V}_{\max }$ or $\mathrm{K}_{\mathrm{m}}$ of DA uptake (Table 4.6).

Table 4.6: Kinetic data for DA uptake in the NAc at $1 \mathrm{hr}$.

\begin{tabular}{|l|l|l|}
\hline Treatment & $\mathbf{V}_{\mathbf{m a x}}(\mathbf{p m o l} / \mathbf{s} / \mathbf{g})$ & $\mathbf{K}_{\mathbf{m}}(\boldsymbol{\mu M})$ \\
\hline Control & $390 \pm 52$ & $1.30 \pm 0.43$ \\
\hline Nicotine $(0.35 \mathrm{mg} / \mathrm{kg})$ & $353 \pm 46$ & $0.89 \pm 0.13$ \\
\hline TPM $(0.35 \mathrm{mg} / \mathrm{kg}$ nicotine $)$ & $339 \pm 40$ & $0.91 \pm 0.15$ \\
\hline
\end{tabular}

Values are mean \pm SEM. 
$\mathbf{A}$

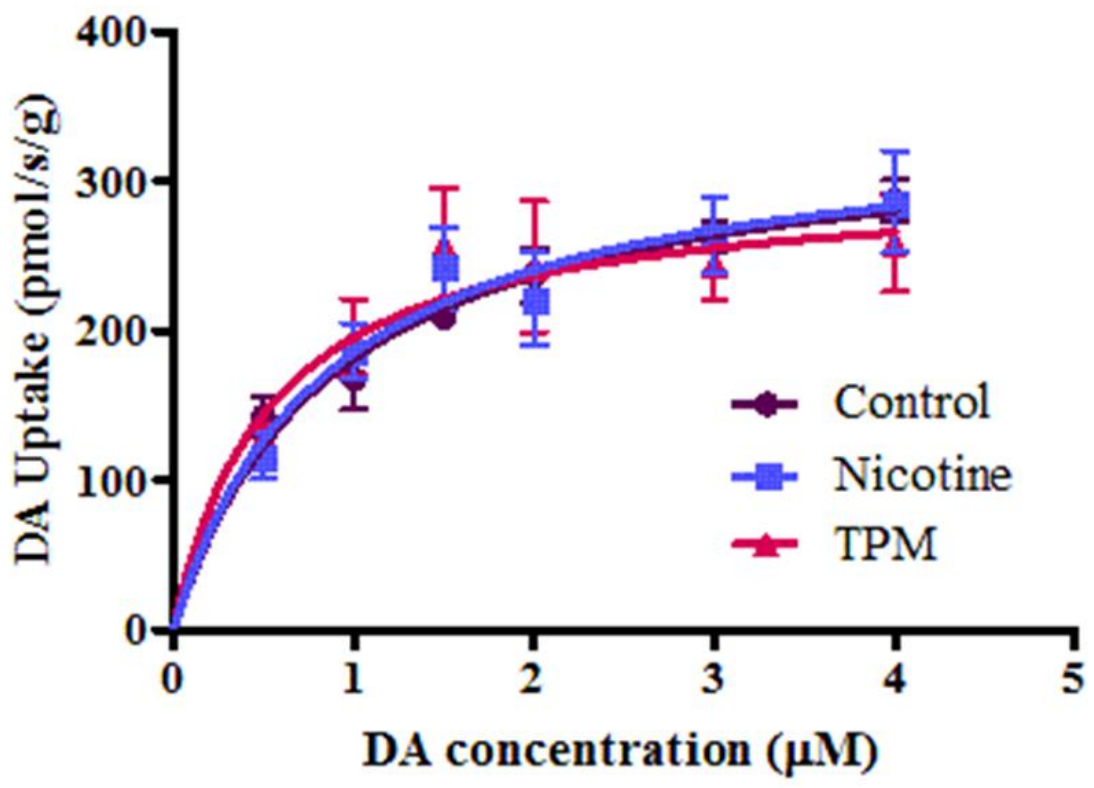

B

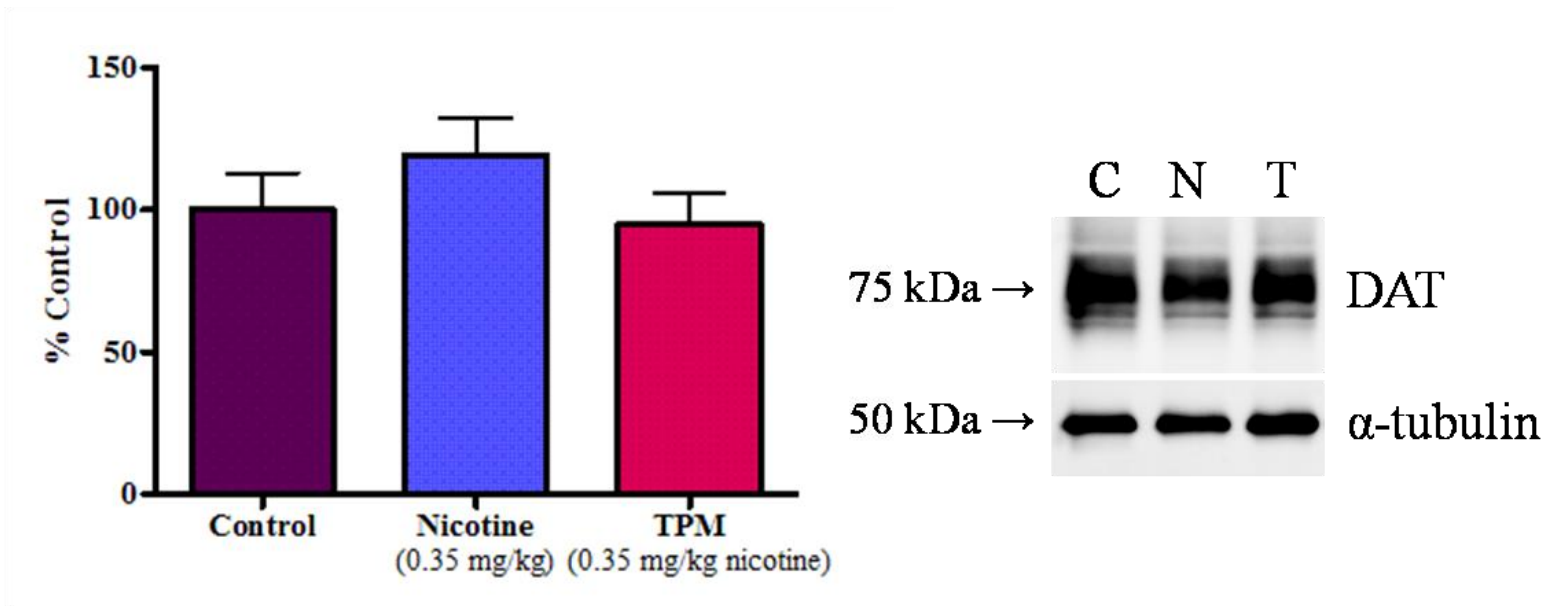

Figure 4.7: Nicotine and TPM have no effect on DAT function and expression in the NAc at $1 \mathrm{hr}$. Tissue from animals treated with nicotine $(0.35 \mathrm{mg} / \mathrm{kg})$ or TPM (containing $0.35 \mathrm{mg} / \mathrm{kg}$ nicotine) showed no significant difference in DA uptake (A) or DAT protein expression (B) compared to control $(n=5-8)$. Data points and bars represent mean \pm SEM. C, control; N, nicotine; T, TPM. 
For striatal samples, animals were pre-treated with PBS vehicle or mecamylamine (1.5 $\mathrm{mg} / \mathrm{kg}$ ) $20 \mathrm{~min}$ prior to control, nicotine $(0.35 \mathrm{mg} / \mathrm{kg}$ ) or TPM (containing $0.35 \mathrm{mg} / \mathrm{kg}$ ) treatment. An increase in DAT function was seen in the PBS/TPM group compared to PBS/Control (Figure 4.8A) that was not accompanied by an increase in protein expression (Figure 4.8B). The Mecamylamine/Control group did not significantly differ from PBS/Control, and mecamylamine pre-treatment did not completely attenuate the increase in uptake observed in the PBS/TPM group (Figure 4.8A). Kinetic data showed a significant increase in $\mathrm{V}_{\max }$ for the PBS/TPM group (40.5\%; $\mathrm{p}<0.05$, Student's t-test), with a slight non-significant increase in $\mathrm{K}_{\mathrm{m}}\left(28.1 \%\right.$ ) (Table 4.7). This increase in $\mathrm{V}_{\max }$ was not completely attenuated with mecamylamine pre-treatment; the Mecamylamine/TPM group had a $33.3 \%$ increase in $\mathrm{V}_{\max }$.

Table 4.7: Kinetic values for DAT function in the striatum at $1 \mathrm{hr}$.

\begin{tabular}{|l|l|l|}
\hline Treatment & $\mathbf{V}_{\mathbf{m a x}}(\mathbf{p m o l} / \mathbf{s} / \mathbf{g})$ & $\mathbf{K}_{\mathbf{m}}(\boldsymbol{\mu M})$ \\
\hline PBS/Control & $342 \pm 50$ & $1.09 \pm 0.10$ \\
\hline PBS/Nicotine $(0.35 \mathrm{mg} / \mathrm{kg})$ & $369 \pm 38$ & $1.09 \pm 0.13$ \\
\hline PBS/TPM $(0.35 \mathrm{mg} / \mathrm{kg}$ nicotine $)$ & $481 \pm 37^{*}$ & $1.39 \pm 0.15$ \\
\hline Mec/Control & $363 \pm 48$ & $0.91 \pm 0.20$ \\
\hline Mec/TPM & $456 \pm 34$ & $1.3 \pm 0.47$ \\
\hline
\end{tabular}

Values are mean \pm SEM. ${ }^{*} \mathrm{p}<0.05$ compared to PBS/Control, Student's t-test. 
A

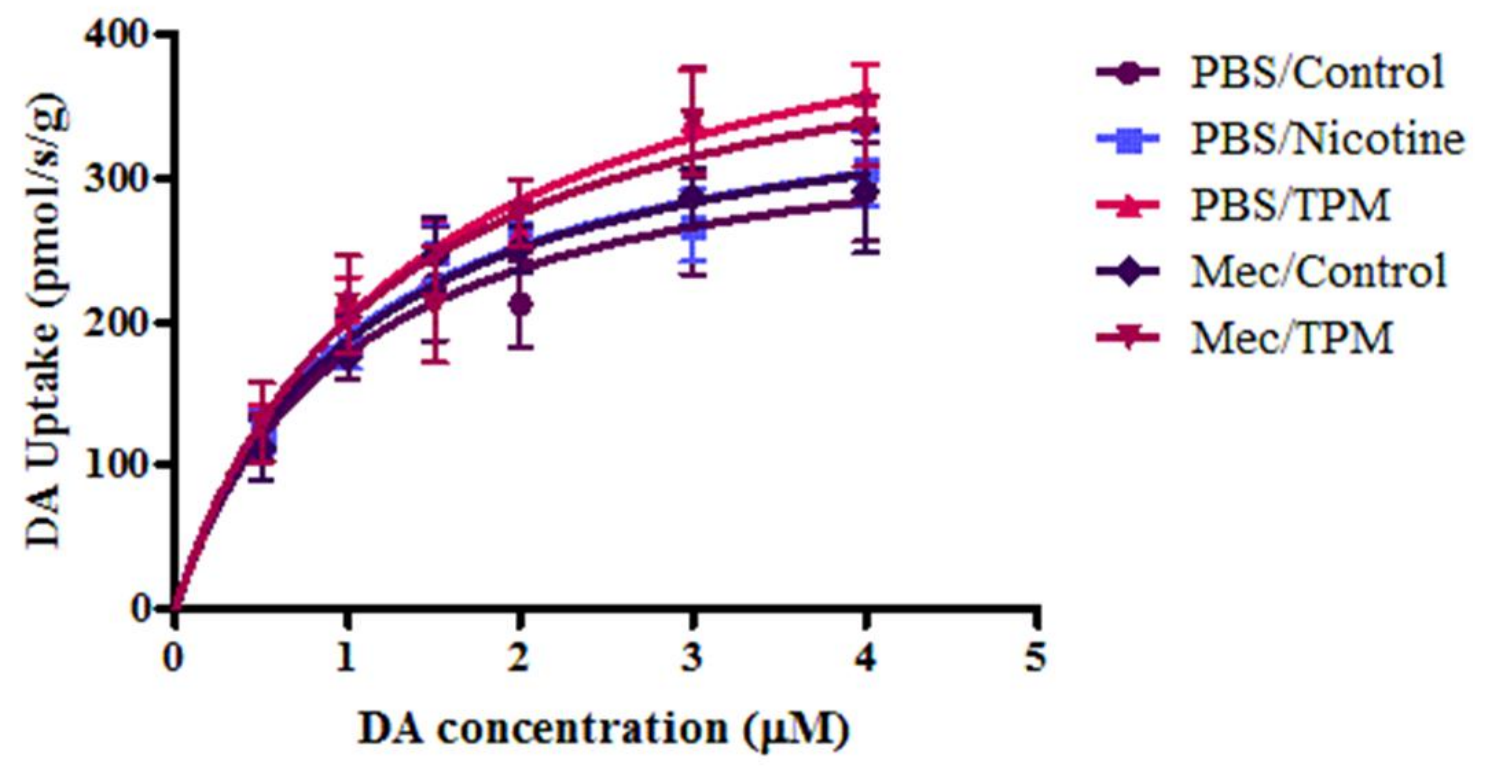

B

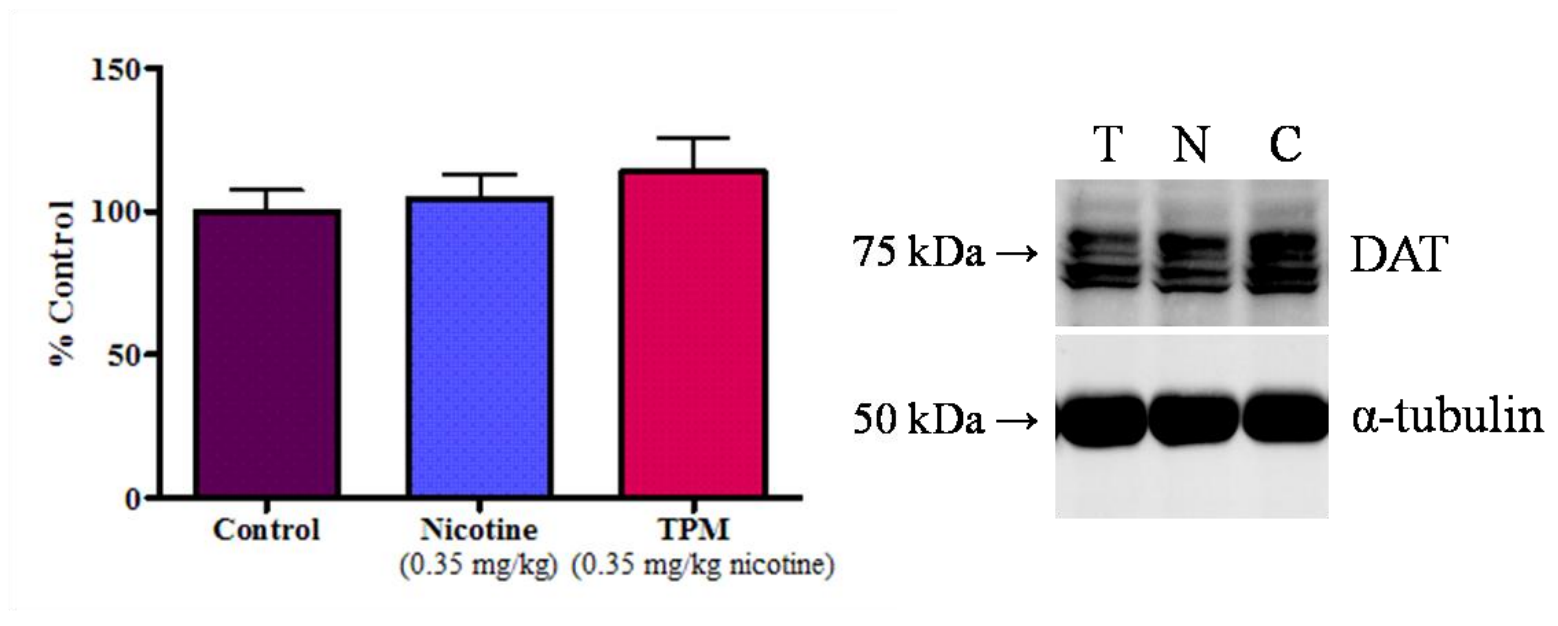

Figure 4.8: TPM, but not nicotine, increased DAT function in the striatum at $1 \mathrm{hr}$. Animals were pre-treated with PBS vehicle or mecamylamine $(1.5 \mathrm{mg} / \mathrm{kg})$ followed by control, nicotine $(0.35 \mathrm{mg} / \mathrm{kg})$, or TPM (containing $0.35 \mathrm{mg} / \mathrm{kg}$ nicotine) $20 \mathrm{~min}$ later. There was a significant increase in DAT function with PBS/TPM compared to PBS/control that was not completely attenuated by mecamylamine pre-treatment $(n=4-9)$ (A). There was no change in DAT protein expression with any treatment $(n=7-8)(B)$. Data points and bars represent mean \pm SEM. C, control; N, nicotine; T, TPM. 
DA uptake by DAT in the PFC was not affected by treatment with nicotine $(0.35 \mathrm{mg} / \mathrm{kg})$ or TPM (containing $0.35 \mathrm{mg} / \mathrm{kg}$ nicotine) (Figure 4.9A); and no change in $\mathrm{V}_{\max }$ or $\mathrm{K}_{\mathrm{m}}$ was observed compared to control (Table 4.8). DAT protein expression in this brain region was also unaffected by nicotine and TPM treatment (Figure 4.9B).

Table 4.8: $V_{\max }$ and $K_{m}$ values for $D A$ uptake in the PFC $1 \mathrm{hr}$ after drug treatment.

\begin{tabular}{|l|l|l|}
\hline Treatment & $\mathbf{V}_{\mathbf{m a x}}(\mathbf{p m o l} / \mathbf{s} / \mathbf{g})$ & $\mathbf{K}_{\mathbf{m}}(\boldsymbol{\mu M})$ \\
\hline Control & $540 \pm 38$ & $1.74 \pm 0.19$ \\
\hline Nicotine $(0.35 \mathrm{mg} / \mathrm{kg})$ & $550 \pm 57$ & $1.69 \pm 0.27$ \\
\hline TPM $(0.35 \mathrm{mg} / \mathrm{kg}$ nicotine $)$ & $517 \pm 72$ & $1.56 \pm 0.17$ \\
\hline
\end{tabular}

Values are mean \pm SEM. 
A

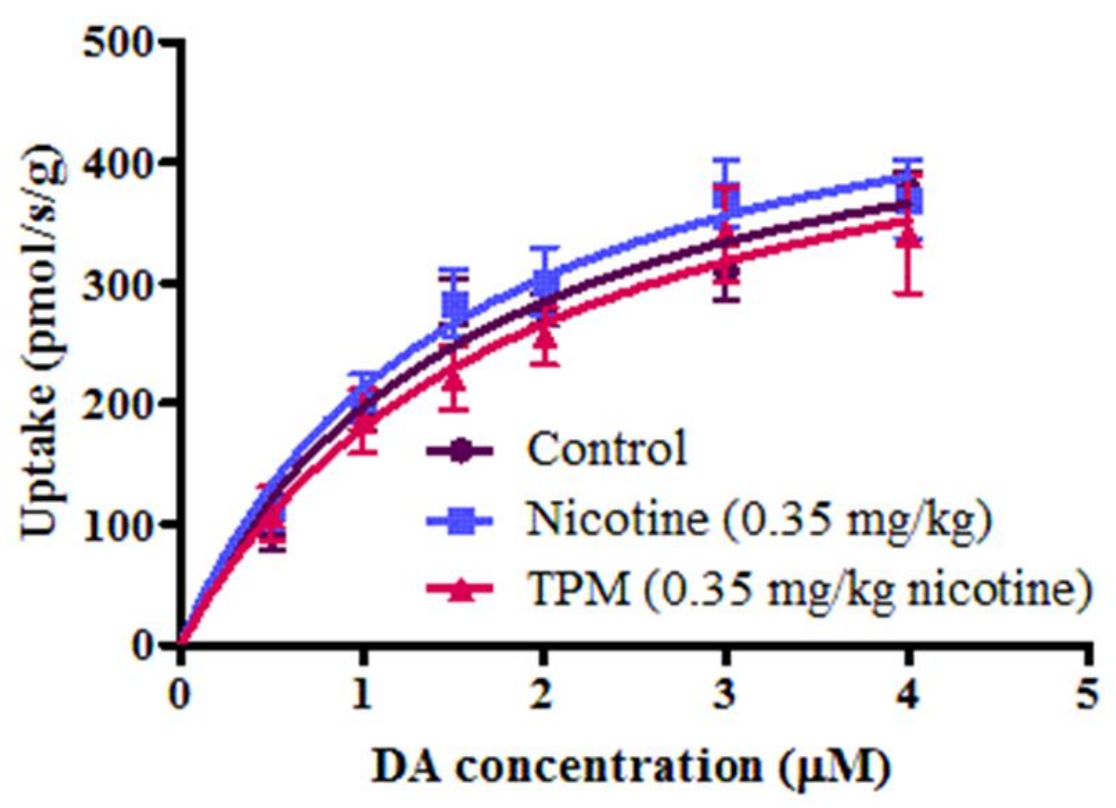

B

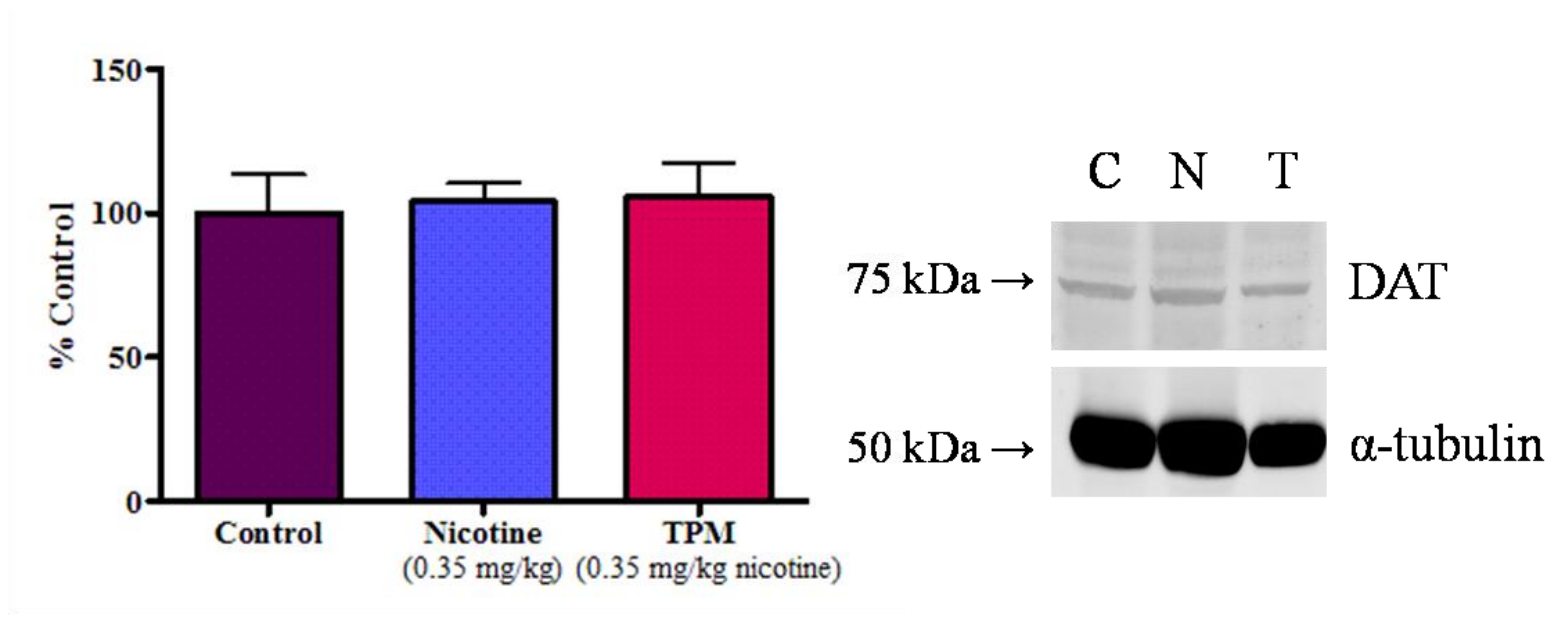

Figure 4.9: Nicotine and TPM have no effect on DA uptake by DAT in the PFC. Tissue from animals sacrificed $1 \mathrm{hr}$ following control, nicotine $(0.35 \mathrm{mg} / \mathrm{kg})$, or TPM (containing $0.35 \mathrm{mg} / \mathrm{kg}$ ) treatment showed no difference in DA uptake (A) or DAT protein expression (B) compared to control in the PFC $(n=6-8)$. Bars and data points represent mean \pm SEM. C, control; N, nicotine; T, TPM. 


\subsubsection{DAT protein and mRNA expression in the VTA and SN}

The VTA and SN were dissected from animals that had been sacrificed $1 \mathrm{hr}$ following control, nicotine $(0.35 \mathrm{mg} / \mathrm{kg}$ ), or TPM (containing $0.35 \mathrm{mg} / \mathrm{kg}$ nicotine) treatment. Protein expression and mRNA were measured using Western blotting and real time PCR. Nicotine $(\mathrm{p}<0.05)$ and TPM $(\mathrm{p}<0.05$, one-way ANOVA with Bonferroni post-hoc analysis) significantly decreased DAT mRNA expression in the VTA, but not the SN (Figure 4.10A). The $\Delta \mathrm{Ct}$ values for nicotine and TPM were 4.78 and $3.89 \mathrm{Ct}$ values greater than control respectively, corresponding to a $96.4 \%$ and $93.3 \%$ reduction in mRNA expression (Table 4.9). This decrease in DAT mRNA expression did not translate to a decrease in protein expression in the VTA and, similarly, there was no change in protein expression in the SN (Figure 4.10B).

Table 4.9: $\Delta C t$ values for DAT mRNA expression in the VTA and SN.

\begin{tabular}{|l|l|l|}
\hline Treatment & $\Delta$ Ct value VTA & $\Delta$ Ct value SN \\
\hline Control & $10.6 \pm 0.7$ & $6.7 \pm 0.9$ \\
\hline Nicotine $(0.35 \mathrm{mg} / \mathrm{kg})$ & $15.4 \pm 0.7^{* *}$ & $7.7 \pm 0.9$ \\
\hline TPM $(0.35 \mathrm{mg} / \mathrm{kg}$ nicotine $)$ & $14.5 \pm 1.0^{*}$ & $8.0 \pm 0.8$ \\
\hline
\end{tabular}

Values are mean \pm SEM. ${ }^{*} \mathrm{p}<0.05,{ }^{*} * \mathrm{p}<0.01$ one-way ANOVA with Bonferroni post-hoc analysis. 


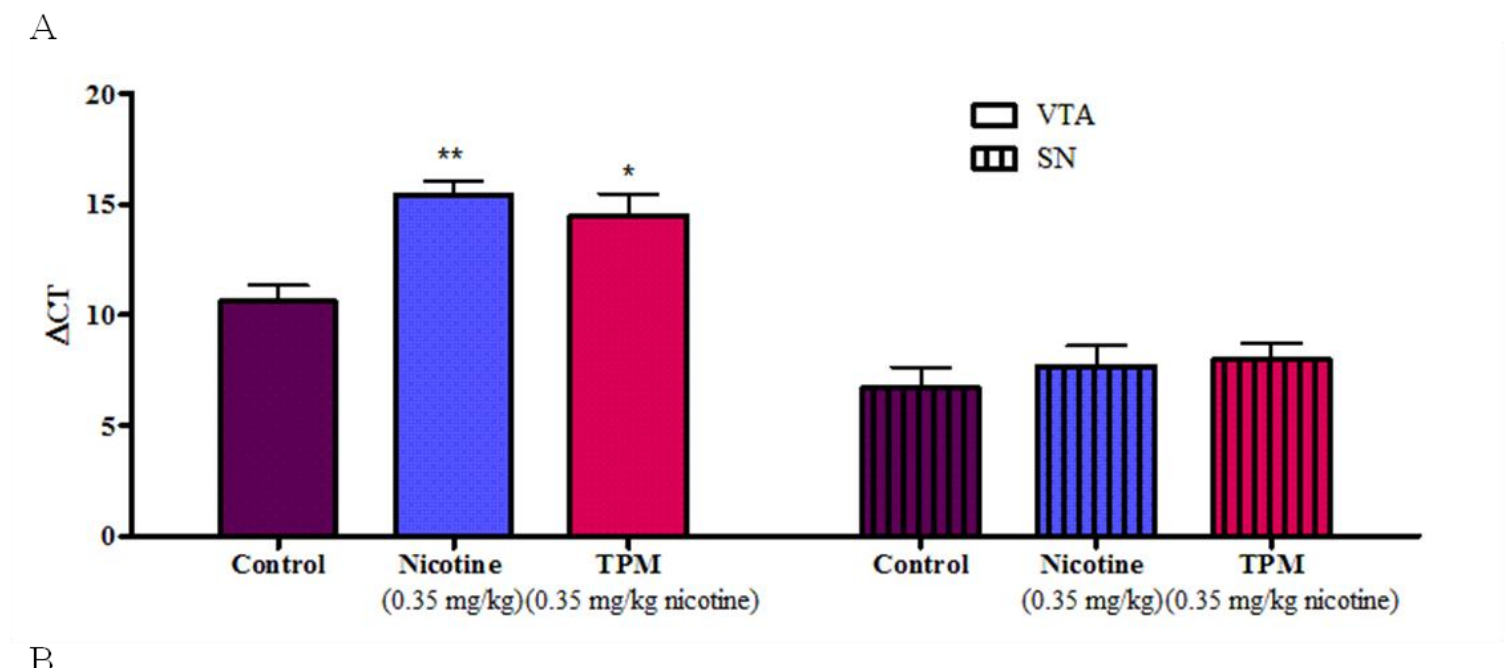

$\mathrm{B}$

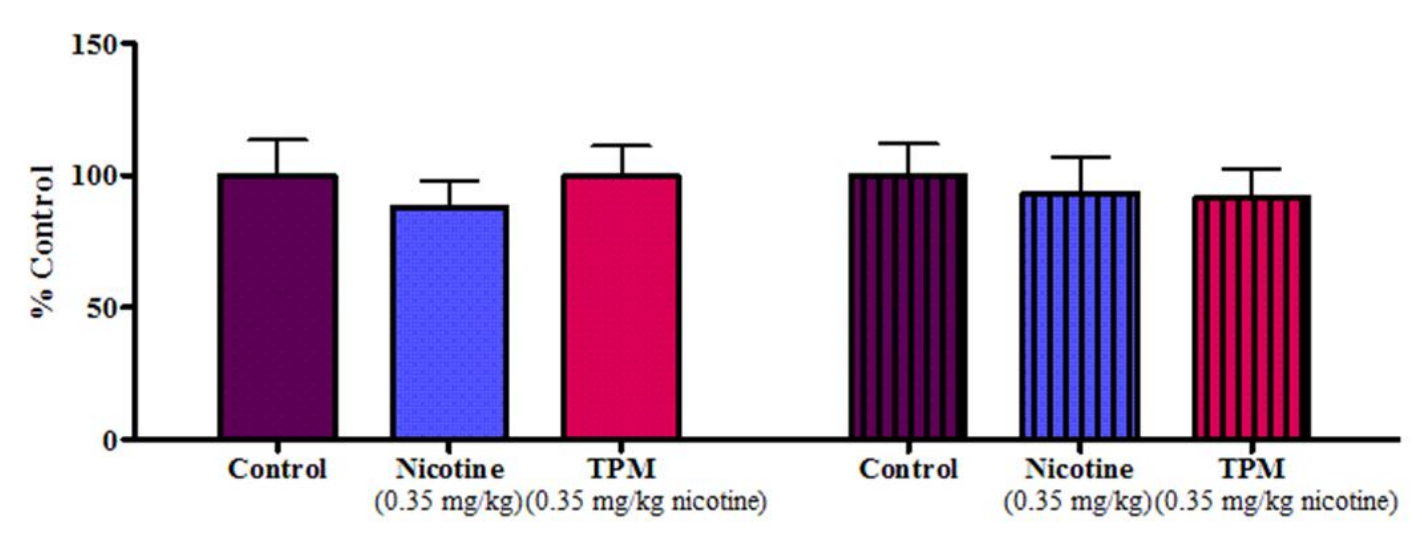

C

D

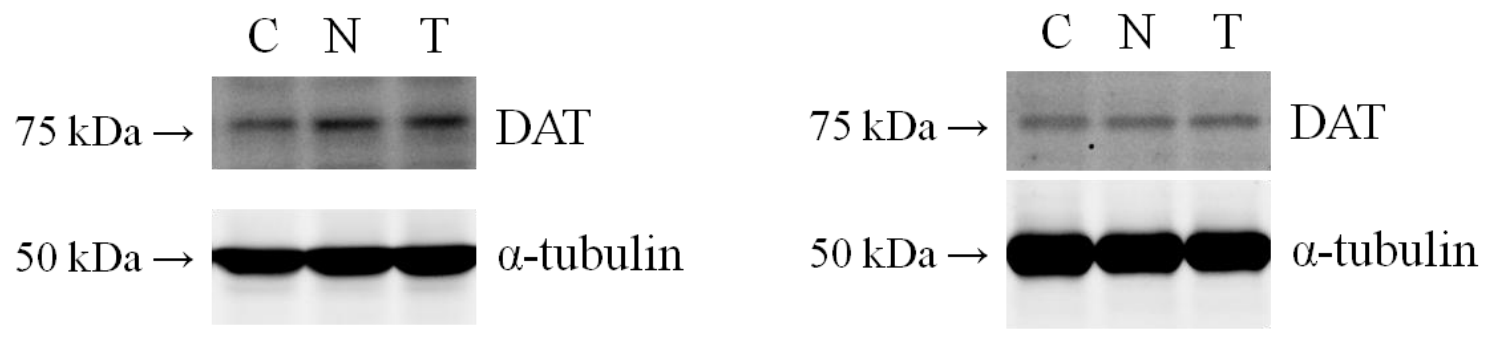

Figure 4.10: DAT mRNA and protein expression in the VTA and SN $1 \mathrm{hr}$ after nicotine or TPM treatment. Animals were treated with control, nicotine $(0.35 \mathrm{mg} / \mathrm{kg})$ or TPM (containing $0.35 \mathrm{mg} / \mathrm{kg}$ nicotine) and sacrificed $1 \mathrm{hr}$ later. (A) Nicotine and TPM caused a significant decrease in DAT mRNA expression in the VTA but not the SN. (B) There were no significant changes in DAT protein expression in either brain region. Representative blots for the VTA (C) and SN (D) are shown. Bars represent mean \pm SEM ( $\mathrm{n}=5-7)$. C, control; N, nicotine; T, TPM. * $\mathrm{p}<0.05, * * \mathrm{p}<0.01$, one-way ANOVA with Bonferroni post-hoc analysis. 


\subsubsection{NET function and expression}

Animals were sacrificed $1 \mathrm{hr}$ after control, nicotine $(0.35 \mathrm{mg} / \mathrm{kg})$, or TPM (containing $0.35 \mathrm{mg} / \mathrm{kg}$ nicotine) treatment and DA uptake by NET and NET protein expression were assessed in the PFC using RDEV and Western blotting. No significant changes in NET function or protein expression were found in the PFC in response to either nicotine or TPM (Figure 4.11), including no change in $\mathrm{K}_{\mathrm{m}}$ or $\mathrm{V}_{\max }$ values (Table 4.10). In addition, NET protein and mRNA expression were measured in the LC using Western blotting and real time PCR. No change in protein expression was found in this brain region, and there was no significant change in mRNA expression with nicotine or TPM treatment compared to control (Figure 4.12). There was, however, a significant difference in mRNA expression between nicotine and TPM treatments. The $\Delta \mathrm{Ct}$ value for nicotine treated animals was $1.28 \mathrm{Ct}$ values greater than that for TPM (Table 4.11). This corresponds to $59 \%$ reduction in mRNA expression in the TPM group compared to the $0.35 \mathrm{mg} / \mathrm{kg}$ nicotine group.

Table 4.10: Kinetic data for DA uptake by NET in the PFC $1 \mathrm{hr}$ after drug treatment.

\begin{tabular}{|l|l|l|}
\hline Treatment & $\mathbf{V}_{\mathbf{m a x}}(\mathbf{p m o l} / \mathbf{s} / \mathbf{g})$ & $\mathbf{K}_{\mathbf{m}}(\boldsymbol{\mu M})$ \\
\hline Control & $586 \pm 66$ & $2.39 \pm 0.46$ \\
\hline Nicotine $(0.35 \mathrm{mg} / \mathrm{kg})$ & $547 \pm 83$ & $1.54 \pm 0.13$ \\
\hline TPM $(0.35 \mathrm{mg} / \mathrm{kg}$ nicotine $)$ & $590 \pm 58$ & $2.07 \pm 0.47$ \\
\hline
\end{tabular}

Values are mean \pm SEM.

Table 4.11: $\Delta C$ t values for mRNA expression in the $L C$ at $1 \mathrm{hr}$.

\begin{tabular}{|l|l|}
\hline Treatment & $\Delta$ CT value \\
\hline Control & $7.1 \pm 0.5$ \\
\hline Nicotine $(0.35 \mathrm{mg} / \mathrm{kg})$ & $6.1 \pm 0.2$ \\
\hline TPM $(0.35 \mathrm{mg} / \mathrm{kg}$ nicotine $)$ & $7.3 \pm 0.4^{*}$ \\
\hline *p<0.05 compared to nicotine, Student's t-test.
\end{tabular}


A

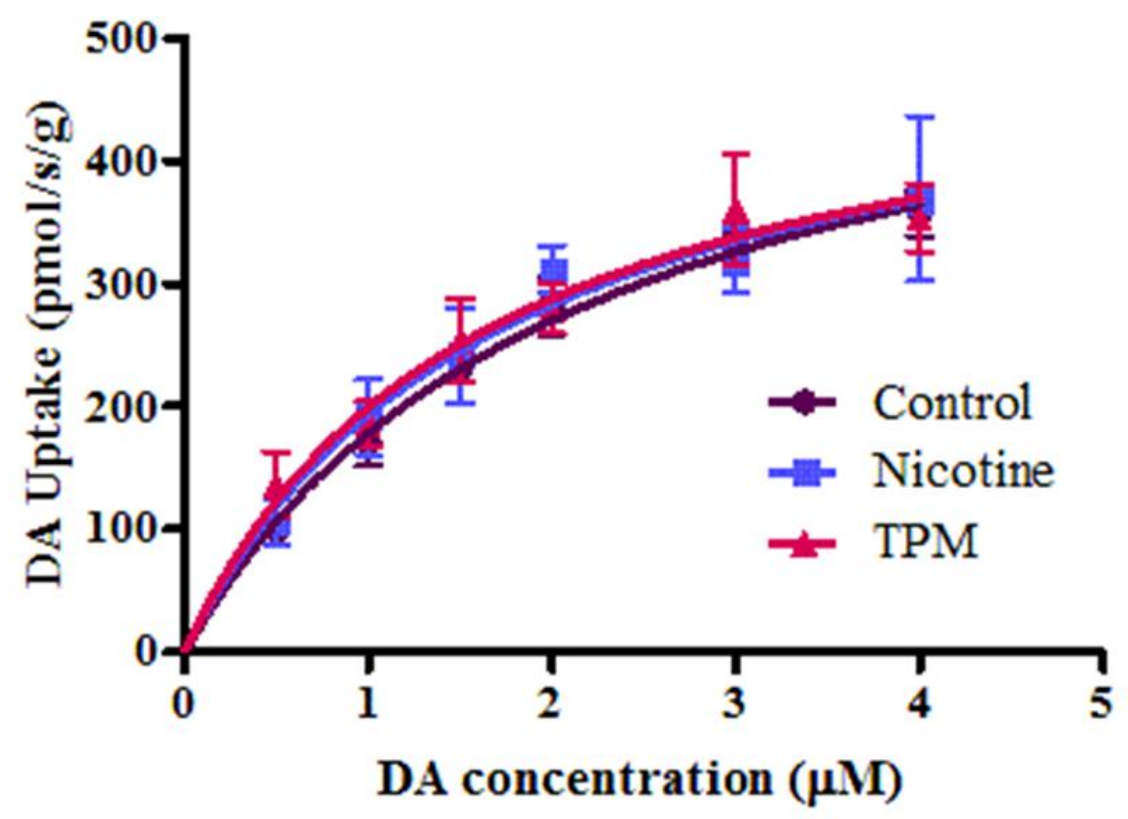

B

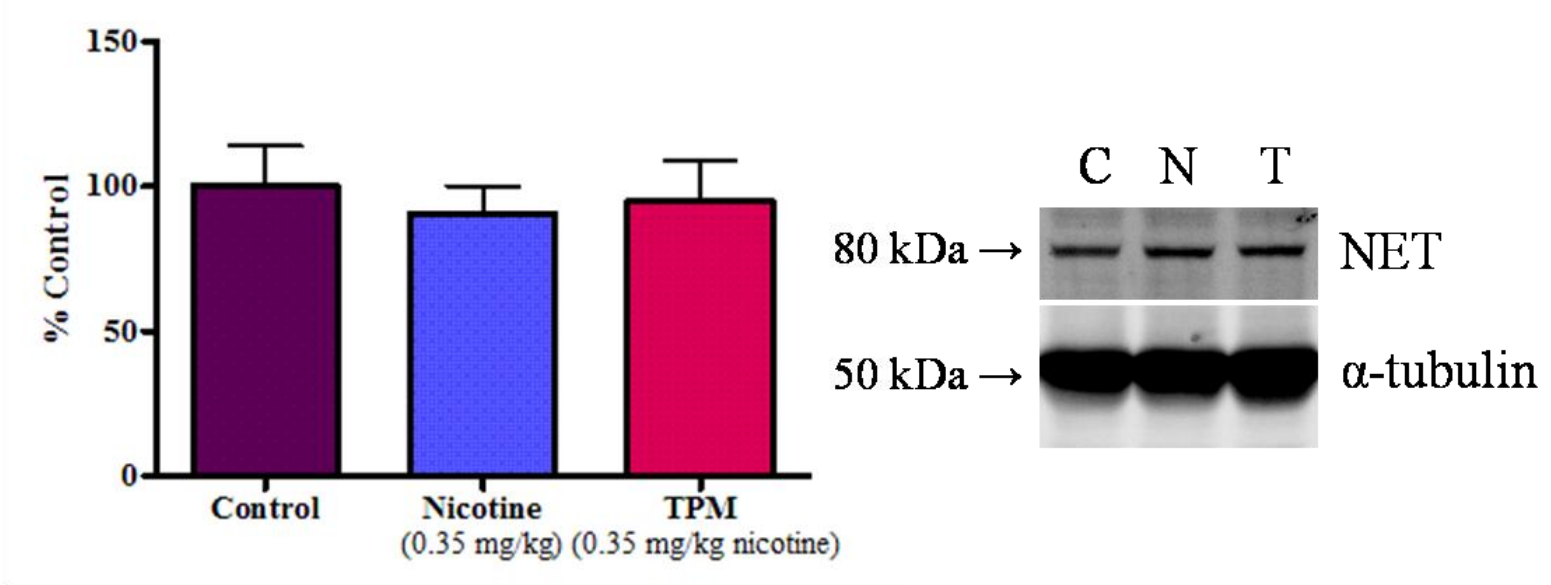

Figure 4.11: DA uptake by NET and NET protein expression in the PFC $1 \mathrm{hr}$ after drug treatment. Nicotine $(0.35 \mathrm{mg} / \mathrm{kg}$ ) and TPM (containing $0.35 \mathrm{mg} / \mathrm{kg}$ ) had no significant effect on DA uptake by NET in the PFC $1 \mathrm{hr}$ after treatment compared to control $(n=4-5)$ (A). There was no change in NET protein expression in the PFC with nicotine or TPM at this time point $(n=6-8)(B)$. Data points and bars represent mean \pm SEM. C, control; N, nicotine; T, TPM. 
A

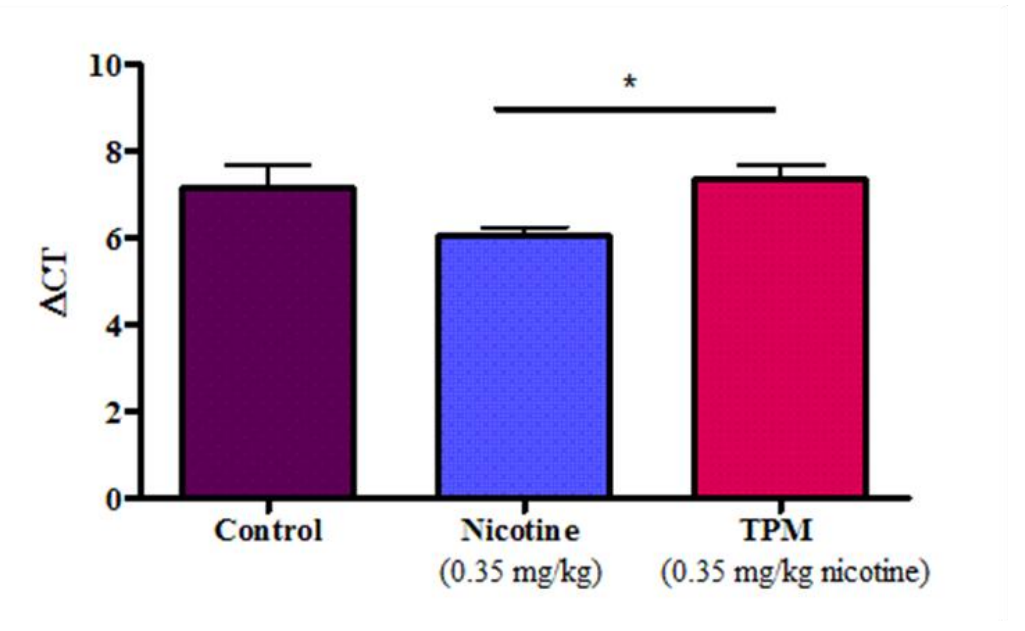

B

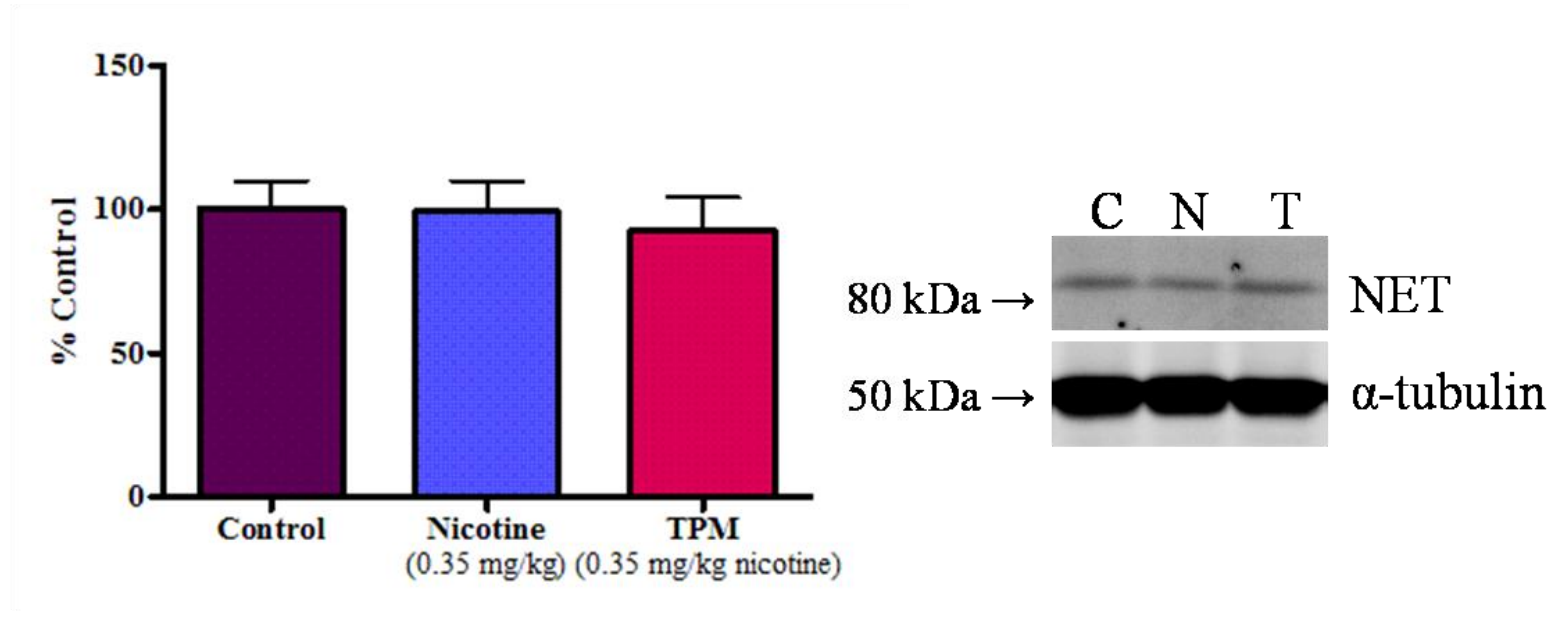

Figure 4.12: NET mRNA and protein expression in the LC $1 \mathrm{hr}$ after drug treatment. Animals were treated with $0.35 \mathrm{mg} / \mathrm{kg}$ nicotine or TPM containing 0.35 $\mathrm{mg} / \mathrm{kg}$ nicotine and sacrificed $1 \mathrm{hr}$ later. (A) NET mRNA expression in the LC was measured using real time PCR. Nicotine and TPM had no significant effect on mRNA expression compared to control; however, the difference in expression between nicotine and TPM was significant $(n=6-7)$. (B) There were no significant changes in NET protein expression in the LC compared to control as measured by Western blotting $(n=8-10)$. Bars represent mean \pm SEM. C, control; N, nicotine; T, TPM. 


\subsubsection{SERT expression and function}

SERT function, mRNA expression and protein expression in rats were measured ex vivo 1 $\mathrm{hr}$ after control, nicotine $(0.35 \mathrm{mg} / \mathrm{kg})$, or TPM (containing $0.35 \mathrm{mg} / \mathrm{kg}$ nicotine) treatment. No change in function or protein expression was found in the striatum (Figure 4.13), including no change in the $\mathrm{V}_{\max }$ or $\mathrm{K}_{\mathrm{m}}$ of 5-HT uptake (Table 4.12). Similarly, in the DRN, no significant changes in SERT mRNA or protein expression were found (Figure 4.14). $\Delta \mathrm{Ct}$ values for mRNA expression are shown in Table 4.13.

Table 4.12: $V_{\max }$ and $K_{m}$ values for 5-HT uptake by SERT in the striatum $1 \mathrm{hr}$ after nicotine or TPM treatment.

\begin{tabular}{|l|l|l|}
\hline Treatment & $\mathbf{V}_{\mathbf{m a x}}(\mathbf{p m o l} / \mathbf{s} / \mathbf{g})$ & $\mathbf{K}_{\mathbf{m}}(\boldsymbol{\mu M})$ \\
\hline Control & $449 \pm 37$ & $1.08 \pm 0.33$ \\
\hline Nicotine $(0.35 \mathrm{mg} / \mathrm{kg})$ & $444 \pm 35$ & $1.18 \pm 0.12$ \\
\hline TPM $(0.35 \mathrm{mg} / \mathrm{kg}$ nicotine $)$ & $438 \pm 50$ & $1.05 \pm 0.22$ \\
\hline
\end{tabular}

Values are mean \pm SEM. 
$\mathbf{A}$

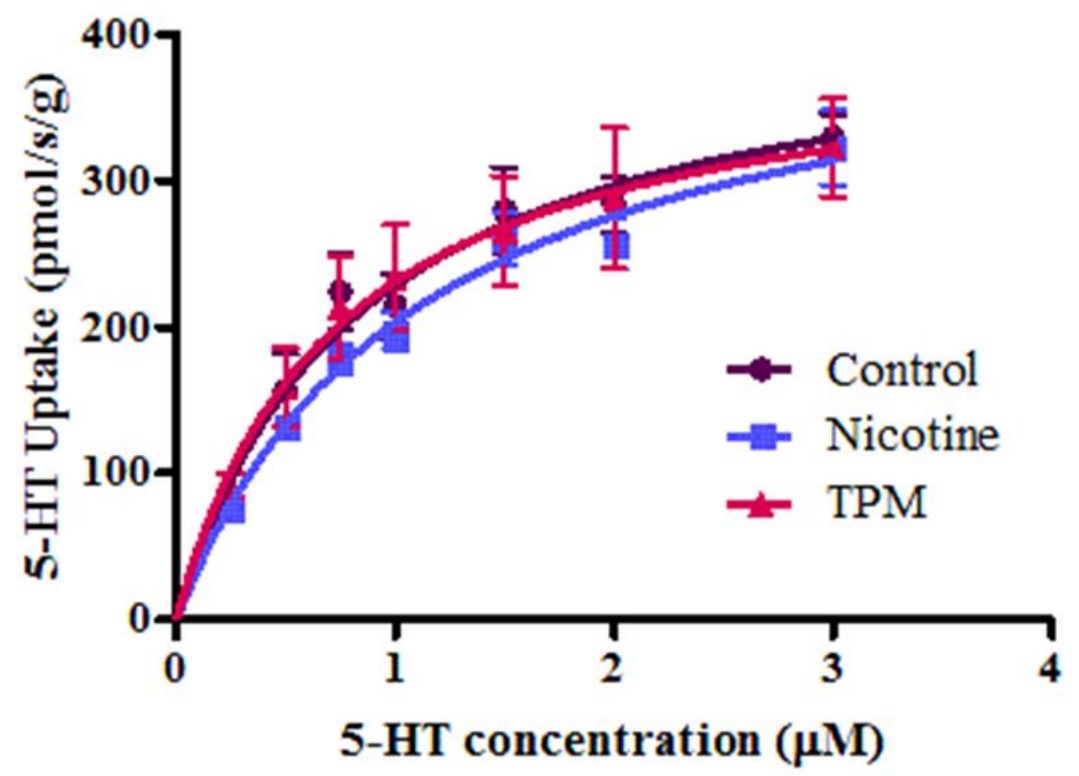

B

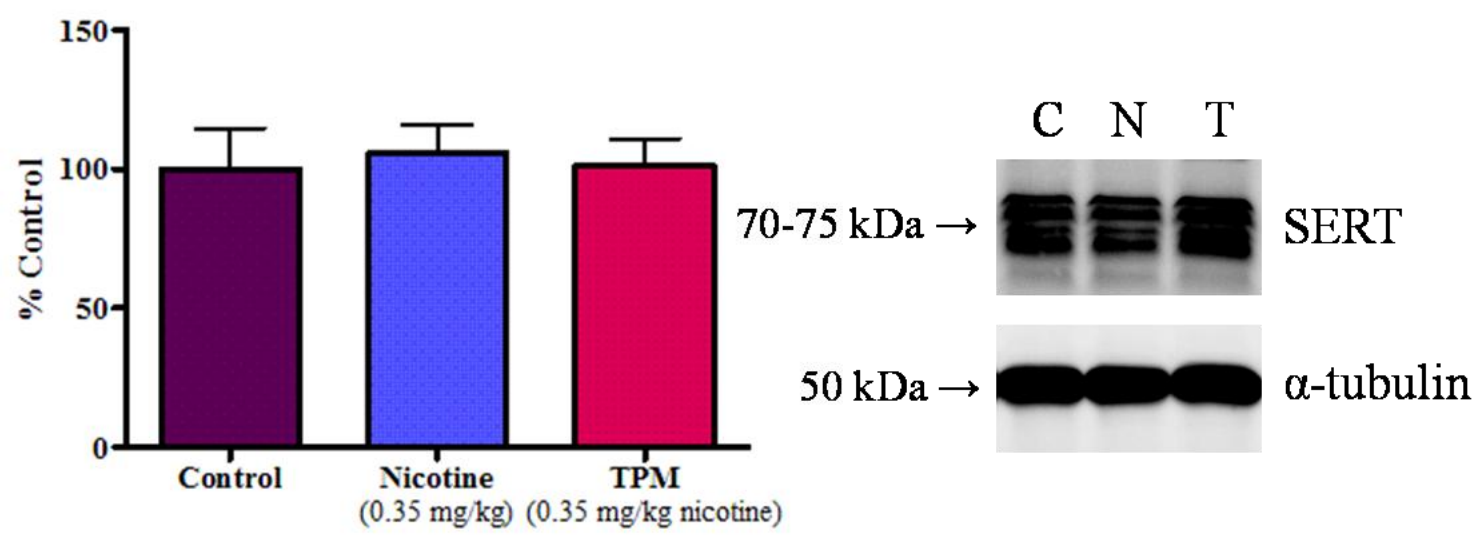

Figure 4.13: SERT function and expression in the striatum at $1 \mathrm{hr}$. No significant changes were found in SERT function $(n=5)(\mathbf{A})$ or protein expression $(n=7-9)(\mathbf{B}) 1 \mathrm{hr}$ following control, nicotine $(0.35 \mathrm{mg} / \mathrm{kg})$, or TPM (containing $0.35 \mathrm{mg} / \mathrm{kg}$ nicotine) treatment. Data points and bars represent mean \pm SEM. C, control; N, nicotine; T, TPM. 
A
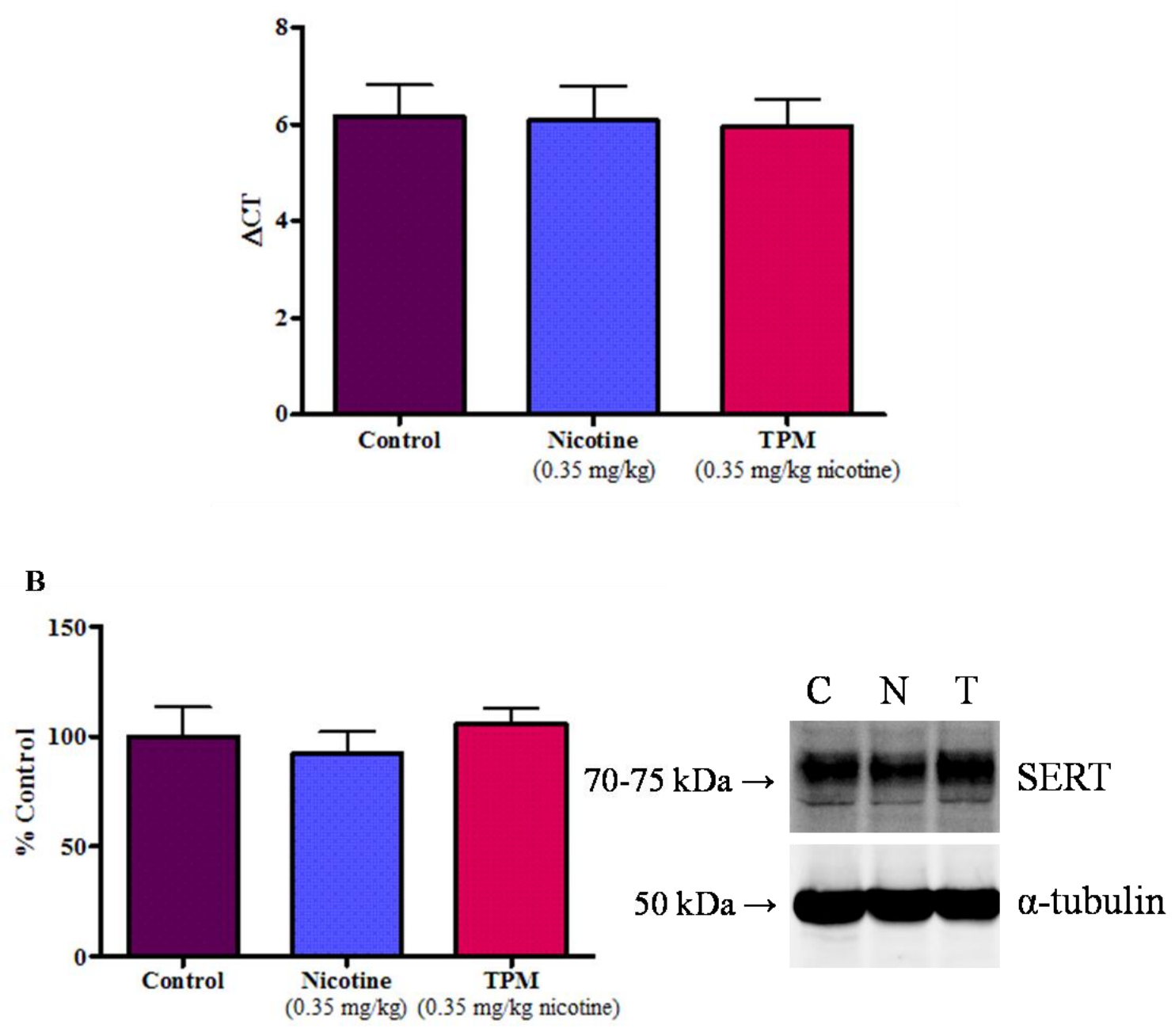

Figure 4.14: SERT mRNA and protein expression in the DRN at $1 \mathrm{hr}$. Rats were treated with control, nicotine $(0.35 \mathrm{mg} / \mathrm{kg}$ ), or TPM (containing $0.35 \mathrm{mg} / \mathrm{kg}$ nicotine) and sacrificed $1 \mathrm{hr}$ after treatment. No change in mRNA (A) or protein expression (B) was seen with any treatment. Bars represent mean \pm SEM ( $n=6-7)$. C, control; $N$, nicotine; $T$, TPM.

Table 4.13: $\Delta C t$ values for SERT mRNA expression in the DRN at $1 \mathrm{hr}$.

\begin{tabular}{|l|l|}
\hline Treatment & $\Delta$ Ct Value \\
\hline Control & $6.2 \pm 0.7$ \\
\hline Nicotine $(0.35 \mathrm{mg} / \mathrm{kg})$ & $6.1 \pm 0.7$ \\
\hline TPM $(0.35 \mathrm{mg} / \mathrm{kg}$ nicotine $)$ & $6.0 \pm 0.6$ \\
\hline
\end{tabular}

Values are mean \pm SEM. 


\section{Chapter 5: Discussion}

\subsection{Significance}

Cigarette smoking is the leading cause of preventable death worldwide, and accounts for almost 6 million deaths every year (WHO, 2011). Current smoking cessation therapies have limited success (Jorenby et al., 2006; Balfour et al., 2000a), which is partially due to an inadequate understanding of the molecular biology of smoking addiction. Nicotine has been shown to act on monoaminergic reward pathways in the brain (Seth et al., 2002; Balfour et al., 2000b) and cause the release of DA, 5-HT, and NE (Singer et al., 2004; Dichiara and Imperato, 1988; Nisell et al., 1996; Ma et al., 2005; Yu and Wecker, 1994; Rossi et al., 2005; Scholze et al., 2007). Uptake of monoamines by the monoamine transporters is the primary mechanism for monoamine clearance from the synapse, and this makes the monoamine transporters integral to the regulation of reward mechanisms in the brain (Howell and Kimmel, 2008). It has previously been reported that nicotine affects the function and expression of the monoamine transporters; however, there is some discrepancy in the literature and our understanding of these effects is incomplete (see Danielson et al., 2011). Emerging evidence suggests that non-nicotinic components of cigarette smoke may also contribute to the development and maintenance of smoking addiction. There is currently very little information in the literature on the effects of nonnicotinic components of cigarette smoke on the monoamine transporters. The aim of this study was to assess the effects of nicotine and a tobacco extract, TPM, on the function and expression of the monoamine transporters DAT, NET, and SERT in the rat brain. This will improve our understanding of the molecular biology of smoking addiction, and could in future lead to the development of more successful smoking cessation therapies.

\subsection{TPM as a model for smoking addiction}

\section{$\underline{\text { 5.2.1 TPM and reward-related neuroadaptations }}$}

Emerging evidence indicates that non-nicotinic components of tobacco smoke may contribute to smoking addiction, and some recent studies have indicated that tobacco extracts have a different pharmacological profile to that of nicotine alone. Firstly, a tobacco extract produced stronger inhibition of dorsal raphe serotonergic neurons when 
compared to a matched dose of nicotine (Touiki et al., 2007). Serotonin has a critical role in reinforcement processes, and this effect could determine reinforcing properties. Secondly, TPM exposure increased nAChR expression in cell cultures to a greater extent than nicotine alone (Ambrose et al., 2007). The functional significance of these findings is unclear; however, it is known that blocking nAChRs inhibits both nicotine selfadministration (O'Connor et al., 2010, Stairs et al., 2010, Toll et al., 2012) and nicotine enhanced brain stimulation reward (Spiller et al., 2009). Furthermore, baseline expression levels of $\alpha_{4} \beta_{2}$ receptors can also predict motivation to self-administer in animals (Le Foll et al., 2009). The monoamine transporters are an integral part of reward circuitry in the brain and nicotine has previously been shown to alter monoamine transporter function and expression (reviewed in Danielson et al., 2011). However, information on the effects of non-nicotinic components of cigarette smoke on monoamine transporter is very limited. This is the first study to describe the effects of a tobacco extract on monoamine transporter function and expression.

\subsubsection{Animal models of tobacco dependence}

The majority of research in pre-clinical models of smoking addiction has focused on nicotine alone, despite the fact that human smokers expose themselves to over 4000 different chemicals. Nicotine is the principal addictive agent in cigarette smoke but increasing evidence suggests that non-nicotinic components of tobacco smoke may also contribute to neuroadaptations related to smoking and the development of smoking addiction. Accordingly, inhalative smoke exposure in animals has been used as a model to examine smoking related neuroadaptations (Harris et al., 2010, Small et al., 2010). This model suffers from several methodological issues, and these limit its usefulness as a smoking dependence model. Firstly, whole body immersion smoke exposure is aversive for animals, and animals must be exposed for at least $4 \mathrm{hrs}$ per day to produce serum and brain nicotine levels that are comparable to human smokers (Harris et al., 2010). Noseonly smoke exposure is also a considerable stressor as it requires restraint of the animal. Stress is known to lead to alterations in monoaminergic system function and should be limited to avoid production of behavioural effects and neuroadaptations that do not relate specifically to drug exposure. Secondly, animals are non-contingently exposed to smoke in inhalative models and it has been demonstrated that the effect of contingency can 
determine drug-produced neuroadaptations (Dworkin et al., 1995, Stefanski et al., 1999, Jacobs et al., 2003).

The present study utilised i.p. injection as the mode of administration for TPM and nicotine. This mode of administration is much less aversive for animals compared with long periods of exposure to cigarette smoke, and allows for greater precision and control of the quantities of smoke constituents being delivered. Additionally, this method did not involve expensive equipment (i.e. smoking chambers) or surgical procedures. Relative ease of producing the animal model allowed for reasonably large sample sizes, and different dosing regimens and time points to be examined. Since this was the first attempt to assess the effects of TPM on monoamine transporter status, the ability to vary several of the parameters was critical.

The main disadvantages of administering TPM in this manner is that infusions are noncontingent and the smoke components will go through first pass metabolism in the liver before reaching the brain. First pass metabolism could result in the relative concentrations of some components being decreased. Given these limitations, an alternative model of tobacco dependence that addresses both of these issues has recently been created by Dr Katie Brennan: intravenous TPM self-administration (School of Psychology VUW, unpublished results). There have been no previous reports of animals voluntarily self-administering tobacco smoke/extracts, thus this new model represents an exciting new advancement in the study of tobacco dependence. Preliminary results indicate that rats respond more for TPM than a matched dose of nicotine, and that TPM self-administration is more resistant to mecamylamine-produced decreases in responding observed in nicotine animals (Katie Brennan, personal communication). Further work is required to interpret these data; however, these results suggest behavioural differences exist between TPM and nicotine, and that there is a potential role for non-nicotinic smoke components in reward.

\subsubsection{TPM composition}

The TPM used in this study is an extract that contains tobacco combustion products that a human smoker would typically inhale. TPM is extracted in ethanol and represents the 
ethanol soluble fraction of compounds present in cigarette smoke. The use of a tobacco extract such as this is preferable to testing individual components of cigarette smoke as components may have additive or synergistic effects on cellular processes. The exact composition of TPM is currently unknown, including the ratio of the (+) nicotine and (-) nicotine isomers. We can assume that the majority of nicotine found in TPM is the (-) isomer as it has been previously shown that (-) nicotine makes up $90 \%$ of the nicotine content in tobacco smoke (Matta et al., 2007). The (-) nicotine isomer is more pharmacologically active than $(+)$ nicotine and more potent in behavioural studies in animals (Matta et al., 2007). It is for this reason that (-) nicotine was used for the nicotine treatment groups. The slightly larger $\mathrm{V}_{\max }$ value for TPM compared to nicotine in the 30 min NAc experiment could, therefore, be due to the isomer composition in TPM (Figure $4.4, \mathrm{p} 77)$.

The presence of the psychoactive $\beta$-carboline alkaloids harman and norharman in TPM has been confirmed (Dr Penelope Truman, personal communication). Harman and norharman exhibit strong MAO inhibitor activity (Rommelspacher et al., 1994; Rommelspacher et al., 2002; Herraiz and Chaparro, 2005) and are present in relatively large amounts in tobacco smoke (Herraiz, 2004). Furthermore, MAO inhibitor drug pretreatment has been shown to enhance the rewarding effects of nicotine (Guillem et al., 2005; Guillem et al., 2006; Villegier et al., 2006; Villegier et al., 2007), and MAO inhibitors accumulate in the rat brain following systemic nicotine injections (Pawlik et al., 1990, Fekkes and Bode, 1993). Harman and norharman present in TPM could, therefore, alter monoaminergic systems through their MAO inhibitory activity and indirectly affect the function of monoamine transporters.

No other specific compounds have been measured in TPM; however, we can assume that ethanol-soluble compounds are present. Candidate compounds known to have pharmacological and behavioural effects in drug addiction models include the minor tobacco alkaloids and acetaldehyde. Rats will respond more for a cocktail of nicotine plus the minor tobacco alkaloids than nicotine alone (Clemens et al., 2009), and the minor tobacco alkaloid nornicotine has been shown to decrease DA uptake in the striatum of rats (Middleton et al., 2007b). Acetaldehyde has long been implicated in the reinforcing 
effects of alcohol (Quertemont et al., 2005), and has more recently been shown to increase acquisition of nicotine self-administration in adolescent rats (Belluzzi et al., 2005). The effects of acetaldehyde on monoamine transporter function have not been extensively examined, although one study reported no change in DAT function in Xenopus oocytes in response to acetaldehyde (Mascia et al., 2001).

\subsubsection{Ethanol content in nicotine and TPM treatments}

Nicotine and TPM treatments used in this study were delivered in a vehicle that contained $8 \%$ ethanol in PBS. This was due to the ethanol content of the TPM originally acquired for experiments. The ethanol content of treatments used in this study should be taken into account when interpreting results for several reasons. Ethanol is known to act on the mesolimbic DA system and cause increases in DA in reward related regions of the brain (Hurley et al., 2012). Furthermore, it has been shown that co-administration of nicotine and alcohol has an additive effect on DA release in the NAc (Tizabi et al., 2007), and the two drugs possibly have synergistic effects on the reward system (Hurley et al., 2012). Cross-potentiation of rewarding effects with nicotine and ethanol has also been reported in human studies. Rose et al. (2004) found that self-reported pleasure from cigarette smoking was increased by alcohol consumption (Rose et al., 2004). It has also been reported that alcohol consumption increased with the smoking of regular cigarettes compared to denicotinised cigarettes (Barrett et al., 2006). Secondly, there is evidence that ethanol affects monoamine transporter function and expression. Data on the effects of ethanol on DAT are conflicting and there have been reports of increases and decreases in function as well as no change (reviewed in Zhu and Reith, 2008). There is very limited information available on the effects of ethanol on SERT and NET expression and function. SERT expression has been shown to be up-regulated in response to ethanol in dendritic cells (Babu et al., 2009). In addition, Hwang et al. (2000) reported that NET expression is higher in the $\mathrm{LC}$ of rats selectively bred for alcohol preference compared to low alcohol drinking and non-preferring rats (Hwang et al., 2000). Finally, acetaldehyde is a metabolic product of ethanol; therefore, the concentration of acetaldehyde that the animals are exposed to will be greater than the actual amount present in TPM. Since acetaldehyde has previously been shown to affect nicotine self-administration in adolescent rats (Beluzzi et al., 2005), and to have reinforcing properties on its own (Amit and Smith, 1985), this increased dose could affect nicotine-derived neuroadaptations. 
The ethanol content of nicotine and TPM treatments used in this study was controlled for with an $8 \%$ ethanol solution in PBS. This should have controlled for the majority of effects possibly produced by ethanol, so that the observed effects were due to nicotine and TPM. However it is possible that there could be synergistic effects of ethanol and nicotine, or ethanol and compounds present in TPM. Furthermore, changes produced by ethanol could have masked some effects that would otherwise be observed with nicotine and TPM. There is a high co-morbidity rate of alcohol consumption and tobacco use in humans (Hurley et al., 2012). In light of this, the present study is still relevant but results need to be interpreted in context as they may be due to the combined effects of ethanol and nicotine. Future studies could be conducted on lower ethanol content models where possible, and repeats of nicotine and control treatments without ethanol could also be performed to confirm that reported findings with nicotine were due to nicotine alone. In the newly established TPM self-administration model ethanol content has been reduced to $1 \%$, which should reduce some of the problems discussed in this section.

\subsection{Chronic effects of nicotine and TPM on monoamine transporter function and expression}

This is the first study to examine the effects of TPM on monoamine transporter function, and because of this it is highly relevant in contributing to our understanding of the effects of tobacco smoke on this system. In order to study the chronic effects of nicotine and TPM on the monoamine transporters, we used a 10 day dosing regimen where rats received a daily total of 0.35 or $3 \mathrm{mg} / \mathrm{kg}$ nicotine, or TPM containing $0.35 \mathrm{mg} / \mathrm{kg}$ nicotine. Since human smokers dose themselves chronically with cigarette smoke, it is important to investigate the effects of chronic nicotine and tobacco extracts in animal models. A 10 day treatment regimen was chosen as previous studies have used this treatment period (Awtry and Werling, 2003; Drew and Werling, 2003), and it is within the median time point used previously in chronic nicotine models. In this model treatments were split across four injections $2 \mathrm{hrs}$ apart to better mimic the rise and fall in nicotine brain and plasma levels that human smokers are exposed to. Animals were 
sacrificed the morning after their final treatment (14-16 hrs later), and thus the effects observed are those of animals in withdrawal. It is important to understand the effects of nicotine and TPM withdrawal as this has considerable implications for the development of smoking cessation aids. Human smokers suffer withdrawal and it is the unpleasant experience of this that often leads to relapse (De Biasi and Dani, 2011). With a greater understanding of the molecular biology of nicotine and TPM withdrawal, it may be possible to develop more effective cessation therapies targeting specific neuroadaptations related to smoking withdrawal. In this study, monoamine transporter function and expression were measured using RDEV, Western blotting, and real time PCR. A summary of the results found are in Table 5.1.

\subsubsection{DAT function and expression following chronic nicotine and TPM treatment}

There is conflicting data in the literature on the effects of chronic nicotine treatment on DAT. Chronic nicotine treatment has been shown to cause no change in $\left[{ }^{3} \mathrm{H}\right] \mathrm{DA}$ uptake in chopped rat NAc or striatal tissue (Izenwasser et al., 1992), rat PFC synaptosomes (Drew and Werling, 2003), or rat striatal and NAc synaptosomes (Carr et al., 1989). However, increases in DAT function in mouse striatal synaptosomes (Hadjiconstantinou et al., 2011), and in the NAc of nicotine self-administering rats (Rahman et al., 2004) have been reported. No changes in DAT function in the NAc (Figure 3.4, p56), striatum (Figure 3.5, p57), or PFC (Figure 3.6, p58) were observed following chronic nicotine $(0.35$ or $3 \mathrm{mg} / \mathrm{kg}$ ) or TPM (containing $0.35 \mathrm{mg} / \mathrm{kg}$ nicotine) treatment in this study.

An important difference in methodology between these studies is the time between final nicotine treatment and sacrifice. Both Izenwasser and Cox (1992) and Carr et al. (1989) utilised osmotic minipumps (s.c.) for delivery of nicotine, and so nicotine treatment would have been continuous up until sacrifice. However, Hadjiconstantinou et al. (2011) and Rahman et al. (2004) found increases in DAT function in animals sacrificed 12-24 hrs after the last nicotine treatment. This means that the effects of nicotine withdrawal on monoamine transporter function were being measured in these studies. In our study, we chose to sacrifice animals at between 14 and $16 \mathrm{hrs}$ after their last nicotine treatment, and thus monoamine transporter function was measured in nicotine withdrawal. It is interesting, therefore, that the increases in DAT function in the striatum and NAc shown 
by Hadjiconstantinou et al. (2011) and Rahman et al. (2004) were not observed in our study. This could be due to several factors in the current study, including the dose chosen, the length of treatment, and the co-administration of alcohol. The two previous studies that showed changes in DAT function in response to chronic nicotine treated animals for 14 and 25 days. This is longer than other studies that have only treated animals for 7-10 days for chronic models. In the current study, animals were treated for 10 days, which may not have been long enough to produce the effects previously shown by Rahman et al. (2004) and Hadjiconstantinou et al. (2011). It would be interesting in future to study the chronic effects of nicotine on DAT function over an extended time period. Furthermore, time-effects could be examined by studying different groups of animals that had been treated for different periods of time. Particularly, it would be of interest to look at the 10-14 day period to see if there is a change evident somewhere during this time.

In this study, rats received 0.35 or $3 \mathrm{mg} / \mathrm{kg} / \mathrm{day}$ nicotine or TPM containing 0.35 $\mathrm{mg} / \mathrm{kg} /$ day nicotine. This is a comparatively low dose of nicotine compared to other chronic studies that used $0.6-6 \mathrm{mg} / \mathrm{kg} /$ day nicotine in chronic treatments for rats. When choosing nicotine doses for study many factors need to be considered including: what an animal will self-administer in a day; what plasma and brain levels of nicotine it is likely to produce; how this compares to human nicotine consumption. The doses chosen in this study fall roughly within the range of what an animal will self-administer in a day (Corrigall and Coen 1989; Boulles et al., 2010), and should produce plasma nicotine levels similar to that seen in human smokers (Matta et al., 2007); however, plasma levels were not actually measured in this study. The $0.35 \mathrm{mg} / \mathrm{kg}$ dose would be expected to produce only moderate plasma and brain nicotine levels (Matta et al., 2007), and was chosen in part because a higher nicotine concentration would require a higher ethanol concentration in the TPM group. Using this dose is still relevant for comparison to human smoking behaviour as it would be comparable to the nicotine consumption of a light smoker. Furthermore, many nicotine studies look at the effect of a single large nicotine dose, or continuous administration through s.c. osmotic minipumps, both of which differ greatly to human smoking behaviour. In this model, a moderate nicotine dose is administered across 4 daily injections so that several rises and falls in nicotine plasma and brain levels are produced throughout the day. This better mimics the 
exposure to nicotine that humans experience. The $3 \mathrm{mg} / \mathrm{kg}$ nicotine dose administered in chronic experiments in this study was used to examine dose effects of nicotine, and to ensure that the $0.35 \mathrm{mg} / \mathrm{kg}$ dose was not too low to produce effects. Since the $3 \mathrm{mg} / \mathrm{kg}$ dose also produced no changes in DA uptake with chronic treatment, it can be concluded that in this model nicotine does not affect DAT function. Future research could examine the effects of a wider range of nicotine doses on DAT function, and a lower ethanol concentration in TPM could allow for higher doses to be used.

A substantial number of studies that have previously examined monoamine uptake in response to nicotine have been conducted using radioactive uptake assays and synaptosomal preparations (Carr et al., 1989; Drew and Werling, 2003; Awtry and Werling, 2003; Middleton et al., 2007a; Zhu et al., 2009). This differs considerably from the methodology employed in the current study, where uptake was measured in chopped tissue using RDEV. Firstly, there is a greater diffusion barrier for drugs and monoamines to cross in chopped tissue compared to synaptosomes, necessitating larger concentrations of these agents to be applied to the chopped tissue (Near et al., 1988). Secondly, RDEV differs from radioactive uptake assays in several respects: measurement of monoamine uptake is immediate with no delay produced by wash steps that are necessary in radioactive uptake; the uptake is measured in real time; and measurement of uptake is continuous and does not rely on discrete data points (Earles et al., 1998). For these reasons RDEV is arguably the more favourable methodology for the measurement of monoamine uptake. Furthermore, the differences between these two methodologies are great enough to warrant consideration when comparing results from this study to previous studies that utilize radioactive uptake techniques.

Although there was no change in DAT function observed with chronic nicotine and TPM treatment in this study, there was a change in total DAT protein expression. In the NAc, an increase of $39.1 \%$ for nicotine $(0.35 \mathrm{mg} / \mathrm{kg}$ ), and $42.8 \%$ for TPM (containing 0.35 $\mathrm{mg} / \mathrm{kg}$ nicotine) was found (Figure 3.4, p56). Furthermore, there was a trend towards an increase of $32.4 \%$ for the $3 \mathrm{mg} / \mathrm{kg}$ nicotine group. No previous studies have shown an increase in DAT protein expression in the NAc, or a decrease in DAT protein expression in the $\mathrm{SN}$ of rats. A decrease in [ $\left.{ }^{99 \mathrm{~m}} \mathrm{Tc}\right] \mathrm{TRODAT}-1$ binding has been reported in the 
striatum of human smokers compared to non-smokers (Krause et al., 2002; Newberg et al., 2007; Yang et al., 2008). However, this may be due to decreased binding affinity of [ $\left.{ }^{99 \mathrm{~m}} \mathrm{Tc}\right]$ TRODAT-1 to DAT rather than a decrease in the amount of DAT present. DAT protein expression in this study was measured using Western blotting with a DATspecific antibody. This method measures the total DAT present on both the cell surface and in the interior of the cell. The observed increase in DAT protein in the NAc may, therefore, not indicate an increase in functional DAT on the cell surface, but an increase in DAT protein in the intracellular pool. Since there was no increase in DA uptake in the NAc, this is more likely.

In addition to the increase in DAT protein found in the NAc, there was a decrease in DAT protein expression found in the $\mathrm{SN}$ with $0.35 \mathrm{mg} / \mathrm{kg}$ nicotine $(27.5 \%), 3 \mathrm{mg} / \mathrm{kg}$ nicotine (33\%) and TPM (containing $0.35 \mathrm{mg} / \mathrm{kg}$ nicotine) (36.1\%) (Figure 3.7, p60). In contrast to this, Miller et al. (2007) reported a 52\% increase in $\left[{ }^{3} \mathrm{H}\right] \mathrm{GBR} 12935$ binding to DAT in crude membrane preparations from the midbrain of guinea pigs exposed chronically to cigarette smoke. This preparation would have included several brain nuclei in addition to the SN. The discrepancy between our findings and the findings by Miller et al. (2007) could also be due to a combination of species and/or treatment differences. The cause for this decrease in DAT expression in the SN is not clear. Since nicotine has been reported to have a neuroprotective role in the SN by several studies (Takeuchi et al. 2009; Quik et al., 2007; Park et al., 2007), it is unlikely that this decrease in DAT protein is due to toxicity or cell death. No change in DAT mRNA expression was found in the SN in this study (Figure 3.7, p60), indicating that the decrease in DAT protein expression was not due to a decrease in gene expression. However, quantifying mRNA only measures changes in gene transcription and the possibility of a reduction in mRNA translation cannot be ruled out.

Chronic nicotine and cigarette smoke treatment have previously been shown to increase DAT mRNA expression in the VTA and SN of rats (Li et al., 2004c; Hadjiconstantinou et al., 2011). Interestingly, Li et al. (2004c) found a greater increase in DAT mRNA expression in animals that had been chronically exposed to passively inhaled cigarette smoke than animals that had received chronic oral nicotine. In contrast, no change in 
DAT mRNA expression in the SN or VTA was found in our study in response to nicotine or TPM. This indicates that changes in protein expression observed in this study are not regulated through gene expression. As mentioned above, discrepancies between this study and previous ones could be explained by factors such as dose and length of treatment. In the study by $\mathrm{Li}$ et al. (2004c) rats received $12 \mathrm{mg} / \mathrm{kg} /$ day oral nicotine for 4 weeks. This is both a significantly longer time period and larger dose than what we used in the present study $(0.35$ or $3 \mathrm{mg} / \mathrm{kg} /$ day nicotine $)$. Similarly, Hadjiconstantinou et al. (2011) treated mice for 14 days to a total of $8 \mathrm{mg} / \mathrm{kg} / \mathrm{day}$.

\subsubsection{NET function and expression}

There have been no previous studies that examined the effects of chronic nicotine administration on DA uptake by NET. $\quad\left[{ }^{3} \mathrm{H}\right] \mathrm{NE}$ uptake by NET has been measured in cultured bovine adrenal medullary cells and Itoh et al. (2010) found a 61\% increase in uptake in response to 5 days nicotine treatment (Itoh et al., 2010). In our study, the effects of chronic nicotine and TPM treatment on DA uptake by NET in the PFC were measured. The chronic treatment regime consisted of a total of 0.35 or $3 \mathrm{mg} / \mathrm{kg} / \mathrm{day}$ nicotine or $0.35 \mathrm{mg} / \mathrm{kg} /$ day TPM over 10 days. An increase in DA uptake by NET (76\% increase in $\mathrm{V}_{\max }$ ) was observed in the PFC following $3 \mathrm{mg} / \mathrm{kg}$ nicotine, but not following $0.35 \mathrm{mg} / \mathrm{kg}$ nicotine or TPM (containing $0.35 \mathrm{mg} / \mathrm{kg}$ nicotine) (Figure 3.8, p62). This increase in uptake appears to be a dose effect of nicotine as both $0.35 \mathrm{mg} / \mathrm{kg}$ nicotine and TPM containing $0.35 \mathrm{mg} / \mathrm{kg}$ nicotine had no effect on NET function. Furthermore, this change is consistent with the increase in NET function shown by Itoh et al. (2010), and suggests that nicotine may up-regulate NET function in a manner that is not discriminatory between DA and NE uptake. It is especially interesting that an increase in DA uptake by NET was observed in this study where there was no increase in DA uptake by DAT in the same brain region and treatment group (Figure 3.6, p58). This difference highlights the specific regulation of the monoamine transporters by nicotine. NET is known to be responsible for a considerable portion of DA uptake in the PFC and this increased uptake could have significant effects on dopaminergic tone (Dichiara et al., 1992). It has previously been shown that, although DA output is decreased in the NAc during nicotine withdrawal, it is increased in the PFC at this stage (De Biasi and Salas, 2008). This increase in DA output is believed to mediate some of the aversive effects of nicotine withdrawal such as anxiety. The increased uptake of DA by NET observed here 
could be a feedback mechanism that partially tempers the increase DA output in this brain region during withdrawal. The mechanism for this change is not currently known. Since there are very little data on the effects of nicotine on NET, future studies examining this would be useful.

The increase in NET function found in this study was not accompanied by an increase in NET protein expression in the PFC (Figure 3.8, p62) or LC (Figure 3.9, p64). Previous studies have found no significant change in NET density in the LC of human post mortem brains of smokers compared to non-smokers (Klimek et al., 2001). Similarly, Andreasen et al. (2009) found no change in NET density in hippocampal and cortical membrane preparations from mice treated chronically with nicotine. This indicates that nicotine does not affect NET protein expression, and that the increase in DA uptake observed here occurred through some other mechanism. An increase in $\mathrm{V}_{\max }$ indicates that the change is due to increased cell surface expression of the transporter, or increased catalytic activity of the transporters present on the cell surface. It should be noted that nicotine also affected the binding properties of DA to NET, as indicated by the increase in $\mathrm{K}_{\mathrm{m}}$. However, the increase in $\mathrm{V}_{\max }$ compensated for the increase in $\mathrm{K}_{\mathrm{m}}$ and an overall increase in DA uptake was observed in Figure 3.8 (p62).

Although we found no significant difference in protein expression of NET with any treatment, a significant decrease in NET mRNA expression was observed with TPM treatment (fig 3.9, p64). This change equated to a $95.5 \%$ reduction in mRNA in the TPM group compared to the control group, and was not seen with either 0.35 or $3 \mathrm{mg} / \mathrm{kg}$ nicotine treatment. It is interesting that TPM caused a change in mRNA expression where the dose matched nicotine did not. This suggests that some component in TPM other than nicotine caused the change; however, the molecular relevance of this finding is questionable due to the lack of an accompanying change in protein. It should also be noted that the standard error (SEM) of the TPM group was $1.5 \mathrm{Ct}$ values which equates to approximately $34 \%$ error in the value. Since no change in protein expression was observed, the reported difference in mRNA between the two groups is most likely inflated. The SEM of the mRNA values was reasonably considerable in this study, and this most likely stems from error in tissue dissections. The four brain regions examined 
for monoamine transporter mRNA expression (LC, DRN, VTA, and SN) are all small and not very clearly defined in the rat. Dissections were performed using a standard protocol routinely used (Heffner et al., 1980; Corcoran et al., 2012) and all samples were weighed in attempt to limit variation (Table 2.1, p38). However, in future it would be beneficial to use laser capture microdissection for more accurate dissection of these regions. At the time of this study, this option was not available to us.

\subsubsection{SERT function and expression}

Chronic nicotine treatment has been previously shown to increase $\left[{ }^{3} \mathrm{H}\right] 5-\mathrm{HT}$ uptake by SERT in PFC and hippocampal synaptosomes (Awtry and Werling, 2003); however, this is the first study to examine 5-HT uptake in response to nicotine in the striatum. No change was observed in SERT function or protein expression in the striatum (Figure 3.10, p66), suggesting that the effects of nicotine on SERT are brain region specific. SERT protein and mRNA expression were also examined in the DRN and no difference was found compared to control. However, a significant difference in SERT mRNA was observed between $0.35 \mathrm{mg} / \mathrm{kg}$ nicotine and TPM (containing $0.35 \mathrm{mg} / \mathrm{kg}$ nicotine) in the DRN (Figure 3.11, p68). This difference equated to a $91 \%$ reduction in mRNA expression in the TPM group compared to the nicotine group. As stated in the previous section, this statistic may be misleadingly large and should be interpreted with caution. It is interesting that for SERT TPM produced a decrease in mRNA expression compared to nicotine. This suggests that TPM may cause some subtle changes in gene expression. Although in this case no significant change compared to control and no change in SERT protein expression occurred, this difference is still worth some consideration. If TPM has subtle effects on the gene expression of multiple components of the 5-HT system it could result in a change in the overall 5-HT tone. Western blotting experiments may not show very small changes $(<10 \%)$ in protein expression, and while a change in protein expression of this size may not be significant when considering a single system, it could cause a significant change in overall 5-HT tone in combination with other subtle changes within the reward circuitry of the brain. Furthermore, it should be noted that the specificity of SERT antibodies has been brought into question. There is some debate in the literature as to how reliable they are, and what product size they should recognise. The antibody used in this study has been previously published and recognises a single distinct band at 70-75 kDA (Appendix) that we believe to be SERT. However, in future it 
would be beneficial to confirm that this band represents SERT using MALDI-TOF or protein sequencing techniques. 
Table 5.1: Summary of results from this study.

\begin{tabular}{|c|c|c|c|c|}
\hline Time point & & Uptake & Protein expression & mRNA expression \\
\hline \multirow{4}{*}{ Chronic } & DAT & $\begin{array}{l}\text { No change in NAc, } \\
\text { striatum, or PFC. }\end{array}$ & $\begin{array}{l}39-43 \% \text { inc in NAc } \\
\text { with nic }(0.35 \\
\mathrm{mg} / \mathrm{kg}) \text { and TPM. } \\
\text { No change in } \\
\text { striatum, PFC or } \\
\text { VTA. Dec in SN } \\
\text { with all treatments } \\
(27-36 \%) \text {. }\end{array}$ & No change in VTA or SN. \\
\hline & NET & $\begin{array}{l}76 \% \text { inc in } V_{\max } \text { with nic ( } 3 \\
\mathrm{mg} / \mathrm{kg} \text { ). }\end{array}$ & $\begin{array}{l}\text { No change in PFC } \\
\text { or LC. }\end{array}$ & $\begin{array}{l}95.5 \% \text { Dec in LC with } \\
\text { TPM }\end{array}$ \\
\hline & SERT & No change in striatum. & $\begin{array}{l}\text { No change in } \\
\text { striatum or DRN. }\end{array}$ & $\begin{array}{l}\text { No change compared to } \\
\text { con in DRN. } 91 \% \text { dec } \\
\text { with TPM compared to nic } \\
(0.35 \mathrm{mg} / \mathrm{kg}) .\end{array}$ \\
\hline & DAT & $\begin{array}{l}\text { No change in NAc or PFC. } \\
\text { Inc in } \mathrm{V}_{\max }(40.5 \%) \text { with } \\
\text { TPM in striatum not } \\
\text { completely attenuated by } \\
\text { mec. }\end{array}$ & $\begin{array}{l}\text { No change in NAc, } \\
\text { striatum, PFC, } \\
\text { VTA, or SN. }\end{array}$ & $\begin{array}{l}\text { Dec in VTA with nic }(0.35 \\
\mathrm{mg} / \mathrm{kg})(96.4 \%) \text { and TPM } \\
(93.3 \%) \text { compared to con, } \\
\text { no change in SN. }\end{array}$ \\
\hline \multirow[t]{3}{*}{$1 \mathrm{hr}$} & NET & No change in PFC. & $\begin{array}{l}\text { No change in PFC } \\
\text { or LC. }\end{array}$ & $\begin{array}{l}\text { No change compared to } \\
\text { con in PFC, TPM dec } \\
\text { compared to nic }(0.35 \\
\mathrm{mg} / \mathrm{kg})(59 \%)\end{array}$ \\
\hline & SERT & No change in striatum. & $\begin{array}{l}\text { No change in } \\
\text { striatum or DRN. }\end{array}$ & No change in DRN. \\
\hline & DAT & $\begin{array}{l}\text { Dec in NAc with nic }(0.35 \\
\mathrm{mg} / \mathrm{kg})(30.6 \%) \text { and TPM } \\
(17.9 \%) \text {, attenuated by mec } \\
\text { and DH } \beta \mathrm{E} \text { but not MLA. } \\
\text { No change in striatum or } \\
\text { PFC. }\end{array}$ & $\begin{array}{l}\text { No change in } \\
\text { protein expression } \\
\text { in the NAc. }\end{array}$ & \\
\hline \multirow{2}{*}{$30 \mathrm{~min}$} & NET & No change in PFC. & & \\
\hline & SERT & No change in striatum. & & \\
\hline \multirow[t]{3}{*}{$15 \min$} & DAT & $\begin{array}{l}\text { No change in NAc, } \\
\text { striatum, or PFC. }\end{array}$ & & \\
\hline & NET & No change in PFC. & & \\
\hline & SERT & No change in striatum. & & \\
\hline \multirow{3}{*}{$\begin{array}{l}\text { In vitro } \\
\text { treatment }\end{array}$} & DAT & $\begin{array}{l}\text { No change in NAc, } \\
\text { striatum, or PFC. }\end{array}$ & & \\
\hline & NET & No change in PFC. & & \\
\hline & SERT & $\begin{array}{l}\text { Dec with TPM }\left(\mathrm{V}_{\max }\right. \\
24.8 \%) \text { in striatum, not } \\
\text { attenuated with mec. }\end{array}$ & & \\
\hline
\end{tabular}

inc, increase; dec, decrease; NAc, Nucleus Accumbens; PFC, Prefrontal Cortex; DRN, dorsal raphe nuclei; $\mathrm{SN}$, substantia nigra; VTA, ventral tegmental area; con, control; nic, nicotine; TPM, tobacco particulate matter; mec, mecamylamine 


\section{Acute effects of nicotine and TPM on monoamine transporter function and expression}

The acute effects of nicotine $(0.35 \mathrm{mg} / \mathrm{kg})$ and dose-matched TPM were examined in this study using RDEV, Western blotting, and real time PCR. Previous literature has reported changes in monoamine transporter function and expression at a range of different time points. For this reason we chose 3 time points for acute treatments: $15 \mathrm{~min}, 30 \mathrm{~min}$, and 1 hr. Function of the transporters was measured at all 3 time points, and transporter protein and mRNA expression were also measured at $1 \mathrm{hr}$ as a representative time point for acute treatment. No previous studies have examined the effects of a tobacco extract on monoamine transporter function or expression, and reports on the effects of nicotine on monoamine transporters are often contradictory. Therefore, it is important to further clarify the effect of nicotine on the transporters with acute treatment, and to elucidate what the comparative effects of TPM are. This could lead to a better understanding of initial neuroadaptations in response to smoking, and how this can lead to smoking addiction in humans.

\subsubsection{DA uptake and DAT protein expression in the NAc}

Few studies have examined the acute effects of nicotine on DAT function in the NAc, which is surprising considering the status of this brain region as the brain's major reward centre (Balfour et al., 2000b). Studies that have examined the effects of nicotine on DAT function in the NAc have found conflicting results. Hart and Ksir (1996) reported an increase in DAT function in the NAc following a single $0.4 \mathrm{mg} / \mathrm{kg}$ s.c. dose of nicotine using in vivo voltammetry. This effect was almost immediate and persistent through to 1 hr. In contrast, Carr et al. (1989) found no change in $\left[{ }^{3} \mathrm{H}\right] \mathrm{DA}$ uptake in NAc synaptosomes from rats that had been treated with $0.1 \mathrm{mg} / \mathrm{kg}$ nicotine for $15 \mathrm{~min}$, or with in vitro nicotine treatment $(0.1-10 \mu \mathrm{M})$ of drug naive synaptosomes. Consistent with Carr et al. (1989), our study found no changes in DA uptake in the NAc with in vitro nicotine $(2 \mu \mathrm{M})$ or TPM (containing $2 \mu \mathrm{M}$ nicotine) treatment (Figure 4.1, p71). There was also no change in DA uptake observed at $15 \mathrm{~min}$ (Figure 4.3, p75) or $1 \mathrm{hr}$ (Figure 4.7, p83) following in vivo nicotine $(0.35 \mathrm{mg} / \mathrm{kg}$ ) or TPM (containing $0.35 \mathrm{mg} / \mathrm{kg}$ nicotine) treatment, and no change in DAT protein expression was found at the $1 \mathrm{hr}$ time point (Figure 4.7, p83). 
In this study, a decrease in DA uptake in the NAc was found at 30 min post nicotine $(0.35$ $\mathrm{mg} / \mathrm{kg}$ ) and TPM (containing $0.35 \mathrm{mg} / \mathrm{kg}$ nicotine) treatment (Figure 4.4, p77). Kinetic analysis showed a significant decrease in $\mathrm{V}_{\max }$ for both nicotine (30.6\%) and TPM (17.9\%) with no change in $\mathrm{K}_{\mathrm{m}}$. This change in uptake is similar in magnitude to previously reported changes in DAT function, which have ranged from $25-87 \%$. As there was no change observed in DAT protein expression, this indicates that the decrease in uptake may be due to either a decrease in DAT cell surface expression or a decrease in DAT catalytic function at the cell surface. The lack of a corresponding change in DAT protein expression at this time point is not surprising. In general, acute monoamine transporter regulation is dependent on transporter redistribution in the cell and posttranslational modifications such as phosphorylation and glycosylation (reviewed in Kristensen et al., 2011). Changes in monoamine transporter number and density is more commonly reported following chronic drug exposures (Miller et al., 2007; Krause et al., 2002; Yang et al., 2008).

The decrease in DA uptake we observed is the opposite effect to that found by Hart and Ksir (1996), which saw an increase in DA uptake in the NAc. There are several differences in methodology used between the Hart and Ksir (1996) study and our study that could account for this discrepancy. As mentioned previously, the ethanol content of the injections used in this study could affect DAT function. Furthermore, Hart and Ksir (1996) measured in vivo DA uptake in live animals under urethane anaesthesia, which could also possibly affect monoamine transporter function. It has been shown that urethane potentiates nAChR function (Hara and Harris, 2002), and the effects of nicotine on monoamine transporter function have consistently been shown to be nAChRdependent. It is possible that because of this, urethane could have an indirect effect on monoamine transporter function. This is worthy of consideration when examining findings from studies using animals under anaesthesia.

To test whether the decrease in DAT function observed in this study was nAChRdependent, animals were pre-treated with the non-specific, non-competitive nAChR antagonist mecamylamine $(1.5 \mathrm{mg} / \mathrm{kg}) 20 \mathrm{~min}$ before nicotine or TPM treatment. This pre-treatment completely attenuated the effects of both nicotine and TPM, indicating that 
the observed decrease in DAT function is mediated entirely through nAChR activation (Figure 4.4, p77). The involvement of specific nAChR subtypes was then investigated using the $\beta 2$ subunit antagonist DH $\beta E$ ( $8 \mathrm{mg} / \mathrm{kg}$ salt weight), and the $\alpha 7$ subunit specific antagonist MLA (10 mg/kg salt weight). The doses selected were based on a previous study by Zhu et al. (2009). Zhu et al. (2009) showed that both drugs attenuate nicotineinduced increases in DAT function. In this study we show that DHßE, but not MLA, attenuates the decrease in DAT function produced by both nicotine and TPM (Figure 4.5, p79). This suggests that receptors containing the $\beta 2$, but not the $\alpha 7$ subunit, mediate this effect. Furthermore, $\mathrm{DH} \beta \mathrm{E}$ is a moderately selective $\alpha 4$ subunit antagonist, so the $\alpha 4 \beta 2$ nAChRs are likely to be involved in this effect. This receptor subtype is the most abundant subtype in the rat brain and blocking this receptor has previously been shown to attenuate nicotine self-administration in rats (O'Conner et al., 2010). Furthermore, previous studies on the effects of nicotine on DAT function have also shown that DH $\beta E$ attenuates nicotine induced increases in DAT function (Zhu et al., 2009; Drew et al., 2000).

Uptake of DA by DAT is the primary mechanism for clearance of this neurotransmitter from the synapse. With a decrease in DAT function observed here, it can be assumed that there is an excess of DA left in the synapse, although this was not directly measured in this study. Nicotine is known to increase extracellular DA in the NAc (Dichiara and Imperato, 1988), and this study further reports that synaptic DA may be increased via a decrease in uptake. The NAc is the brain's major reward centre and part of the mesolimbic DA system, which all drugs of abuse act on either directly or indirectly. An increase in synaptic DA in the NAc incurs reward and reinforcement and is implicated in the development of drug dependence. This decrease in DAT function observed with nicotine and TPM treatment may, therefore, be one of the mechanisms partially responsible for initiation of smoking dependence. Drugs of abuse such as cocaine and amphetamines have previously been shown to interact with DAT to exert their addictive properties by increasing extracellular DA concentrations. However, nicotine appears to affect DAT function through an indirect mechanism, particularly through $\beta 2$-containing nAChRs. How this effect occurs is not currently known and future studies into the mechanism of nAChR modulation of DAT function would be beneficial. 


\subsubsection{DA uptake and DAT protein expression in the striatum}

The effects of nicotine on DAT function in the striatum are not currently clear. An increase in DAT function has previously been shown to occur in the rat striatum at 10 and 40 min post-treatment (Middleton et al., 2007a); however, Zhu et al. (2009) have also reported no change in $\left[{ }^{3} \mathrm{H}\right] \mathrm{DA}$ uptake in striatal synaptosomes at $30 \mathrm{~min}$. Similarly Carr et al. (1989) found no change in DAT function in the striatum of rats with in vitro or 15 min in vivo nicotine treatment. This indicates that the effects of nicotine on striatal DAT function are both time-dependent and require intact brain circuitry. In the current study the effects of nicotine and TPM were examined with in vitro treatment as well as in vivo treatment at 15 and $30 \mathrm{~min}$, and $1 \mathrm{hr}$. No change in DA uptake in the striatum was observed with in vitro nicotine $(2 \mu \mathrm{M})$ or TPM (containing $2 \mu \mathrm{M}$ nicotine) treatment (Figure 4.1, p71), consistent with the study by Carr et al. (1989). There was also no change found with in vivo nicotine $(0.35 \mathrm{mg} / \mathrm{kg}$ ) or TPM (containing $0.35 \mathrm{mg} / \mathrm{kg}$ nicotine) treatment at 15 (Figure 4.3, p75) or 30 min (Figure 4.6, p80).

Interestingly, treatment with TPM (containing $0.35 \mathrm{mg} / \mathrm{kg}$ nicotine), but not nicotine $(0.35 \mathrm{mg} / \mathrm{kg})$, induced an increase in DAT function in the striatum at $1 \mathrm{hr}$ that was not accompanied by a change in DAT protein expression (Figure 4.8, p85). The $\mathrm{V}_{\max }$ of the TPM group was increased by $40.5 \%$ with no change in $\mathrm{K}_{\mathrm{m}}$, indicating that the change was due to an increase in DAT cell surface expression or catalytic activity. To determine whether the increase in DAT function in response to TPM was nAChR-dependent the non-specific nAChR antagonist mecamylamine was used. Animals were pre-treated with mecamylamine $(1.5 \mathrm{mg} / \mathrm{kg}) 20 \mathrm{~min}$ prior to TPM treatment and function was measured. It was found that the increase in DAT function was not completely attenuated by mecamylamine, with a $\mathrm{V}_{\max }$ value $33 \%$ greater than control for the mecamylamine/TPM group compared to $40.5 \%$ for the PBS/TPM group ( $p<0.05$, Studen't t-test). This difference is marginal and most probably represents no real change between the two groups. Furthermore, because the nicotine group did not differ significantly from control, it can be assumed that the increase in DAT function in response to TPM is due to one or several non-nicotinic components of TPM. This is highly relevant to the molecular biology of smoking addiction, especially because the majority of work conducted on 
smoking addiction has examined nicotine alone. In particular, there have been no previous studies on the effects of a tobacco extract on monoamine transporter function.

Human smokers are exposed to a mixture of compounds more closely resembling an extract such as TPM than nicotine alone. Differences between the two treatment groups are, therefore, significant for the understanding of how human smoking addiction develops. The specific content of TPM used in this study is not currently known. This makes it difficult to speculate on what components in TPM may be responsible for the observed change. As mentioned previously, the MAO inhibitors harman and norharman are known to be present in TPM. Furthermore, the presence of other pharmacologically active compounds such as acetaldehyde and the minor tobacco alkaloids are a probability. Cigarette smoke contains a cocktail of over 4000 different compounds, and it can be assumed that TPM should contain a great number of these. It is possible that a combination of these compounds act additively or synergistically to produce neuroadaptations such as the increase in DAT function observed here. This specific change could be the result of various interactions between TPM constituents and cellular processes in neuronal tissue leading to an indirect effect on DAT. In contrast it is also possible that one or more particular compounds are interacting more directly with DAT; however, this is unlikely given that in vitro TPM treatment had no effect on DAT function in striatal tissue. Future research should address specific compounds and combinations of compounds within TPM that could be responsible for the change observed here.

The mechanism responsible for the observed increase in DAT function in response to TPM is not yet known. It is not nAChR-dependent and could be produced in response to a number of different compounds present in TPM. One possibility is that it could be the result of an increase in DA release induced by TPM. The $\mathrm{D}_{2} \mathrm{DA}$ receptors are known to interact with DAT and modulate its function (Bolan et al., 2007), and excess DA in the synapse could stimulate $\mathrm{D}_{2}$ receptors and thereby cause an increase in DAT function. Dopamine output produced by nicotine and TPM was not measured in this study, and so this theory would need to be confirmed in future experiments. 


\subsubsection{DA uptake by DAT and DAT protein expression in the PFC}

Increases in DA uptake by DAT in the PFC have previously been found in response to nicotine (Middleton et al., 2004; Zhu et al., 2009). In this study, nicotine $(0.35 \mathrm{mg} / \mathrm{kg})$ and TPM (containing $0.35 \mathrm{mg} / \mathrm{kg}$ ) had no significant effect on DA uptake by DAT in the PFC at any acute time point. Furthermore, DAT protein expression in the PFC was not affected by nicotine or TPM at the $1 \mathrm{hr}$ time point (Figure 4.9, p87). This is inconsistent with previous reports and could be accounted for by methodological differences including nicotine dose, and time points examined in the different studies. Using in vivo voltammetry techniques, Middleton et al. (2004) found increases in DA uptake from 10 min following a single $0.14 \mathrm{mg} / \mathrm{kg}$ (free base) nicotine injection, with a maximal increase in uptake at $30 \mathrm{~min}$ post injection. Interestingly, this effect was also dose-dependent and no significant changes in DAT function were found at any other dose ranging from 0.03$0.3 \mathrm{mg} / \mathrm{kg}$. Zhu et al. (2009) found an increase in DAT function in PFC synaptosome at 15 and $30 \mathrm{~min}$ with $0.8 \mathrm{mg} / \mathrm{kg}$ nicotine, but not $0.3 \mathrm{mg} / \mathrm{kg}$ nicotine. This suggests that the effects of nicotine on DAT in the PFC are heavily dose- and time-dependent. No previous studies have examined the effects of TPM on DAT function in the PFC; therefore, it would be useful to investigate more nicotine doses and treatment time-points in future studies.

\subsubsection{DAT protein and mRNA expression in the VTA and SN}

The protein and mRNA expression of DAT was measured in the VTA and SN after $1 \mathrm{hr}$ nicotine $(0.35 \mathrm{mg} / \mathrm{kg})$ and TPM (containing $0.35 \mathrm{mg} / \mathrm{kg}$ ) treatment. It was found that DAT mRNA expression was decreased with both nicotine (4.78 Ct values) and TPM (3.89 $\mathrm{Ct}$ values) treatment in the VTA $1 \mathrm{hr}$ after treatment (Figure 4.10, p89). This corresponds to a decrease in DAT mRNA expression of $96.4 \%$ for nicotine and $93.3 \%$ for TPM. This decrease in DAT mRNA expression is inconsistent with an earlier study by Ferrari et al. (2002) who found no change in DAT mRNA levels in the VTA or SN of rats. However, this study measured mRNA $24 \mathrm{hrs}$ after a single nicotine injection, and so any earlier effects of the injection may have disappeared by this point. As mentioned earlier, the large decreases in mRNA expression found in this study should be interpreted with caution as they may be inflated due to large error in real time PCR experiments. 
There was no corresponding change in DAT protein expression in the $\mathrm{SN}$ at this time point, which further questions the molecular relevance of the observed change. It is possible; however, that the $1 \mathrm{hr}$ time point was not long enough to observe changes in protein expression. As mentioned previously, acute changes in monoamine transporter function are commonly reported to be due to cellular redistribution rather than alterations in overall protein expression. In this study, nicotine and TPM did induce a decrease in DAT protein expression in the $\mathrm{SN}$ following chronic treatment. This suggests that an earlier decrease in mRNA expression may have only been measurable at the protein level at a later time point. Although there was no change in mRNA expression at the chronic time point, the decrease in protein expression at this time could in part be due to a latent effect of earlier mRNA depletion. Further examination into the persistence of the acute depletion of mRNA, as well as investigation of DAT protein expression at more subchronic time points would be required to validate this speculation.

\subsubsection{NET function and expression in the PFC and LC}

There is a severe lack of information in the literature on the effects of nicotine on NET function and expression. NET is responsible for a considerable portion of DA uptake in the PFC, and for this reason DA uptake by NET was measured in the PFC in this study. Zhu et al. (2009) have previously reported finding no change in DA uptake by NET in PFC synaptosomes $30 \mathrm{~min}$ following $0.8 \mathrm{mg} / \mathrm{kg}$ nicotine. We examined DA uptake by NET at $15 \mathrm{~min}, 30 \mathrm{~min}$, and $1 \mathrm{hr}$ following in vivo nicotine and TPM treatment and found no significant change in uptake at any time point. Furthermore, no change in NET protein expression in the PFC or LC, or NET mRNA expression in the LC compared to control, was found at the $1 \mathrm{hr}$ time point (Figure 4.11, p91; Figure 4.12, p92). It is interesting that no difference in NET function was found at the acute time points when an increase in function was seen with chronic nicotine treatment. This suggests that the increase in NET function observed with chronic treatment is time-dependent and occurs only in response to long-term nicotine exposure.

As previously reported for SERT mRNA expression in the DRN following chronic treatment, there was a significant difference in mRNA expression between nicotine $(0.35$ $\mathrm{mg} / \mathrm{kg}$ ) and TPM (containing $0.35 \mathrm{mg} / \mathrm{kg}$ nicotine) treatment groups (Figure 4.12, p92). This was a difference of $1.28 \mathrm{Ct}$ values, corresponding to a $59 \%$ decrease in mRNA 
content in the TPM compared to the nicotine group. This suggests that non-nicotinic components of TPM may have some subtle effects on gene expression in both the DRN and LC. This difference between nicotine and TPM may have no significant effect on mRNA or protein expression compared to control, but, in combination with other subtle changes in gene expression, it could cause a significant change in overall NE tone.

\subsubsection{SERT function and expression in the striatum and DRN}

There has been only one study on the effects of acute nicotine on SERT function to date. Awtry and Werling (2003) found significant increases in SERT $\mathrm{V}_{\max }$ following in vitro nicotine treatment of PFC and hippocampal synaptosomes. In addition, a single 0.7 $\mathrm{mg} / \mathrm{kg}$ nicotine injection produced increases in 5-HT uptake in synaptosomes of the PFC and hippocampus. The current study is the first that has examined the acute effects of nicotine and TPM on SERT function in the striatum. In vitro TPM (containing $2 \mu \mathrm{M}$ nicotine), but not nicotine $(2 \mu \mathrm{M})$, treatment decreased SERT function in the striatum (Figure 4.2, p73). This effect was shown to not be attenuated by mecamylamine, indicating that some component other than nicotine in the TPM was responsible for the change. Furthermore, because this change occurred with in vitro treatment it is possible that a component of TPM is interacting more directly with SERT. However, this was not tested in this study, and it is also possible that a component of TPM is acting on SERT in an indirect manner.

This change with in vitro treatment was not seen with any of the in vivo nicotine or TPM treatment groups, where no change in 5-HT uptake was seen. Due to this, the molecular relevance of the TPM induced decrease in SERT function with in vitro treatment is questionable. The lack of any change in SERT function with in vivo nicotine treatment found in this study contrasts to the increases in SERT $V_{\max }$ described by Awtry and Werling (2003) in PFC and hippocampal synaptosomes in response to nicotine. However, this could be attributed to brain region-specific effects of nicotine in affecting SERT function. No change in SERT protein expression in the striatum or DRN was found, and no change in SERT mRNA expression in the DRN was observed in this study (Figure 4.13, p94; Figure 4.14, p95). This is in agreement with the findings of Semba and 
Wakuta (2008) who found no difference in SERT mRNA expression compared to control following a single $0.5 \mathrm{mg} / \mathrm{kg}$ nicotine injection $2 \mathrm{hrs}$ before sacrifice.

\section{Key Findings}

\section{Nicotine and TPM alter DAT function and expression in the NAc}

The NAc is the brain's major reward centre and all drugs of abuse cause increases in extracellular DA in this region (Vokow et al., 2008). In this study we found a significant decrease in DAT function in the NAc at 30 min post in vivo nicotine $(0.35 \mathrm{mg} / \mathrm{kg})$ and TPM (containing $0.35 \mathrm{mg} / \mathrm{kg}$ nicotine) treatment (Figure 4.4, p77). No previous studies have shown a decrease in DAT function in the NAc in response to nicotine treatment; therefore, this presents a novel mechanism through which nicotine may produce rewarding effects. This decrease would result in a decrease in DA uptake and likely an increase in the reward and reinforcement produced by nicotine. The effect was mecamylamine and $\mathrm{DH} \beta \mathrm{E}$ sensitive, indicating that it is mediated by nAChRs containing the $\beta 2$ subunit (Figure 4.5, p79). DH $\beta E$ has been shown to attenuate nicotine selfadministration in rats (Watkins et al., 1999) and baseline expression of $\alpha 4 \beta 2$ receptors can predict motivation to self-administer in animals (Le Foll et al., 2009). Decreasing DAT function in the NAc, and thus increasing DA availability in the synapse, may be one mechanism through which $\alpha 4 \beta 2$ stimulation produces reward.

It is interesting that with chronic nicotine and TPM treatment there was no change in DA uptake in the NAc, but there was an increase in protein expression (Figure 3.4, p56). It is possible that the initial decrease in DAT function is due to a decrease in catalytic activity of the transporter. Following this, an increase in DAT protein expression with chronic nicotine treatment could be a compensatory mechanism for the loss of functional DAT. This could result in more DAT being expressed on the cell surface to compensate for less functional DAT. Alternatively, the intracellular pool of DAT could be increased and higher turnover of cell surface DAT could occur, ultimately resulting in a return to normal levels of uptake. This would in part explain the initial reinforcing effects of nicotine and the later reinforcement being attributed more to sensory cues such as the taste of tobacco smoke. Cell surface expression of DAT and DA output following 
nicotine and TPM treatment has not been measured in this study. Future studies should examine this to determine whether the above speculation is valid.

\section{TPM causes changes in monoamine transporter function independent of nicotine}

This is the first study to examine the effects of TPM on monoamine transporter function and expression. To do this, we measured the effects of nicotine $(0.35 \mathrm{mg} / \mathrm{kg})$ and dosematched TPM in both acute and chronic models. Interestingly, there were some differences in effect between nicotine and TPM. In the striatum, in vivo TPM treatment increased DAT function at $1 \mathrm{hr}$ where nicotine did not, and this effect was not completely attenuated by mecamylamine pre-treatment (Figure 4.8, p85). This strongly indicates that the effect was independent of the nicotine content in TPM, and must instead be due to one or more non-nicotinic components of TPM. In addition, TPM produced a significant decrease in 5-HT uptake with in vitro nicotine treatment in the striatum that was also not attenuated by mecamylamine pre-treatment (Figure 4.2, p73). It is interesting that both of these differences were found in the striatum, albeit in different neurotransmitter systems. The dorsal striatum is important in habit response learning, an important process in the development of drug addiction (Everitt and Robins, 2005). As mentioned previously, preliminary work in the School of Psychology by Dr Katie Brennan has shown that rats respond more for TPM than nicotine alone (personal communication). This could theoretically be due to neuroadaptations in response to TPM in this region, and future studies on the effects of contingent TPM treatment on striatal DAT and SERT would be a promising direction.

Studying the effects of a tobacco extract such as TPM is preferable to studying nicotine alone in relation to human smoking addiction. Human smokers are exposed to over 4000 components in tobacco smoke (Burns et al., 1991) and recent studies have shown that some of these non-nicotinic constituents may have rewarding properties. In particular, the MAO inhibitors, minor tobacco alkaloids, and acetaldehyde have all been shown to be pharmacologically active (Herraiz and Chaparro, 2005; Middleton et al., 2007a; Foddai et al., 2004) and the minor tobacco alkaloids and acetaldehyde have effects on selfadministration in rats (Clemens et al., 2009; Belluzzi et al., 2005). There is also evidence that tobacco smoke is more rewarding than nicotine in humans (Barrett, 2010; Rose et al., 
2010). Smokers will choose de-nicotinised tobacco smoke over i.v. nicotine (Rose et al., 2010), and de-nicotinised tobacco smoke decreases cigarette craving more than nicotine inhalers (Barrett, 2010). This makes the use of tobacco extracts for the study on smoking addiction highly relevant, and this is the first study to show that TPM has different effects on monoamine transporter function compared to nicotine alone. Further research on the mechanisms responsible for these effects and elucidation of the wider effects of TPM on monoaminergic systems would be an exciting future avenue in smoking research.

\section{Future Directions}

This study has identified several novel brain regions and time points where nicotine and/or TPM affect monoamine transporter function. However it has not examined the mechanisms responsible for the observed changes, and future studies should be directed towards elucidating these mechanisms. The majority of the alterations in monoamine transporter function observed in this study have occurred due to changes in the $V_{\max }$ of monoamine uptake with no change in $\mathrm{K}_{\mathrm{m}}$. Increases or decreases in $\mathrm{V}_{\max }$ with no change in $\mathrm{K}_{\mathrm{m}}$ indicate that the change is due to a change in cell surface expression or catalytic activity of the transporter. To determine whether or not the observed changes were due to a change in cell surface expression, experiments such as synaptosomal biotinylations could be used. This is an established technique, and previous work by Zhu et al. (2009) has shown an increase in DAT function in PFC synaptosomes at $30 \mathrm{~min}$ post nicotine treatment to be due to an increase in cell surface expression using synaptosomal biotinylation techniques. In contrast Middleton et al. (2007a) reported that nicotine induced increases in DA uptake in striatal synaptosomes were not trafficking-dependent. The changes we have reported in this thesis with in vivo treatment were: a decrease in DAT function in the NAc in response to nicotine and TPM; an increase in DAT function in the striatum in response to TPM only; and an increase in DA uptake by NET in the $\mathrm{PFC}$ in response to $3 \mathrm{mg} / \mathrm{kg}$ nicotine. These changes have not been previously been shown; therefore, it is not known whether or not they are trafficking-dependent. Once it has been established whether or not the changes in monoamine transporter function are due to trafficking, investigation into the cell signalling systems responsible for this can be examined. PKC is the most thoroughly studied kinase known to phosphorylate the 
monoamine transporters. It has been shown to down-regulate DAT function through trafficking dependent (Boudanova et al., 2008) and independent mechanisms (Foster et al., 2008), and is one pathway that could be explored.

The decrease in DAT function in the NAc at 30 min with both nicotine and TPM (in vivo treatment) was mecamylamine- and DH $\beta E$-sensitive, indicating that the changes are dependent on $\beta 2$ subunit containing nicotinic receptors. The mechanism by which nAChRs modulate monoamine transporter function is currently unclear, and future studies should be directed accordingly. We have shown that changes in transporter function are not consistent between in vivo and in vitro nicotine and TPM treatment. This indicates that whole brain circuitry is required for the effects to be seen. Therefore, it is unlikely that changes are due to a direct interaction between the nAChRs and monoamine transporters. Instead, signalling pathways involved in this effect could be investigated. Previous research by Awtry et al. (2006) has shown that the PKA inhibitor Rp-cAMP blocked 5-HT uptake following nicotine treatment. Investigation into the role of PKA and other kinases in nAChR modulation of monoamine transporters would be a worthwhile endeavour.

Another possible mechanism for changes observed in DA uptake is interaction of the $\mathrm{D}_{2}$ DA receptor with DAT. $\mathrm{D}_{2}$ DA receptors have previously been shown to interact with DAT (Bolan et al., 2007), and $D_{2} / D_{3}$ receptor agonists increase DA clearance in the striatum (Meiergerd et al., 1993). Tobacco particulate matter, but not nicotine, increased DA uptake by DAT in striatum at $1 \mathrm{hr}$ in this study. A possible mechanism for this effect would be that TPM caused a greater outflow of DA than nicotine alone, stimulating the $\mathrm{D}_{2}$ DA receptors, and resulting in increased DAT function. No previous studies have investigated the effects of a tobacco extract on DA concentrations in discrete brain regions. This could be examined using high-performance liquid chromatography or microdialysis studies to establish whether or not there is increased DA outflow in response to TPM compared to nicotine. Furthermore, pre-treatment with a $\mathrm{D}_{2} \mathrm{DA}$ receptor antagonist prior to TPM treatment could be used to determine the role of $\mathrm{D}_{2} \mathrm{DA}$ receptors in the observed increase in DA uptake in response to TPM. 
This study has found some changes in monoamine transporter function in response to TPM but not nicotine treatment; however, the exact composition of the TPM utilised is not known. It would be beneficial to ascertain what compounds are present in TPM so that directed studies could examine the effects of individual compounds, and combinations of compounds, on the monoamine transporters. In addition, other components of reward-related pathways in the brain could be examined. The levels of specific compounds that are known to be pharmacologically active and likely to be present in TPM could be tested for, including acetaldehyde and the minor tobacco alkaloids. The changes observed with TPM but not nicotine treatment in this study were not completely attenuated by mecamylamine pre-treatment. This strongly indicates that the effects were due to non-nicotinic components of TPM. To further confirm this, a denicotinised TPM solution could be used to determine whether results are comparable to the nicotinised TPM solution.

As well as changes in monoamine transporter function in response to TPM, there were some changes in transporter mRNA expression observed in this study. Chronic TPM, but not nicotine, treatment significantly decreased NET mRNA expression in the LC compared to control. Furthermore, chronic TPM treatment significantly decreased SERT mRNA expression compared to dose matched nicotine, and $1 \mathrm{hr}$ TPM treatment decreased NET mRNA in the LC compared to control. None of these changes resulted in a change in protein expression; however, Western blotting may not detect small changes $(<10 \%)$ in total protein. This indicates that TPM could have subtle effects on gene expression that differ from nicotine alone. While these individual effects appear to have no significant outcome, multiple subtle changes in gene expression with TPM could result in a significant change in overall monoaminergic tone compared to nicotine alone. Gene expression profiles have previously been conducted for nicotine in cell (Konu et al., 2004) and animal models ( $\mathrm{Li}$ et al., 2004d). Similar profiles could be repeated with TPM and compared to nicotine to establish whether TPM causes any significant or profound changes in gene activation. This could lead to the discovery of new molecular targets for study in smoking addiction, and for the development of smoking cessation therapies. 
As mentioned previously, contingent TPM administration in rats has been established, and preliminary results show that animals respond for TPM more than nicotine alone (Katie Brennan, personal communication). Contingency has previously been shown to affect drug produced neuroadaptations (Dworkin et al., 1995; Stefanski et al., 1999; Jacobs et al., 2003); therefore, comparisons of molecular data from animals that have selfadministered TPM to the findings from non-contingent animals used in this study would be of interest. Furthermore, examination of other reward-related cellular mechanisms in contingent animals could be conducted. This could include assessment of monoamine oxidase activity, nAChR expression, monoamine receptor expression, and studies on other neural circuitry such and GABA and glutamatergic systems.

It is well established that there are differences in response to drugs of abuse between adult and adolescent subjects in animal models of addiction (Schramm-Sapyta et al., 2009). In humans, adolescence is associated with high rates of initiation in drug taking, and increased risk of developing drug dependence (Laviola et al., 1999). This is true for smoking, with approximately $75 \%$ of adult smokers reporting that they first began smoking between 11 and 17 years of age (Eissenberg and Balster, 2000). It has been previously shown that acetaldehyde, which is present in the combustion products of tobacco, increases nicotine self-administration in adolescent, but not adult rats. Investigating the effects of TPM compared to nicotine alone in an adolescent animal model would be highly significant. This would include both the self-administering behaviour of adolescent animals compared to adults, and the molecular changes resultant from exposure to TPM. Findings from this could aid in the development of smoking cessation agents or preventative measures tailored specifically towards adolescents.

Finally, there is currently a lack of information in the literature on the effects of nicotine on NET, despite the fact that bupropion works in part by blocking NET (Dwoskin et al, 2006). This study has shown that nicotine (3 mg/kg) increases DA uptake by NET in the PFC following chronic treatment. It would be beneficial to study the effects of NE uptake by NET in the PFC and other areas of the brain. Several anti-depressants that affect the function of NET are currently being trialled as smoking cessation therapies. These therapies could be better targeted to find the most effective treatment with a greater 
understanding of the effects of nicotine and tobacco smoke on cellular components such as NET.

\section{Overall Significance}

Cigarette smoking is the single largest cause of preventable mortality worldwide (WHO, 2011). Despite this, smoking addiction at the molecular level is still poorly understood, and current smoking cessation aids are only marginally effective (Jorenby, 2006; Balfour et al., 2000a). The majority of smoking research to date has been conducted on nicotine alone; however, there are over 4000 chemicals present in tobacco smoke. Some of these chemicals have been shown to be pharmacologically active and to be self-administered in animal models. Previous studies on the effects of nicotine on monoamine transporters have shown that nicotine does, in some cases, modulate their function, and that this effect is dependent on nAChRs. However, the current literature is often contradictory and more research is needed to develop a better understanding of how nicotine affects the monoamine transporters. This thesis has examined the effects of nicotine and dosematched TPM on the monoamine transporters. It is the first study to investigate the effects of a tobacco extract on monoamine transporters, and has found some differences between the effects of TPM and nicotine alone. This is highly important because human smokers are exposed to tobacco smoke, not nicotine alone, and these findings contribute to a growing body of evidence that non-nicotinic components of cigarette smoke may contribute to tobacco addiction. This is also the first study to report a nicotine-induced decrease in DAT function in the NAc, which could contribute to the initial rewarding effects of cigarette smoking. Findings from this study have contributed to the understanding of the molecular biology of smoking addiction, which could in future lead to the development of more effective smoking cessation therapies. Furthermore, these findings have highlighted the use of TPM as an exciting new avenue for studying smoking addiction. 


\section{Appendices}

\section{Appendix I: Solutions}

$10 \times$ Phosphate Buffered Saline (PBS) pH 7.4

$\begin{array}{lll} & \text { Concentration } & \mathrm{g} / \mathrm{L} \\ \mathrm{NaCl} & 1.4 \mathrm{M} & 80 \\ \mathrm{KCl} & 26.8 \mathrm{mM} & 2.0 \\ \mathrm{Na}_{2} \mathrm{HPO}_{4} & 81.0 \mathrm{mM} & 26.8 \\ \mathrm{KH}_{2} \mathrm{PO}_{4} & 14.7 \mathrm{mM} & 2.4\end{array}$

$\underline{\text { KREBS Buffer } \mathrm{pH} 7.4}$

$\begin{array}{lll} & \text { Concentration } & \mathrm{g} / \mathrm{L} \\ \mathrm{NaCl} & 130 \mathrm{mM} & 7.6 \\ \mathrm{KCl} & 1.3 \mathrm{mM} & 0.10 \\ \mathrm{CaCl}_{2} & 2.2 \mathrm{mM} & 0.24 \\ \mathrm{MgSO}_{4} \cdot 6 \mathrm{H}_{2} \mathrm{O} & 1.2 \mathrm{mM} & 0.27 \\ \mathrm{KH}_{2} \mathrm{PO}_{4} & 1.2 \mathrm{mM} & 0.16 \\ \mathrm{HEPES} & 10 \mathrm{mM} & 2.6 \\ \text { D-Glucose } & 10 \mathrm{mM} & 1.8\end{array}$

$\underline{\text { RIPA buffer } \mathrm{pH} 7.5}$

$\begin{array}{lll} & \text { Concentration } & \mathrm{g} / \mathrm{L} \\ \text { Tris-HCl } & 10 \mathrm{mM} & 1.2 \\ \mathrm{NaCl} & 150 \mathrm{mM} & 8.766 \\ \text { EDTA } & 1 \mathrm{mM} & 0.37 \\ \text { Triton-X-100 } & 1 \% & 10 \mathrm{~mL} \\ \text { SDS } & 0.1 \% & 1.0\end{array}$

Sodium deoxycholate $1 \%$

10 
$\underline{5 \times \text { Reducing buffer }}$

Concentration

Tris-HCl, pH $6.8 \quad 62.5 \mathrm{mM}$

SDS $2 \%$

Glycerol $20 \%$

Bromophenol Blue $1 \%$

$\underline{\text { Gels }}$

Enough for 2 gels

$10 \%$ Separating Gel

$\mathrm{dH} 2 \mathrm{O} \quad 8 \mathrm{~mL}$

1.5 M Tris pH $8.8 \quad 5 \mathrm{~mL}$

$10 \%$ SDS $200 \mu \mathrm{L}$

Acrylamide (30\% acrylamide/Bis solution) $\quad 6.66 \mathrm{~mL}$

$10 \%$ APS $100 \mu \mathrm{L}$

TEMED $10 \mu \mathrm{L}$

The gel was layered with $100 \%$ isopropanol while setting, which was then poured off prior to addition of the stacking gel.

4\% Stacking Gel

$\mathrm{dH} 2 \mathrm{O} \quad 6.1 \mathrm{~mL}$

$0.5 \mathrm{M}$ Tris pH 6.8

$10 \%$ SDS $\quad 100 \mu \mathrm{L}$

Acrylamide $\quad 1.33 \mathrm{~mL}$

$10 \%$ APS $\quad 50 \mu \mathrm{L}$

TEMED $10 \mu \mathrm{L}$

10 x Running buffer

$\begin{array}{lll} & \text { Concentration } & \mathrm{g} / \mathrm{L} \\ \mathrm{SDS} & 35 \mathrm{mM} & 10 \\ \text { Tris-HCl } & 250 \mathrm{mM} & 30.3 \\ \text { Glycine } & 1.9 \mathrm{M} & 144.1\end{array}$


$\underline{\text { Western Transfer Buffer }}$

$\begin{array}{lll} & \text { Concentration } & \mathrm{g} / \mathrm{L} \\ \text { Glycine } & 190 \mathrm{mM} & 14.4 \\ \text { Tris-HCl } & 25 \mathrm{mM} & 3.03 \\ \text { Methanol } & 20 \% & 200 \mathrm{~mL}\end{array}$

$\underline{10 \times \mathrm{TBS} p H 7.5}$

$\begin{array}{lll} & \text { Concentration } & \mathrm{g} / \mathrm{L} \\ \text { TrisHCl } & 500 \mathrm{mM} & 60.5 \\ \mathrm{NaCl} & 1.5 \mathrm{M} & 87.6\end{array}$

\section{$\underline{\text { T-TBS }}$}

$1 \times$ TBS containing $0.1 \%$ Tween-20

Stripping buffer

SDS $\quad 69 \mathrm{mM}, 20 \mathrm{~g} / \mathrm{L}$

0.05 M TrisHCl, pH 6.8 $992.5 \mathrm{~mL}$

$\beta$-mercaptoethanol $\quad 7.5 \mathrm{~mL}$

$\underline{50 \times \mathrm{TAE}}$

TrisHCl $242 \mathrm{~g} / \mathrm{L}$

0.5 $\mathrm{M} \mathrm{Na}_{2}$ EDTA (pH8.0) $100 \mathrm{~mL}$

Glacial acetic acid $\quad 57.1 \mathrm{~mL}$

$\underline{1 \times \mathrm{TE}}$

$\begin{array}{ll}1 \mathrm{M} \text { Tris (pH8.0) } & 10 \mathrm{~mL} \\ 0.5 \mathrm{M} \mathrm{Na}_{2} \text { EDTA (pH8.0) } & 2 \mathrm{~mL} \\ \mathrm{dH}_{2} \mathrm{O} & 88 \mathrm{~mL}\end{array}$




\section{Appendix II: Representative Western blots}

Western blots were performed to measure the total protein present in brain tissue lysates using specific antibodies for DAT, NET, SERT, and the housekeeper protein $\alpha$-tubulin. Distinct bands were found with the use of each antibody that corresponded to an expected size for the proteins (Figure A2.1). Non-specific binding in other parts of the membrane was minimal. A control blot of samples with secondary antibody only was also performed to check for non-specific binding (Figure A2.1 E). This showed minimal nonspecific binding of the secondary antibody to protein in the membrane. 
A

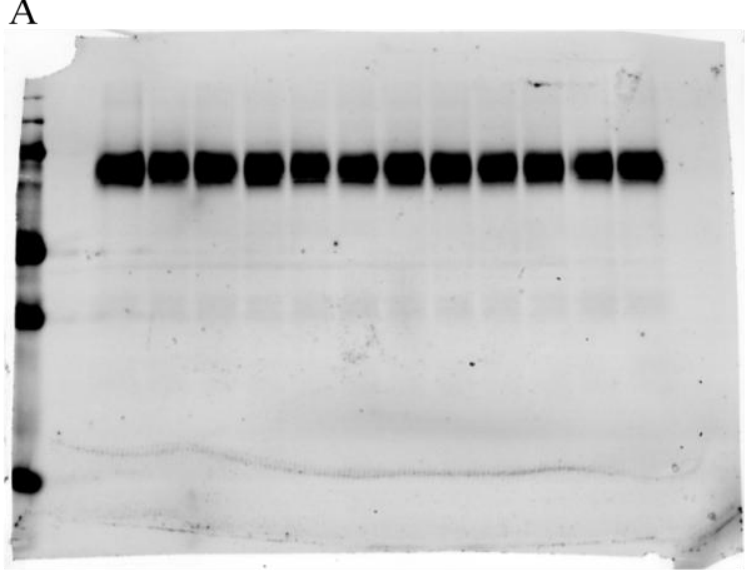

$\mathrm{C}$

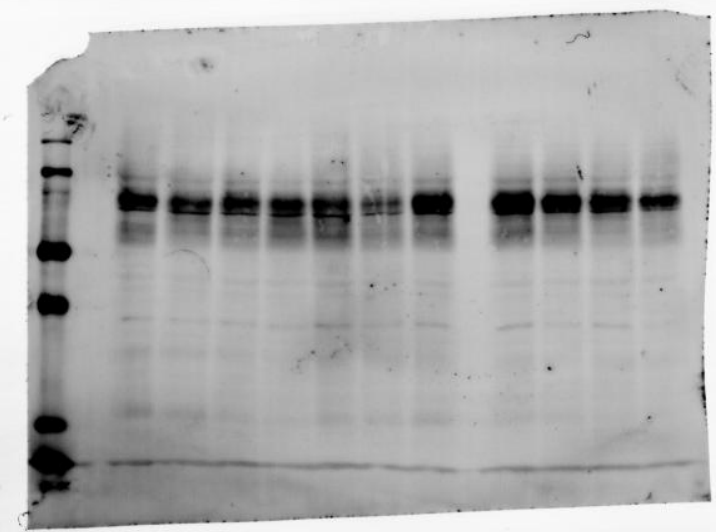

$\mathrm{E}$

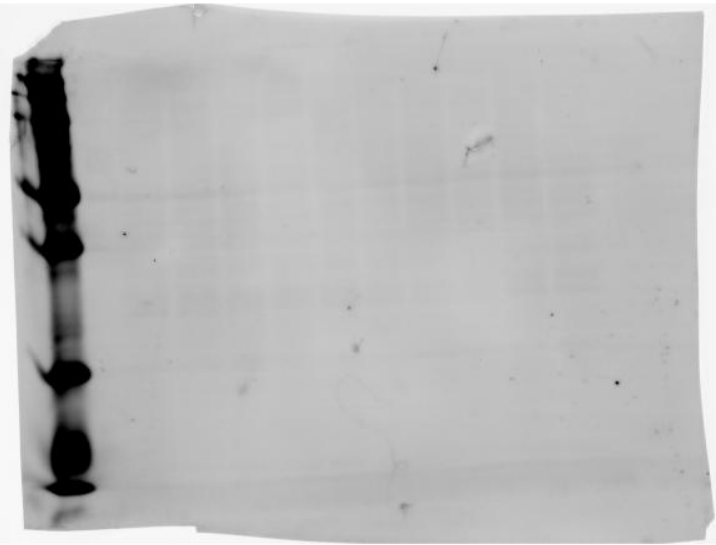

B

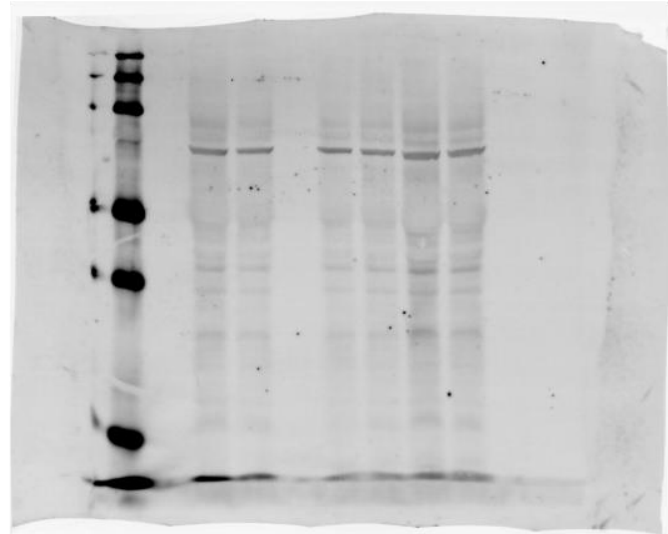

$\mathrm{D}$

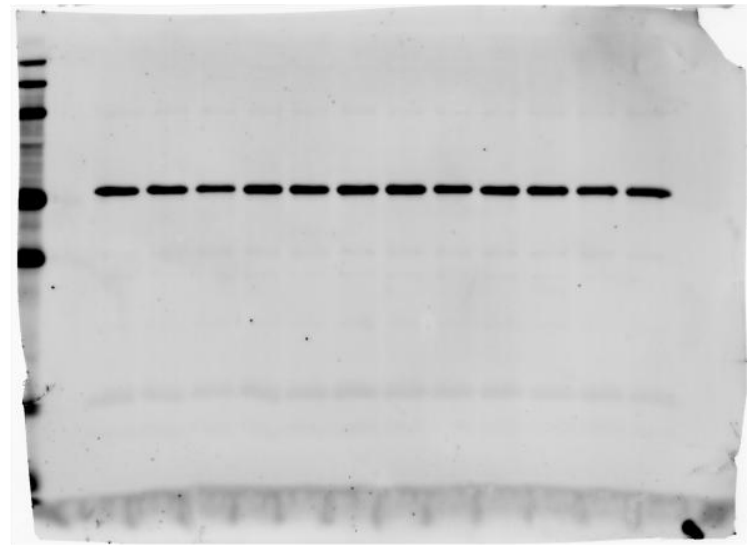

Figure A2.1: Representative Western blots for antibodies used in this study.

Antibodies used for DAT (75-80 kDa) (A), NET (75 kDa) (B), SERT (70-75 kDa) (C) and tubulin $(50 \mathrm{kDa})$ (D) all showed distinct bands corresponding to expected protein sizes; (E) shows a membrane probed with secondary antibody only. 


\section{Appendix III: Cyclophilin A mRNA expression across treatment groups}

The mean $\mathrm{Ct}$ value for cyc A was compared across treatment groups for each real time PCR experiment to ensure that there was no significant difference between treatment groups. Statistical analysis showed no significant change (one-way ANOVA with Bonferroni post-hoc analysis). From this we concluded that nicotine and TPM did not affect cyc A mRNA expression. This validated the use of cyc A as a housekeeper gene for real time PCR experiments. Mean Ct values for cyc A in chronic and acute treatments are shown in Table A3.1 and Table A3.2 respectively.

Table A3.1: Mean cyc A Ct values for chronic nicotine and TPM treatments.

\begin{tabular}{|l|l|l|l|l|}
\cline { 2 - 5 } \multicolumn{1}{c|}{} & Control & $\begin{array}{l}\text { Nicotine } \\
(0.35 \mathrm{mg} / \mathrm{kg})\end{array}$ & $\begin{array}{l}\text { Nicotine } \\
(3 \mathrm{mg} / \mathrm{kg})\end{array}$ & $\begin{array}{l}\text { TPM (containing } \\
0.35 \mathrm{mg} / \mathrm{kg} \text { nicotine) }\end{array}$ \\
\hline VTA & $13.6 \pm 0.5$ & $13.2 \pm 0.3$ & $14.0 \pm 0.3$ & $13.7 \pm 0.4$ \\
\hline SN & $13.3 \pm 0.7$ & $13.2 \pm 0.5$ & $13.3 \pm 0.7$ & $14.0 \pm 0.5$ \\
\hline LC & $13.8 \pm 0.5$ & $13.8 \pm 0.5$ & $14.1 \pm 0.3$ & $13.3 \pm 0.4$ \\
\hline DRN & $15.2 \pm 1.2$ & $14.6 \pm 1.2$ & $14.9 \pm 0.3$ & $14.4 \pm 1.0$ \\
\hline
\end{tabular}

Values represent mean \pm SEM.

Table A3.2: Mean cyc A Ct values for acute nicotine and TPM treatments.

\begin{tabular}{|l|l|l|l|}
\cline { 2 - 4 } \multicolumn{1}{c|}{} & Control & Nicotine $(0.35 \mathrm{mg} / \mathrm{kg})$ & $\begin{array}{l}\text { TPM } \\
\text { (containing } 0.35 \mathrm{mg} / \mathrm{kg} \text { nicotine })\end{array}$ \\
\hline VTA & $19.5 \pm 0.9$ & $18.9 \pm 1.6$ & $19.1 \pm 0.9$ \\
\hline SN & $18.1 \pm 0.8$ & $17.8 \pm 0.8$ & $17.7 \pm 0.6$ \\
\hline LC & $16.7 \pm 0.3$ & $17.3 \pm 0.5$ & $16.9 \pm 0.3$ \\
\hline DRN & $17.6 \pm 0.3$ & $18.4 \pm 1.5$ & $17.4 \pm 1.1$ \\
\hline
\end{tabular}

Values represent mean \pm SEM. 


\section{References}

Ambrose V, Miller JH, Dickson SJ, Hampton S, Truman P, Lea RA, Fowles J. 2007. Tobacco particulate matter is more potent than nicotine at upregulating nicotinic receptors on SH-SY5Y cells. Nicotine \& Tobacco Research 9(8):793-799.

Amit Z, Smith BR. 1985. A multi-dimensional examination of the positive reinforcing properties of. Alcohol 2(2):367-370.

Anand R, Conroy WG, Schoepfer R, Whiting P, Lindstrom J. 1991. Neuronal nicotinic acetylcholine-receptors expressed in Xenopus oocytes have a pentameric quaternary structure. Journal of Biological Chemistry 266(17):11192-11198.

and clinical profile of bupropion, an antidepressant and tobacco use cessation agent. CNS Drug Reviews 12(3-4):178-207.

Anderson DJ, Puttfarcken PS, Jacobs I, Faltynek C. 2000. Assessment of nicotinic acetylcholine receptor-mediated release of [H-3]-norepinephrine from rat brain slices using a new 96-well format assay. Neuropharmacology 39(13):2663-2672.

Andreasen JT, Nielsen EO, Redrobe JP. 2009. Chronic oral nicotine increases brain [H3 ] epibatidine binding and responsiveness to antidepressant drugs, but not nicotine, in the mouse forced swim test. Psychopharmacology 205(3):517-528.

Apparsundaram S, Sung UH, Price RD, Blakely RD. 2001. Trafficking-dependent and independent pathways of neurotransmitter transporter regulation differentially involving p38 mitogen-activated protein kinase revealed in studies of insulin modulation of norepinephrine transport in SK-N-SH cells. Journal of Pharmacology and Experimental Therapeutics 299(2):666-677.

Arib O, Rat P, Molimard R, Chait A, Faure P, de Beaurepaire R. 2010. Electrophysiological characterization of harmane-induced activation of mesolimbic dopamine neurons. European Journal of Pharmacology 629(1-3):47-52.

Arinami T, Ishiguro H, Onaivi ES. 2000. Polymorphisms in genes involved in neurotransmission in relation to smoking. European Journal of Pharmacology 410(23):215-226.

Awtry TL, Frank JG, Werling LL. 2006. In vitro regulation of serotonin transporter activity by protein kinase $\mathrm{A}$ and nicotinic acetylcholine receptors in the prefrontal cortex of rats. Synapse 59(6):342-349.

Awtry TL, Werling LL. 2003. Acute and chronic effects of nicotine on serotonin uptake in prefrontal cortex and hippocampus of rats. Synapse 50(3):206-211.

Babu DK, Diaz A, Samikkannu T, Rao KVK, Saiyed ZM, Rodriguez JW, Nair MPN. 2009. Upregulation of Serotonin Transporter by Alcohol in Human Dendritic Cells: Possible Implication in Neuroimmune Deregulation. Alcoholism 33(10):1731-1738.

Balfour D, Benowitz N, Fagerstrom K, Kunze M, Keil U. 2000a. Diagnosis and treatment of nicotine dependence with emphasis on nicotine replacement therapy - A status report. European Heart Journal 21(6):438-445.

Balfour DJK, Ridley DL. 2000c. The effects of nicotine on neural pathways implicated in depression: A factor in nicotine addiction? Pharmacology Biochemistry and Behavior 66(1):79-85.

Balfour DJK, Wright AE, Benwell MEM, Birrell CE. 2000b. The putative role of extrasynaptic mesolimbic dopamine in the neurobiology of nicotine dependence. Behavioural Brain Research 113(1-2):73-83.

Balfour DJK. 2002. The neurobiology of tobacco dependence: A commentary. 
Bardo MT, Green TA, Crooks PA, Dwoskin LP. 1999. Nornicotine is self-administered intravenously by rats. Psychopharmacology 146(3):290-296.

Barrett SP, Boileau I, Okker J, Pihl RO, Dagher A. 2004. The hedonic response to cigarette smoking is proportional to dopamine release in the human striatum as measured by positron emission tomography and [C-11]raclopride. Synapse 54(2):65-71.

Barrett SP. 2010. The effects of nicotine, denicotinized tobacco, and nicotine-containing tobacco on cigarette craving, withdrawal, and self-administration in male and female smokers. Behavioural Pharmacology 21(2):144-152.

Batchelor M, Schenk JO. 1998. Protein kinase A activity may kinetically upregulate the striatal transporter for dopamine. Journal of Neuroscience 18(24):10304-10309.

Belluzzi JD, Wang RH, Leslie FM. 2005. Acetaldehyde enhances acquisition of nicotine self-administration in adolescent rats. Neuropsychopharmacology 30(4):705-712.

Benowitz NL. 1995. Acute biological effects of nicotine and its metabolites. In: Clarke PBS, Quik M, Adlkofer F, Thurau K, editors. Effects of Nicotine on Biological Systems Ii. p. 9-16.

Bitner RS, Nikkel AL. 2002. Alpha-7 nicotinic receptor expression by two distinct cell types in the dorsal raphe nucleus and locus coeruleus of rat. Brain Res 938(1-2):45-54.

Blakely RD, Defelice LJ, Hartzell HC. 1994. Molecular Physiology of Norepinephrine and Serotonin Transporters. Journal of Experimental Biology 196:263-281.

Blondal T, Gudmundsson LJ, Tomasson K, Jonsdottir D, Hilmarsdottir H, Kristjansson F, Nilsson F, Bjornsdottir US. 1999. The effects of fluoxetine combined with nicotine inhalers in smoking cessation - a randomized trial. Addiction 94(7):1007-1015.

Bolan EA, Kivell B, Jaligam V, Oz M, Jayanthi LD, Han Y, Sen N, Urizar E, Gomes I, Devi LA, Ramamoorthy S, Javitch JA, Zapata A, Shippenberg TS. 2007. D-2 receptors regulate dopamine transporter function via an extracellular signal-regulated kinases 1 and 2-dependent and phosphoinositide 3 kinase-independent mechanism. Mol Pharmacol 71(5):1222-1232.

Bortolato M, Chen K, Shih JC. 2008. Monoamine oxidase inactivation:

Boudanova E, Navaroli DM, Stevens Z, Melikian HE. 2008. Dopamine transporter endocytic determinants: Carboxy terminal residues critical for basal and PKCstimulated internalization. Mol Cell Neurosci 39(2):211-217.

Boules M, Oliveros A, Liang YQ, Williams K, Shaw A, Robinson J, Fredrickson P, Richelson E. 2010. A neurotensin analog, NT69L, attenuates intravenous nicotine self-administration in rats. Neuropeptides 45(1):9-16.

Bozarth MA, Pudiak CM, KuoLee R. 1998. Effect of chronic nicotine on brain stimulation reward I. Effect of daily injections. Behavioural Brain Research 96(1-2):185-188.

Brennan KA, Lea RA, Fitzmaurice PS, Truman P. 2010. Nicotinic receptors and stages of nicotine dependence. Journal of Psychopharmacology 24(6):793-808.

Burnette WB, Bailey MD, Kukoyi S, Blakely RD, Trowbridge CG, Justice JB. 1996. Human norepinephrine transporter kinetics using rotating disk electrode voltammetry. Analytical Chemistry 68(17):2932-2938.

Burns DM. 1991. CIGARETTES AND CIGARETTE-SMOKING. Clin Chest Med 12(4):631-642.

Butler SG, Meegan MJ. 2008. Recent developments in the design of anti-depressive therapies: Targeting the serotonin transporter. Current Medicinal Chemistry 15(17):1737-1761.

Carboni E, Silvagni A, Vacca C, Di Chiara G. 2006. Cumulative effect of norepinephrine and dopamine carrier blockade on extracellular dopamine increase in the nucleus accumbens shell, bed nucleus of stria terminalis and prefrontal cortex. Journal of Neurochemistry 96(2):473-481. 
Carr LA, Rowell PP, Pierce WM. 1989. Effects of Subchronic Nicotine Administration on Central Dopaminergic Mechanisms in the Rat. Neurochemical Research 14(6):511515.

Chi LM, Reith MEA. 2003. Substrate-induced trafficking of the dopamine transporter in heterologously expressing cells and in rat striatal synaptosomal preparations. Journal of Pharmacology and Experimental Therapeutics 307(2):729-736.

Christman AK, Fermo JD, Markowitz JS. 2004. Atomoxetine, a novel treatment for attention-deficit-hyperactivity disorder. Pharmacotherapy 24(8):1020-1036.

Ciliax BJ, Drash GW, Staley JK, Haber S, Mobley CJ, Miller GW, Mufson EJ, Mash DC, Levey AI. 1999. Immunocytochemical localization of the dopamine transporter in human brain. Journal of Comparative Neurology 409(1):38-56.

Clarke H, Flint J, Attwood AS, Munafo MR. 2010. Association of the 5-HTTLPR genotype and unipolar depression: a meta-analysis. Psychological Medicine 40(11):1767-1778.

Clemens KJ, Caille S, Stinus L, Cador M. 2009. The addition of five minor tobacco alkaloids increases nicotine-induced hyperactivity, sensitization and intravenous selfadministration in rats. International Journal of Neuropsychopharmacology 12(10):1355-1366.

Coe JW, Brooks PR, Vetelino MG, Wirtz MC, Arnold EP, Huang JH, Sands SB, Davis TI, Lebel LA, Fox CB, Shrikhande A, Heym JH, Schaeffer E, Rollema H, Lu Y, Mansbach RS, Chambers LK, Rovetti CC, Schulz DW, Tingley FD, O'Neill BT. 2005. Varenicline: An alpha 4 beta 2 nicotinic receptor partial agonist for smoking cessation. Journal of Medicinal Chemistry 48(10):3474-3477.

Corcoran ME, Kroes RA, Burgdorf JS, Moskal JR. Regional Changes in Gene Expression after Limbic Kindling. Cell Mol Neurobiol 31(6):819-834.

Cordeiro Q, Siqueira-Roberto J, Vallada H. 2010. Association between the SLC6A3 A1343G polymorphism and schizophrenia. Arquivos De Neuro-Psiquiatria 68(5):716-719.

Corrigall WA, Coen KM. 1989. Nicotine maintains robust self-administration in rats on a limited-access scheduleI. Psychopharmacology 99(4):473-478.

Cousins MS, Stamat HM, de Wit H. 2001. Acute doses of d-amphetamine and bupropion increase cigarette smoking. Psychopharmacology 157(3):243-253.

Crooks PA, Li M, Dwoskin LP. 1997. Metabolites of nicotine in rat brain after peripheral nicotine administration - Cotinine, nornicotine, and norcotinine. Drug Metabolism and Disposition 25(1):47-54.

Danielson K, Truman P, Kivell BM. 2011. The Effects of Nicotine and Cigarette Smoke on the Monoamine Transporters. Synapse 65(9):866-879.

Database Systematic Review (1):77

Daws LC, Callaghan PD, Moron JA, Kahlig KM, Shippenberg TS, Javitch JA, Galli A. 2002. Cocaine increases dopamine uptake and cell surface expression of dopamine transporters. Biochemical and Biophysical Research Communications 290(5):15451550.

De Biasi M, Dani JA. 2011. Reward, Addiction, Withdrawal to Nicotine. In: Hyman SE, Jessell TM, Shatz CJ, Stevens CF, Zoghbi HY, editors. Annual Review of Neuroscience, Vol 34. Palo Alto: Annual Reviews. p. 105-130.

Deutch AY, Holliday J, Roth RH, Chun LLY, Hawrot E: Immunohistochemical localization of a neuronal nicotinic acetylcholine-receptor in mammalian brain. Proceedings of the National Academy of Sciences of the United States of America 1987, 84:86978701. 
Di Matteo V, Cacchio M, Di Giulio C, Esposito E. 2002. Role of serotonin(2C) receptors in the control of brain dopaminergic function. Pharmacology Biochemistry and Behavior 71(4):727-734.

Di Matteo V, Pierucci M, Di Giovanni G, Benigno A, Esposito E. 2007. The neurobiological bases for the pharmacotherapy of nicotine addiction. Current Pharmaceutical Design 13(12):1269-1284.

Dichiara G, Imperato A. 1988. Drugs abused by humans preferentially increase synaptic dopamine concentrations in the mesolimbic system of freely moving rats. Proceedings of the National Academy of Sciences of the United States of America 85(14):5274-5278.

Dichiara G, Tanda GL, Frau R, Carboni E. 1992. HETEROLOGOUS MONOAMINE REUPTAKE - LACK OF TRANSMITTER SPECIFICITY OF NEURONSPECIFIC CARRIERS. Neurochemistry International 20:S231-S235.

Dipace C, Sung U, Binda F, Blakely RD, Galli A. 2007. Amphetamine induces a calcium/calmodulin-dependent protein kinase II-dependent reduction in norepinephrine transporter surface expression linked to changes in syntaxin 1A/transporter complexes. Mol Pharmacol 71(1):230-239.

Dougherty JJ, Nichols RA. 2009. Cross-regulation between colocalized nicotinic acetylcholine and 5-HT3 serotonin receptors on presynaptic nerve terminals. Acta Pharmacologica Sinica 30(6):788-794.

Drew AE, Derbez AE, Werling LL. 2000. Nicotinic receptor-mediated regulation of dopamine transporter activity in rat prefrontal cortex. Synapse 38(1):10-16.

Drew AE, Werling LL. 2001. Protein kinase C regulation of dopamine transporter initiated by nicotinic receptor activation in slices of rat prefrontal cortex. Journal of Neurochemistry 77(3):839-848.

Drew AE, Werling LL. 2003. Nicotinic receptor-mediated regulation of the dopamine transporter in rat prefrontocortical slices following chronic in vivo administration of nicotine. Schizophrenia Research 65(1):47-55.

Dworkin SI, Co C, Smith JE (1995) Rat brain neurotransmitter turnover rates altered during withdrawal from chronic cocaine administration. Brain Res 682:116-126.

Dwoskin LP, Rauhut AS, King-Pospisil KA, Bardo MT. 2006. Review of the pharmacology

Dwoskin LP, Teng LH, Crooks PA. 2001. Nornicotine, a nicotine metabolite and tobacco alkaloid: desensitization of nicotinic receptor-stimulated dopamine release from rat striatum. European Journal of Pharmacology 428(1):69-79.

Earles C, Wayment H, Green M, Schenk JO. 1998. Resolution of biogenic amine transporter kinetics by rotating disk electrode voltammetry: Methodology and mechanistic interpretations. Neurotransmitter Transporters 296:660-675.

Eissenberg T, Balster RL. 2000. Initial tobacco use episodes in children and adolescents: current knowledge, future directions. Drug Alcohol Depend 59:S41-S60.

Etter JF. 2006. Cytisine for smoking cessation - A literature review and a meta-analysis. Archives of Internal Medicine 166(15):1553-1559.

Everitt BJ, Robbins TW. 2005. Neural systems of reinforcement for drug addiction: from actions to habits to compulsion. Nature Neuroscience 8(11):1481-1489.

Fagerstrom K. 2002. The epidemiology of smoking - Health consequences and benefits of cessation. Drugs 62:1-9.

Fekkes D, Bode WT (1993) Occurrence and partition of the beta-carboline norharman in rat organs. Life Sci 52:2045-2054.

Ferrari R, Le Novere N, Picciotto MR, Changeux JP, Zoli M. 2002. Acute and long-term changes in the mesolimbic dopamine pathway after systemic or local single nicotine injections. European Journal of Neuroscience 15(11):1810-1818. 
Fletcher PJ, Le AD, Higgins GA. 2008. Serotonin receptors as potential targets for modulation of nicotine use and dependence. Serotonin-Dopamine Interaction: Experimental Evidence and Therapeutic Relevance. p. 361-383.

Foddai M, Dosia G, Spiga S, Diana M. 2004. Acetaldehyde increases dopaminergic neuronal activity in the VTA. Neuropsychopharmacology 29(3):530-536.

Foster JD, Adkins SD, Lever JR, Vaughan RA. 2008. Phorbol ester induced traffickingindependent regulation and enhanced phosphorylation of the dopamine transporter associated with membrane rafts and cholesterol. Journal of Neurochemistry 105(5):1683-1699.

Fowles J, Dybing E. 2003. Application of toxicological risk assessment principles to the chemical constituents of cigarette smoke. Tobacco Control 12(4):424-430.

Franke B, Hoogman M, Vasquez AA, Heister J, Savelkoul PJ, Naber M, Scheffer H, Kiemeney LA, Kan CC, Kooij JJS, Buitelaar JK. 2008. Association of the Dopamine Transporter (SLC6A3/DAT1) Gene 9-6 Haplotype With Adult ADHD. American Journal of Medical Genetics Part B-Neuropsychiatric Genetics 147B(8):1576-1579. From pathophysiology to therapeutics. Advanced Drug Delivery Reviews 60(1314):1527-1533.

Gainetdinov RR, Caron MG. 2003. Monoamine transporters: From genes to behavior. Annual Review of Pharmacology and Toxicology 43:261-284.

Gerra G, Garofano L, Zaimovic A, Moi G, Branchi B, Bussandri M, Brambilla F, Donnini C. 2005. Association of the serotonin transporter promoter polymorphism with smoking behavior among adolescents. American Journal of Medical Genetics Part BNeuropsychiatric Genetics 135B(1):73-78.

Goddard AW, Ball SG, Martinez J, Robinson MJ, Yang CR, Russell JM, Shekhar A. CURRENT PERSPECTIVES OF THE ROLES OF THE CENTRAL NOREPINEPHRINE SYSTEM IN ANXIETY AND DEPRESSION. Depression and Anxiety 27(4):339-350.

Gray KM, Upadhyaya HP. 2009. Tobacco Smoking in Individuals with Attention-Deficit Hyperactivity Disorder Epidemiology and Pharmacological Approaches to Cessation. Cns Drugs 23(8):661-668.

Green TA, Crooks PA, Bardo MT, Dwoskin LP. 2001. Contributory role for nornicotine in nicotine neuropharmacology: nornicotine-evoked [H-3]dopamine overflow from rat nucleus accumbens slices. Biochemical Pharmacology 62(12):1597-1603.

Gu H, Wall SC, Rudnick G. 1994. Stable expression of biogenic-amine transporters reveals differences in inhibitor sensitivity, kinetics, and ion dependence. Journal of Biological Chemistry 269(10):7124-7130.

Guillem K, Vouillac C, Azar MR, Parsons LH, Koob GF, Cador M, Stinus L. 2006. Monoamine oxidase A rather than monoamine oxidase B inhibition increases nicotine reinforcement in rats. European Journal of Neuroscience 24(12):3532-3540.

Guillem K, Vouillac C, Azar MR, Parsons LH, Koob GF, Cador M, Stinus L. 2005. Monoamine oxidase inhibition dramatically increases the motivation to selfadminister nicotine in rats. Journal of Neuroscience 25(38):8593-8600.

Hadjiconstantinou M, Duchemin AM, Zhang HL, Neff NH. 2010. Enhanced Dopamine Transporter Function in Striatum During Nicotine Withdrawal. Synapse 65(2):91-98.

Hagan CE, Neumaier JF, Schenk JO. 2010. Rotating disk electrode voltammetric measurements of serotonin transporter kinetics in synaptosomes. Journal of Neuroscience Methods 193(1):29-38.Hajek P, West R, Foulds J, Nilsson F, Burrows S, Meadow A. 1999. Randomized comparative trial of nicotine polacrilex, a transdermal patch, nasal spray, and an inhaler. Archives of Internal Medicine 159(17):2033-2038. 
Hall SM, Humfleet GL, Reus VI, Munoz RF, Hartz DT, Maude-Griffin R. 2002. Psychological intervention and antidepressant treatment in smoking cessation. Archives of General Psychiatry 59(10):930-936.

Hara K, Harris RA. 2002. The anesthetic mechanism of urethane: The effects on rotransmitter-gated ion channels. Anesth Analg 94(2):313-318.

Harris AC, Mattson C, Lesage MG, Keyler DE, Pentel PR (2010) Comparison of the behavioral effects of cigarette smoke and pure nicotine in rats. Pharmacol Biochem Behav 96:217-227.

Hart C, Ksir C. 1996. Nicotine effects on dopamine clearance in rat nucleus accumbens. Journal of Neurochemistry 66(1):216-221.

Heal DJ, Cheetham SC, Smith SL. 2009. The neuropharmacology of ADHD drugs in vivo: Insights on efficacy and safety. Neuropharmacology 57(7-8):608-618.

Heffner TG, Hartman JA, Seiden LS. 1980. A RAPID METHOD FOR THE REGIONAL DISSECTION OF THE RAT-BRAIN. Pharmacology Biochemistry and Behavior 13(3):453-456.

Heils A, Teufel A, Petri S, Stober G, Riederer P, Bengel D, Lesch KP. 1996. Allelic variation of human serotonin transporter gene expression. Journal of Neurochemistry 66(6):2621-2624.

Herraiz T (2002) Identification and occurrence of the bioactive beta-carbolines norharman and harman in coffee brews. Food Addit Contam 19:748-754.

Herraiz T (2004) Relative exposure to beta-carbolines norharman and harman from foods and tobacco smoke. Food Addit Contam 21:1041-1050.

Herraiz T, Chaparro C. 2005. Human monoamine oxidase is inhibited by tobacco smoke: beta-carboline alkaloids act as potent and reversible inhibitors. Biochemical and Biophysical Research Communications 326(2):378-386.

Hoffman BJ, Hansson SR, Mezey E, Palkovits M. 1998. Localization and dynamic regulation

Howell LL, Kimmel HL. 2008. Monoamine transporters and psychostimulant addiction. Biochemical Pharmacology 75(1):196-217.

Hughes JR, Stead LF, Lancaster T. 2007. Antidepressants for smoking cessation. Cochrane

Hurley LL, Taylor RE, Tizabi Y. 2012. Positive and Negative Effects of Alcohol and Nicotine and Their Interactions: A Mechanistic Review. Neurotoxicity Research 21(1):57-69.

Hurt RD, Sachs DPL, Glover ED, Offord KP, Johnston JA, Dale LC, Khayrallah MA, Schroeder DR, Glover PN, Sullivan CR, Croghan IT, Sullivan PM. 1997. A comparison of sustained-release bupropion and placebo for smoking cessation. N Engl J Med 337(17):1195-1202.

Hwang BH, Wang GM, Wong DT, Lumeng L, Li TK. 2000. Norepinephrine uptake sites in the locus coeruleus of rat lines selectively bred for high and low alcohol preference: A quantitative autoradiographic binding study using [H-3]-tomoxetine. Alcoholism 24(5):588-594.

Ishikawa H, Ohtsuki T, Ishiguro H, Yamakawa-Kobayashi K, Endo K, Lin YL, Yanagi H, Tsuchiya S, Kawata K, Hamaguchi H, Arinami T. 1999. Association between serotonin transporter gene polymorphism and smoking among Japanese males. Cancer Epidemiol Biomarkers Prev 8(9):831-833.

Itoh H, Toyohira Y, Ueno S, Saeki S, Zhang H, Furuno Y, Takahashi K, Tsutsui M, Hachisuka K, Yanagihara N. 2010. Upregulation of norepinephrine transporter function by prolonged exposure to nicotine in cultured bovine adrenal medullary cells. Naunyn-Schmiedebergs Archives of Pharmacology 382(3):235-243. 
Izenwasser S, Cox BM. 1992. Inhibition of Dopamine Uptake by Cocaine and Nicotine Tolerance to Chronic Treatments. Brain Research 573(1):119-125.

Izenwasser S, Jacocks HM, Rosenberger JG, Cox BM. 1991. Nicotine indirectly inhibits [H3] dopamine uptake at concentrations that do not directly promote [H-3] dopamine release in rat striatum. Journal of Neurochemistry 56(2):603-610.

Jacobs EH, Smit AB, de Vries TJ, Schoffelmeer AN (2003) Neuroadaptive effects of active versus passive drug administration in addiction research. Trends Pharmacol Sci 24:566-573.

Janhunen S, Ahtee L. 2007. Differential nicotinic regulation of the nigrostriatal and mesolimbic dopaminergic pathways: Implications for drug development. Neuroscience and Biobehavioral Reviews 31(3):287-314.

Jones IW, Wonnacott S. 2004. Precise localization of alpha 7 nicotinic acetylcholine receptors on glutamatergic axon terminals in the rat ventral tegmental area. Journal of Neuroscience 24(50):11244-11252.

Jorenby DE. 2006. Efficacy of varenicline, an alpha 4 beta 2 nicotinic acetylcholine receptor partial agonist, vs placebo or sustained-release bupropion for smoking cessation: A randomized controlled trial (vol 296, pg 56, 2006). Journal of the American Medical Association 296(11):1355-1355.

Joung Y, Kim CH, Moon J, Jang WS, Yang J, Shin D, Lee S, Kim KS. 2009. Association Studies of-3081(A/T) Polymorphism of Norepinephrine Transporter Gene With Attention Deficit/Hyperactivity Disorder in Korean Population. American Journal of Medical Genetics Part B-Neuropsychiatric Genetics 153B(2):691-694.

Jutkiewicz EM, Nicolazzo DM, Kim MN, Gnegy ME. 2008. Nicotine and amphetamine acutely cross-potentiate their behavioral and neurochemical responses in female Holtzman rats. Psychopharmacology 200(1):93-103.

Kalman D, Morissette SB, George TP. 2005. Co-morbidity of smoking in patients with psychiatric and substance use disorders. American Journal on Addictions 14(2):106123.

Kandel D, Chen K, Warner LA, Kessler RC, Grant B. 1997. Prevalence and demographic correlates of symptoms of last year dependence on alcohol, nicotine, marijuana and cocaine in the US population. Drug Alcohol Depend 44(1):11-29.

Kang AM, Palmatier MA, Kidd KK. 1999. Global variation of a 40-bp VNTR in the 3 'untranslated region of the dopamine transporter gene (SLC6A3). Biological Psychiatry 46(2):151-160.

Kelley AE, Berridge KC. 2002. The neuroscience of natural rewards: Relevance to addictive drugs. Journal of Neuroscience 22(9):3306-3311.

Klimek V, Zhu MY, Dilley G, Konick L, Overholser JC, Meltzer HY, May WL, Stockmeier CA, Ordway GA. 2001. Effects of long-term cigarette smoking on the human locus coeruleus. Archives of General Psychiatry 58(9):821-827.

Konu O, Xu XY, Ma JZ, Kane J, Wang J, Shi SJ, Li MD. 2004. Application of a customized pathway-focused microarray for gene expression profiling of cellular homeostasis upon exposure to nicotine in PC12 cells. Molecular Brain Research 121(1-2):102113.

Krause KH, Dresel SH, Krause J, Kung HF, Tatsch K, Ackenheil M. 2002. Stimulant-like action of nicotine on striatal dopamine transporter in the brain of adults with attention deficit hyperactivity disorder. International Journal of Neuropsychopharmacology 5(2):111-113.

Kristensen AS, Andersen J, Jorgensen TN, Sorensen L, Eriksen J, Loland CJ, Stromgaard K, Gether U. 2011. SLC6 Neurotransmitter Transporters: Structure, Function, and Regulation. Pharmacol Rev 63(3):585-640. 
Lasser K, Boyd JW, Woolhandler S, Himmelstein DU, McCormick D, Bor DH. 2000. Smoking and mental illness - A population-based prevalence study. Jama-Journal of the American Medical Association 284(20):2606-2610.

Laucht M, Becker K, Frank J, Schmidt MH, Esser G, Treutlein J, Skowronek MH, Schumann G. 2008. Genetic variation in dopamine pathways differentially associated with smoking progression in adolescence. J Am Acad Child Adolesc Psychiatr 47(6):673-681.

Laviola G, Adriani W, Terranova ML, Gerra G. 1999. Psychobiological risk factors for vulnerability to psychostimulants in human adolescents and animal models. Neuroscience and Biobehavioral Reviews 23(7):993-1010.

Le Foll B, Chefer SI, Kimes AS, Shumway D, Stein EA, Mukhin AG, Goldberg SR (2009) Baseline expression of alpha4beta2* nicotinic acetylcholine receptors predicts motivation to self-administer nicotine. Biol Psychiatry 65:714-716.

Le Foll B, Wertheim C, Goldberg SR. 2007. High Reinforcing Efficacy of Nicotine in NonHuman Primates. PLoS One 2(2):9.

Lerman C, Caporaso NE, Audrain J, Main D, Bowman ED, Lockshin B, Boyd NR, Shields PG. 1999. Evidence suggesting the role of specific genetic factors in cigarette smoking. Health Psychol 18(1):14-20.

Lerman C, Shields PG, Audrain J, Main D, Cobb B, Boyd NR, Caporaso N. 1998. The role of the serotonin transporter gene in cigarette smoking. Cancer Epidemiology Biomarkers \& Prevention 7(3):253-255.

Leroy C, Bragulat V, Berlin I, Gregoire MC, Bottlaender M, Roumenov D, Dolle F, Bourgeois S, Penttila J, Artiges E, Martinot JL, Trichard C. 2009. Cerebral Monoamine Oxidase A Inhibition in Tobacco Smokers Confirmed With PET and [C11]Befloxatone. Journal of Clinical Psychopharmacology 29(1):86-88.

Lewis A, Miller JH, Lea RA. 2007. Monoamine oxidase and tobacco dependence.

Li LB, Chen NH, Ramamoorthy S, Chi LM, Cui XN, Wang LJC, Reith MEA. 2004a. The role of N-glycosylation in function and surface trafficking of the human dopamine transporter. Journal of Biological Chemistry 279(20):21012-21020.

Li MD, Kane JK, Ju W, Ma JZ. 2004d. Time-dependent changes in transcriptional profiles within five rat brain regions in response to nicotine treatment. Molecular Brain Research 132(2):168-180.

Li MD, Ma JZ, Beuten J. 2004b. Progress in searching for susceptibility loci and genes for smoking-related behaviour. Clinical Genetics 66(5):382-392.

Li SP, Kim KY, Kim JH, Kim JH, Park MS, Bahk JY, Kim MO. 2004c. Chronic nicotine and smoking treatment increases dopamine transporter mRNA expression in the rat midbrain. Neuroscience Letters 363(1):29-32.

Ling DJ, Niu TH, Feng Y, Xing HX, Xu XP. 2004. Association between polymorphism of the dopamine transporter gene and early smoking onset: an interaction risk on nicotine dependence. J Hum Genet 49(1):35-39.

Little KY, Elmer LW, Zhong HL, Scheys JO, Zhang L. 2002. Cocaine induction of dopamine transporter trafficking to the plasma membrane. Mol Pharmacol 61(2):436-445.

Ma Z, Strecker RE, McKenna JT, Thakkar MM, McCarley RW, Tao R. 2005. Effects on serotonin of (-)nicotine and dimethylphenylpiperazinium in the dorsal raphe and nucleus accumbens of freely behaving rats. Neuroscience 135(3):949-958.

Marchi M, Grilli M. 2010. Presynaptic nicotinic receptors modulating neurotransmitter release in the Central Nervous System: Functional interactions with other coexisting receptors. Prog Neurobiol 92(2):105-111. 
Mascia MP, Maiya R, Borghese CM, Lobo IA, Hara K, Yamakura T, Gong DH, Beckstead MJ. 2001. Does acetaldehyde mediate ethanol action in the central nervous system? Alcoholism 25(11):1570-1575.

Matta SG, Balfour DJ, Benowitz NL, Boyd RT, Buccafusco JJ, Caggiula AR, Craig CR, Collins AC, Damaj MI, Donny EC, Gardiner PS, Grady SR, Heberlein U, Leonard SS, Levin ED, Lukas RJ, Markou A, Marks MJ, McCallum SE, Parameswaran N, Perkins KA, Picciotto MR, Quik M, Rose JE, Rothenfluh A, Schafer WR, Stolerman IP, Tyndale RF, Wehner JM, Zirger JM. 2007. Guidelines on nicotine dose selection for in vivo research. Psychopharmacology 190(3):269-319.

Meiergerd SM, Patterson TA, Schenk JO. 1993. D2 receptors may modulate the function of the striatal transporter for dopamine - kinetic evidence from sties in-vitro and invivo. Journal of Neurochemistry 61(2):764-767.

Melikian HE. 2004. Neurotransmitter transporter trafficking: endocytosis, recycling, and regulation. Pharmacology \& Therapeutics 104(1):17-27.

Middleton LS, Apparsundarain S, King-Pospisil KA, Dwoskin LP. 2007a. Nicotine increases dopamine transporter function in rat striatum through a traffickingindependent mechanism. European Journal of Pharmacology 554(2-3):128-136.

Middleton LS, Cass WA, Dwoskin LP. 2004. Nicotinic receptor modulation of dopamine transporter function in rat striatum and medial prefrontal cortex. Journal of Pharmacology and Experimental Therapeutics 308(1):367-377.

Middleton LS, Crooks PA, Wedlund PJ, Cass WA, Dwoskin LP. 2007b. Nornicotine inhibition of dopamine transporter function in striatum via nicotinic receptor activation. Synapse 61(3):157-165.

Miller DK, Wong EHF, Chesnut MD, Dwoskin LP. 2002. Reboxetine: Functional inhibition of monoamine transporters and nicotinic acetylcholine receptors. Journal of Pharmacology and Experimental Therapeutics 302(2):687-695.

Miller LR, Mukherjee S, Ansah TA, Das SK. 2007. Cigarette smoke and dopaminergic system. Journal of Biochemical and Molecular Toxicology 21(6):325-335.

Moron JA, Zakharova I, Ferrer JV, Merrill GA, Hope B, Lafer EM, Lin ZC, Wang JB, Javitch JA, Galli A, Shippenberg TS. 2003. Mitogen-activated protein kinase regulates dopamine transporter surface expression and dopamine transport capacity. Journal of Neuroscience 23(24):8480-8488.

Murphy DL, Lerner A, Rudnick G, Lesch KP. 2004. Serotonin transporter: Gene, genetic disorders, and pharmacogenetics. Molecular Interventions 4(2):109-123.

Nayak SV, Ronde P, Spier AD, Lummis SCR, Nichols RA. 2000. Nicotinic receptors colocalize with 5-HT3 serotonin receptors on striatal nerve terminals. Neuropharmacology 39(13):2681-2690.

Neurotoxicology 28(1):182-195.

Near JA, Bigelow JC, Wightman RM. 1988. Comparison of uptake of dopamine in rat striatal chopped tissue and synaptosomes. Journal of Pharmacology and Experimental Therapeutics 245(3):921-927.

New Zealand Ministry of Health. 2005. Tobacco Facts 2005. Wellington: Ministry of Health.

Newberg A, Lerman C, Wintering N, Ploessl K, Mozley PD. 2007. Dopamine transporter binding in smokers and nonsmokers. Clinical Nuclear Medicine 32(6):452-455.

Nisell M, Nomikos GG, Hertel P, Panagis G, Svenssom TH. 1996. Condition-independent sensitization of locomotor stimulation and mesocortical dopamine release following chronic nicotine treatment in the rat. Synapse 22(4):369-381.

O'Connor EC, Parker D, Rollema H, Mead AN (2010) The alpha4beta2 nicotinic acetylcholine-receptor partial agonist varenicline inhibits both nicotine self- 
administration following repeated dosing and reinstatement of nicotine seeking in rats. Psychopharmacology (Berl) 208:365-376.

of biogenic amine transporters in the mammalian central nervous system. Frontiers in Neuroendocrinology 19(3):187-231.

Ohyama K, Sogawa C, Sogawa N, Morita K, Dohi T, Kitayama S. 2010. Nicotine stimulates transcriptional activity of the human dopamine transporter gene. Neuroscience Letters 471(1):34-37.

Park HJ, Lee PH, Ahn YW, Choi YJ, Lee G, Lee DY, Chung ES, Jin BK. 2007. Neuroprotective effect of nicotine on dopaminergic neurons by anti-inflammatory action. European Journal of Neuroscience 26(1):79-89.

Paterson NE, Balfour DJ, Markou A. 2007. Chronic bupropion attenuated the anhedonic component of nicotine withdrawal in rats via inhibition of dopamine reuptake in the nucleus accumbens shell. European Journal of Neuroscience 25(10):3099-3108.

Paterson NE, Semenova S, Markou A. 2008. The effects of chronic versus acute desipramine on nicotine withdrawal and nicotine self-administration in the rat. Psychopharmacology 198(3):351-362.

Paterson NE. 2009. Behavioural and pharmacological mechanisms of bupropion's antipathway for the reinforcing effect of drugs of abuse? Neuroscience and Biobehavioral Reviews 30(2):215-238.

Pawlik M, Kaulen P, Baumgarten HG, Rommelspacher H (1990) Quantitative autoradiography of $[3 \mathrm{H}]$ norharman $[(3 \mathrm{H}]$ beta-carboline) binding sites in the rat brain. J Chem Neuroanat 3:19-24.

Paxinos, G. and Watson, C. (2005) The rat brain in stereotaxic coordinates, 5th ed.,

Academic Press, New York.

Peters IR, Helps CR, Hall EJ, Day MJ. 2004. Real-time RT-PCR: considerations for efficient and sensitive assay design. Journal of Immunological Methods 286(1-2):203217.Pierce RC, Kumaresan V. 2006. The mesolimbic dopamine system: The final common

Polosa R, Benowitz NL. 2011. Treatment of nicotine addiction: present therapeutic options and pipeline developments. Trends Pharmacol Sci 32(5):281-289.

Prochazka AV, Weaver MJ, Keller RT, Fryer GE, Licari PA, Lofaso D. 1998. A randomized trial of nortriptyline for smoking cessation. Archives of Internal Medicine 158(18):2035-2039.

Quertemont E, Tambour S, Tirelli E. 2005. The role of acetaldehyde in the neurobehavioral effects of ethanol: A comprehensive review of animal studies. Prog Neurobiol 75(4):247274.

Quik M, O'Neill M, Perez XA. 2007. Nicotine neuroprotection against nigrostriatal damage: importance of the animal model. Trends Pharmacol Sci 28(5):229-235.

Rahman S, Zhang J, Corrigall WA. 2003. Effects of acute and chronic nicotine on somatodendritic dopamine release of the rat ventral tegmental area: in vivo microdialysis study. Neuroscience Letters 348(2):61-64.

Rahman S, Zhang J, Engleman EA, Corrigalla WA. 2004. Neuroadaptive changes in the mesoaccumbens dopamine system after chronic nicotine self-administration: A microdialysis study. Neuroscience 129(2):415-424.

Rao TS, Correa LD, Adams P, Santori EM, Sacaan AI. 2003. Pharmacological characterization of dopamine, norepinephrine and serotonin release in the rat prefrontal cortex by neuronal nicotinic acetylcholine receptor agonists. Brain Res 990(1-2):203-208.

Rauhut AS, Mullins SN, Dwoskin LP, Bardo MT. 2002. Reboxetine: Attenuation of intravenous nicotine self-administration in rats. Journal of Pharmacology and Experimental Therapeutics 303(2):664-672. 
Reuben M, Clarke PBS. 2000. Nicotine-evoked [H-3]5-hydroxytryptamine release from rat striatal synaptosomes. Neuropharmacology 39(2):290-299.

Rommelspacher H, May T, Salewski B (1994) Harman (1-methyl-beta-carboline) is a natural inhibitor of monoamine oxidase type A in rats. Eur J Pharmacol 252:51-59.

Rommelspacher H, Meier-Henco M, Smolka M, Kloft C (2002) The levels of norharman are high enough after smoking to affect monoamineoxidase B in platelets. Eur J Pharmacol 441:115-125.

Rose JE, Brauer LH, Behm FM, Cramblett M, Calkins K, Lawhon D. 2004. Psychopharmacological interactions between nicotine and ethanol. Nicotine Tob Res 6(1):133-144.

Rose JE, Salley A, Behm FM, Bates JE, Westman EC. Reinforcing effects of nicotine and non-nicotine components of cigarette smoke. 2010. Psychopharmacology 210(1):112.

Rossi S, Singer S, Shearman E, Sershen H, Lajtha A. 2005. Regional heterogeneity of nicotine effects on neurotransmitters in rat brains in vivo at low doses. Neurochemical Research 30(1):91-103.

Rush CR, Higgins ST, Vansickel AR, Stoops WW, Lile JA, Glaser PEA. 2005. Methylphenidate increases cigarette smoking. Psychopharmacology 181(4):781-789.

Salminen O, Drapeau JA, McIntosh JM, Collins AC, Marks MJ, Grady SR. 2007. Pharmacology of alpha-conotoxin MII-sensitive subtypes of nicotinic acetylcholine receptors isolated by breeding of null mutant mice. Mol Pharmacol 71(6):1563-1571.

Salminen O, Murphy KL, McIntosh JM, Drago J, Marks MJ, Collins AC, Grady SR. 2004. Subunit composition and pharmacology of two classes of striatal presynaptic nicotinic acetylcholine receptors mediating dopamine release in mice. Mol Pharmacol 65(6):1526-1535.

Saunders C, Ferrer JV, Shi L, Chen JY, Merrill G, Lamb ME, Leeb-Lundberg LMF, Carvelli L, Javitch JA, Galli A. 2000. Amphetamine-induced loss of human dopamine transporter activity: An internalization-dependent and cocaine-sensitive mechanism. Proceedings of the National Academy of Sciences of the United States of America 97(12):6850-6855.

Schmid B, Blomeyer D, Becker K, Treutlein J, Zimmermann US, Buchmann AF, Schmidt MH, Esser G, Banaschewski T, Rietschel M, Laucht M. 2009. The interaction between the dopamine transporter gene and age at onset in relation to tobacco and alcohol use among 19-year-olds. Addiction Biology 14(4):489-499.

Scholze P, Orr-Urtreger A, Changeux JP, McIntosh JM, Huck S. 2007. Catecholamine outflow from mouse and rat brain slice preparations evoked by nicotinic acetylcholine receptor activation and electrical field stimulation. British Journal of Pharmacology 151(3):414-422.

Schramm-Sapyta NL, Walker QD, Caster JM, Levin ED, Kuhn CM. 2009. Are adolescents more vulnerable to drug addiction than adults? Evidence from animal models. Psychopharmacology 206(1):1-21.

Semba J, Wakuta M. 2008. Chronic effect of nicotine on serotonin transporter mRNA in the raphe nucleus of rats: Reversal by co-administration of bupropion. Psychiatry and Clinical Neurosciences 62(4):435-441.

Seth P, Cheeta S, Tucci S, File SE. 2002. Nicotinic-serotonergic interactions in brain and behaviour. Pharmacology Biochemistry and Behavior 71(4):795-805.

Shearman E, Fallon S, Sershen H, Lajtha A. 2008. Nicotine-induced monoamine neurotransmitter changes in the brain of young rats. Brain Research Bulletin 76(6):626-639. 
Sieminska A, Buczkowski K, Jassem E, Niedoszytko M, Tkacz E. 2009. Influences of polymorphic variants of DRD2 and SLC6A3 genes, and their combinations on smoking in Polish population. BMC Medical Genetics 10.

Singer S, Rossi S, Verzosa S, Hashim A, Lonow R, Cooper T, Sershen H, Lajtha A. 2004. Nicotine-induced changes in neurotransmitter levels in brain areas associated with cognitive function. Neurochemical Research 29(9):1779-1792.

Small E, Shah HP, Davenport JJ, Geier JE, Yavarovich KR, Yamada H, Sabarinath SN, Derendorf H, Pauly JR, Gold MS, Bruijnzeel AW (2010) Tobacco smoke exposure induces nicotine dependence in rats. Psychopharmacology (Berl) 208:143-158. smoking effects: Recent preclinical and clinical insights. European Journal of Pharmacology 603(1-3):1-11.

Sofuoglu M, Sewell RA. 2009. Norepinephrine and stimulant addiction. Addiction Biology 14(2):119-129.

Spiller K, Xi ZX, Li X, Ashby CR, Jr., Callahan PM, Tehim A, Gardner EL (2009) Varenicline attenuates nicotine-enhanced brain-stimulation reward by activation of alpha4beta2 nicotinic receptors in rats. Neuropharmacology 57:60-66.

Stairs DJ, Neugebauer NM, Bardo MT (2010) Nicotine and cocaine self-administration using a multiple schedule of intravenous drug and sucrose reinforcement in rats. Behav Pharmacol 21:182-193.

Stedman RL. 1968. Chemical composition of tobacco and tobacco smoke. Chemical Reviews 68(2):153-\&.

Stefanski R, Ladenheim B, Lee SH, Cadet JL, Goldberg SR (1999) Neuroadaptations in the dopaminergic system after active self-administration but not after passive administration of methamphetamine. Eur J Pharmacol 371:123-135.

Stolerman IP, Jarvis MJ. 1995. The Scientific Case That Nicotine Is Addictive. Psychopharmacology 117(1):2-10.

Tidey JW, O'Neill SC, Higgins ST. 2000. d-Amphetamine increases choice of cigarette smoking over monetary reinforcement. Psychopharmacology 153(1):85-92.

Tizabi Y, Bai L, Copeland RL, Taylor RE. 2007. Combined effects of systemic alcohol and nicotine on dopamine release in the nucleus accumbens shell. Alcohol and Alcoholism 42(5):413-416.

Toll L, Zaveri NT, Polgar WE, Jiang F, Khroyan TV, Zhou W, Xie XS, Stauber GB, Costello MR, Leslie FM (2012) AT-1001: A High Affinity and Selective alpha3beta4 Nicotinic Acetylcholine Receptor Antagonist Blocks Nicotine SelfAdministration in Rats. Neuropsychopharmacology 37:1367-1376.

Torres GE, Gainetdinov RR, Caron MG. 2003. Plasma membrane monoamine transporters: Structure, regulation and function. Nature Reviews Neuroscience 4(1):13-25.

Touiki K, Rat P, Molimard R, Chait A, de Beaurepaire R. 2007. Effects of tobacco and cigarette smoke extracts on serotonergic raphe neurons in the rat. Neuroreport 18(9):925-929.

Vansickel AR, Poole MM, Stoops WW, Hays KE, Upchurch MB, Glaser PEA, Rush CR. 2009. Stimulant-induced changes in smoking and caloric intake: Influence of rate of onset. Pharmacology Biochemistry and Behavior 92(4):597-602.

Vansickel AR, Stoops WW, Glaser PEA, Rush CR. 2007. A pharmacological analysis of stimulant-induced increases in smoking. Psychopharmacology 193(3):305-313.

Villegier AS, Lotfipour S, McQuown SC, Belluzzi JD, Leslie FM. 2007. Tranylcypromine enhancement of nicotine self-administration. Neuropharmacology 52(6):1415-1425.

Volkow ND, Fowler JS, Wang GJ, Swanson JM, Telang F. 2007. Dopamine in drug abuse and addiction - Results of imaging studies and treatment implications. Archives of Neurology 64(11):1575-1579. 
Volz TJ, Farnsworth SJ, Hanson GR, Fleckenstein AE. 2009. Measurement of plasmalemmal dopamine transport, vesicular dopamine transport, and $\mathrm{K}+$-stimulated dopamine release in frozen rat brain tissue. Journal of Neuroscience Methods 180(2):317-320.

Watkins SS, Epping-Jordan MP, Koob GF, Markou A. 1999. Blockade of nicotine selfadministration with nicotinic antagonists in rats. Pharmacology Biochemistry and Behavior 62(4):743-751.

Weinshenker D, Schroeder JP. 2007. There and back again: A tale of norepinephrine and drug addiction. Neuropsychopharmacology 32(7):1433-1451.

Weisinger G, Gavish M, Mazurika C, Zinder O. 1999. Transcription of actin, cyclophilin and glyceraldehyde phosphate dehydrogenase genes: tissue- and treatmentspecificity. Biochimica Et Biophysica Acta-Gene Structure and Expression 1446(3):225-232.

West R, Hajek P, Foulds J, Nilsson F, May S, Meadows A. 2000. A comparison of the abuse liability and dependence potential of nicotine patch, gum, spray and inhaler. Psychopharmacology 149(3):198-202.

West R, Zatonski W, Cedzynska M, Lewandowska D, Pazik J, Aveyard P, Stapleton J. 2011. Placebo-Controlled Trial of Cytisine for Smoking Cessation. N Engl J Med 365(13):1193-1200.

WHO 2011. Tobacco Fact Sheet No 339.: World Health Organisation.

Wooters TE, Neugebauer NM, Rush CR, Bardo MT. 2008. Methylphenidate enhances the abuse-related behavioral effects of nicotine in rats: Intravenous self-administration, drug discrimination, and locomotor cross-sensitization. Neuropsychopharmacology 33(5):1137-1148.

Xue Y, Domino EF. 2008. Tobacco/nicotine and endogenous brain opioids. Progress in Neuro-Psychopharmacology \& Biological Psychiatry 32(5):1131-1138.

Yamashita H, Kitayama S, Zhang YX, Takahashi T, Dohi T, Nakamura S. 1995. Effect of nicotine on dopamine uptake in COS cells possessing the rat dopamine transporter and PC12 cells. Biochemical Pharmacology 49(5):742-745.

Yang YK, Yao WJ, Yeh TL, Lee IH, Chen PS, Lu RB, Chiu NT. 2008. Decreased dopamine transporter availability in male smokers - A dual isotope SPECT study. Progress in Neuro-Psychopharmacology \& Biological Psychiatry 32(1):274-279.

Yu GL, Chen H, Wu XJ, Matta SG, Sharp BM. 2010. Nicotine self-administration differentially modulates glutamate and GABA transmission in hypothalamic paraventricular nucleus to enhance the hypothalamic-pituitary-adrenal response to stress. Journal of Neurochemistry 113(4):919-929.

Yu ZJ, Wecker L. 1994. Chronic nicotine administration differentially affects neurotransmitter release from rat striatal slices. Journal of Neurochemistry 63(1):186-194.

Zhu CB, Hewlett WA, Feoktistov I, Biaggioni I, Blakely RD. 2004. Adenosine receptor, protein kinase $\mathrm{G}$ and p38 mitogen-activated protein kinase-dependent up-regulation of serotonin transporters involves both transporter trafficking and activation. Molecular Pharmacology 65(6):1462-1474.

Zhu J, Apparsundaram S, Dwoskin LP. 2009. Nicotinic Receptor Activation Increases [H3]Dopamine Uptake and Cell Surface Expression of Dopamine Transporters in Rat Prefrontal Cortex. Journal of Pharmacology and Experimental Therapeutics 328(3):931-939.

Zhu J, Reith MEA. 2008. Role of the Dopamine Transporter in the Action of Psychostimulants, Nicotine, and Other Drugs of Abuse. Cns \& Neurological Disorders-Drug Targets 7(5):393-409. 
